\title{
Creating Ethical Markets or Marketing Ethics? \\ A Critical Exploration of Ethical Value Networks in Chilean and Peruvian Viticulture and Oenology
}

\author{
By
}

\section{Peter Bryan Foster Williams}

A thesis submitted to the Victoria University of Wellington in fulfilment of the requirements for the degree of Doctor of Philosophy.

Victoria University of Wellington 



\section{ABSTRACT}

The global integration of agriculture has increasingly exposed rural groups in Latin America, and other regions of the Global South, to external economic forces. This integration, encouraged by neoliberal ideology, has in many ways exacerbated underdevelopment and peripherality of these regions. Small-scale farmers tend to disproportionately suffer from trade inequality and a range of negative social, economic, and environmental outcomes associated with the integration of agriculture. In response, consumers in the Global North have become more concerned about how food is being produced and to what standards, particularly when production takes place in the South. In part, this has driven the rise of what this research theorises as ethical value networks and linked product labels. Diverse networks and product labels based in social justice, sustainability, quality and origin have been promoted as alternative models to globalised agriculture. It is claimed that these alternative networks assist rural groups otherwise disadvantaged by neoliberal globalisation by facilitating access to higher-value ethical niche markets, while encouraging localised ethical forms of development.

This research critically explores two examples of ethical value networks in South American viticulture. It examines the use of fair trade certifications in Chilean wine and the protected designation of origin mark on pisco from Peru. This research emphasises the importance of local social, economic, and political contexts in the formation and outcomes of ethical value networks. It argues that despite the potential of the two studied networks to encourage local social and community development, entrenched socio-economic inequalities in Chile and Peru have hindered the expected positive outcomes of these ethical value networks. Moreover, this thesis argues that the studied networks have in many ways worsened local rural inequalities by supporting industrial and newer producers while excluding the most vulnerable actors in the wine and pisco sectors. Therefore, although this thesis illustrates the potential capacities of ethical value networks in fostering local development outcomes through product labelling, it also reveals the main limitations of these networks as currently implemented. 


\section{ACKNOWLEDGEMENTS}

To my primary supervisor Professor Warwick Murray, thank you for all of your support, guidance, interesting discussions and laughs over the years. Ten years ago, you ignited my interest in Latin America, globalisation and development and it has since been an honour to have you as my supervisor and friend. To my secondary supervisor Professor Johannes Rehner, thank you for all of your guidance and insightful conversations during my time in South America. I would also like to thank Professor John Overton, Director of Development Studies at VUW, for providing great support and mentoring over the years.

I thank all of the research participants, without your ideas and experiences this thesis would not have been possible. I truly appreciated the time, ideas and information you shared with me. In Peru, I would like to give special thanks to Pepe Moquillaza, Teresa Oré, Jorge Llanos, Eduardo Dargent, Karl Mendoza, Lorenzo Huertas, Beatriz Salazar, Carlos Romero, Jhon Léon, Marco Zúñiga, and Matías Grados for the invaluable conversations and for helping me during my time in Peru. I would also like to thank Alfonso and Guillermina, as well as Claudia, Patricia and Pablo, for welcoming me into your family. In addition, I would like to thank all of my friends in Ica and Lima for their hospitality. In Chile, I would like to especially thank Gerardo Wijnant, Gonzalo Rojas, Claudio Jorquera, Rodrigo Valenzuela, Daniella Gac, Lionel Valenzuela, Raúl Navarrete, Yenny Llanos, Germán López, Rodrigo Constandil, and Pablo Lacoste for the helpful conversations and the assistance while I was in Chile. I would also like to thank my friends Victor, Luis, Gustavo, as well as Miguel and Leticia for making me feel welcome during my time in Santiago and Curicó. Finally, I would like to thank all my friends in Chile for their kindness.

I would also like to thank my friends and family in New Zealand and beyond for their continued support. To my parents, Jo and John, and my siblings Tim and Felicity, thank you for all the encouragement and love over the years. I am very fortunate to have such a wonderful and supportive family. I thank all of my amazing friends at VUW for being such a considerate and great group of people. I would like to especially mention Kelle, Lorena, Stephen, Claire, Simon and the two Andrews for encouraging me, listening to me rant, and for making my PhD an enjoyable experience. I wish to thank Stephen and Kelle a second time for reading my work and giving me invaluable feedback. To my darling Luciana, thank you for your unconditional love, support and patience, and for sharing this adventure with me.

This PhD was funded by the Royal Society's/Te Apārangi's Marsden Fund. This financial assistance has been gratefully appreciated. 


\section{TABLE OF CONTENTS}

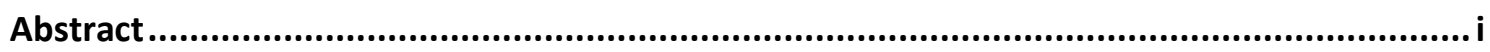

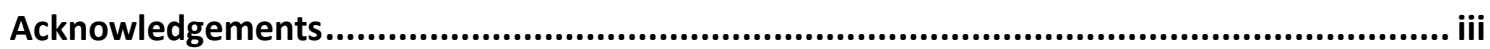

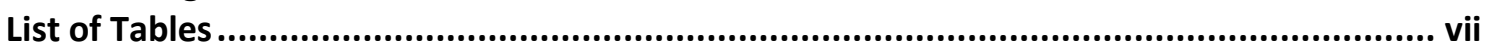

List of Figures.................................................................................................. vii

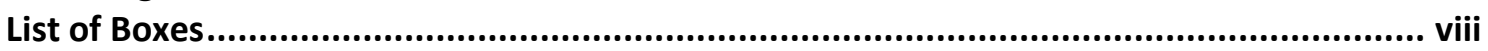

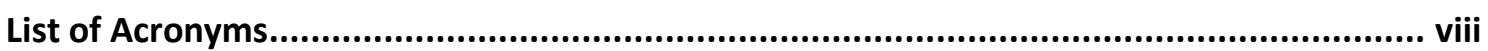

Chapter One. Thesis Introduction ........................................................................ 1

1.1 Research Rationale and Context......................................................................

1.2 Relevance of Study: Theorising Ethical Value Networks in South America ......................6

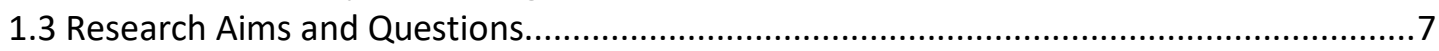

1.4 Thesis Structure ............................................................................................

Chapter Two. Describing the Research Process: Methodology ..................................... 10

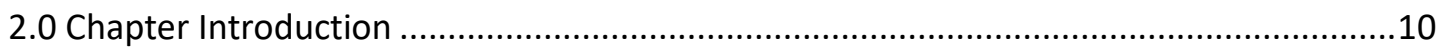

2.1 Critical Realism Epistemology .........................................................................11

2.2 Principles of Ethical Research ......................................................................... 11

2.3 Theoretical Foundations of this Research ...........................................................16

2.4 Global Value Chains and Global Production Networks...............................................22

2.5 Research Methods .........................................................................................29

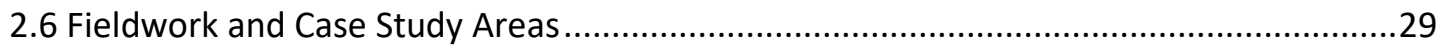

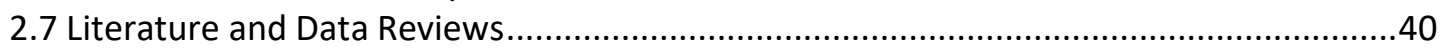

2.8 Semi-structured Interviews and Participant Selection ...............................................40

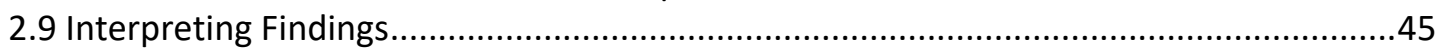

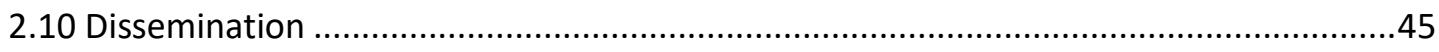

2.11 Chapter Two Discussion and Link to Chapter Three .................................................45

Chapter Three. Placing Value on Ethical Production: Globalisation and Ethical Value

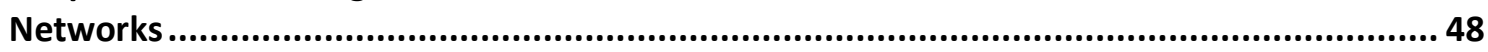

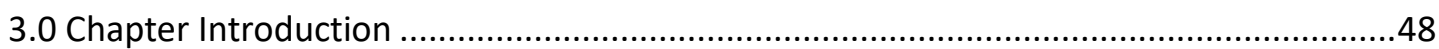

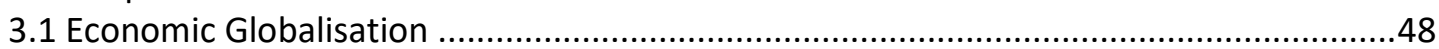

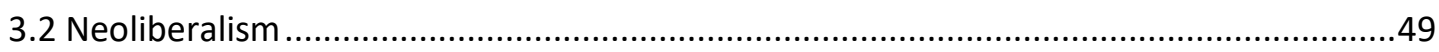

3.3 The Evolution of the Global Agro-food System .......................................................5 51

3.4 Costs and Benefits of Globalisation in the Global South ............................................53

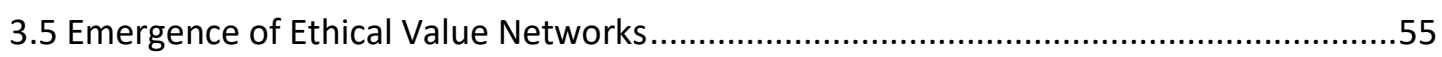

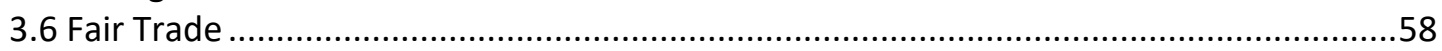

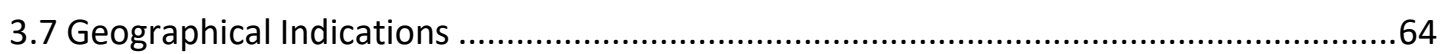

3.8 Chapter Three Discussion and Link to Chapter Four .................................................73

Chapter Four. Grounding Ethical Value One: Historical Evolution of Peruvian Viticulture..... 76

4.0 Chapter Introduction ..................................................................................76

4.1 The Arrival and Expansion of Viticulture in the Spanish American Colonies...................76

4.2 The Historical Evolution of Peruvian Viticulture .......................................................79

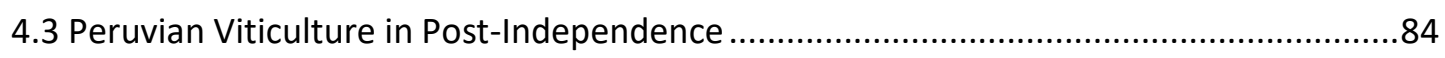

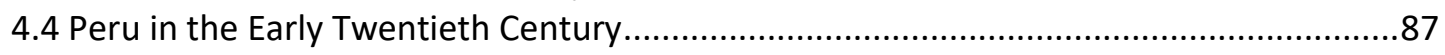

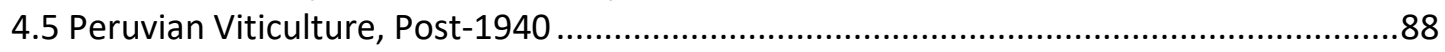

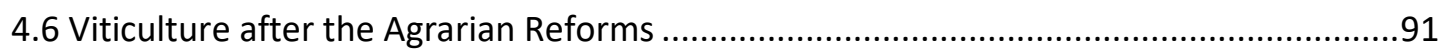

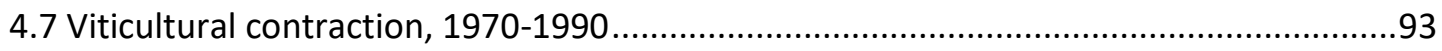

4.8 Fujimori Government and Neoliberal Reforms ..................................................93

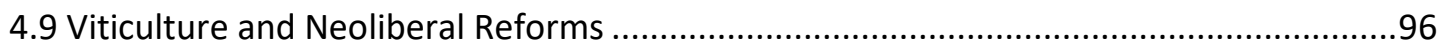

4.10 The Evolution of the Peruvian DO for Pisco............................................................98

4.11 Reactivation of Peruvian Viticulture, 2000-2010...................................................100

4.12 Peruvian Politics and Economy, Post-2010...........................................................105

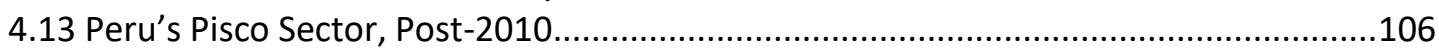

4.14 Chapter Four Discussion and Link to Chapter Five ...............................................108

Chapter Five. Grounding Ethical Value Two: Historical Evolution of Chilean Viticulture ..... 111 
5.0 Chapter Introduction

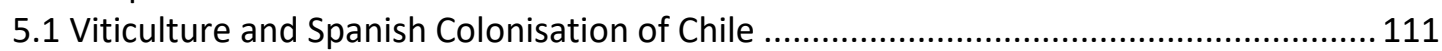

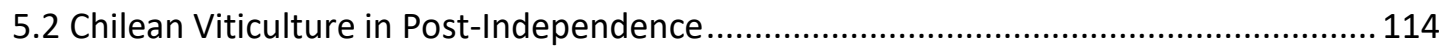

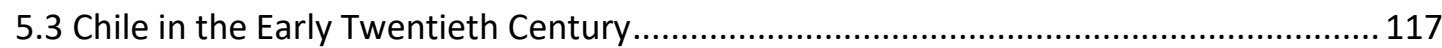

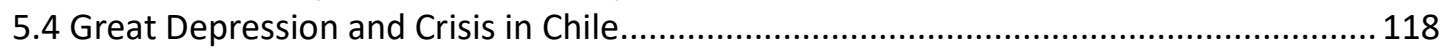

5.5 Chile and the Developmentalist State, 1932-1973.................................................... 118

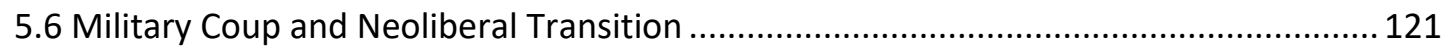

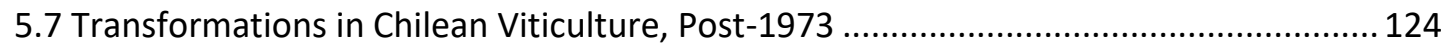

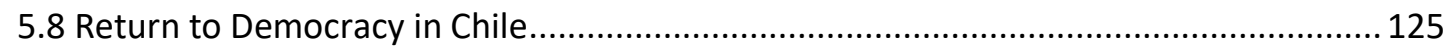

5.9 The Chilean Wine Sector during the Transition to Democracy, 1990-2010 ................... 127

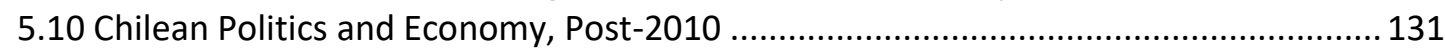

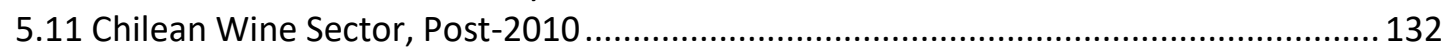

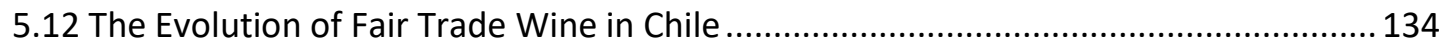

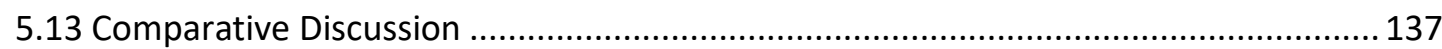

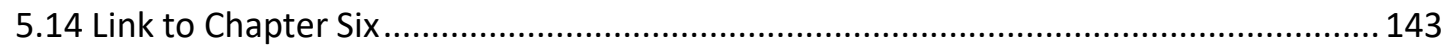

Chapter Six. Mapping Ethical Value: Motivations, Governance and Power in Chilean and

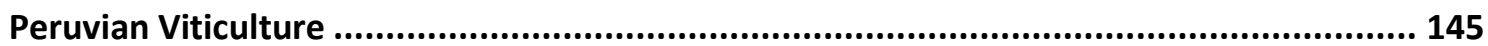

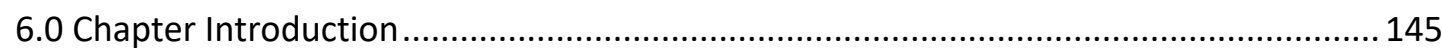

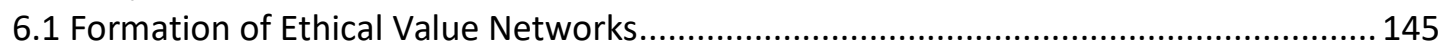

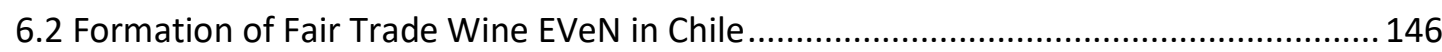

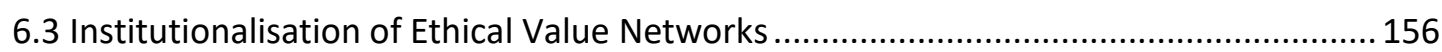

6.4 Institutionalisation of Fair Trade Wine EVeN in Chile ................................................. 157

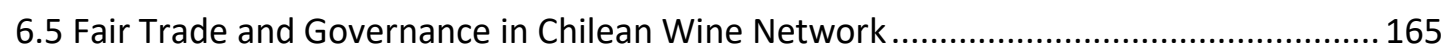

6.6 Formation of Designation of Origin Pisco EVeN in Peru............................................... 170

6.7 Institutionalisation of Designation of Origin Pisco EVeN in Peru ................................... 179

6.8 Governance in the Designation of Origin Pisco EVeN in Peru.................................... 181

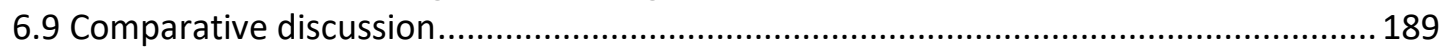

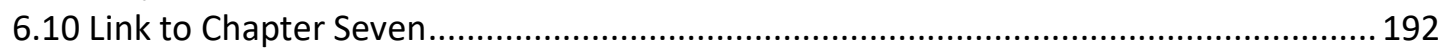

Chapter Seven. Evaluating Ethical Value: Critical Investigation of Ethical Claims and Local

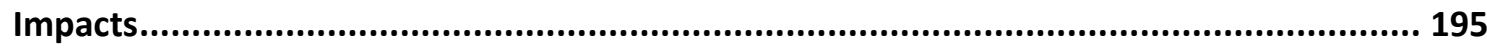

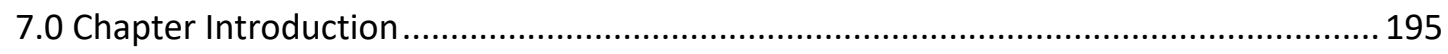

7.1 Idealisation and Realisation of Fair Trade Wine in Chile ............................................ 195

7.2 Summary: Idealisation and Realisation of EVeN in Fair Trade Wine in Chile ................. 213

7.3 Idealisation and Realisation of EVeN in DO Pisco from Peru ........................................2. 215

7.4 Summary: Idealisation and Realisation of the DO for Pisco from Peru......................... 235

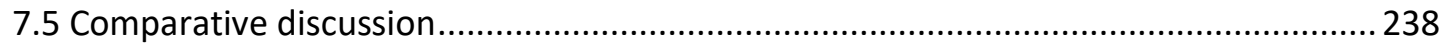

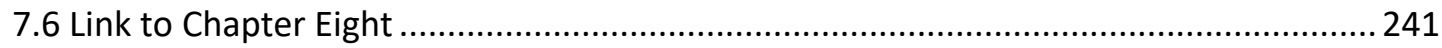

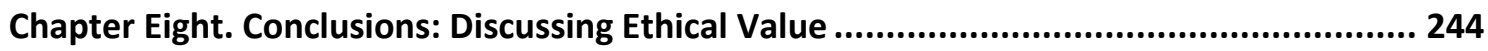

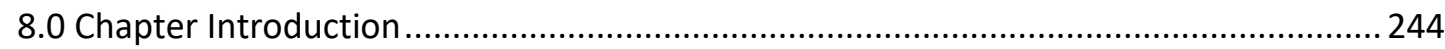

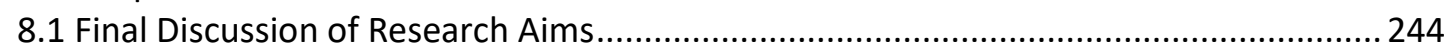

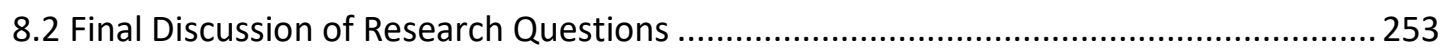

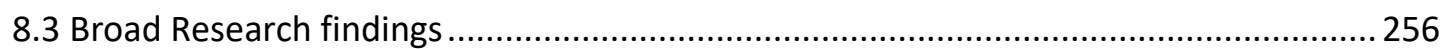

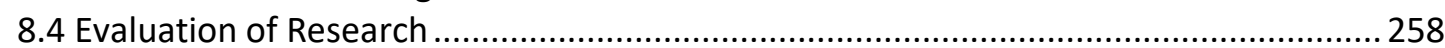

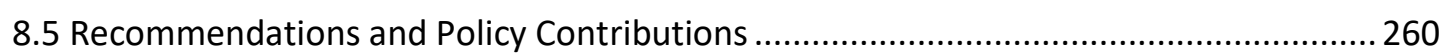

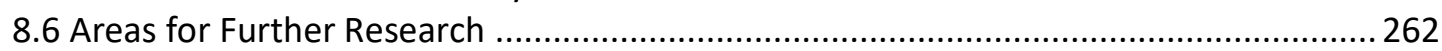

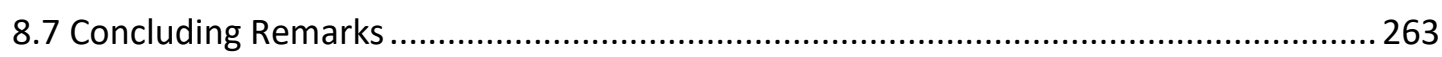

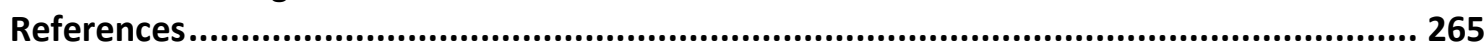




\section{LIST OF TABLES}

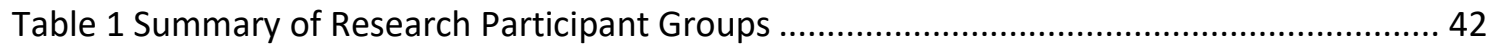

Table 2 Key Literature and Concepts Contributing to the Theorisation of EVeNs ...................... 57

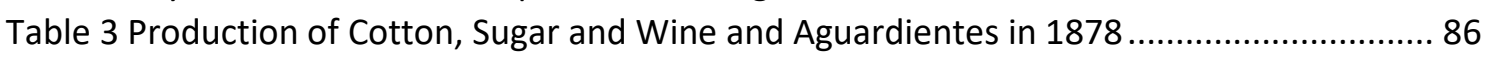

Table 4 Legal and Institutional Evolution of Peruvian DO for Pisco........................................... 99

Table 5 Number of Vineyards According to Area, 1995-2007 .............................................. 129

Table 6 Key Producer Groups of Fair Trade Certification in Chilean Wine Sector .................... 136

Table 7 Transformations in the Peruvian and Chilean Viticultural Sectors over History........... 138

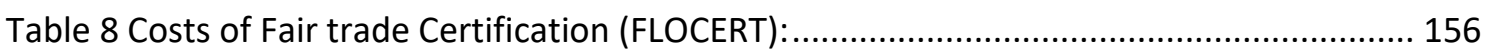

Table 9 Summary of Ethical Claims and Outcomes ............................................................. 237

\section{LIST OF FIGURES}

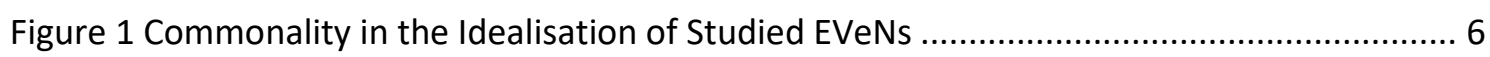

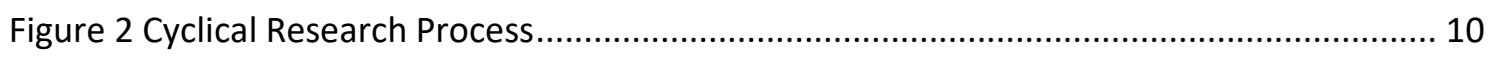

Figure 3 Visualisation of Core-Periphery Model from Dependency Theory Literature ............... 18

Figure 4 Visualisation of Core, Semi-periphery and Periphery Model in World-Systems Theory

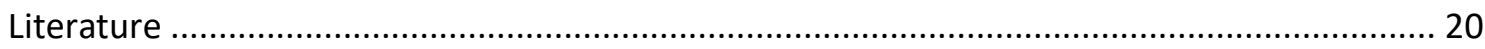

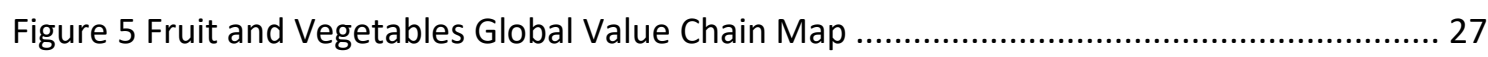

Figure 6 A Heuristic Framework for Analysing the Global Economy ........................................ 28

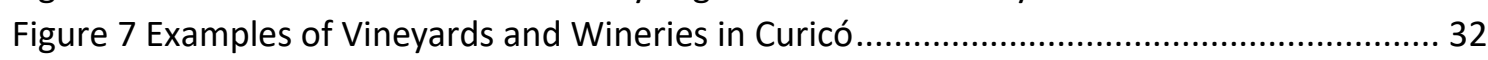

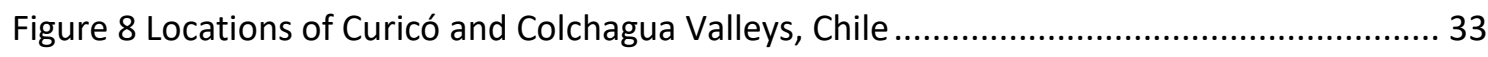

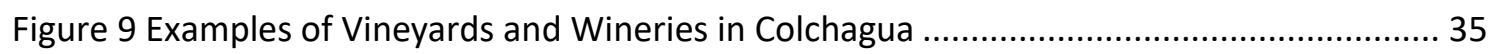

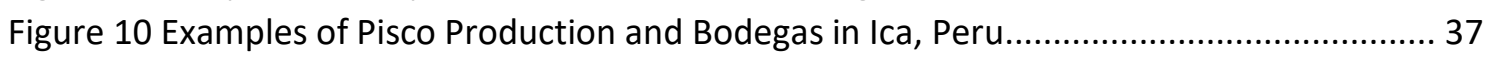

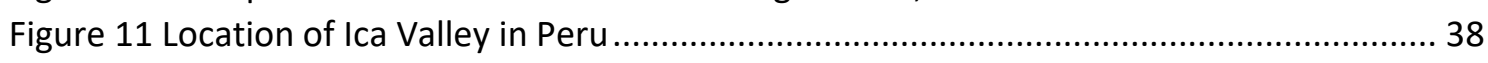

Figure 12 Designated Pisco Producing Areas under Pisco DO Regulations in Peru .................... 39

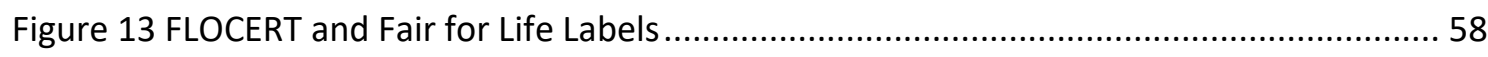

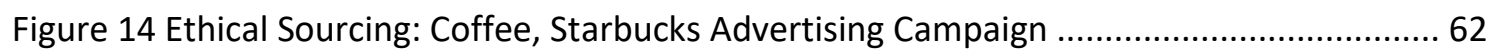

Figure 15 Pishkos used to Store and Transport Wine and Pisco............................................... 82

Figure 16 Propaganda used During Peruvian Agrarian Reforms ............................................ 90

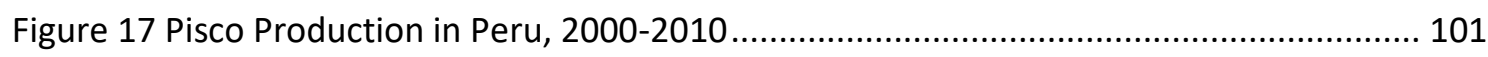

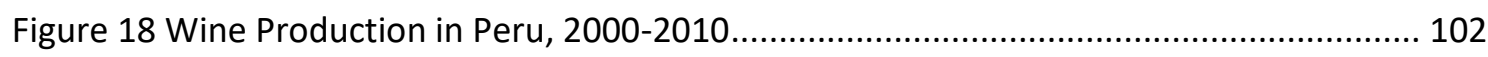

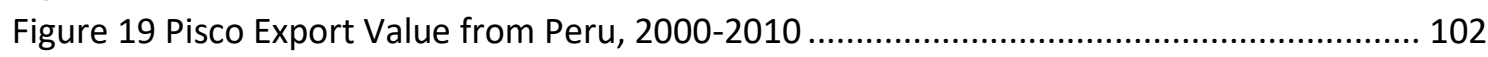

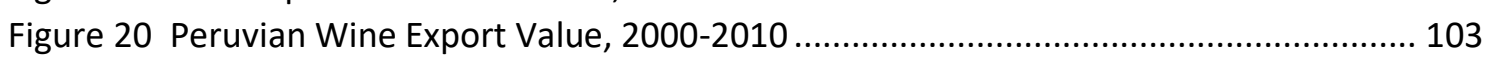

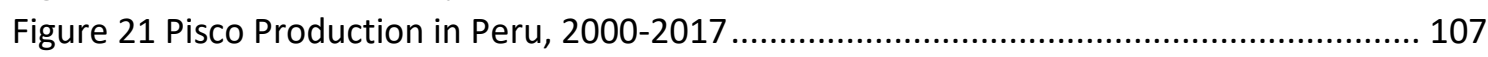

Figure 22 Evolution of Total Pisco Exports from Peru in Value and Weight, 2000-2017.......... 107

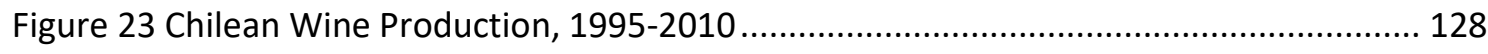

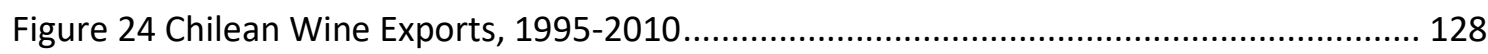

Figure 25 Total Chilean Wine Production, 1991-2017 ........................................................ 133

Figure 26 Evolution of Chilean Wine Exports in Value and Volume, 2000-2017 ...................... 134

Figure 27 Small-Scale Grape Producers in Bío Bío Region Protest Low Grape Prices in Chile.. 150

Figure 28 Five Types of Global Value Chain Governance.................................................. 157

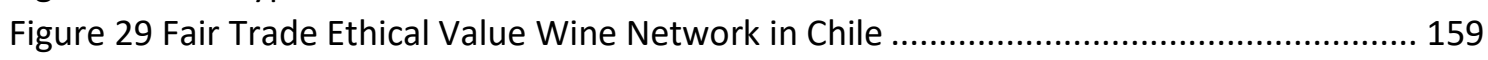

Figure 30 Visualisation of Governance in Chilean Conventional Wine Network...................... 165 
Figure 31 Visualisation of More Evenly Distributed Value Capture and Governance in Chilean

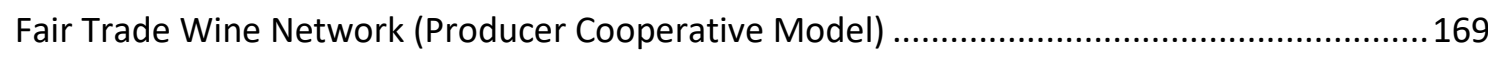

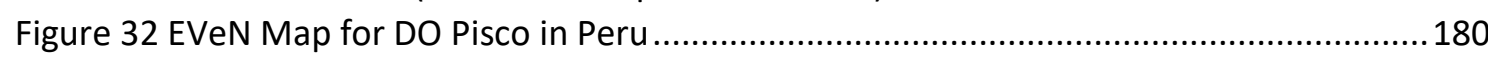

Figure 33 Visualisation of Governance in DO Pisco Network in Peru.........................................189

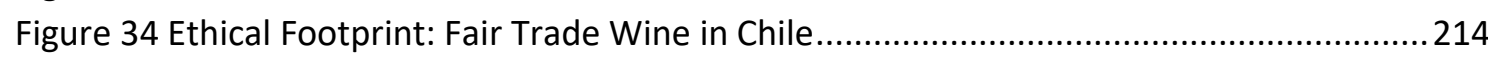

Figure 35 Ethical Footprint: Designation of Origin Pisco in Peru ...........................................235

Figure 36 Comparative Ethical Footprint: Designation of Origin Pisco in Peru and Fair Trade

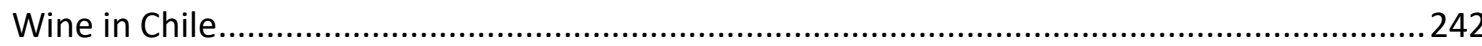

\section{LIST OF BOXES}

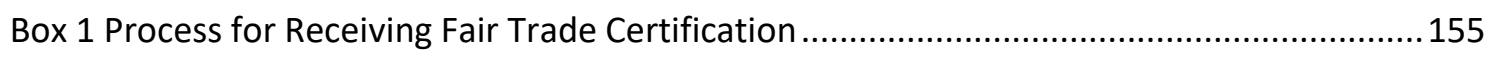

Box 2 Process for Receiving the Authorisation to Use the Pisco DO Mark ................................. 175

\section{LIST OF ACRONYMS}

\begin{tabular}{|c|c|}
\hline APEVIBOPA & $\begin{array}{l}\text { Association of Small-scale Viticulturists Bodega el } \\
\text { Palto Pachacutec }\end{array}$ \\
\hline APP & Peruvian Academy for Pisco \\
\hline CITEagroindustrial & $\begin{array}{l}\text { Centre of Innovation and Technology for Agro- } \\
\text { Industry }\end{array}$ \\
\hline CR & $\begin{array}{l}\text { Regulatory Council for the Designation of Origin for } \\
\text { Pisco }\end{array}$ \\
\hline DO & Protected designation of origin \\
\hline EVeNs & Ethical value networks \\
\hline FFV & Fresh fruit and vegetables \\
\hline FLO & Fair Trade International \\
\hline FLOCERT & Fairtrade International certification \\
\hline GDP & Gross domestic product \\
\hline GI & Geographical indication \\
\hline GPN & Global production network \\
\hline GVC & Global value chain \\
\hline IMO & Institute for Marketecology \\
\hline INDECOPI & $\begin{array}{l}\text { National Institute for the Defence of the Competition } \\
\text { and the Protection of Intellectual Property }\end{array}$ \\
\hline ISI & Import-substitution industrialisation \\
\hline NGO & Non-governmental organisation \\
\hline NIDL & New international division of labour \\
\hline ODEPA & Office of Studies and Agrarian Policies \\
\hline SAPs & Structural adjustment policies \\
\hline TNC & Transnational corporation \\
\hline TRIPS & Trade-Related Aspects of Intellectual Property Rights \\
\hline WTO & World Trade Organization \\
\hline
\end{tabular}




\section{CHAPTER ONE. THESIS INTRODUCTION}

"The division of labor among nations is that some specialize in winning and others in losing. Our part of the world, known today as Latin America [...] has specialized in losing ever since those remote times when Renaissance Europeans ventured across the ocean and buried their teeth in the throats of the Indian civilizations. Centuries passed, and Latin America perfected its role [...] It continues to exist at the service of others' needs, as a source and reserve of oil and iron, of copper and meat, of fruit and coffee, the raw materials and foods destined for rich countries which profit more from consuming them than Latin America does from producing them [...] to speak of fair prices is a "medieval" concept, for we are in the era of free trade." - Galeano (1997, p. 12)

This passage from Galeano's influential work 'Open veins of Latin America: Five Centuries of the Pillage of a Continent' encapsulates the European colonisation of Latin America and the ensuing processes of uneven development and underdevelopment which have occurred in the region since. For many, this colonial legacy and the associated underdevelopment have united the otherwise diverse Latin American countries (Gerdes, 2009). Predominant Latin American scholars have demonstrated that unequal exchanges were established by colonialism and reinforced by neo-colonialism. These scholars have illustrated that these unequal exchanges have consolidated the region's role as a resource-dependent periphery in the global economy (Dos Santos, 1970; Frank, 1969b). In this context, Latin American countries have long served the needs of foreign powers for raw materials, creating long-standing social and economic inequalities in the region. The benefits of Latin America's integration into the global economy have been concentrated by minority groups of external and internal elites, which have excluded the majority of the region's populations (Silva, 2009). Literature across Latin America, illustrates that small-scale farmers and rural labourers have been some of the groups most disadvantaged by the legacies of European colonialism and neo-colonialism in these countries (Hopkins, 1998; Kay, 1980; Murray, 2002a).

In this context of entrenched underdevelopment and socio-economic inequality, diverse attempts have been made to encourage more inclusionary and even forms of development across Latin America (Kay, 2002a; Thorp, 1998). This research explores recent efforts to better include ethical considerations into the development and trade priorities in Latin American 
countries. In particular, this thesis investigates what our research group ${ }^{1}$ has theorised as the evolution of ethical value networks, which will be defined later in this introductory chapter.

\subsection{RESEARCH RATIONALE AND CONTEXT}

\subsubsection{The Globalisation of Agriculture and the Global South}

Accelerated economic globalisation and the withdrawal of state regulation has fuelled the significant restructuring of national-economies, particularly in parts of Latin America and other regions of the South. This economic globalisation has been encouraged by neoliberal ideology which promotes economic liberalisation (Murray, 2009). In particular, agricultural sectors have been further integrated into the global economy through complex agro-food networks (Winter, 2004). This has been largely driven by the rise of transnational corporations (TNCs) mainly from the Global North (North American and European countries) which, facilitated by neoliberal policies, have expanded their operations across vast distances, especially in the South (Sturgeon, 2008). A number of Latin American countries have experienced some of the most dramatic neoliberal reforms since the 1980s. This has tended to reconsolidate the roles of these countries as resource peripheries in the global economy (Murray \& Overton, 2014). Despite some positive outcomes of this economic integration, recent attention has focused on a range of negative social, economic and environmental outcomes this has had in Latin America and in other Southern regions (Bryant \& Goodman, 2004). Facing colonial legacies, increased global competition, reduced governmental support, small-scale farmers and rural labourers in the South have mainly experienced negative outcomes from economic liberalisation and the globalisation of agriculture (McMichael, 2012; Murray, 2006b).

\subsubsection{The Evolution of Ethical Value Networks}

As countries of the South have been increasingly integrated into the global economy as suppliers of agro-food products, there have been reactionary concerns among Northern consumers over social justice, food authenticity, safety and quality, and environmental sustainability. Therefore, consumers are demonstrating greater scepticism over how, where and to what standards food is being produced (Goodman, 2004; Mutersbaugh, 2005). Consumer scepticism has been recognised as forms of reaction and resistance to the growing 'placelessness' of food production generated by the increasing globalisation of agriculture (Murdoch, Marsden, \& Banks, 2000). The globalising agro-food networks have therefore created a paradox. On one hand, global consumers and local producers have become

\footnotetext{
${ }^{1}$ This doctoral research contributes to the collective work of a wider research group at Victoria University of Wellington. This research group consists of Warwick Murray, John Overton, Peter Williams, Kelle Howson and Simon Bidwell.
} 
increasingly dependent on Northern TNCs which dominate agro-food networks. However, on the other hand, consumers are more concerned with the negative outcomes linked to the globalisation of agriculture and have begun to search for alternatives to conventional global agro-food networks. A significant factor encouraging these changes in consumer demands has been increased exposure to the negative outcomes globalisation can cause for the small-scale producers, rural labourers and local communities (Barrientos \& Dolan, 2006b; Bowen \& Zapata, 2009). Similarly, consumers have become more aware of health concerns linked to the globalisation of agriculture, which has increased demands for products which demonstrate food-quality, authenticity and origin (Bowen, 2010a). These consumer concerns over the globalisation of agriculture have encouraged the emergence of what our wider research group have labelled as 'ethical value networks' (EVeNs). We have theorised that EVeNs are diverse networks which emphasise and certify ideas of ethical and high-quality production through labels such as fair trade labels, geographical indication marks, and organic or sustainability certifications. A common defining factor of these diverse EVeNs is the claimed objective to create 'ethical value' by linking producers and consumers through ethical labelling. In this research, ethical labelling refers to the use of a visible product label which demonstrates that the product has passed a set of ethical criteria controlled by an external accreditor.

EVeNs have become increasingly important in Latin American countries and other Southern regions which experience high dependency on low-value primary products and suffer from asymmetric neo-colonial integration in the global economy. Diverse EVeNs based in social justice, sustainability and localised production labels have therefore been promoted as alternative models to support groups to transition from low-value production to higher-valued ethical production, which supports local development.

\subsubsection{Ethical Value Networks in South American Viticulture}

This research further develops the theoretical and practical understandings of what our research group has defined as EVeNs, using case studies from viticulture in South American countries. South America represents a particularly important region for commodity studies due to the region's significant integration into the global agro-food markets. As mentioned, this dependence on resources was first established through European colonisation and later maintained through the spread of neoliberal globalisation (Escobar, 2010). Furthermore, similar colonial legacies across South American countries have entrenched long-term discrimination against small-scale producers and labourers in rural areas (Murray \& Overton, 2014), thus signifying the potential importance of EVeNs in encouraging more even forms development. 
This research represents an innovative project which studies two distinct EVeNs in Peru and Chile. Fair trade labelling on Chilean wine and the protected designation of origin (DO) mark on pisco ${ }^{2}$, a distilled grape spirit from Peru, have been selected as EVeNs case studies. It is important to note that Chile also produces a distilled spirit under the name, which has led to a long-lasting debate over the geographical origin of pisco between Peru and Chile (Mitchell \& Terry, 2011). For the purpose of this research, only the Peruvian DO for pisco has been investigated in detail.

While there are diverse fair trade certifications, the common principles of the fair trade movement include a stable 'fair trade price' which covers more than the costs of production and protects producers from market fluctuations, as well as a 'fair trade premium' which is used to support community and producer development (Fair Trade International, 2014). A DO mark is a specific form of protection under the broader concept of geographical indications (GIs) (WIPO, 2013). GIs provide legal protection for the intellectual property of agricultural products which possess unique high-qualities due to their place of origin and the local knowledge linked to these unique products. DOs represent the strictest form of GI protection (Josling, 2006). This thesis proposes that both the fair trade certifications in Chilean wine and the DO for pisco from Peru represent EVeNs for the following reasons: (1) fair trade wine in Chile is considered to contribute to ethical production by supporting small-scale producers, viticultural employees and the broader community through the fair price, premium and other benefits associated with fair trade. (2) The DO on pisco in Peru is considered to encourage localised and ethical production by supporting the development of traditional and small-scale producers and the wider communities in the production areas. Moreover, these EVeNs represent possible alternatives to the model of low-value, mass-produced, agro-food products encouraged by neoliberal ideology which has long dominated most South American economies (Barham \& Weber, 2012; Grugel \& Riggirozzi, 2012; Mancini, 2013).

The two country studies, Peru and Chile, were selected as they provide interesting comparative cases. Both of these South American countries represent important case studies for research on commodities as both countries share historical and contemporary dependencies on primary resources (Días \& Korovkin, 1990; Gwynne \& Kay, 2000). Additionally, Peru and Chile share comparable Spanish colonial legacies and associated deep-set socio-economic inequalities,

\footnotetext{
${ }^{2}$ According to the National Commission of Pisco (Peru) the full definition of "...is a product made exclusively from the distillation of fresh grape musts from 'pisco grapes' recently fermented, using methods which maintain principles of tradition and quality, and produced along the coast in the regions of Lima, Ica, Arequipa, Moquegua and in the valleys of Locumba, Sama and Caplina in Tanca." (Author's translation). From (Comisión Nacional del Pisco, ND).
} 
especially in rural areas (Kay, 2001). Furthermore, both countries have experienced important land reforms and neoliberal counter-reforms (Eguren, Eguren, \& Durand, 2018; Murray, 2006b; Philip, 2013). Despite these similarities, there are important differences between the studied countries. For instance, Peru was established as a centre of the Spanish American Empire while Chile was a peripheral colonial territory. This generated important differences in how each territory functioned and developed before and after independence (Lockhart, 1994; Lynch, 1985). In modern times, Chile ranks higher than Peru in economic and human development indices ${ }^{3}$, although income inequality is higher in Chile ${ }^{4}$.

The wine and pisco sector case studies were selected for similar reasons, providing comparative case studies with significant similarities and differences. To begin, both wine and pisco are viticultural products which use the same raw material, grapes, follow similar production processes and involve similar actors. As will be demonstrated, the sectors are very different in scale: Chile's wine sector is much larger in production, exports and value when compared to Peru's pisco sector. Nonetheless, recently both sectors have experienced important growth which has been associated with neoliberal policies and sectoral concentration by large-scale producers (del Pozo, 2014; Huertas Vallejos, 2004). Moreover, pisco and wine are deeply rooted in the colonial histories in both countries. Similarly, both products have grown to represent important symbols of modern Peruvian and Chilean identities, yet are also associated with rural socio-economic inequalities and exclusionary practices against small-scale grape producers. Finally, the use of fair trade in Chilean wine and the DO for pisco from Peru were selected as case studies as these EVeNs have been promoted as potential tools to encourage localised and ethical development through viticulture. Figure 1 below visualises this commonality between the ethical idealisation of these two EVeNs. This study, therefore, investigates these networks through a multi-scale cross-national research approach. This approach aims to improve the understanding of these EVeNs at the global, regional and local scales.

\footnotetext{
${ }^{3}$ According to GDP statistics from the World Bank Chile's GDP reached US\$277,079 billion while Peru's GDP measured at US\$211,389 billion. United National Human Development Reports for Peru and Chile from 2016 show that Chile reached the human develop index (HDI) of 0.847 while Peru reached a lower HDI of 0.740 (World Bank, 2018a, 2018b); and (United Nations Human Development Programme, 2016a, 2016b).

${ }^{4}$ The Gini index measure distribution of incomes, whereby 0 represents perfect equality, and 100 implies perfect inequality. According to these measure, Peru sat at 43.5 and Chile at 47.7 in 2015 according to World Bank estimates (World Bank, 2018a, 2018b).
} 


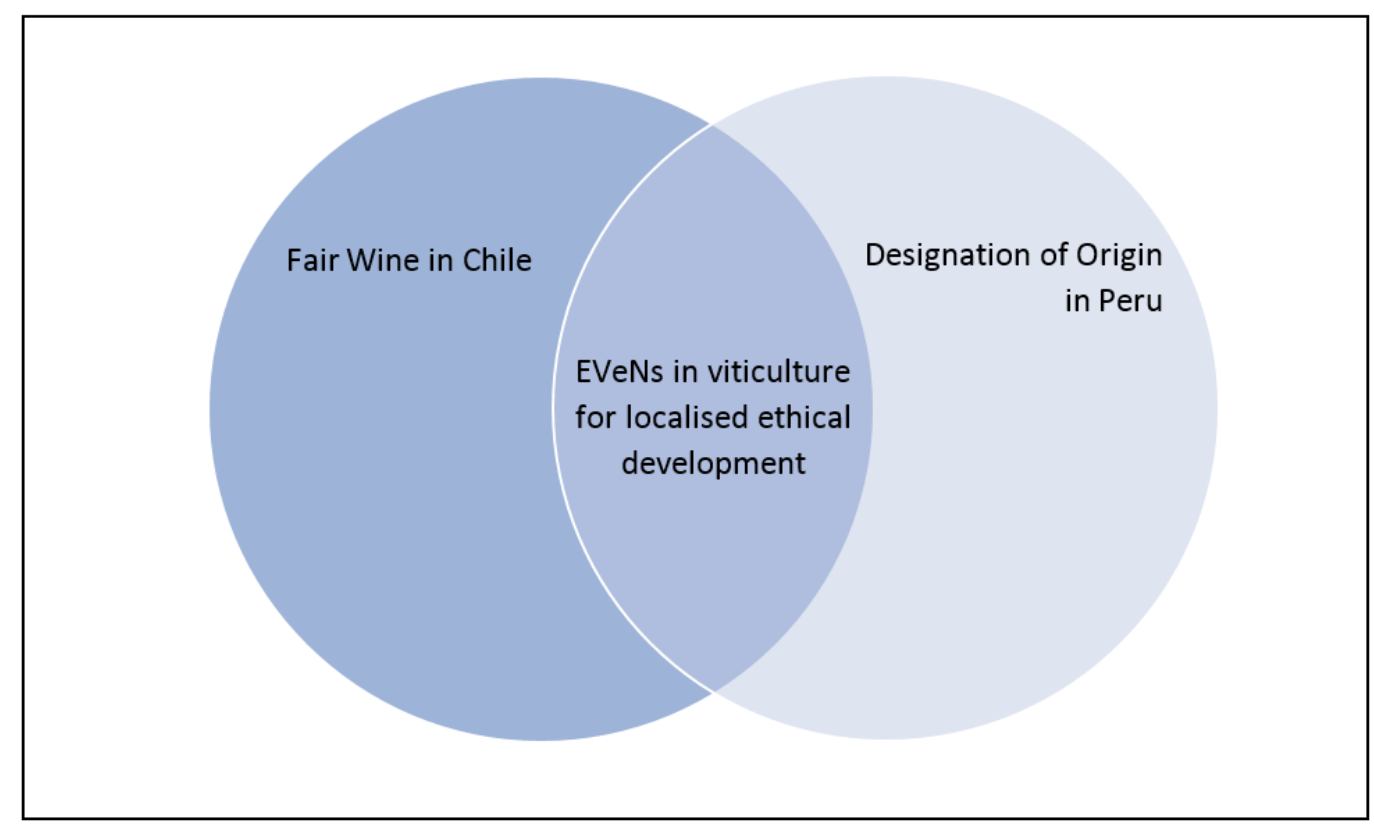

Source: Elaborated by the author

\subsection{RELEVANCE OF STUDY: THEORISING ETHICAL VALUE NETWORKS IN SOUTH AMERICA}

This innovative research project provides a relevant contribution to the theorisation of EVeNs surrounding the growing number of ethical labels in the global market. In particular, this research contributes to studies on the globalisation of agriculture and responses to this process in South America. Moreover, these contributions can be extended and compared with other 6experiences in Latin America and in other regions of the Global South (Biénabe \& MarieVivien, 2015; Linton, 2012). This original research also demonstrates the importance of local contexts in shaping the evolution and outcomes of EVeNs, through the cases studies in Peru and Chile. Therefore, this research contributes to a better understanding of how global EVeNs are realised in the local areas where these networks are embedded. In doing so, this research makes relevant contribution to the broader literature on geographical indications (Bowen, 2010b; Hughes, 2009; Larson, 2007) and fair trade (Barham \& Weber, 2012) which tend to contest the validity of the local outcomes of these EVeNs in Latin America. However, limited research, based in Latin America, has concentrated on the commonalities across these diverse EVeNs, how they have emerged, and which groups participate in them. Furthermore, limited work has identified the ethical claims made to support these EVeNs or the realisation of these claims across different scales. This doctoral research explores these knowledge gaps and contributes to addressing these research areas by investigating local contexts and outcomes in the locations where these EVeNs are 'embedded' through the South American case studies of fair trade wine in Chile and DO in pisco from Peru. 


\subsection{RESEARCH AIMS AND QUESTIONS}

This project is guided by three central research aims, which have aided the critical investigation of the two EVeNs embedded in Chilean and Peruvian viticulture. The first research aim is to complete a comparative exploration of the historical evolution of viticultural sectors in Chile and Peru. This will generate a more informed understanding of the modern contexts where the EVeNs have developed. The second research aim is to critically investigate the construction of, participation in, and governance of EVeNs using examples from the fair trade and DO networks in viniculture in Chile and Peru. The third research aim is to identify the ethical claims utilised to promote these fair trade and DO networks and evaluate how these claims are realised through detailed investigation in the localities where the selected EVeNs are embedded. To achieve these aims, this research seeks to answer the following multi-scale research questions:

\section{Global Level}

1.1 What has motivated the evolution of EVeNs in fair trade and DO globally?

1.2 What actors participate in the construction and regulation of these global EVeNs?

1.3 What ethical claims are applied to promote these networks, and do they represent valid alternatives to conventional trade?

\section{Regional/National Level}

2.1 What historical and contemporary factors have caused the expansion of EVeNs in viticulture in Peru and Chile?

2.2 What actors participate in these DO pisco and fair trade wine networks nationally, and how is the 'ethical value' distributed between these actors?

2.3 What ethical claims have been applied to promote these networks at the national level?

\section{Local Level}

3.1 What has encouraged small-scale producer and rural labourer engagement in the pisco and wine EVeNs in the local case study areas?

3.2 To what extent have local actors been included and excluded in the expansion of these EVeNs in the production areas?

3.3 Are the ethical claims used to promote wine and pisco EVeNs being realised in the communities where these networks are embedded?

\subsection{THESIS STRUCTURE}

Following this introductory chapter, this thesis has been divided into eight chapters. Chapter Two ('Describing the Research Process: Methodology') outlines the methodology, research design and methods and discusses my positionality as the researcher. Chapter Three ('Placing 
Value on Ethical Production: Globalisation and Ethical Value Networks') examines the evolution of EVeNs with particular emphasis on the growth of fair trade and DO marks. This chapter introduces the key theoretical foundations and debates involved in these networks. Chapter Four ('Grounding Ethical Value One: Historical Evolution of Peruvian Viticulture') explores the historical and contemporary development of Peru through the lens of viticulture. Chapter Five ('Grounding Ethical Value Two: Historical Evolution of Chilean Viticulture') examines the historical and modern development of Chile through viticulture. Chapter Six ('Mapping Ethical Value: Motivations, Governance and Power in Chilean and Peruvian Viticulture') explores the formation and institutionalisation of the EVeNs surrounding the studied EVeNs using primary data from the research interviews. Chapter Seven ('Evaluating Ethical Value: Critical Investigation of Ethical Claims and Local Outcomes') critically examines the idealisation, realisation and failed realisation, of the ethical claims used to promote the studied networks. Chapter Seven is also based on primary data from the research interviews. Chapter Eight ('Conclusions: Discussing Ethical Value') closes the thesis by reflecting on the key findings and links to broader contributions to the relevant theories. Additionally, this chapter provides concluding remarks and evaluates the research: exploring the benefits and areas for further investigation. 


\section{CHAPTER TWO. DESCRIBING THE RESEARCH PROCESS: METHODOLOGY}

\subsection{CHAPTER INTRODUCTION}

This methodology chapter explains each step of the cyclical research process which has been used to ensure a succinct and effective doctoral thesis. As displayed in Figure 2 below, the research process is represented as a cycle of interacting components. Rather than following a linear research model, the cyclical process emphasises the interactions between the different stages of the research.

Figure 2 Cyclical Research Process

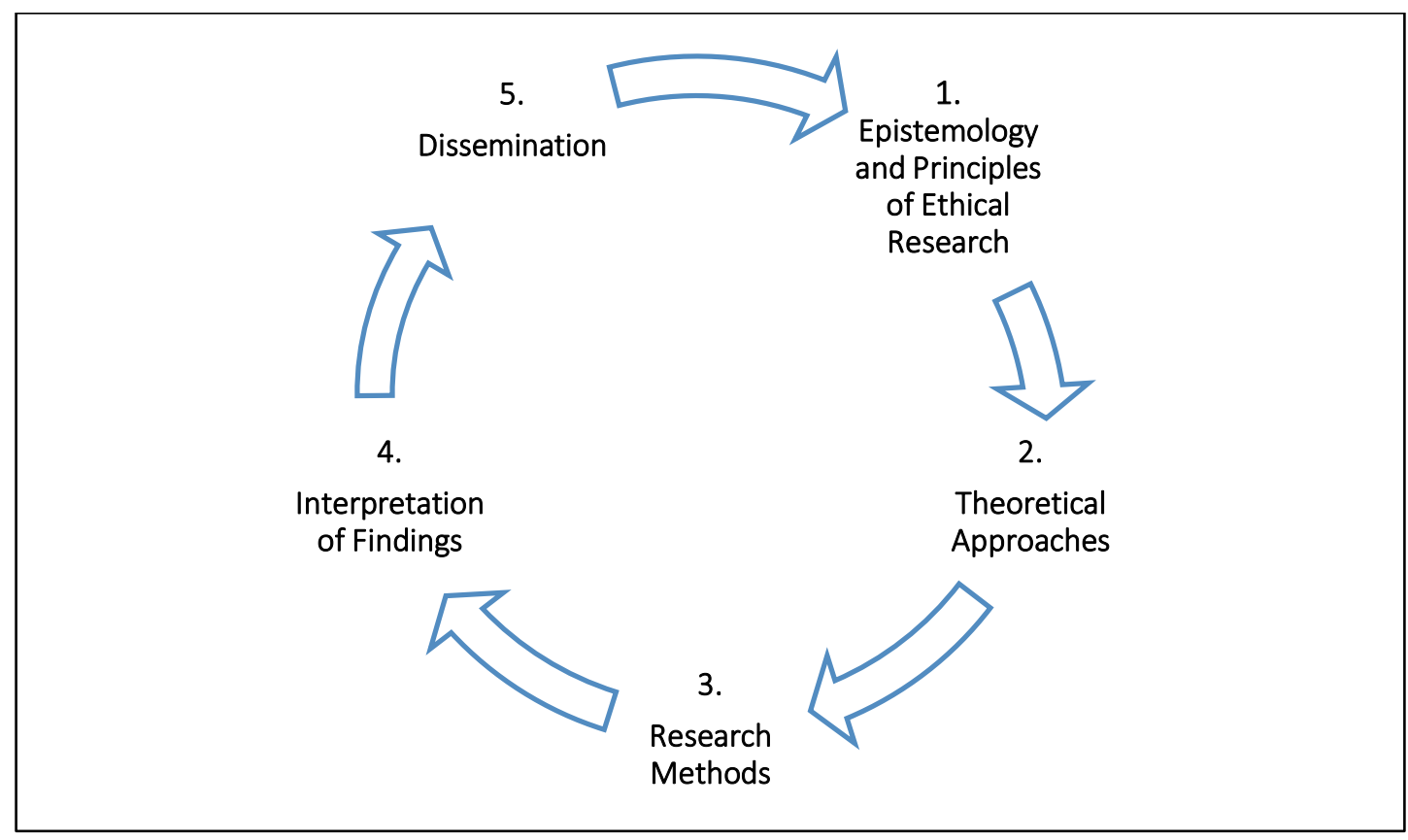

Source: Elaborated by the author

This chapter follows the same structure as the cyclical research process. First discussing the critical realist epistemology which has been applied and the key positions within epistemological debates in social sciences. This section also observes the core principles of ethical research which have been implemented when carrying out this doctoral research. Subsequently, the chapter explores the theoretical approaches which have underpinned this research. Following this, the chapter provides an outline of the research methods as well as a description of the fieldwork, case study areas, and the selection of the research participants. In addition, the chapter discusses how the findings were interpreted and how these findings were disseminated amongst the research participants. Finally, the chapter closes with a discussion and a link to Chapter Three. 


\subsection{CRITICAL REALISM EPISTEMOLOGY}

This research applies a critical realist approach. Debates surrounding ontology and epistemology in social science have commonly been framed as dichotomies between opposing approaches, for example, positivism versus constructionism, or quantitative versus qualitative (Della Porta \& Keating, 2008). However, it is useful to observe these approaches as existing on a continuum as there are significant overlaps, positivist empirical-analytical approaches would be at one end while constructionist approaches, which to differing degrees reject the empirical worldview, would be at the other end. The midpoint of this continuum is critical realism, where this research fits within (Murray \& Overton, 2003).

Critical realism assumes that a material world exists and that it is impossible to disprove or prove this hypothesis. However, critical realists accept that the researcher's knowledge of the world is also socially conditioned and therefore can be challenged or interpreted in different ways (Easton, 2010; Sayer, 2000). Central to critical realism is prioritisation and discovering the unobserved and non-explicit processes and interactions with a clear inclusion of moral questions. In critical research, the communication of the findings seek to stimulate progressive social transformations (Della Porta \& Keating, 2008; Murray \& Overton, 2003). Critical realism research applies a selection of research methods according to what is appropriate for the research project. In this sense, critical realism does not subscribe to a 'one size fits all' methodology and encourages a mixed-method approach (Ackroyd \& Fleetwood, 2005).

This research has implemented a critical realism approach in order to reveal the less explicit motivations, processes, power dynamics and claims involved in EVeNs in the studied sectors in Chile and Peru, and more widely in Latin America. Accordingly, this research does not reject the view that a real-world exists or ignore the value of empirical data which is used to support the explored case studies. Nevertheless, I also acknowledge that the findings have been influenced by social conditioning. The research aims and questions, as well as the interpretation of the case studies, have been socially constructed to some degree (Della Porta $\&$ Keating, 2008). Following the central elements of critical science, this work has developed findings through a set of research questions which attempt to encourage positive social transformation (Murray \& Overton, 2003). Critical realism, therefore, provides a balanced and useful framework which has allowed me to effectively investigate EVeNs in Latin America.

\subsection{PRINCIPLES OF ETHICAL RESEARCH}

Throughout the planning, fieldwork, analytical and writing stages of the research there has been central importance placed on the following principles for ethical research: self-critical 
reflection, positionality, avoiding 'research tourism' and extractive research. These principles will be explored in the proceeding sections. Interestingly, the post-completion stage (when the research is completed) is often omitted in the increasingly diverse discussions around ethical research (Zhang, 2017). This research, however, seeks to extend ethical considerations into the post-completion phase through knowledge sharing with the research participants. This incorporation has enriched the study and ensured that it has not harmed any of those who have been part of the research process.

\subsubsection{Self-Critical Reflection}

Since the 1980s, there has been growing criticism directed at researchers who conduct social science research in countries of the Global South ${ }^{5}$ and/or in marginalised communities within their own countries (Chacko, 2004; Sidaway, 1992). The relevance of this kind of academic research has been questioned as past experiences have shown that often there are no benefits for the 'researched' communities (Edwards, 1989). In the worst-case scenarios, researchers have prioritised their own career progression over the rights of the research participants and have used exploitative research methods. In response to these criticisms and concerns, social scientists are beginning to engage in self-critical reflection over their research, and their actions and non-actions as researchers (Scheyvens \& Storey, 2003). According to Chambers (2007, p. 12) self-critical reflection is the process of "...being critically reflective about one's own ways of being, mindset, categories, ways of framing reality, perceptions, prejudices and predispositions...". Self-critical reflection allows us to reflect on how our thoughts and ideas are created and the actions and non-actions we take. It is the personal responsibility of the researcher to reflect on their actions and non-actions (Chambers, 1997). I have engaged in selfcritical reflection throughout the research and taken care to think about the consequences of my actions and non-actions, particularly when in the field. Central to this is the application of high ethical standards throughout the research and following a principle of 'do no harm' (Chambers, 2012). This has been particularly central in fieldwork and in the ways I have presented the opinions and experiences of the research participants. Furthermore, the research outputs and relevant knowledge were shared with the diverse groups of research

\footnotetext{
${ }^{5}$ The Global South, sometimes referred to as the periphery or the Developing World, are the regions which have been considered to be less economically advanced. These include; Africa, Latin America, developing Asia, the Middle East and the Pacific States. The Global North, is also referred to as the Core or the Developed World, is made up of countries which are considered to be economically advanced. These include the United States, Canada, Western Europe, developed parts of East Asia as well as New Zealand and Australia (Odeh, 2010). It is important to note that these terms have been criticised as being Eurocentric over-implication of diverse regions (Sachs, 2013; Ziai, 2017).
} 
participants, hence attempting to create a benefit for these groups. This dissemination of knowledge as a principle of ethical research will be examined later in this chapter.

Finally, this research received Victoria University of Wellington (VUW) Human Ethics Approval from the VUW Human Ethics Committee prior to fieldwork. This ensured that the research was conducted in accordance with the University's Human Ethics Policy. Following requirements from the Human Ethics Committee, participant names have only been included when written permission for this was provided by these participants. This was explained to the participants before the interviews were conducted and participants had the ability to withdraw from the project before the $1^{\text {st }}$ of January 2018. Before an interview could take place, consent forms were signed and an information sheet was left with the participant with contact details. The data from the interviews has been stored securely and will be destroyed five years after the competition of the project in accordance with the Human Ethics Approval.

\subsubsection{Positionality}

Many of the concerns surrounding the ethical legitimacy of research in the Global South are based on the unequal power relations which exist when comparatively privileged Western, or Western-trained, researchers engage in fieldwork on marginalised people in the South (Scheyvens \& Storey, 2003). This kind of fieldwork has been critically labelled as a mere process of 'academic tourism' or 'research tourism' (Mowforth \& Munt, 1998). These research experiences are essentially a form of tourism based on the extraction of a cultural and social experience. Rather than returning to their home countries with photos to show their friends and families, these researchers come back with findings to be used for academic articles and to progress in their academic careers (Saldanha \& Klopfer, 2014).

These critiques and concerns have forced researchers to be more aware of themselves and of how their 'positionality' influences their research (Madge, 1997). As explained by Chacko (2004, p. 52)

\footnotetext{
"..."positionality" here refers to aspects of identity in terms of race, class, gender, caste, sexuality and other attributes that are markers of relational positions in society, rather than intrinsic qualities. Unequal power relations are implicit in positionality."
}

The perception that fieldwork is just a question of applying the relevant techniques in the field is challenged when the consequences of our positionalities are acknowledged. Complications are formed through differences in identities when relatively privileged Western researchers seek interviews and other interactions with marginalised research participants. This is because 
a level of unequal power relations between the researcher and the research participants usually exists. The positionalities of these two groups can, therefore, lead to uneasiness on behalf of the research participants when sharing personal information, and in their representation through the researcher, it can also create the risk of exploitation and ethical dilemmas for the researcher. These concerns do, however, ignore the different forms of power held by participants, for example, their power to withhold certain information. Power in fieldwork, therefore, sits on a continuum, where both researcher and research participants hold different forms of power (Scheyvens \& Storey, 2003). Different methods can be used to help balance the unequal power relations and create positive relationships between the researcher and research participant. These methods include: being open about the research, encouraging reciprocal sharing of information, being accommodating around the participants' time constraints and commitments, and focusing on the lived experiences of the participants (Zhang, 2017). A crucial element of fieldwork is therefore based on forming and maintaining researcher-participant relationships. This creates relationships which are mutually rewarding and encourages more valuable and fulfilling fieldwork (Chacko, 2004).

\subsubsection{Positionality of the Researcher}

Following the notions of acknowledging one's own positionality and engaging in self-critical reflection, it is important for me, as the researcher, to briefly discuss my positionalities and the influences of these positions on the research. I am a Western university-educated, middleclass, male of European ancestry from New Zealand working in South American contexts. In the field, I was an 'outsider' as a foreign researcher in Peru and Chile. I have, however, spent a considerable amount of time in Latin American countries: I conducted my Master's research in Peru in 2011 and I have since lived in and visited other Latin American countries. With this experience, I possess a working-fluency in the Spanish language and an understanding of life in Latin America. This understanding is limited when one considers the diversity of lived experiences that exist in one of the world's most unequal continents by socio-economic measures (Hoffman \& Centeno, 2003; Wade, 2017). My country of origin, New Zealand, is situated in the South Pacific but is considered to be part of the Global North or West for historical, political, cultural and economic reasons. New Zealand was established as an English colony. This has affected the society I was raised in, the education I received and the language I speak. My university education and experience have been an influential part of my personal development. I would consider myself to be a progressive thinker influenced by ideas of social justice. These experiences and positions have therefore influenced the topics explored and the questions asked throughout the research. 
In conducting semi-structured interviews with campesinos (which generally had lower levels of formal education, yet significant lived experiences and knowledge unknown to myself), it was important to acknowledge my position as a university-trained foreign researcher. It was also important to implement actions to counter some of the associated unequal power relations that existed (Chacko, 2004). For instance, the fieldwork was completed over a relatively long period with an initial pilot-study component. This extended period of time in Peru and Chile was used to build relationships of trust with the participants and community leaders. This also provided the necessary time to explain the aims of the research and be open about my objectives as a researcher, while giving a potential participant time to ask questions and decide if they wanted to participate. A longer time period and also dedicating some time for interviews in the evenings and weekends meant I could be as accommodating as possible for participants. Discussing the lived experiences of the participants was a rewarding experience, and at the end of the interviews, many participants mentioned that they had talked a lot more and knew more about the topics than they had expected to prior to the interview. In order to equalise the unequal power relations that sometimes existed, I applied different measures such as taking time to build important relationships in the field, being open about the research project, as well as making accommodations for the time availability of the research participants, and also focusing on their learned experiences (Chacko, 2004).

My gender, as a male researcher, also had implications on the research. For instance, I found it easier to find and make connections with male research participants. I attempted to counter this by making conscious efforts to include female research participants. However, it is important to acknowledge that a male bias did exist in the interviews as more interview participants in the Peru and Chile studies were males. These numbers reflected the male bias which existed in the viticultural and wine and pisco making sectors in both countries. This demonstrated that females tend to be under-represented in leadership roles in these sectors, despite playing important roles in grape, pisco and wine production. The roles of women in the studied EVeNs represents an important theme and provides space for future research.

\subsubsection{Avoiding 'Research Tourism' and Extractive Research}

As the researcher, I have made, and continue to make, significant efforts not to become engaged in what has been labelled as 'research tourism'. Researchers, particularly when conducting cross-cultural research, need to be 'committed, embedded, and culturally engaged' in order to avoid becoming research tourists. There is, however, no blueprint plan for achieving this kind of committed and embedded cultural engagement. By dedicating relatively large periods of time in Peru and Chile, I attempted to explore and better understand the local socialcultural contexts. It is hoped that this time spent exploring, observing, discussing and sharing 
with local people from the case study areas over longer periods of time, has helped me better understand and represent my participants. It is crucial in any research project that the participants do not become a data source, used only to advance the career of the researcher. There should be instead a reciprocal process between the research participant and the researcher (Scheyvens \& Storey, 2003; White, 1993). Research should not be an extractive process and ethical research should ensure that there are positive implications for the participants (Saldanha \& Klopfer, 2014; Sidaway, 1992). I have made important efforts to share the research findings with the participants. Following the suggestion from Zhang (2017, p. 147) "that by reciprocating kindness in humble but practical ways, one may also contribute to an ethical research." I have always been open to assisting my research participants where I have the capacity to do so.

Although this research is not located in post-development or alternative theories of development, as a researcher I have been influenced by these theories. The central arguments of these perspectives are that the failures of development mean that development as a concept is in ruins. It has been claimed that development has been largely a negative force which has allowed the extension of the Global North's powers in the South and harmed Southern populations by doing so (Andrews \& Bawa, 2014; Parfitt, 2011). A central argument of the post-development school was that the term 'underdevelopment' was first created in the Cold War and decolonisation context, and used to extend Northern power throughout the 'underdeveloped' regions thereby spreading neo-colonial structures. Post-development theorists have criticised development discourses for depoliticising poverty and inequality by focusing on solutions based on technical assistance while overlooking deeper problems of asymmetric power relations. The characterisation of the Southern countries as 'underdeveloped' has also been criticised by the post-development school. By defining the Western way of life as 'developed' and the rest of the world's population as 'underdeveloped', development suffers from Eurocentrism (Esteva \& Escobar, 2017). While this research is not situated in post-development or alternatives theories of development, ideas from these perspectives have assisted me to think and engage critically with ideas of development.

\subsection{THEORETICAL FOUNDATIONS OF THIS RESEARCH}

\subsubsection{Dependency Theory}

Dependency theory has supported this research by proving a critical lens for studying global capitalism and the economic integration of the Global South into the world economy. Similarly, this research has contributed to dependency theory by demonstrating its modern relevance in critically investigating economic globalisation. Dependency theory, along with structuralism, 
grew from a rising disillusionment in the Global South, particularly from Latin America, with the failings of the modernisation development paradigm which became dominant following the end of WWII. Proponents of modernisation had claimed that countries in the Global South or in 'underdeveloped' areas would 'take-off' towards development and modernisation with more contact with North America and European countries and would ultimately attain similar political and economic features of these Northern countries (Halperin, 2013a). By the 1960s, it became evident that the claims of modernisation had not been realised as most of the Global South continued to suffer from underdevelopment (Halperin, 2013a).

In response to the failings of modernisation, structuralist and dependency scholars argued that Southern regions have been structured and integrated into the global economy differently to the Global North and therefore need to be 'developed' through different processes (Halperin, 2013b). According to these perspectives, modernisation failed to understand and act upon problems of development and underdevelopment in Latin America and beyond (Gwynne \& Kay, 2000). Dependency theory follows Marxist theories of imperialism and divides the world by an international division first established during colonisation. This international division separates the wealthy industrialised 'core' countries and the marginalised 'peripheral' countries (Dos Santos, 1970; Halperin, 2013b). Following from this, a central argument of dependency theory is that the problems experienced in underdeveloped areas are not caused by the peripheral countries. Instead, dependency theory argues that underdevelopment is a process which has been caused by the historical integration of the periphery (Global South) into the global economy, causing the transfer of wealth from these underdeveloped countries to more developed ones in the core (Global North) (Frank, 1966; Riddell, 1968) (see Figure 3). According to dependency theorists, the dual processes of underdevelopment and development, in turn, create wealth in the core countries and poverty in the peripheral ones. As argued by Frank (1969a, p. 9) underdeveloped and development are interrelated and contradictory processes of the same capitalist system;

"Economic development and underdevelopment are the opposite faces of the same coin. Both are the necessary result and contemporary manifestation of internal contradictions in the world capitalist system. Economic development and underdevelopment are not just relative and quantitative, in that one represents more economic development than the other; economic development and underdevelopment are relational and qualitative, in that each is structurally different from, yet caused by its relation with, the other." 


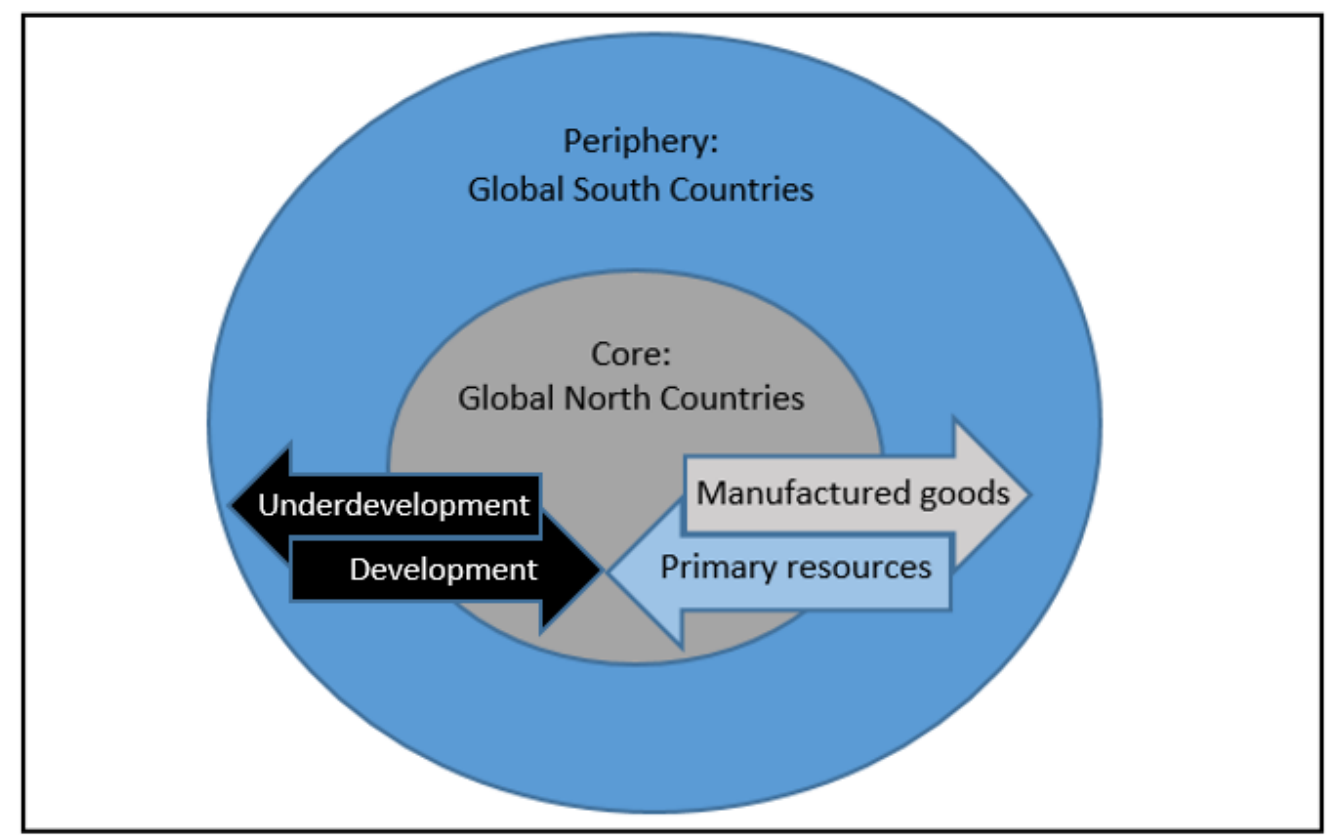

Source: Elaborated by the author using ideas from (Frank, 1969b) and (Dos Santos, 1970)

After a country is integrated into the periphery of the global capitalist structure, it is challenging for this country move from this position as the development of the dominant countries, or the core, relies on the underdevelopment of the peripheral countries (Frank, 1966; Riddell, 1968). Dependency theorists also argue that the global system of capitalism based on the period of colonisation has created a process of dependency where the development of the peripheral countries is conditioned by the development of one or more core countries. As explained by Dos Santos (1970, p. 231) dependence is when;

“...some countries (the dominant ones) can expand and can be self-sustaining, while other countries (the dependent ones) can do this only as a reflection of that expansion, which can have either a positive or a negative effect on their immediate development."

According to dependency theory, this 'development of dependent capitalism' in the periphery prevents these countries from fully advancing domestically and internationally and therefore causes marginalisation and poverty in the peripheral countries (Dos Santos, 1970). Dependency theory argues that the inequalities between the cores and peripheries, and the transfer of resources and wealth from the dependent and marginalised countries to the advanced and powerful founded and then worsened global inequalities. According to dependency thought, these inequalities have since become a required and central component to the structure of global capitalism (Dos Santos, 1970; Frank, 1969a). The radical Marxist camps of dependency theory thus argue that a shift from capitalism to a new global economic system is needed to 
break the processes of underdevelopment while structuralism and structuralist strands of dependency claim that reforming capitalism both internationally and nationally could resolve underdevelopment (Gwynne \& Kay, 2000).

\subsubsection{World-Systems Theory}

Largely a Northern American adaption of dependency theory, world-systems theory has provided this research thesis with an important theoretical lens to investigate global capitalism and globalisation. From the 1970s, world-systems theory authors have concentrated on understanding the global capitalist economy as a system of interacting actors, rather than nation-state units (Chase-Dunn \& Hall, 2012a). This change in primary focus from nation-states to the global capitalist economy has been labelled as the main innovation of world-systems theory (Petras, 1981). Under world-systems theory, the entire world is viewed as a single capitalist system which, since the Sixteenth Century, has been based on an 'international division of labour' consisting of a 'core', 'periphery' and 'semi-periphery' (Halperin, 2013b; Wallerstein, 2004). The core is made up of the Global North which has benefited the most from global capitalism, while the periphery includes the underdeveloped Global South and the semiperiphery is a combination of core regions which are declining and peripheral regions which are improving their position in the global economy (Sorinel, 2010).

According to world system theory, the most important interaction is between the core and the periphery while the semi-periphery acts as a 'buffer-zone' between the regions (Halperin, 2013a; Sorinel, 2010). By using the core-periphery perspective, world system theory represents an adaption of dependency theory as it uses structuralist and neo-Marxist explanations of global development (Sorinel, 2010). World-systems theorists argue that the interactions between the different regions, as well as the labour conditions and political systems of these regions, is determined by their position in the international division of labour (Halperin, 2013a; Wallerstein, 2004).

An important argument of world system theory is that core, through its political, economic and military dominance, has exploited the periphery through different forms of unequal exchange and trade relations (Petras, 1981; Wallerstein, 2004). Marxist analysis of the theory of labour value is used to explain how the capital surplus generated by the working classes in the peripheral regions are appropriated to the core through unequal trade relations (Petras, 1981). The semi-periphery is seen to benefit from the global economy but not as much as the core (Halperin, 2013a). The unequal exchange between the core, semi-periphery and periphery is shown in Figure 4 below. World-systems theory has therefore provided an additional perspective for understanding the capitalist system and the interactions between its different 
actors and represented a shift from analysing nation-states to studying global systems (ChaseDunn \& Hall, 2012b; Sorinel, 2010).

Figure 4 Visualisation of Core, Semi-periphery and Periphery Model in World-Systems Theory Literature

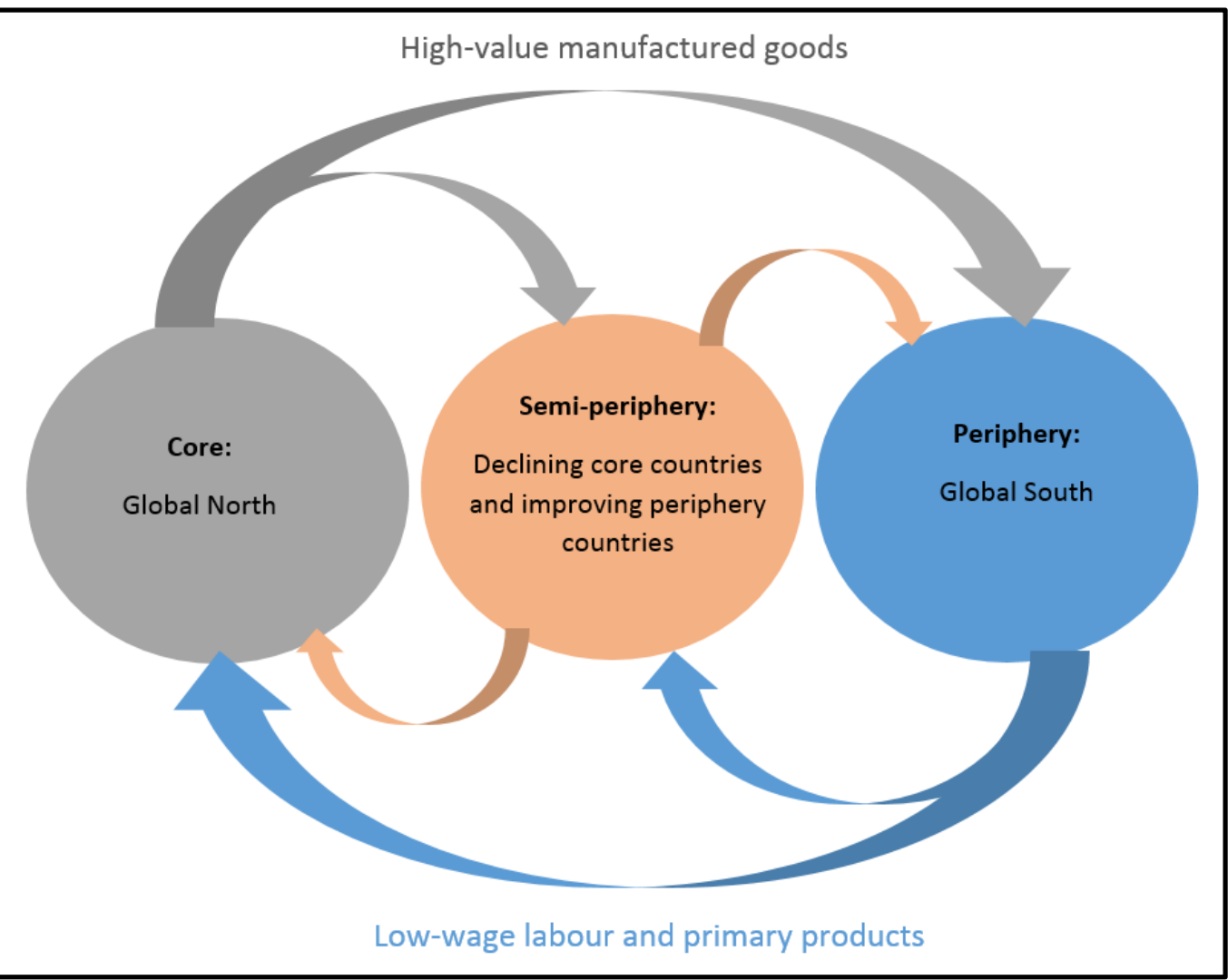

Source: Elaborated by the author using ideas from (Wallerstein, 2004)

\subsubsection{Neostructuralism}

Neostructuralism, as a body of theory and related policy, has also contributed to the critical study of contemporary global trade provided in this thesis. Neostructural thought grew principally in Latin America from the 1990s as a development and policy discourse which challenged the predominant neoliberal approach in the region (Bárcena \& Prado, 2016; Barton, Gwynne, \& Murray, 2007; Grugel \& Riggirozzi, 2012; Leiva, 2008; Murray \& Overton, 2011b). As defined by Leiva (2008, p. xix) Latin American neostructuralism represents:

“...(1) an alternative vision to neoliberal dogmatism; (2) a comprehensive development strategy; (3) an integrated policy framework; and (4) a grand narrative about the path toward modernity that the twenty-first century offers Latin American and Caribbean societies."

Largely as a response to negative social outcomes of neoliberal reform, neostructuralism has been increasingly influential in Latin America. The theory is based in the legacy of structuralist theory which emerged in the 1950s and prompted inward-oriented growth through import substitution industrialisation (Leiva, 2008; Murray \& Overton, 2011b). Neostructuralism does 
however include some important differences to structuralism, representing a post-neoliberal development paradigm rather than a response to the failings of modernisation theory. Since the 1990s, neostructural ideas have been applied by centre-left governments which have moved away from neoliberalism's unquestioning belief in the free-market. Instead, these governments have argued that governments need to play a selective role to ensure economic growth is associated with broad equality (Leiva, 2008; Murray \& Overton, 2011b). However, like neoliberalism, the neostructural paradigm is linked to similar objectives of globalised modernity. In this sense, neostructuralism has been critiqued for representing neoliberalism with a human face and as new rhetoric applied by neo-populist governments to win elections (Grugel \& Riggirozzi, 2012). These critiques, however, tend to ignore the clear insertion of the state into trade and economic policy as prescribed by neostructural thought and an important shift from neoliberal budget austerity (Leiva, 2008; Murray \& Overton, 2011b).

Importantly for this research, neostructuralism advocates for state intervention in economic affairs and a move away from a comparative advantage in natural resources. Neostructural thought argues that these shifts support peripheral economies to escape cycles of development based on resource dependence while encouraging value-added production (Leiva, 2008; Murray \& Overton, 2011b). As EVeNs have emerged from critiques and concerns with neoliberal trade, neostructural ideas have provided significant theoretical groundings for this research. Similarly, EVeNs and neostructuralism share similar objectives of creating equality through global trade.

\subsubsection{Dependency, World-systems and Neostructuralism and this Research}

Dependency, world-systems and neostructural theories have been central in critically exploring how value is created, distributed and appropriated by different actors in the EVeNs. In particular, dependency and world-systems theories have been applied to reveal the risks of value appropriation by the more powerful corporate actors in the studied EVeNs. Similarly, dependency and world-systems approaches have been useful in exploring the roles of capital and investment in the studied EVeNs. As will be discussed in later chapters, corporate actors have entered EVeNs in search of opportunities for profits while creating asymmetric relationships and unequal exchanges within these networks. Dependency and world-systems perspectives have been central in studying these processes and relationships. In addition, the dependency and world-systems perspectives have supported a deeper understanding of the historical and contemporary development and underdevelopment in Latin America, therefore having important applicability to this research. While there are important differences between the two theories, they both propose that to understand development and underdevelopment in the Global South, we need to consider the historical integration of these peripheral countries 
into the global economy, as well as the socio-economic structures that have been established within these countries through this integration (Dos Santos, 1970; Frank, 1966; Wallerstein, 2004).

Neostructuralism has also provided an important theoretical base for this research and has strengthened the conceptual grounding of EVeNs. In line with neostructural critiques of neoliberalism, this thesis demonstrates the need to shift from a neoliberal economic model which has resulted in uneven and resource-dependent development in much of Latin America. Likewise, the theorisation of EVeNs have been partially based on the neostructural policies of fostering development within by shifting from policies of comparative advantage in low-value resources through selective state intervention, value-adding and upgrading (Murray \& Overton, 2011b). More specifically, this thesis evaluates the use of fair trade certification in Chilean wines and DO mark for pisco from Peru, as potential alternative forms of trade. EVeNs are proposed as a potential way of encouraging more inclusive forms of development in Latin America and easing resource dependence. As will be discussed in more detail in the final chapters, DO protected products which are regulated and promoted nationally and internationally by states show clear neostructural tendencies. Fair trade certified products, on the other hand, tend to be associated with neoliberalism as regulation and promotion are controlled by private actors. This said, neostructural policies are increasingly applied to fair trade as states are now becoming more involved in promoting the growth and exportation of these products while DO products are increasingly included in free trade agreements linked with neoliberal economics.

Dependency, world-systems and neostructuralist theories, therefore, provide theoretical understandings of the processes and socio-economic structures which occur in Latin America at the regional scale and in Chile and Peru at the national scales. These theories have been central in critically exploring the use of EVeNs in the viticultural sectors of two Latin American countries which continue to experience neoliberal models, with neostructural tendencies, in a number of cases. This thesis also highlights the continued importance and relevance of these perspectives in studies of development.

\subsection{GLOBAL VALUE CHAINS AND GLOBAL PRODUCTION NETWORKS}

\subsubsection{Global Value Chains Framework}

Important changes took place during the 1980s and 1990s in Latin America, East Asia, in the former Soviet Union and Eastern Europe creating a shift from the post-WWII 'development project' to what is often considered as the 'globalisation project' (Kay, 2008). This shift coincided with the abandonment of state-led development and import-substitution 
industrialisation (ISI) strategies, and saw the rise of export-oriented strategies in semiperipheral and peripheral regions (Gwynne, 2004). These changes caused increased interaction between the core and the peripheral and semi-peripheral regions which signified the need for new concepts to study these changing economic processes and relations. Since the early 1990s, global commodity chains (GCC) and later global value chains (GVC), have proven to be important analytical tools to understand the changing dynamics of international trade, economic globalisation and economic governance (Bolwig, Ponte, Du Toit, Riisgaard, \& Halberg, 2010; Gibbon, Bair, \& Ponte, 2008). GVC frameworks were derived from both worldsystems and dependency theories due to the use of the spatial categories (core, semi-periphery and periphery) (Gibbon, 2001; Gwynne, 2008).

The GVC framework has shown that in the current period of economic globalisation, most international trade occurs through TNCs or through governance systems which link companies through different contract arrangements. As a result, global trade can no longer be investigated through arms-lengths interactions (Gereffi, 2001). Instead, GVC literature shows that we need to investigate global trade and global economic governance through the complex operations of TNCs, as well as inter- and intra-firm interconnections (Gwynne, 2008). GVC analysis provides an important methodological tool for studying global trade by examining specific value chains where the input supply, production, trade, consumption and disposal are interconnected to some extent (Bolwig et al., 2010). GVC approach allows us to better study globalisation and development issues which cannot be explained through older paradigms due to the changes in the capitalist economy associated with accelerated globalisation. Moreover, the GVC framework helps us to better explore and explain shifts in global-local interactions which have emerged over the last three decades. According to Gereffi and Fernandez-Stark (2011, p. 4), the GVC framework examines four core dimensions ${ }^{6}$ :

“... (1) an input-output structure, which describes the process of transforming raw materials into final products; (2) a geographical consideration; (3) a governance structure, which explains how the value chain is controlled; and (4) an institutional context in which the industry value chain is embedded."

According to the GVC framework, a 'vertical' relationship exists between suppliers and buyers, and in the transfer of products from producers to consumers, in a value chain. The analysis focuses on the 'flows' of resources, capital and information between suppliers and buyers, whereby downstream refers to the flows towards consumption and upstream towards

\footnotetext{
${ }^{6}$ For full explanation of these dimensions see (Gereffi \& Fernandez-Stark, 2011)
} 
production (Bolwig et al., 2010). Additionally, the GVC framework distinguishes between producer-driven and buyer-driven global value chains which have been established by both the industrial and commercial companies which take advantage of the processes of globalisation. Producer-driven chains occur when large manufacturing firms have a central role in the coordination of the value chain, while buyer-driven chains are where larger retail stores and marketers have established decentralised manufacturing in a number of exporting countries, usually located in the Global South (Gereffi, 2001).

The GVC analysis has, therefore, become an important framework for studying the increasingly important role of powerful companies in the control and governance of the global economy. Rather than examining the ways in which these companies can influence international trade organisations and regulation for their benefit, many GVC authors consider these 'lead firms' to be the central actors in the governance of the global economic system. As explored in more detail in the following chapter, these powerful firms are usually from the Global North. As a result, it is likely that there is currently a period of globalisation where unseen levels of financial and retail power is being concentrated in the North (or core regions) while the South (or peripheral and semi-peripheral countries) are experiencing growing barriers to entry to GVCS in manufacturing and commodities due to increased global competition and protectionist policies which favour the North (Gibbon et al., 2008; Murray \& Overton, 2014). Participation in GVCs has, therefore, also been used to explore international development. Accordingly, the focus of the GVC framework has been altered to a large degree. For instance, the GVC approach initially concentrated on economic outcomes and competitiveness, particularly in business studies literature. However, the GVC approach is been increasingly applied in human-economic geography and development studies. It is now common for the GVC approach to study the social and environmental outcomes of economic globalisation. For instance, GVC analysis has been used to investigate new dimensions such as labour and environmental concerns in value chains and ethical labelling (Challies, 2008; Gereffi \& Fernandez-Stark, 2011). GVC literature frequently discusses 'upgrading' as a path to development. Upgrading refers to improving a firm's position in a value chain to retain more value (Ponte \& Ewert, 2009).

\subsubsection{Global Production Networks}

Global production network (GPN) methodology has emerged as a similar tool of analysis to GVC for understanding and exploring the global economy (Dicken, Kelly, Olds, \& Wai-Chung Yeung, 2001). As summarised by Coe, Dicken, and Hess (2008, p. 287);

"GPN analysis combines insights gained from GCC/GVC analysis with ideas derived from the actor-network theory (ANT) and varieties of capitalism/business systems 
literature, and aims to reveal the multi-actor and multi-scalar characteristics of transnational production systems through intersecting notions of power, value and embeddedness."

In contrast to the GVC approach, which is influenced by world-systems and dependency perspectives and focus on firm interactions, GPN analysis is based on actor-network theory (ANT) (Latour, 1996), which focuses on intentional human agency and therefore examines the intentions, actions and practices performed by actors in global production networks ${ }^{7}$. Rather than focusing on firms, it is the individual actors, nation-states, networks and human agency that become the foundational elements for investigating the global economy under GPN (Coe et al., 2008). Similar to GVC methodology, GPN also considers 'institutional frameworks', 'governance structures' and 'territorial embeddedness' to be important elements for understanding the global economy (Dicken et al., 2001). According to the GPN approach, global production networks are conceptualised as 'organisational platforms' where different groups from national and local economies both cooperate and compete for the largest possible portion of the value creation, transformation, and capture through an economic activity that crosses different geographical scales (Yeung \& Coe, 2015).

While GPN researchers acknowledge that GVC approaches have contributed towards a methodology for investigating the global economy, they argue that GVC has failed in some important aspects. According to the GPN approach, it is vital to have a 'relational' perspective of networks which moves beyond a structural exploration of the global economy undertaken through GVC analysis. GPN researchers argue that to understand the global economy and global changes, it is not enough to only concentrate on individual firms and organisations. It is also necessary to study the power dynamics and intentions of non-firm actors and organisations. Similarly, GVC analysis has been criticised by GPN authors for its undertheorisation of the origins and changing relations of the global organisational platforms, while overly focusing on different models of global value chain governance (Yeung \& Coe, 2015). GPN attempts, therefore, to combine the useful structural understanding of the global economy developed through GVC methodology with the important considerations of human agency and the relationality of networks as explored by ANT (Dicken, et al., 2001; Coe, et al., 2008).

\subsubsection{Relevance of Chains and Networks to this Research}

Both GVC and GPN represent valuable methodologies for exploring the global economy and have proven to be central for understanding the studied EVeNs. A full definition of EVeNs as

\footnotetext{
${ }^{7}$ For more details on actor-network theory and global production networks see (Henderson, Dicken, Hess, Coe, \& Yeung, 2002).
} 
theorised by this thesis and the larger research project it contributes to will be further explained in the following chapter. GVC methodology has been valuable in simplifying the complexities of the global economy by studying two products, wine and pisco, as they have passed through the different stages of their respective value chains (Kleine, 2008). The GVC approach, in so doing, grounds intangible ideas of market globalisation through the analysis of the market's most tangible elements: commodities (Gibbon et al., 2008). It does so by mapping GVCs through simplified yet useful diagrams (Gereffi, Humphrey, \& Sturgeon, 2005). Figure 5 on the following page provides an example of a GVC map of fruit and vegetables. GPN, on the other hand, has extended from GVC methodologies to include a focus on human agency and relationality in global networks. It has provided a central tool for understanding the complexities of the studied networks in Peru and Chile (Dicken et al., 2001). The GPN methodology has therefore assisted me to form a deeper line of enquiry to study the complex relations and processes of the EVeNs surrounding the fair trade in wine in Chile and DO pisco from Peru, with a special focus on human agency and the intentions of different actors. Through engaging with GPN analysis this research has studied the interactions between and decisions made by grape producers, wine and pisco makers as well as regulatory bodies, actors from public and private sectors, among others, to better understand the two studied EVeNs. Figure 6 provides a framework for using GPN analysis. 
Figure 5 Fruit and Vegetables Global Value Chain Map

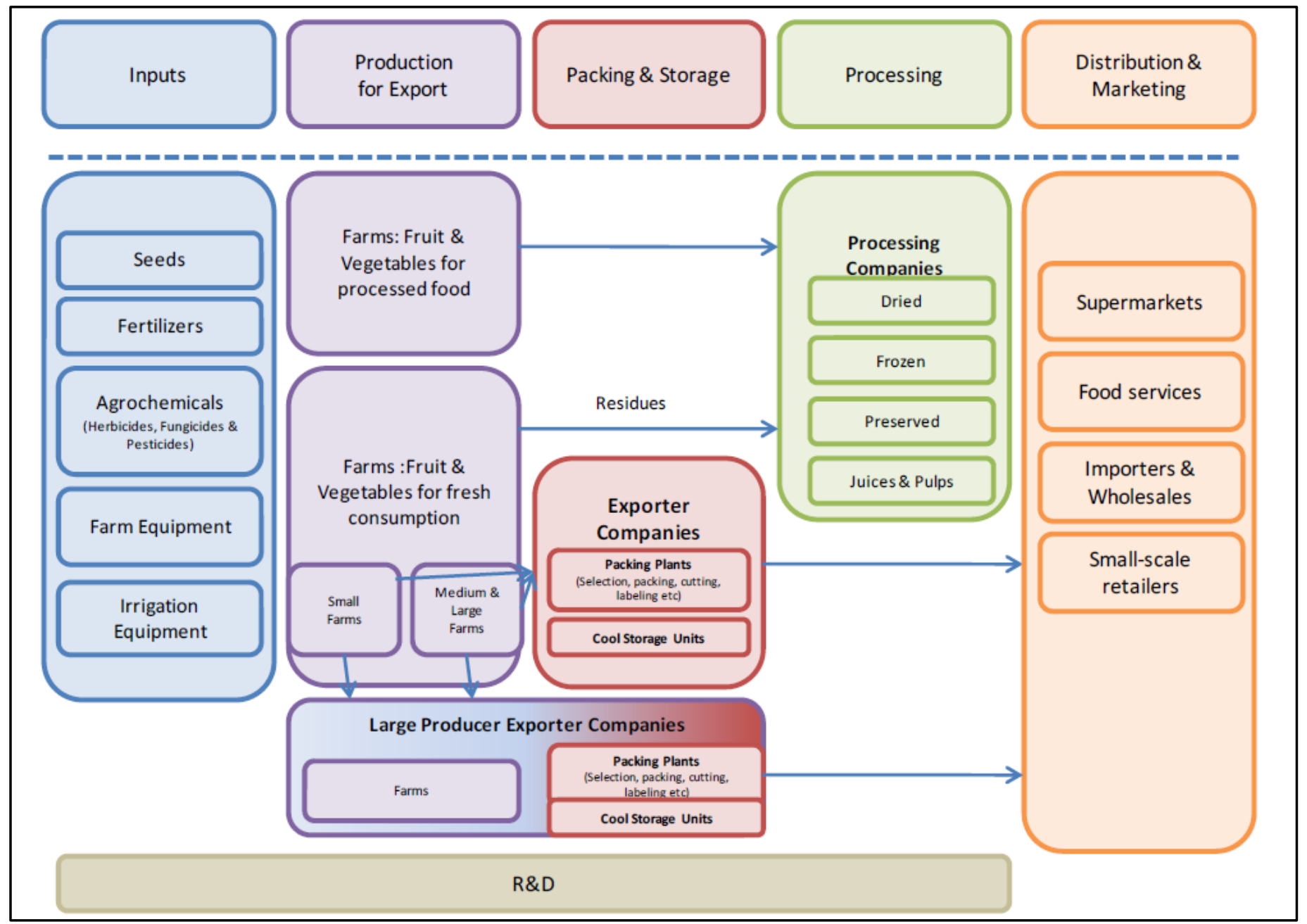

Source: (Gereffi \& Fernandez-Stark, 2011) 
Figure 6 A Heuristic Framework for Analysing the Global Economy

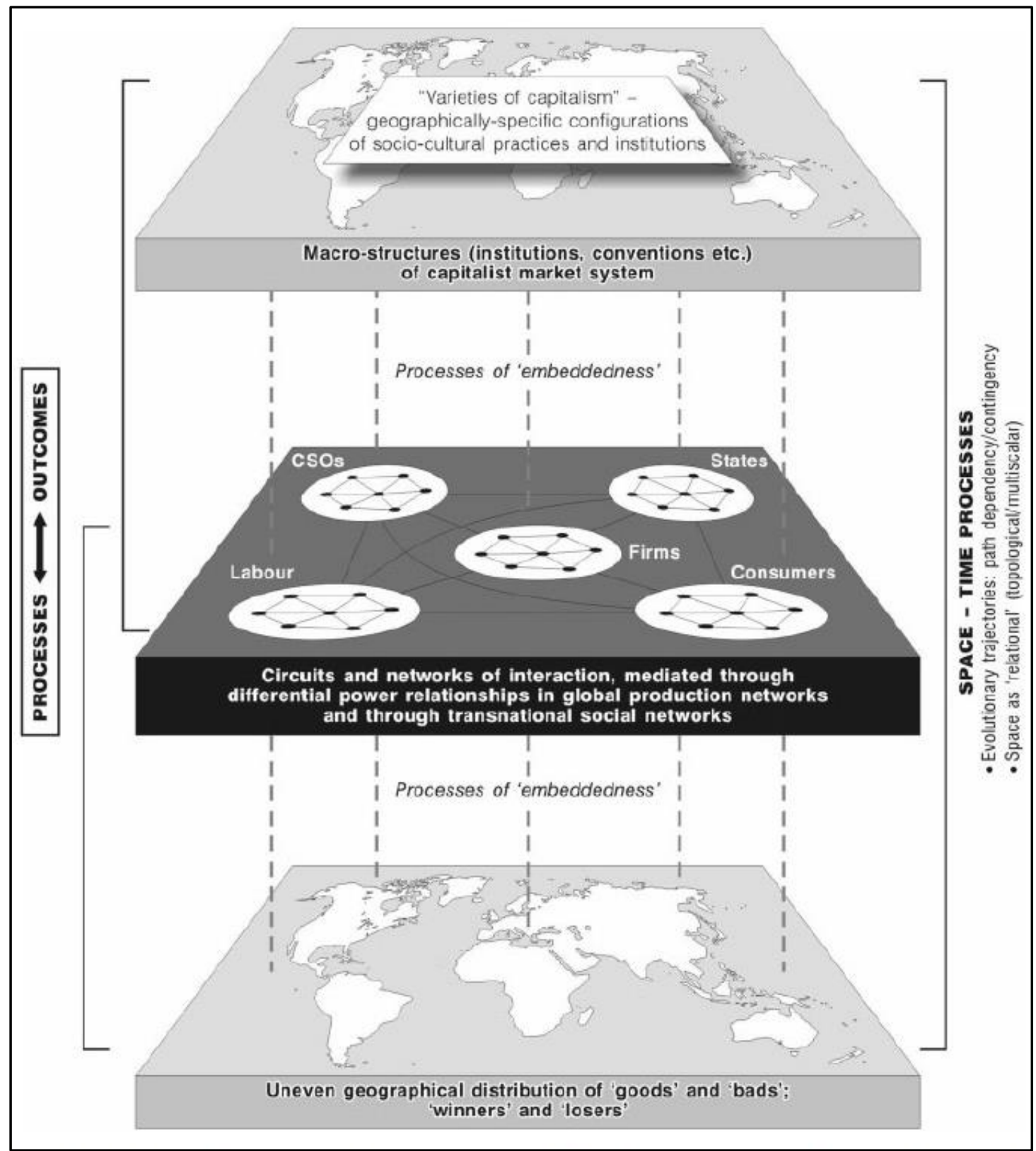

Source: (Coe et al., 2008) 
By applying GVC and GPN methodologies, this research has critically evaluated the validity of the two studied EVeNs in Chile and Peru. This doctoral thesis has therefore contributed to GVC and GPN literature by extending these two approaches through the EVeN approach.

\subsection{RESEARCH METHODS}

This section summarises the methods which have been applied: from data collection in the field, through the interpretation of the findings, in the writing stages, and finally the dissemination of information following the completion of the research.

\subsubsection{Adaptive, Multiscale, Mixed-Method Framework}

The research uses an adaptive framework based in critical realism and GVC/GPN analysis. As discussed, critical realist epistemology encourages the selection of different research methods depending on the research in question, and therefore endorses an adaptive framework based on a range of different research methods (Ackroyd \& Fleetwood, 2005). GVC/GPN methodologies, on the other hand, require multiscale investigation due to their shared examination of the global economy through local-global interactions (Coe et al., 2008; Gereffi \& Lee, 2012). Accordingly, the research has employed an adaptive framework based on globallocal scale and mixed-method techniques. Following the adaptive nature of this research, alterations have been constantly made when ideas and priorities changed over different stages of the research process (Murray \& Overton, 2003).

\subsubsection{Case Study Research}

This research has been based on case studies at the national and local scales in Peru and Chile. Case study research is based on methods which focus on a limited sample of social actors or situations, with data about these cases is collected from various sources, resulting in a holistic understanding of the studied cases (Easton, 2010). As there is an important focus on the local areas where the EVeNs are embedded (the production zones), these localities represent the most important case study areas of this research. In adopting the terminology of GVC methodology, much of the research is therefore based on case studies at the 'upstream' part of the value chain, where the primary producers in the viticultural sectors and their communities are located. However, following the nature of network research, this thesis also examines the influence and role of 'downstream' actors, such as retailers, in Chile and Peru, as well as in international markets (Gereffi \& Lee, 2012).

\subsection{FIELDWORK AND CASE STUDY AREAS}

Fieldwork was conducted over an eleven-month period (from July 2016 until January 2017 in Peru, and in Chile from January 2017 until June 2017). This extensive fieldwork period was 
required to study two different sectors, in two separate countries, and provided the necessary time to become familiar in fieldwork locations and build contacts and relationships of trust. Additional to the fieldwork, the research also included an initial pilot study trip to Peru and Chile, undertaken in January-February 2016. A central objective of this trip was to develop a network of contacts for the research. As will be explained later in this chapter, semi-structured interviews were the main research method during the fieldwork period. This research is based on 82 semi-structured interviews, 41 in Peru and 41 in Chile.

In line with the comparative nature of this study, one of the case study areas is located in Peru - the Ica Valley in the Ica Region - and two case study areas in Chile - the Curicó Valley in the Maule Region and the Colchagua Valley in the O'Higgins Region. Following the adaptive nature of critical realism, it was decided to remove a proposed case study area, Lunahuaná in Peru. This decision was made during the fieldwork when it became evident that the Ica provided an ample case study for the purpose of the research. This allowed me to better focus on Ica, which is Peru's most important and diverse pisco producing area. Throughout the fieldwork stages in Chile, the research expanded beyond the Curicó and Colchagua Valleys to include a fair trade certified wine cooperative Cooperativa Vitivinicola Loncomilla located to the south of Curicó, in San Javier de Loncomilla. Fieldwork in Chile also included the producer union Coalición Nacional de Viñateros por una Industria $\operatorname{Sin}$ Abusos $^{8}$ whose directive is based in the Itata Valley in the Bío Bío Region in Southern Chilean. While the Coalición Nacional de Viñateros is not directly involved with fair trade, time with representatives of the coalition enriched the study by providing context surrounding the abuses that exist in the Chilean wine sector. Additionally, my doctoral supervisor, Professor Warwick Murray, has completed research in Curicó and Colchagua and has supervised student research in these areas (Challies \& Murray, 2011; Murray, 1997). Moreover, I conducted my master's research in the Ica Valley in 2011. This previous experience in these areas was invaluable in informing this research. The following sub-sections briefly outline the research case study areas.

\subsubsection{Curicó Valley, Maule Region, Chile}

Curicó is one of four provinces located in the Maule Region (VII), approximately 220 kilometres to the south of Chile's capital, Santiago. Its Mediterranean climate and permeable soils support important conditions for winemaking. As a result, Curicó is one of Chile's most important and oldest viticultural zones (Lacoste, 2006). According to the latest government statistics, the Maule Region is the most important wine-producing area in Chile, making up 38\% of the total

\footnotetext{
${ }^{8}$ Translates to National Coalition of Viticulturists for an Industry without Abuses. (Translations by author unless stated otherwise).
} 
land dedicated to wine grapes in Chile (Servicio Agrícola y Ganadero, 2015). Within Maule, the Curicó Valley has gained a reputation for producing reliable, consistent value wines. While fair trade certification remains relatively limited in Chile's wine sector, multiple certified wine and grape-producing groups have been established in Curicó: including Miguel Torres Wines, Vinos Lautaro, Viñas Caupolicán, Viña La Fortuna, as well as Viña Casas Patronales located further to the South of the Maule region. These groups, which use fair trade certifications, provided varied and important case studies for this research. For example, Miguel Torres represents a large-scale and long-established winery with Spanish ownership while Viñas Caupolicán, on the other hand, is an association comprising small-scale grape producers from the area. These cases provided interesting comparative studies of fair trade within the same zone. These different actors and their roles in the emergence of fair trade certification in Chilean viticulture will be further introduced in Chapter Five. Figure 7 below displays photos of vineyards and wineries in Curicó and Figure 8 on the following page indicates where Curicó is located within Chile (indicated with number 1.). 
Figure 7 Examples of Vineyards and Wineries in Curicó

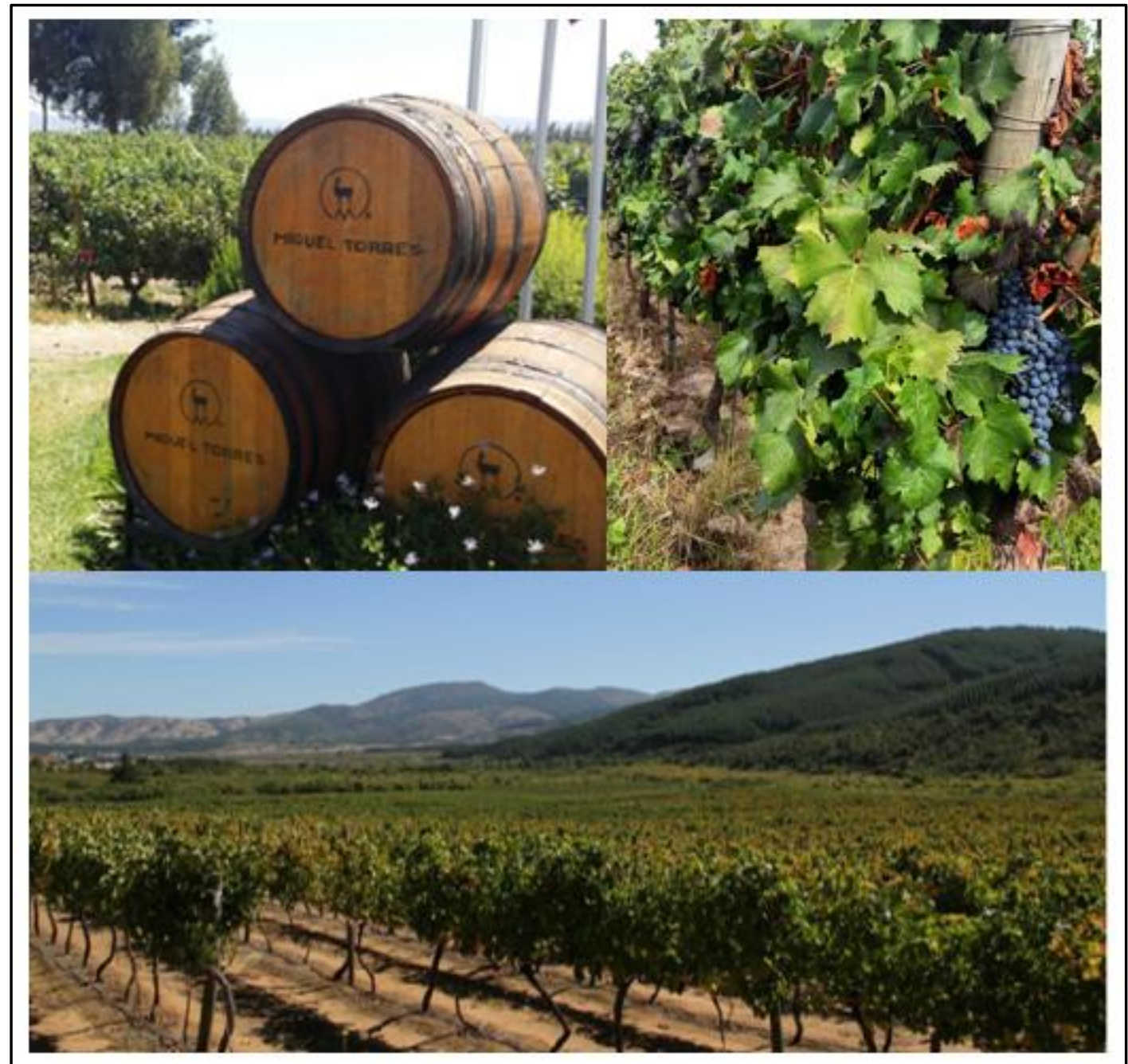

Note. All photos were taken in Curicó Valley. Top-left; wine barrels at Miguel Torres Winery,

top-right; wine grapes on the property of a small-scale grape producer, bottom; unnamed vineyard. Sources: taken by the author. 
Figure 8 Locations of Curicó and Colchagua Valleys, Chile

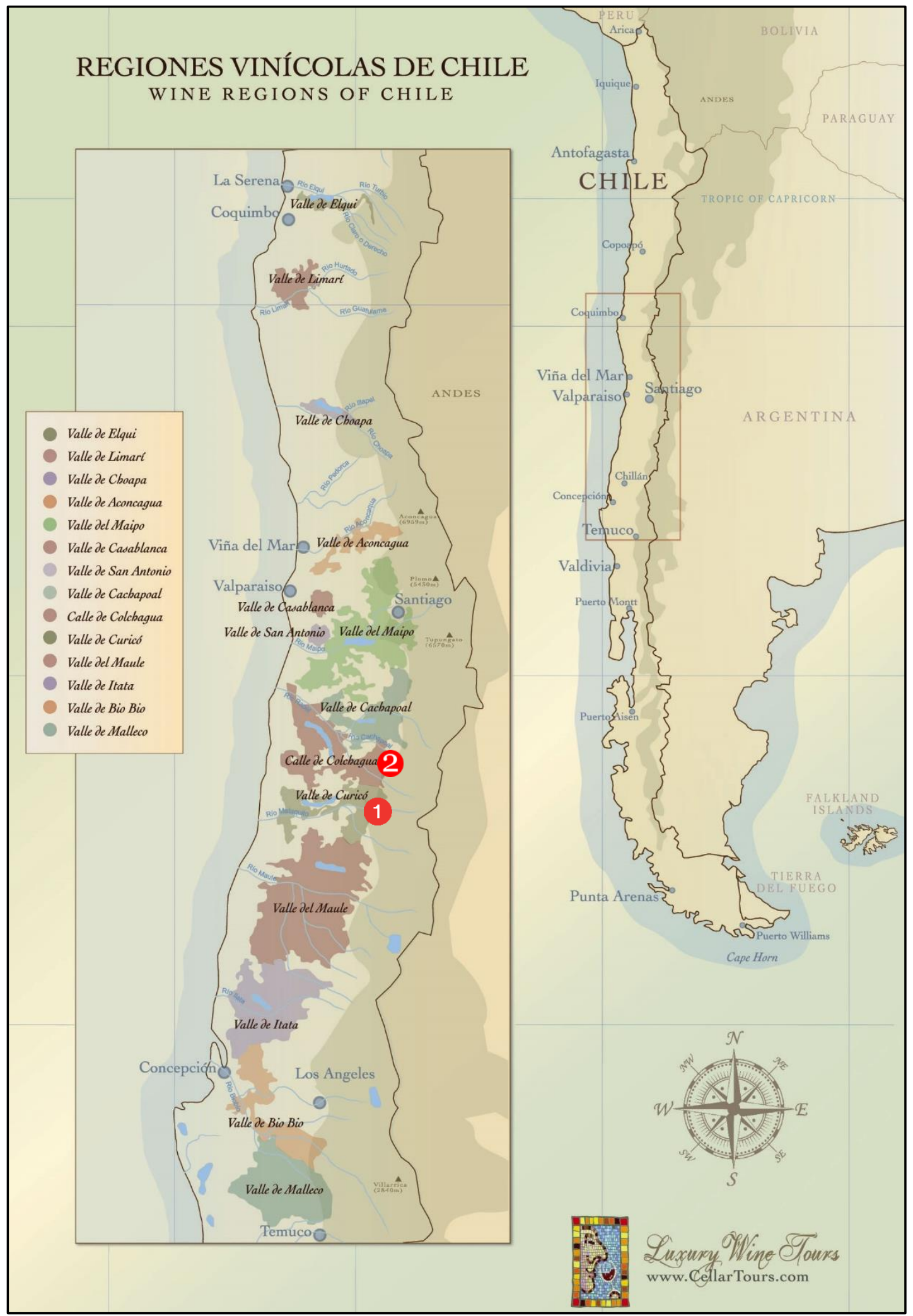

Note. Location of Curicó indicated with number 1. and Colchagua Valley indicated with number 2.

Source: (Cellar Tours, ND) 


\subsubsection{Colchagua, O’Higgins Region, Chile}

Colchagua Province is one of three provinces in the O'Higgins Region (VI), bordering Curicó to the south and is approximately 150 kilometres to the south of Santiago. The area has an ideal climate for wine production: it is hot and dry but irrigated by the Tinguiririca River and with limited rainfall (Parra, 2009). The area has specialised in higher-end wines than in Curicó and the wineries in Colchagua have been established with a focus on wine tourism (Zamora \& Barril, 2007). Santa Cruz evolved from a small rural town to become the centre of wine tourism in Colchagua after receiving significant investment from Carlos Cardoen, a businessman from Colchagua who amounted a large fortune from arms-dealing and other activities (Banks \& Overton, 2010). The O'Higgins Region is also one of Chile most important wine-producing regions, representing close to 33\% of the total land dedicated to wine grapes in Chile in 2015 (Servicio Agrícola y Ganadero, 2015).

Red del Vino ${ }^{9}$, an association of small-scale producers in Colchagua was particularly interesting for this research. Red del Vino is an association involved in grape and wine production, formed in 2004 by 19 small-scale farmers. Red del Vino received the Fairtrade International FLOCERT certification in 2010 and has a tourism programme based on ethical production and campesino traditions. This group is one of the central motivations for the selection of Colchagua as a case study area. This provided a separate case to be compared and contrasted with the case studies in Curicó. Moreover, a number of vineyards in Colchagua are implementing alternative ethical trade schemes, such as Montes wines which became Fair for Life certified (IMO) and Polkura wines which is B-Corp certified. Figure 9 on the following page shows examples of vineyards and wineries in the Colchagua Valley while Figure 8 above indicates the location of Colchagua in Chile (indicated as number 2.).

\footnotetext{
${ }^{9}$ Wine Network.
} 
Figure 9 Examples of Vineyards and Wineries in Colchagua

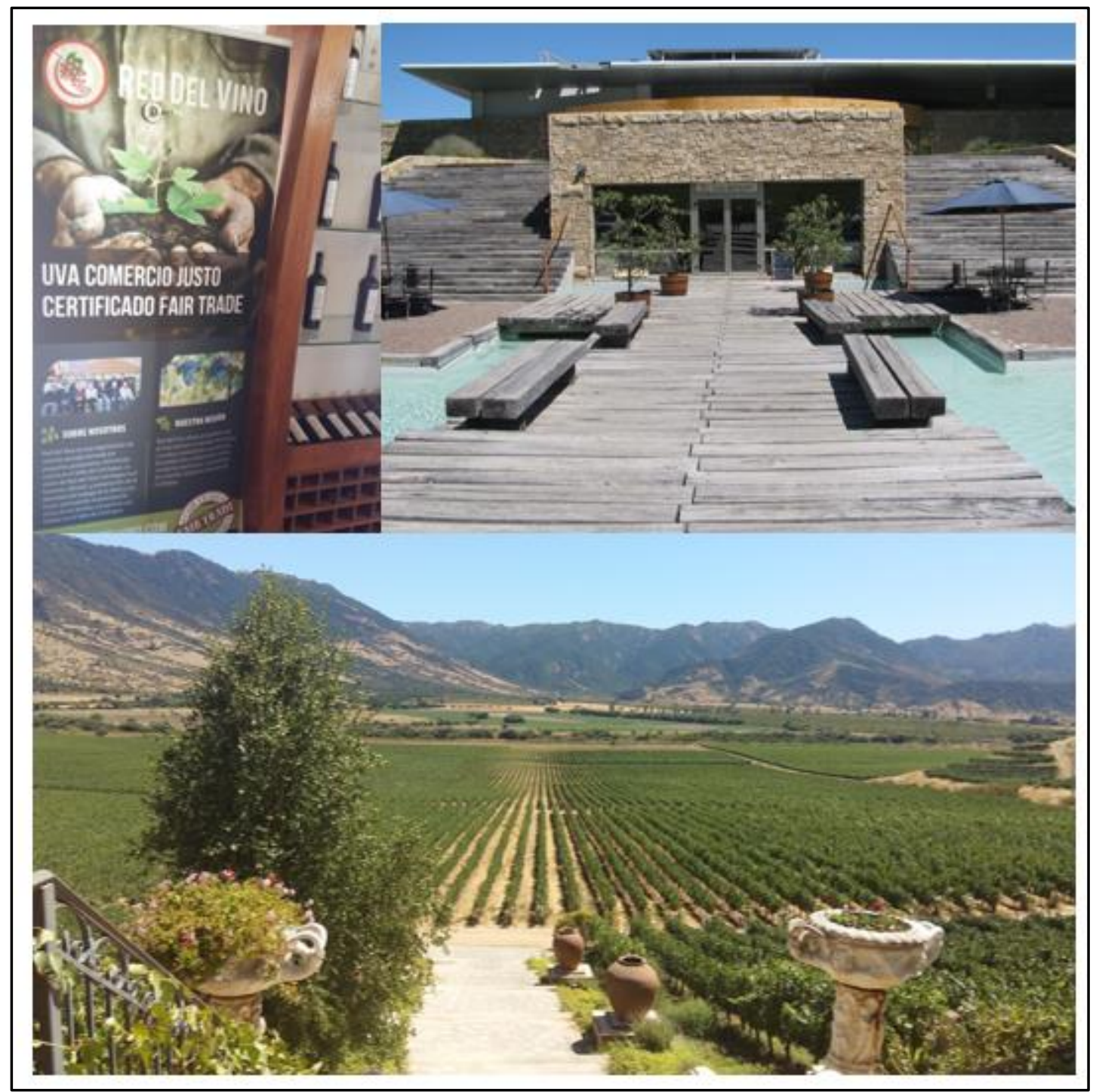

Note. All Photos were taken in Colchagua Valley. Top-left; banner explaining fair trade grape production at Red del Vino office, top-right; Montes Winery cellar door, bottom; vineyards at Santa Cruz Winery. Sources: taken by the author. 


\subsubsection{Ica Valley, Ica Region, Peru}

Ica Valley is located 300 kilometres south of Peru's capital Lima, in the Ica Region. The area has an arid and hot desert climate. Despite this, the area has been one of Peru's main pisco and wine-producing areas since the Spanish conquest in the Sixteenth Century. The Ica Region has the largest proportion of land dedicated to pisco grapes in all of Peru, representing an estimated ${ }^{10} 52 \%$ of the total pisco grape crops in Peru. Within the Ica Region, an estimated $65 \%$ of these crops are located in the Ica Valley (Pflucker, 2015). Production is supported by extensive groundwater resources from the Ica-Villacurí aquifer, as well as seasonal irrigation from the Ica River. Ancient mudslides in the valley formed stony and loamy alluvial soils suited to producing grapes for pisco. Pisco production has a long and rich history in Ica and it is now deeply rooted in the area's local culture (Huertas Vallejos, 2004). Ica is one of the five regions where pisco from Peru can be produced according to the technical requirements of the pisco DO. Ica's pisco sector remains an important source of income for small-scale producers and despite a handful of large pisco distillers, artisanal producers outnumber other producers in the area (Gerencia de Estudios Económicos, 2016). However, large-scale producers concentrate overall production and markets as discussed in more detail in Chapters Five and Seven. Ica was selected for this research as it provided a valuable case study of an EVeN based on a DO protected product with a long history and clear link to local traditions and culture. Moreover, Ica represents an important cross-section for the study of the pisco DO as it is Peru's pisco producing centre, and the product has economic and cultural significance for the local population. Figure 10 on the subsequent page shows examples of pisco production and bodegas $^{11}$. Figure 11 demonstrates the location of the Ica Valley within Peru and Figure 12 displays the designated pisco producing zones under the pisco DO regulations in Peru.

\footnotetext{
${ }^{10}$ These estimates are based official statistics which are limited to the formal pisco sector and omits the significant informal sector which exists in Peru. Following from personal communication with local experts, it is possible that up to $50 \%$ of pisco production is not officially recorded or included in the official statistics.

${ }^{11}$ The distillery plants where pisco is produced.
} 
Figure 10 Examples of Pisco Production and Bodegas in Ica, Peru

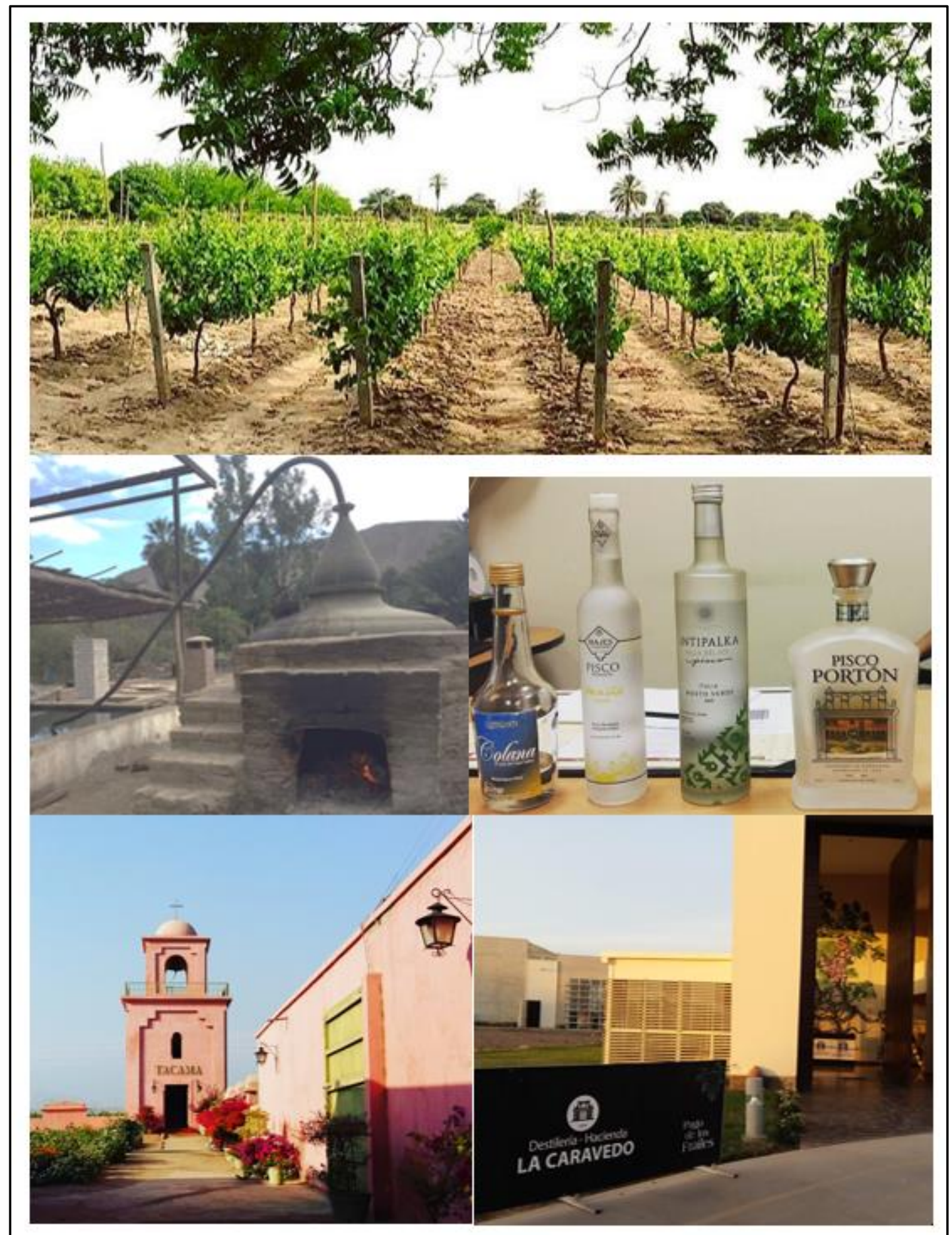

Note. All photos were taken in the Ica Valley (expect middle-right, taken in Lima). Top; pisco

grapevines on the property of a small-scale producer, middle-left; pisco being distilled by traditional producer, middle-right; examples of different pisco bottles, bottom-left; colonial architecture at Tacama Winery and Bodega, bottom-right; modern infrastructure at La Caravedo Bodega. Sources: taken by the author. 
Figure 11 Location of Ica Valley in Peru

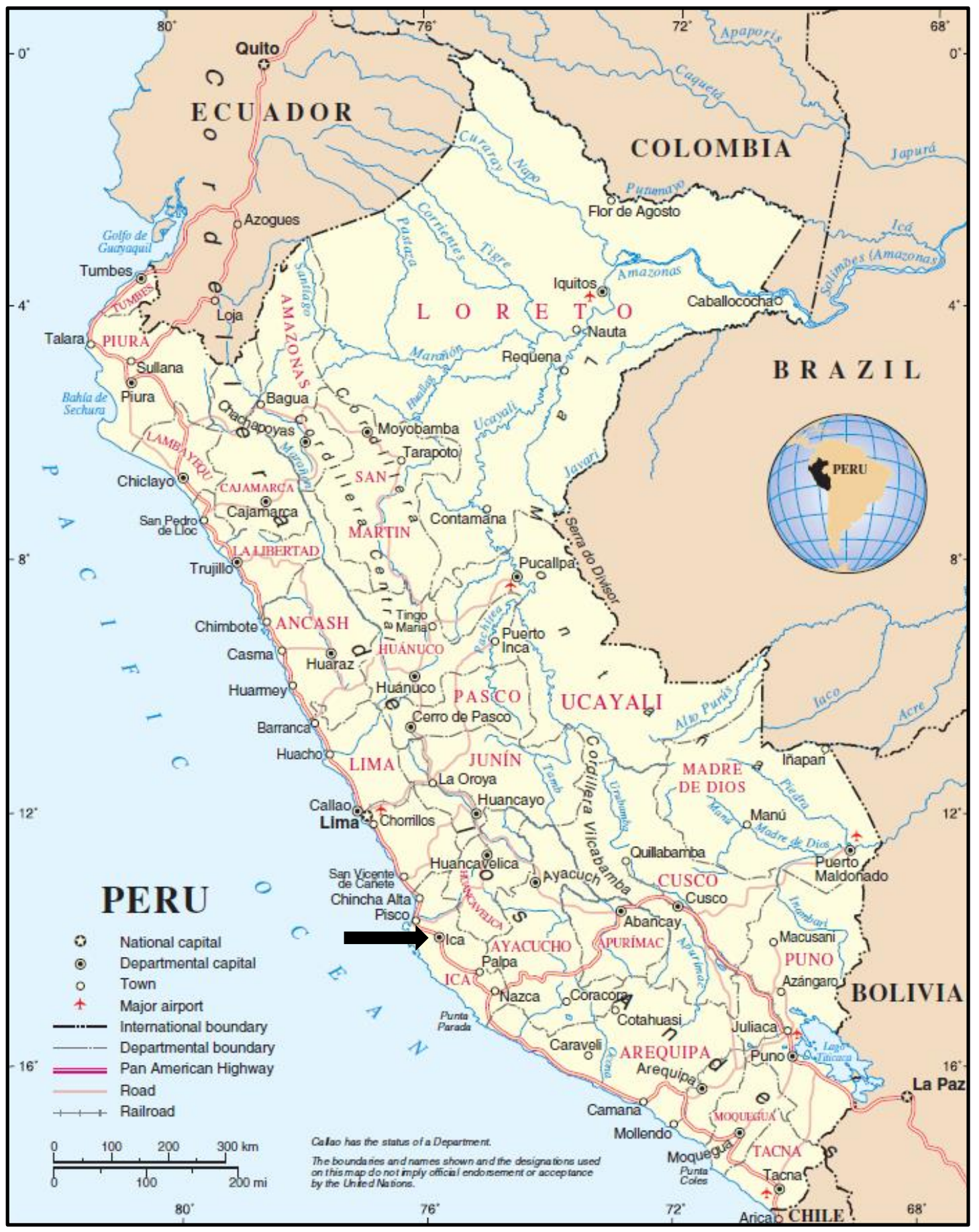

Source: (United Nations, 2011) 
Figure 12 Designated Pisco Producing Areas under Pisco DO Regulations in Peru

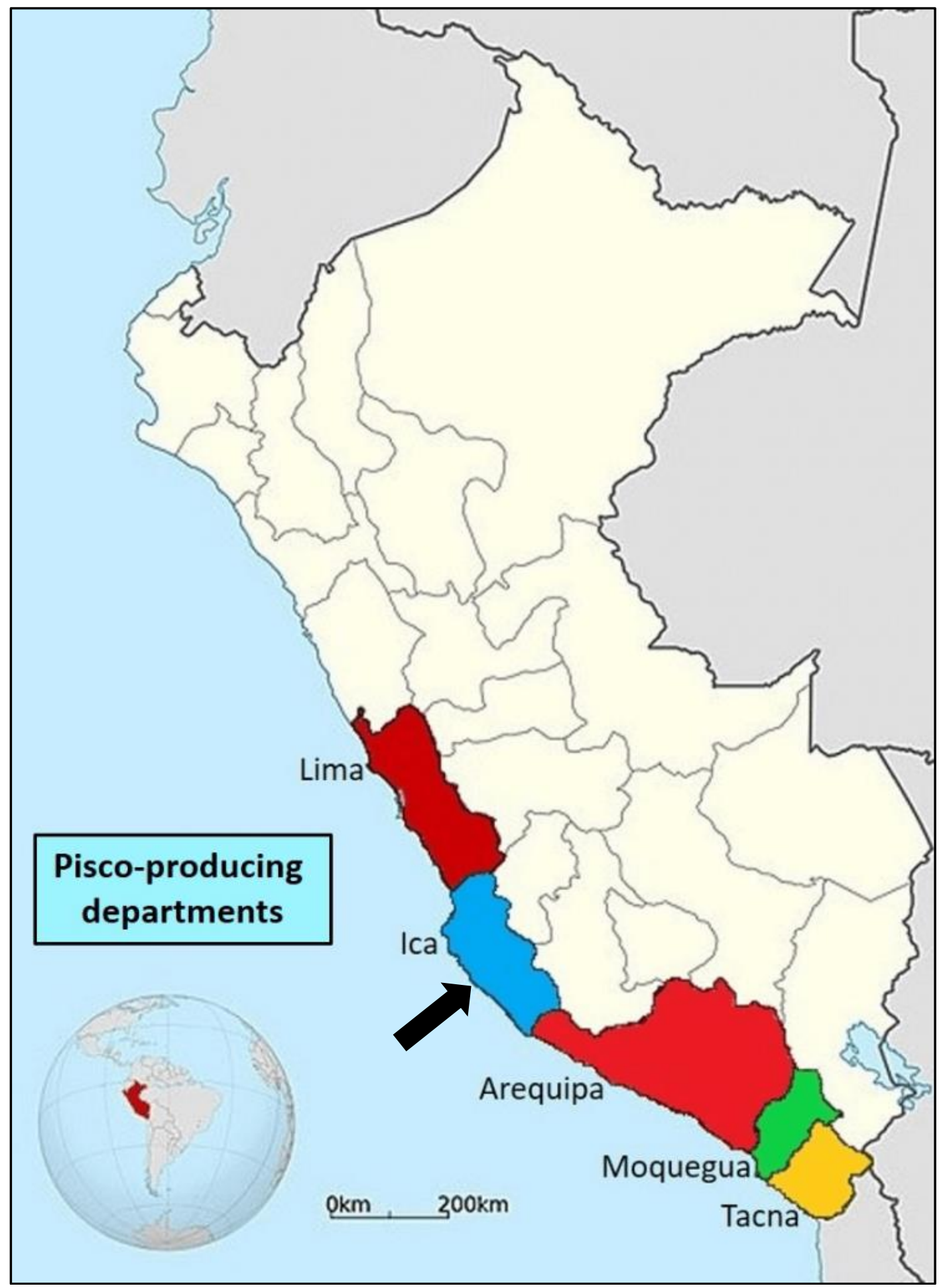

Source: (Muñoz, 2017) 


\subsection{LITERATURE AND DATA REVIEWS}

Relevant literature and data sets were reviewed and analysed to establish a base understanding of the social and economic motivations for the rise of EVeNs. Literature reviews investigated the ethical claims used to promote these networks and the certifications used by actors within them again at a global level. These reviews also explored key historical and contemporary events in Peru and Chile. This stage of review also attempted to gain a deeper understanding of the social context and development challenges which were present where the research and the EVeNs are grounded. Special emphasis was placed on the evolution of EVeNs and viticulture in both countries. These reviews revealed the importance of local history and social context in shaping the evolution and outcomes of EVeNs (Bowen, 2010a; Larson, 2007).

In completing these reviews, I was able to better explore and comprehend the complexities of the networks and actors surrounding the two studied networks and the influence that the local settings have had on the evolution of these networks. These reviews were critical in informing this research, and for generating the interview questions for the fieldwork component. At the later stages of the research, the reviews were used to enrich, compare and contrast with the information that was generated through the semi-structured interviews.

\subsection{SEMI-STRUCTURED INTERVIEWS AND PARTICIPANT SELECTION}

The primary data for this thesis was derived from semi-structured interviews with 82 participants from five broad groups in both Peru and Chile. Different interview plans were used for the following groups:

1. Small-scale producers without DO/fair trade

2. Small-scale producers with DO/fair trade

3. Medium and large-scale producers with DO/fair trade

4. Local Experts

5. Regulatory groups

Semi-structured interviews, using sets of open-ended questions, were deemed the most appropriate approach for interviews, as they provided the participants with the opportunity to discuss their experiences and perspectives while also retaining enough structure to identify common themes (Given, 2008). Consent forms were signed before an interview could take place. The consent form gave the participants the options to select whether or not they wished to have their name and/or organisation included in the thesis. The conditions of reporting the 
research findings were explained to the participants before the interviews were conducted and participants had the ability to withdraw from the project before the $1^{\text {st }}$ January 2018.

\subsubsection{Research Participants}

As mentioned, the primary participants of this research are principally located at the 'upstream' of the value network (primary producers). However, as encouraged by GVC and GPN methodologies, participants from further 'downstream' (regulatory groups and distributors) in Chile and Peru have also been included. This has allowed me to investigate governance and identify a range of unequal power relations in both of the studied networks (Coe et al., 2008; Gereffi \& Fernandez-Stark, 2011). While there are no participants from the final 'downstream' (international retail and consumers) stages of the networks, these groups have been included where possible through reviewing secondary sources and interview topics. For example, the roles of international buyers in value networks have been explored in other academic sources. Moreover, the roles of 'downstream' actors were important topics of the interviews in Peru and Chile.

Different groups in Peru and Chile assisted me to first select research participants and then assisted me to make the first contact with them. In general, these individuals and groups were happy to take part in an interview, yet there was no pressure to take part for those unhappy to do so. In Peru, I was able to build upon contacts that I made during my Master's research. In the case of Chile, I was helped by the many contacts of my doctoral supervisor. The initial help from these pre-existing contacts proved to be instrumental in forming the networks necessary to identify and connect with research participants. In Peru, the universities Universidad de San Martín de Porres, Pontifica Universidad Católica del Perú, Universidad Ricardo Palma, and Universidad Nacional Agraria La Molina helped me locate some of the participants. In Chile, the universities Pontificia Universidad Católica de Chile, Universidad de Chile, Universidad de Santiago de Chile, Universidad de Los Lagos, Universidad Técnica Federico Santa María and Universidad de Talca (Campus Colchagua) also assisted me to locate some of the participants. A number of non-governmental organisations (NGOs) in Peru and Chile were also central in helping to select and contact participants. These NGOs usually supported smallscale producers in Chile and Peru and represented important participant gatekeepers (Mandel, 2003). By taking the time to build positive professional relationships with these NGOs, I was able to build upon the relationships of trust between the NGOs and the small-scale producers and local activists. Staff from central and local government institutions, from both countries, were also instrumental in building the contact networks that were required for this study. Finally, influential individuals in the pisco and wine sectors were also very important for finding participants. For example, the general managers and presidents of different producer 
cooperatives acted as local gatekeepers for the producers. My association with these individuals opened the 'gates' to make contact with otherwise remote producers. Table 1 on the following page summarises the research participants involved in this project.

Table 1 Summary of Research Participant Groups

\begin{tabular}{|c|c|c|c|c|}
\hline Peru & $\begin{array}{l}\text { Number of } \\
\text { participants }\end{array}$ & Chile & $\begin{array}{l}\text { Number of } \\
\text { participants }\end{array}$ & Total \\
\hline $\begin{array}{l}\text { Group } 1 \\
\text { Small-scale } \\
\text { producers without } \\
\text { DO }\end{array}$ & 6 & $\begin{array}{l}\text { Group } 1 \\
\text { Small-scale producers } \\
\text { without fair trade }\end{array}$ & 5 & 11 \\
\hline $\begin{array}{l}\text { Group } 2 \\
\text { Small-scale } \\
\text { producers with DO }\end{array}$ & 4 & $\begin{array}{l}\text { Group } 2 \\
\text { Small-scale producers } \\
\text { with fair trade }\end{array}$ & 12 & 16 \\
\hline $\begin{array}{l}\text { Group } 3 \\
\text { Medium and large- } \\
\text { scale producers with } \\
\text { DO }\end{array}$ & 13 & $\begin{array}{l}\text { Group } 3 \\
\text { Medium-large scale } \\
\text { producers with fair } \\
\text { trade }\end{array}$ & 6 & 19 \\
\hline $\begin{array}{l}\text { Group } 4 \\
\text { Local experts }\end{array}$ & 16 & $\begin{array}{l}\text { Group } 4 \\
\text { Local experts }\end{array}$ & 16 & 32 \\
\hline $\begin{array}{l}\text { Group } 5 \\
\text { Regulatory groups }\end{array}$ & 2 & $\begin{array}{l}\text { Group } 5 \\
\text { Regulatory groups }\end{array}$ & 2 & 4 \\
\hline Peru Total & 41 & Chile Total & 41 & 82 \\
\hline
\end{tabular}

Source: Elaborated by author

The following sub-sections briefly introduce the five broad interview groups in Peru and Chile summarised in Table 1.

\section{Group one: small-scale producers without pisco designation of origin mark or fair trade wine certification}

In Peru and Chile, this group consisted of the smallest-scale grape producers and pisco/wine makers. In Peru, a producer is considered to be small-scale in the pisco sector when they produce 3,000 litres or less of pisco annually or own less than five hectares of agricultural land (INEI, 2012). For this study, the small-scale pisco grape and pisco producers were located in the Ica Valley. In Chile, a producer is considered to be small-scale if they own twelve hectares or less of agricultural land with basic irrigation, whose assets do not exceed the equivalent of 
3,500 Unidades de Fomento ${ }^{12}$ and whose income comes chiefly from agriculture (INDAP, 2014). This group consisted of small-grape growers which were concentrated in the Itata, Colchagua, and Curicó Valleys. These participants answered questions relating to their farms, their production and history, their livelihoods, the changes the participants have experienced, their perceptions around the DO (pisco in Peru) or fair trade (wine in Chile), why they do not use this label, the relationships they have with their buyers, experiences of exclusion and inclusion, the problems and barriers they perceive to exist in the DO/fair trade networks and finally any support they have received.

\section{Group two: small-scale producers with pisco designation of origin mark or fair trade wine certification}

These groups consisted of small-scale producers in the wine/pisco sector which have received the DO for their pisco production (Peru) or fair trade certification for their wine or grapes (Chile). These producers had the same profile of same-scale producers as the producers in group one, however, the point of difference is that the producers from group two have received the right to use the DO (pisco in Peru) or fair trade certification (wine in Chile) (INDAP, 2014; INEI, 2012). These participants answered questions about their land, production and history, their livelihoods, experienced changes over time, their perceptions around the DO (pisco in Peru) or fair trade (wine in Chile), why they use the product label, the relationships they have with their buyers and the impact the label may have on this relationship, the problems that they perceive to exist in the DO/fair trade networks, as well as any support they may have received.

Group three: medium and large scale producers with the designation of origin in pisco/fair trade in wine

These participants were producers defined as medium and large-scale producers in the pisco and wine sectors. This signifies that they were larger than the small-scale producer segment defined above. These producers usually had multiple and complex roles in their network. For example, they were: grape purchasers, grape growers, and wine or pisco makers. These participants were asked about the company's ownership and history, the core principles of the company, their production and markets, their relationships with primary producers, the use of the DO (pisco in Peru) or fair trade (wine in Chile), the motives for using these labels, the nature of their sector and the impacts of the labels have.

12 Units of account is a currency unit indexed according to inflation used in Chile. 1 Chilean Unit of Account (UF) equalled 66.23 New Zealand Dollars on the 24/09/18 


\section{Group four: local experts}

Group four in both Peru and Chile represented a diverse participant group, consisting of central and local government officials, university staff, producer cooperative administration members, as well as other experts such as independent researchers and social activists. These experts were based in the capitals Lima (Peru) and Santiago (Chile) as well in the case study areas of Ica (Peru) and Colchagua and Curicó (Chile). The interview questions for these participants varied largely and the questions were tailored to the expertise of each participant. However, overarching themes in these interviews included: the expert's role and involvement in one of the studied sectors or labels, their understanding of one of the studied sectors or labels, the motivation for the growth in one of the studied sectors or labels, the problems or challenges that exist, the benefits that may have been created, and the impacts that the sector or label has. In Peru, this group included five participants from government institutions, four participants from universities, and seven other experts. In Chile, this group consisted of five participants from government institutions, eight participants from universities, and three other experts.

\section{Group five: regulatory groups}

The final interview group consisted of regulatory groups involved in the pisco DO (Peru) and fair trade wine (Chile). In Peru, these were national organisations. The first of these organisations was the Peruvian State institution Instituto Nacional de Defensa de la Competencia y de la Protección de la Propiedad Intelectual ${ }^{13}$ (INDECOPI). INDECOPI is the titleholder of the pisco DO and in charge of protecting it. The other national organisation was the private sector group known as the Consejo Regulador de la Demoninación de Origen Pisco ${ }^{14}$ (CR). The main functions of the CR are to administer and verify the pisco DO and defend the quality of the product. In Chile, there were two regulatory groups which certified and supported the use of the fair trade certifications. These groups are international organisations which have national offices in Chile. They included Fair Trade International (FLO) which uses the FLOCERT certification and Institute for Marketecology (IMO) which certifies the Fair for Life certification. These participants answered questions about the reasons for the evolution of the different labels (DOs in Peru and fair trade in Chile), the processes and governance of these labels, their organisation's involvement with these labels, the benefits these can have, the knowledge producers have about these labels and how producers are involved, and finally problems that exist.

\footnotetext{
${ }^{13}$ National Institute for the Defence of the Competition and the Protection of Intellectual Property.

${ }^{14}$ Regulatory Council for the Designation of Origin Pisco.
} 


\subsection{INTERPRETING FINDINGS}

The initial stage of interpreting the research findings involved translating and transcribing the interviews from Spanish into English. Following this, Nvivo software was used to code and analyse these findings in order to find patterns, construct the networks, and compare and contrast the content of the interviews. I developed and implemented an FII framework (Formation, Institutionalisation and Idealisation) to investigate the studied EVeNs. The FII framework has extended from the lines of enquiry described in Chapter One. The exploration of formation sought to better understand the motives which have encouraged the evolution of the EVeNs of DO pisco in Peru and fair trade wine in Chile. The study of the institutionalisation of these EVeNs attempted to explore and construct a complete picture of the different actors who participate in the networks. Idealisation involved a somewhat deeper investigation to explore the ethical claims which have been created and applied to promote these EVeNs and attempted to evaluate how, or if, these claims are being realised in the communities where the EVeNs are grounded. A multiscale approach which investigated the interactions between the global, national and local scales and the outcomes of these interactions at the different scales has been applied.

\subsection{DISSEMINATION}

An important component of ethical research includes ethical considerations at postcompletion stages. Accordingly, the sharing and dissemination of the results with the research participants who wished to receive this information has been an important component of this research, and in non-extractive research in general (Sidaway, 1992). All research participants for this thesis were asked formally if they would like to receive a summary based on the findings. These summaries have been written in Spanish and sent to the participants. Producing relevant and useful findings that can benefit the participants was a central consideration of this work. Moreover, there are plans to publish a number of articles in both Spanish and English which will be accessible to the wider communities. It is hoped that these measures will help to 'give back' and have positive impacts in the studied communities (Pain, 2004; Zhang, 2017).

\subsection{CHAPTER TWO DISCUSSION AND LINK TO CHAPTER THREE}

This methodology chapter first explored the cyclical research process which has guided this thesis. Following this, the chapter discussed the selection of critical realism as the epistemological approach of this research. The chapter subsequently explained the principles of ethical research which have been implemented. In addition, an overview of the theoretical underpinnings of this research was provided. Subsequently, the chapter examined the 
different research approaches and methods that were implemented. These sections also provided details about the case study areas used and the selection of the research participants. The chapter then briefly described how the findings were interpreted and how the information is being disseminated. The following chapter, 'Chapter Three, Placing Value on Ethical Production: Globalisation and Ethical Value Networks', examines relevant processes of globalisation and the emergence of as ethical value networks. 


\section{CHAPTER THREE. PLACING VALUE ON ETHICAL PRODUCTION: GLOBALISATION AND ETHICAL VALUE NETWORKS}

\subsection{CHAPTER INTRODUCTION}

This chapter discusses the broader processes which form the contextual foundations of this research and further defines EVeNs. To begin, this chapter discusses the processes of economic globalisation and neoliberalisation, and explains the relevance of these. The sections that follow, explore the globalisation of agriculture and the rise of global agro-food systems. Moreover, these sections discuss the important implications the expansion of global agro-food systems have had for rural groups in the Global South. The second half of this chapter further defines what this research has labelled as ethical value networks (EVeNs), and discusses the emergence of these networks. Finally, the chapter critically explores the studied EVeNs of fair trade (fair trade) and geographical indications (GIs) at a theoretical level.

\subsection{ECONOMIC GLOBALISATION}

Following the Industrial Revolution (1760-1840) local and national economies have experienced rapid and complex global economic integration. Existing literature has demonstrated that this has increasingly exposed these economies to global forces and economic shifts, posing both opportunities and risks (Murray \& Overton, 2014; Sturgeon, 2008). These shifts and processes have been labelled as globalisation, and specifically, economic globalisation. A number of varying definitions of economic globalisation were found while reviewing the existing literature. Economist Joseph Stiglitz (2002, p. 9) defined globalisation as:

"... the closer integration of the countries and peoples of the world which has been brought about by the enormous reduction of costs of transportation and communication, and the breaking down of artificial barriers to the flows of goods, services, capital, knowledge, and (to a lesser extent) people across borders".

This definition is particularly useful as it highlights some of the interrelated elements which have driven the closer integration into the global economy. The Organisation for Economic Cooperation and Development (OECD) $(1997$, p. 7) defined economic globalisation as “...a process in which the structures of economic markets, technologies, and communication patterns become progressively more international over time." This definition is also valuable as it emphasises economic globalisation as a temporal and spatial process, rather than an outcome. The processes of economic globalisation, and indeed the globalisation of other realms, such as politics and cultures, have had very real implications for how people live, in some case for the 
better and in other cases for the worse. Work by Murray and Overton (2014) illustrated that the rapid unfolding of economic globalisation has been uneven and exclusionary. These unfolding processes of globalisation have integrated specific groups while marginalising others.

\subsection{NEOLIBERALISM}

Literature has revealed that the transition from the 'old world economic system', based on relatively separate national economies, to the current globalising economy has been driven by neoliberal economics, particularly since the 1980s (Bonanno, Busch, Friedland, Goveia, \& Migione, 1994; McMichael, 1994). Neoliberalism represents an economic-political ideology which promotes free-market policies. A formal definition of neoliberal is provided by Murray (2009, p. 379):

"Neoliberalism is an economic, political, and it can be argued, cultural paradigm, which is all but hegemonic at the governmental scale across the globe. Echoing back to early capitalist thinking, neoliberalism argues that governments fail inherently."

Neoliberal ideology is usually associated with the political new-right, and argues that government economic planning and regulation are inefficient and limit economic expansion. The neoliberal argument is based on the idea that market liberalisation will drive investment and economic growth which will eventually maximise global welfare. Instead of a single economic theory, neoliberal ideology is, therefore, best conceptualised as a change in economic-political thinking which has driven the withdrawal of national governments in regulating their economies (Harvey, 2007). Neoliberal policies push for fiscal austerity, economic liberalisation, the removal of trade barriers, the privatisation of state assets, competitive exchange rates, and an overall reduction in the role of the state in the economy (Cesano \& Gustafsson, 2000; Mendoza, 2011; Murray, 2009).

Existing literature shows that there was a return to economic liberalism following the end of WWII which partially eliminated widespread economic protectionism triggered by the Great Depression in the 1930s (Murray, 2006a). This global economic restructuring was especially facilitated by the General Agreement on Tariffs and Trade (GATT), which attempted to boost global trade and investment through the promotion of free trade. This established the environment for the initial spread of neoliberal policies which expanded following economic stagnation caused by the Oil Crises of 1973 and $1979^{15}$ (Mendoza, 2011; Murray \& Overton, 2014). These free market measures were encouraged by international financial institutions and

${ }^{15}$ For a full explanation of these debt crises see (Murray, 2006a) 
fostered the conditions for the expansion of neoliberal globalisation from the 1980s (Harvey, 2007).

\subsubsection{Globalisation and the New International Division of Labour}

The Oil Crises had significantly impacted the formation of the current globalising economy. Resulting from the rising debt these crises provoked, neoliberal reforms were spread globally in an attempt to alleviate widespread economic recession. The crises, in turn, encouraged the rise of neoliberal capitalism which now represents the dominant economic framework, and fuelled the emergence of a new phase of economic globalisation. There is agreement among economists, geographers and sociologists that this phase of globalisation has created and continues to shape a new international division of labour (NIDL) (Murray \& Overton, 2014). This NIDL has re-organised spheres of production, governance and finances (Bonanno et al., 1994). The NIDL effectively gave rise to first value networks which were truly global in scope compared to the value networks which existed before WWII. In relation to this research, these global networks would eventually lay the foundations for the EVeNs, as will be discussed later. Existing work demonstrates that a NIDL started in the period following the end of WWII and accelerated following the debt crises in the early and late 1970s (Murray \& Overton, 2014). Northern TNCs represented a driving force behind the creation of a NIDL. These powerful corporations, in the search of lower production costs, especially in labour, shifted their manufacturing functions from the Global North to the Global South. This re-organisation of the global economy simultaneously caused the deindustrialisation in the North, and industrialisation in the South. The 'old' international divisions of labour were based on the role of the South as suppliers of crude resources while the North represented the industrial core (Cantin, 2010). The creation of a NIDL and the relatively new industrial role of the South illustrates the growing influence of TNCs and their role in re-organising the global economy. It is, however, important to note that the capital and financial centres have remained concentrated in the North (Gibbon et al., 2008).

Facilitated by global economic liberalisation, Northern TNCs have spread their operations internationally (Feenstra \& Hamilton, 2006; Gereffi \& Korzeniewicz, 1994). As the roles of TNCs have expanded, the nation-state no longer represents the hegemonic authority for how trade is regulated or capital is accumulated, as was the case previously (Heffernan \& Constance, 1994). The liberalisation of the global economy has thereby created new opportunities for these TNCs which have concentrated as buyers, suppliers, distributors and service providers across sectors (Sturgeon, 2008). These shifts, explain the growing literature on GVCs and GPNs over the last 30 years. 


\subsection{THE EVOLUTION OF THE GLOBAL AGRO-FOOD SYSTEM}

Throughout modern history, food production and consumption systems have experienced dramatic transformations. A key driver of change has been constant urbanisation which has followed from the Industrial Revolution. Urbanisation, and the associated lack of available land and longer working hours, instigated a steady decline in self-produced food. This created the need for food to be transported from rural spheres to urban centres. As this model expanded the first specialised agricultural production areas began to emerge. This model, particularly in grain production, eventually expanded internationally leading to the formation of the early global agro-food system (Bonanno et al., 1994; McMichael, 1994). This saw the creation of large grain distributing companies Cargill and Bunge, amongst others, during the mid-Ninetieth Century. Continuing Improvements in food producing and transport, especially in canning and subsequently in frozen foods, allowed the rise of food-processing TNCs such as Campbell, Heinz and Nestle from the latter half of the Ninetieth Century (Friedland, 1994).

Demand in the Global North in the late-Twentieth and early-Twenty First Centuries has concentrated in fresh fruit and vegetables (FFV). This has further expanded the different roles of TNCs in the global agro-food system. This was first seen in the fresh banana sector which integrated parts of Central and South America into the Northern market. Since the 1980s, there have been two major demand shifts in the North in FFV systems: (1) the 'all-year' demand for FFVs and (2) the demand for 'exotic' FFVs. All-year demand in FFVs has created niche counterseason markets through a process labelled 'annualisation', which has created more need for TNCs in the global agro-food system. While annualisation requires the local production of fruits and vegetables in the Global South, the transportation and distribution of these products across long distances to North markets is largely controlled by large TNCs (Raynolds, 1997). The demand for 'exotic' FFVs from tropical areas has also augmented the roles of TNCs, expanding their transport and distribution roles (Friedland, 1994). Demand in both off-season and exotic FFVs has seen the entry of TNCS into the South and has driven unprecedented levels of globalisation in agro-food systems. The extensive control over production, transportation and distribution held by TNCs, as well as their access to capital, creates significant power for TNCS in influencing domestic affairs. TNC supermarkets for instance, now hold an increasing bilateral oligopolistic role in the international food market, and some now argue that the economy is now supermarket driven and controlled (Barrientos \& Dolan, 2006b). This raises questions around who can regulate TNCs, especially when they operate in Southern countries which usually have weaker institutional environments. As a result, there are growing issues around the enforcement of corporate responsibility in the realms of social and environmental 
protection as it remains unclear who should regulate and hold TNCS accountable (Heffernan \& Constance, 1994).

\subsubsection{Global Integration of Agricultural in the Global South}

Neoliberal policies, the spread of Northern TNCs, and global forces have restructured the world economy as discussed in the previous section. This has caused the creation of a NIDL and a global agro-food system which further integrated the Global South into the world economy. It is important to note that, agricultural and commodity sectors remain important in most of the South; in terms of overall economic earnings, the employment generation, and as a share of global agriculture (Challies, 2008; Swinnen \& Maertens, 2007). Moreover, it has been highlighted that a large percentage of those involved in these sectors in developing regions make up low socio-economic and vulnerable groups (Allen \& Wilson, 2008).

Since the 1980s and 1990s, many countries in the South have experienced a large shift from agriculture based on state-lead agricultural planning to sectors determined by global market forces (Gwynne \& Kay, 2000). This has been encouraged by a neoliberal project in agriculture based on liberalisation and World Trade Organisation (WTO) trade regulations which push for the expansion of agro-exports and the opening of South economies. More specially, this has reduced agricultural protectionism and state support in South countries (McMichael, 2012). The most obvious change has been the rising participation of the South in the global agro-food system (Bonanno et al., 1994). There have been noticeable changes in the volume of exports entering the global market from the South. Figures from the 'Human Development Report 2013. The Rise of the South: Human Progress in a Diverse World' by Malik (2013 p. 16) for example showed that: "The South now accounts for half of global trade flows, up from barely a quarter 30 years ago." Furthermore, there has been an increase in the amount of foreign investment which has gone into the agricultural sectors in the South (Swinnen \& Maertens, 2007). The structure of the agricultural sectors in many Southern countries have also been altered due to economic liberalisation. For instance, the traditional agricultural exports established by the older international division of labour were based on colonial structures. This has been largely replaced by the expansion of non-traditional agricultural exports (NTAXs) production (Thrupp, 1995).

These shifts, however, do not imply that states have become redundant in the South. More detailed exploration highlights the paradoxical roles of governments in this global restructuring. For instance, governments in the South do not only engage by removing barriers to free trade, instead, they actively implement reforms and policies which facilitate global economic and political transformations (Raynolds, 1997). In doing so, these states establish 
and sustain environments for stable local economic activity. The rapid growth of NTAXs has, therefore, been driven through the duel processes of market forces, as well as the active roles of states in Southern countries which encourage export-oriented economies (Murray, 2002a).

\subsection{COSTS AND BENEFITS OF GLOBALISATION IN THE GLOBAL SOUTH}

The integration of the Southern countries into the global economy, and more specifically the agricultural and commodity sectors within these countries has had a diverse range of costs and benefits for these societies. As discussed, the processes of globalisation continue to cause varied and uneven implications. The literature on globalisation shows that these processes have generated international macro-economic growth (Stiglitz, 2002). In addition to economic benefits, increased access to global communication has spread social awareness and improved channels for advocacy in the areas of human rights and environmental protection (Swinnen \& Maertens, 2007). However, globalisation has also generated a number of new risks and costs for individuals, nation-states, and natural environments. Research continues to reveal that globalisation has driven social disparities both between and within countries, fuelled financial instability and caused environmental damage (Martens \& Rotmans, 2005; Murray \& Overton, 2014; Reardon \& Barrett, 2000).

\subsubsection{Key Arguments for the Globalisation of Agriculture in the Global South}

Existing research has highlighted that globalisation and the associated transformation from domestically oriented agricultural sectors to those based on agro-exports, has assisted the economic performance in many countries of the South. This existing research demonstrates the efficiency gains which often result from transforming from government-controlled agriculture to private sector-controlled agriculture. It is argued that farmers benefit from improved yields, efficiency, product quality, and income growth due to the increased inputs and productivity linked to private sector engagement (Swinnen \& Maertens, 2007). These, usually neoliberal oriented, researchers emphasise the potential benefits that globalisation creates for countries in the South through increased access to international markets (Pingali, 2007). Furthermore, similar research states that the global integration of agriculture from the South has a positive indirect impact of expanding non-agricultural industries by fostering macro-economic growth (Pingali \& Khwaja, 2004).

\subsubsection{Key Arguments against the Globalisation of Agriculture in the Global South}

While it has been illustrated that global integration of agriculture and commodities in the South has supported macro-economic development through market access and efficiency gains, other scholars highlight some of the risks and costs associated with the liberalisation of agricultural sectors in these regions. The liberalisation of South economies in general, and of 
the agricultural sectors more specifically, has created different forms of economic discrimination. A core driver of economic liberalisation in the South has been the recommendations of international financial organisations. Organisations such as the WTO have pushed for economic liberalisation in the South affirming that these reforms will promote economic development.

Despite these claims, research has since demonstrated that the gains of liberalisation tend to have been limited in the South, which as a group has generally experienced losses (Polaski, 2006). These studies have revealed that the gains have largely been concentrated in the Global North, which as a group, continues its historically dominant position in the economic system as colonial and neo-colonial cores (Esteva \& Escobar, 2017; Wallerstein, 2004). Moreover, a select number of transitioning Southern economies such as Brazil and China, have been able to concentrate the benefits of neoliberal globalisation as semi-peripheries. An important disparity in the global economy, is that the agricultural sectors of most Northern countries remain strategically protected. This signifies an asymmetric implementation of neoliberal policies. Partly caused by this uneven implementation of economic liberalisation, the majority of countries from the South struggle to compete globally. Importantly, the main groups to benefit within the South are the rural elites, the industrialised producers, who have connections to global markets and the resources to compete. The smallest-scale producers conversely have benefited the least from liberalisation as domestic-oriented farming is generally not supported by neoliberal restructuring. Moreover, these small-scale producers are economically disadvantaged by dual processes of economic globalisation. Firstly, they suffer from the withdrawal of government support and protection as a result of the neoliberal policies. Secondly, they face increased competition from usually subsidised, cheap imported food from the international market. These dual processes are causing a process depeasantization in the South, which has caused the further exclusion of groups already living in precarious conditions in rural areas (Kay, 2008; McMichael, 2012; Murray, 2006b; Wise, 2009).

The global integration of agriculture in Southern regions, has therefore tended to cause the concentration of farm ownership, excluded local firms and small-scale producers, and replaced national workers with foreign managers and technological equipment. Conversely, those that usually benefit are the local elites which thereby worsens local socio-economic disparities within these countries (Reardon \& Barrett, 2000).

Existing research demonstrates a number of negative social and environmental outcomes in countries in the South resulting from the liberalisation of agricultural sectors. This increased 
industrialisation of Southern agriculture has been closely linked to economic globalisation (Reardon \& Barrett, 2000). This has had direct negative consequences, including deforestation, land degradation, and the intensification of agricultural production practices in the South (Barbier, 2000; Lambin \& Meyfroidt, 2011). The rate of economic globalisation has outpaced the creation of organisations able to deal with the socio-environmental challenges which have emerged, thus exacerbating these negative outcomes. This has been labelled as a 'global governance gap', which disproportionately impacts upon vulnerable groups in the South (Muradian, 2004).

\subsection{EMERGENCE OF ETHICAL VALUE NETWORKS}

Throughout the period of Global South integration into the global agro-food system, there have been growing consumer concerns in Northern markets surrounding notions of social justice, food quality and authenticity, environmental consequences, and impacts on human health in agricultural and commodity products (Goodman, 2004; Hughes, Wrigley, \& Buttle, 2008; Mutersbaugh, 2005). As a result, we are witnessing mounting levels of scepticism around how, where and to what standards food is being produced (van de Kop, Sautier, \& Gerz, 2006). It has been recognised that this scepticism and the changes in consumer preferences have evolved, in part, as a reactionary resistance to what has been labelled as the increasingly 'placelessness' of global agro-food networks (Bowen \& Mutersbaugh, 2014; Murdoch et al., 2000).

The global agro-food system is, therefore, experiencing a growing paradox. On the one hand, there has been a growing dominance of TNCs in agricultural production as already explored. In this sense, consumers have become more dependent on the large corporations which dominate the global agro-food market. As also examined, this has caused the global integration of the South as agricultural suppliers, which is having both positive and negative consequences in these countries. On the other hand, however, Northern consumers have become more concerned with the negative impacts of the globalisation of agriculture. This is pressuring the TNCs to change how they operate, and more importantly, this has created the demand for alternative agriculture networks (Bowen \& Mutersbaugh, 2014). The reasons for these growing concerns are multifaceted. Consumers have become concerned with the negative implications that the globalisation of agro-foods is having, especially when production takes place in Southern countries. A central reason for this has been further exposure of Northern consumers to global social issues through media and communications, travel and the internet. Additionally, NGOs have become increasingly engaged in advocacy centred on the negative impacts that the globalisation of agriculture has had on small-scale producers and farm workers, especially when production takes place in the South (Swinnen \& Maertens, 2007). 
Others have linked the export-oriented model of agricultural to the decline of local-oriented production, leading to food insecurity and livelihoods erosion for small-scale producers in the South (Bowen \& Zapata, 2009). At the same time, consumers have also become more concerned about food quality and health implications associated with globalising agro-food systems. Health scares linked to the globalisation of agriculture such as salmonella, foot and mouth, and mad cow disease have driven consumer apprehension around food safety, quality and authenticity (Swinnen \& Maertens, 2007). Similarly, the industrialisation of farming practices, growing chemical use, mono-cropping - again linked to globalised agro-food systems - have been criticised for their negative impacts on human health and environmental conditions in production areas (Barrientos \& Dolan, 2006b).

These social, health, environmental, and quality concerns surrounding global agricultural production have fuelled the rapid emergence of EVeNs. EVeNs have been theorised by the broader research project which this thesis contributes to. The term EVeNs was originally created by Warwick Murray and John Overton, and has since been further explored by PhD researchers Kelle Howson and myself. As introduced in Chapter One, EVeNs are defined as value networks which emphasise and certify ideas of ethical and high-quality production and consumption such as fair trade labels, organic or sustainable certification, and geographical indications. EVeNs represent both a description of the networks which surround ethical labels, and also the aspirations of these networks to generate different forms of local development. Table 2 below, unpacks the key concepts and literature which have been applied by the larger research team to theorise EVeNs. As summarised in this table, EVeNs have drawn from broad literatures and concepts widely centred on economic globalisation, international development, neostructuralism and neoliberalism. 
Table 2 Key Literature and Concepts Contributing to the Theorisation of EVeNs

\begin{tabular}{|c|c|c|c|}
\hline & Ethical (E) & Value (Ve) & Network (N) \\
\hline \multirow[t]{2}{*}{ Literature } & Ethical product labels & \multicolumn{2}{|c|}{ Dependency/world-systems theories } \\
\hline & $\begin{array}{l}\text { Neostructuralism } \\
\text { Alter-Globalisation } \\
\text { Geographical indications } \\
\text { Fair trade }\end{array}$ & $\begin{array}{l}\text { Global value } \\
\text { chains }\end{array}$ & $\begin{array}{l}\text { Global production } \\
\text { networks }\end{array}$ \\
\hline Concepts & $\begin{array}{l}\text { Ethical production and } \\
\text { consumption } \\
\text { Embeddedness } \\
\text { Sustainability } \\
\text { Inclusiveness } \\
\text { Localisation } \\
\text { Social justice } \\
\text { Quality and authenticity }\end{array}$ & $\begin{array}{l}\text { Governance } \\
\text { Firm inter/intra- } \\
\text { linkages } \\
\text { Value creation and } \\
\text { distribution } \\
\text { Up-grading } \\
\text { Unequal exchange }\end{array}$ & $\begin{array}{l}\text { Non-firm actors } \\
\text { Human agency } \\
\text { Relationality } \\
\text { Importance of local } \\
\text { social contexts }\end{array}$ \\
\hline
\end{tabular}

Source: adapted from (Howson, 2018).

EVeNs have gained significant economic and social importance in the last decade. The common factor between these different networks is an attempt to increase product values through the generation of an 'ethical premium'. This premium seeks to create a connection between Northern consumers and Southern producers. In addition to ethical and environmental concerns, EVeNs represent a shift from mass-produced agro-production systems to these of high-value niche production which emphasises quality, diversification, and place. Over recent decades, increasing amounts of agricultural products have been marketed and labelled to demonstrate how they have been produced, by who, where, and to what standards (Gereffi et al., 2005; Goodman \& Watts, 1997; Hughes, 2005; Ponte \& Ewert, 2009). Each of these labels are associated with some form of EVeN.

EVeNs have become particularly important in the Global South. As discussed, many of these countries have become highly dependent on the export of agriculture and commodities through their integration into the global economy through colonial and neo-colonial processes (Auty, 1994; Gwynne \& Kay, 2000). In an attempt to counter increased competition due to market forces, these Southern countries have become progressively dependent on massproduction and low value-add commodities (Gereffi et al., 2005; Goodman \& Watts, 1997). It is suggested that the value-add offered by various ethical, sustainability and localised production labels may provide alternative models for easing the low-value commodity dependence of small-scale producers in the South (McCarthy, 2006; Raynolds, 2012). 
The validity of EVeNs has however recently come under contestation. Academic interest has begun to concentrate on the marketing and market spaces of some of the groups engaged in the diverse and growing EVeNs (Bowen, 2010b; Renard, 2005). As mentioned, EVeNs are based on claims which appeal to global consumer concerns and demands for ethical, sustainable, localised or high-quality production. Some critical exploration has illustrated that marketing groups utilise these ethical claims to establish and exploit the niche markets which appeal to these consumers (McCarthy, 2006; Raynolds, 2012). What remains unclear is which groups are truly benefiting from these ethical claims. The following sections will critically explore two important and distinct EVeNs: fair trade certification and geographical indication marks (GI), at a global and theoretical level. These two EVeNs have formed the central cases studies of this research.

\subsection{FAIR TRADE}

\subsubsection{The Origins and Key Objectives of Fair Trade}

Fair trade is part of an increasingly diverse group of ethical labels which seek to regulate global agro-food systems (Raynolds, 2012). When the two words 'fair trade' are used, the term refers to the overall movement which seeks to promote more equitable trade for small-scale producers (and more recently hired labourers) in the Global South. The fair trade movement as a whole includes a number of social certifications. When one word 'Fairtrade' or 'FLOCERT' are used, these terms refer to the specific certification mark of Fairtrade International (FLO) and its member organisations (Barrientos \& Dolan, 2006b). This thesis also discusses 'Fair for Life' which is administered by the Institute for Marketecology (IMO) and refers to an alternative fair trade mark to the FLO label (see Figure 13 below for examples of labels).

Figure 13 FLOCERT and Fair for Life Labels

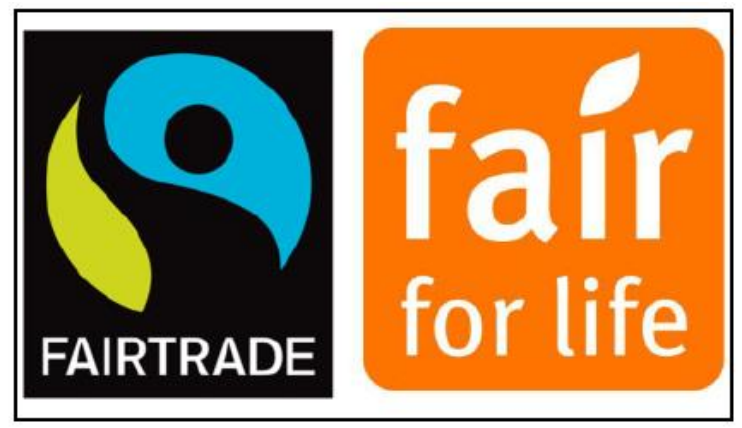

Sources: (Fairtrade International, 2015; Trade for Development Centre, 2005).

A founding principle of the fair trade movement has been securing fair prices for producers in the South by making global value networks shorter and fairer. While there are some differences within the different fair trade certification schemes, producers usually obtain a guaranteed 
minimum price which protects them from market crashes and fluctuations, while also covering the costs of production. Moreover, producers receive a fair trade or social 'premium' which is used to promote community development. The profits from fair trade, including from the social premium, are invested in a variety of activities which bring community benefits, such as infrastructure, schools, health clinics and transport (Jaffee, Kloppenburg, \& Monroy, 2004).

The fair trade movement has a range of diverse objectives. One of the important objectives is the promotion of basic livelihoods for Global South producers through the provision of fairer prices. The Fairtrade mark also promotes environmentally sustainable and organic production (Dragusanu, Giovannucci, \& Nunn, 2014). The movement also promotes deeper transformative or social re-regulatory objectives. In an attempt to ethically re-regulate the global market, the movement seeks to empower producers in the South through trade. This is achieved through the establishment of long-term and stable trading links and community development funding. In the Global North, the transformative objective of fair trade is to offer socially ethical products and promote conscious consumption. The fair trade movement has been labelled as a challenge to the commodification of goods. The commodification of goods has disconnected them from the farmers and workers who produce them. Therefore, it is suggested that fair trade is not just about fairer prices for farmers and workers, but instead seeks to de-commodify goods by linking them to those involved in their production, and criticises the core motivations of capitalist globalisation of market competition, profitability and accumulation (Fridell, 2007). Fair trade, therefore has been promoted as a critique and a re-regulatory alternative to the neoliberal market (Raynolds, 2012). Others, however, have argued that fair trade most likely represents a symbol of differentiation to be used within the neoliberal market rather than challenging this market (Barrientos \& Dolan, 2006b).

The fair trade movement started from humble beginnings as 'alternative trade' from the 1960s, and continued to expand into a multi-billion dollar fair trade sector (Fair Trade International, 2014). The precursor to fair trade, alternative trade, began in the 1960 s, developing during the 1970 s and 1980s with limited success. Alternative trade ran parallel to the larger conventional commodity trade. These alternative networks linked marginalised producers in the Global South to consumers in the Global North, particularly in Europe (Dragusanu et al., 2014). These marginalised producers supported by alternative trade shops, usually had limited markets, such as handicrafts, suffered in asymmetrical value chains, such as coffee, or were based in countries facing political sanctions, for instance, Nicaragua (Jaffee et al., 2004). Products were mainly artisanal with narrow industrial value and were expensively priced in comparison to their conventional counterparts. The customers who supported these stores did so to explicitly 
support marginalised producer groups and as a political statement in resistance to the inequalities worsened by neoliberal trade (Renard, 2005).

A significant moment in the fair trade movement was in 1988, when a Mexican coffee-growing cooperative known as the Union of Indigenous Communities in the Isthmus Region (UCIRI) partnered with Dutch NGO Solidaridad (Jaffee et al., 2004). UCIRI wanted to expand their coffee market out of the restrictive alternative trade stores and into mainstream retail (Renard, 2005). In response, Solidaridad created a fair trade label for their products. The label was named Max Havelaar which celebrated a fictional Dutch man who supported the fair treatment of coffee pickers in the Dutch colonies (Dragusanu et al., 2014). The label aimed to ensure 'sufficient wages' for small-scale producers from the South. This resulted in the emergence of the first modern fair trade label.

The fair trade movement continued to expand throughout Europe and to North America during the following decades, under the Max Havelaar, Fairtrade and Transfair labels. In 1997, several national certification initiatives collectively founded a fair trade umbrella organisation, Fairtrade International. In 2003, FLO launched a common Fairtrade certification mark FLOCERT, that provided a single and identifiable fair trade label for consumers in Northern markets (Dragusanu, et al, 2014; Renard, 2005). In 2006, IMO's 'Fair for Life' fair trade and social certification emerged in Switzerland separately to the FLO system. It emerged as an alternative to FLOCERT and attempted to include those who were unable to use the FLOCERT but wished to receive certification for promoting safe and decent working conditions and certify against the use of forced and child labour, among other core criteria. Fair for Life certification differed to FLOCERT as it had a central focus on hired labourers as well as small-scale producers in the Global South (Trade for Development Centre, 2005). In 2011, Fair Trade USA split from FLO over longstanding ideological differences (Raynolds, 2012). These differences will be examined later in this chapter.

\subsubsection{The Successes of Fair Trade}

The economic growth in fair trade has been impressive, particularly when its relatively short history is considered. In 2004, global annual sales of products with the FLO Fairtrade mark were $€ 832$ million, and by 2014 these sales had reached $€ 5.9$ billion (Fair Trade International, 2015). It is important to note that this remains a small share of the total agricultural and commodity markets. Nevertheless, the growth in key FLOCERT certified products and the emergence of new FLOCERT products has been impressive. For instance, sales in the most significant Fairtrade labelled product; coffee, increased from 12,000 tonnes in 2000 to 93,154 tonnes in 2014 (Dragusanu et al., 2014). It is also important to note that this does not include alternative 
fair trade and social labels, such as Fair for Life which hold smaller but growing markets compared to FLO Fairtrade.

The economic benefits for producers are observed as an important success for those that promote the fair trade movement. Existing research illustrates that producers with fair trade certifications receive higher prices compared to their conventional counterparts. These fair trade certified producers are also more likely to have access to credit and be better connected to global networks (Méndez et al., 2010). It has been claimed that the minimum price paid to producers represents another important success of fair trade. Studies have shown that the fair trade minimum price has protected certified farmers during price crashes such as a dramatic crash in coffee prices, between the late 1990s and the early 2000s (Jaffee et al., 2004). Studies have also demonstrated that producers involved in fair trade certifications enjoy greater transparency, improved participation, and better producer-buyer relationships which enhances market stability (Fair Trade International, 2015). Furthermore, research shows that producers involved in fair trade can benefit from better access to training and services which improves the quality of their production (Murray, Raynolds, \& Taylor, 2003). It has also been documented by a number of studies that Fair trade has some positive spill-over impacts, with members of the local communities benefitting from the social premium, which provides transport infrastructure, health clinics, and schools, among other important benefits, to the broader community (Dragusanu et al., 2014; Méndez et al., 2010).

\subsubsection{The Fair Trade Crisis}

Despite the impressive successes of the fair trade movement during a relatively short history highlighted in different studies, a number of changes have occurred which threaten to erode the movement's core values. These threats have signified a possible crisis in fair trade. A striking alteration in fair trade has been a rapid integration of TNCs in this ethical niche market. A central concern is that these TNCs tend to impose their own versions of 'ethical trade' which avoid the regulations of more meaningful fair trade certifications. In doing so, these newer schemes exploit producers' needs for larger markets, while diluting the principles of the fair trade movement. The proliferation of 'ethical' trade certifications ultimately confuses consumers and damages the value of fair trade labels. This process has been labelled 'fairwashing' (Raynolds, 2012). Another important shift is the growing dependence on TNCs for the distribution and sale of fair trade certified products. This has eroded the power of the fair trade movement to criticise and highlight the unequal and unethical practices of these mainstream companies as fair trade now rely on them as distributors and sellers (Figure 14 highlights growing roles of large corporations such as Starbucks in fair trade). This could eventually lead to the exclusion of small-scale producers from ethical markets and eventually diminish the 
consumer appeal of fair trade (McMurtry, 2009). Moreover, TNCs possess substantial marketing power making it easier for these groups to expand into markets and further displace smaller-scale fair trade groups (Fridell, 2007). The growth in different fair trade labelling such as the examples of FLOCERT, World Fair Trade Organisation (WFTO) and Fair for Life exacerbates this problem, as the multitude of labels of creates confusion amongst the consumers (Renard, 2005).

Figure 14 Ethical Sourcing: Coffee, Starbucks Advertising Campaign

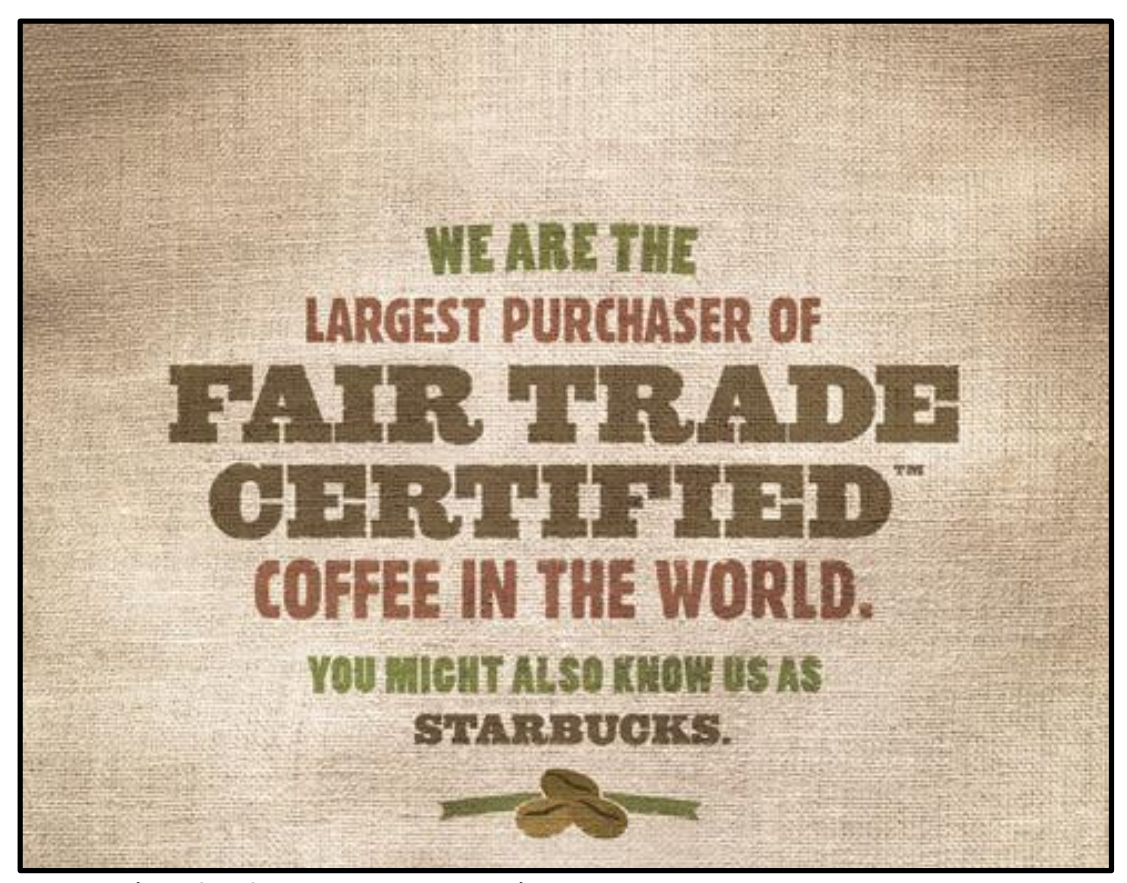

Source: (Starbucks Corporation, ND).

Another central critique is that although fair trade was founded to improve the conditions and positions of small-scale producers, the inclusion of large plantations under hired labour in the FLOCERT and in Fair for Life certifications has represented a fundamental shift in the fair trade movement. In fact, large plantations now outnumber producer co-operatives in a range of fair trade sectors including fruits, tea and juices. Some proponents of fair trade have been critical of the plantation model. This group has asserted that fair trade was created to provide market access for smaller producers and assist them to escape cycles of poverty, rather than generating profits for plantations (Equal Exchange, 2012). The dominance of industrial-scale producers through the fair trade plantation model represents an important and largely negative shift in the fair trade movement (Raynolds, 2012). This broadening of the Fairtrade model under the plantation model has, on one hand, increased the volume of sales of fair trade product. However, the inclusion of hired labour in fair trade certifications has also risked higher prices of fair trade products in the long-term, as larger-scale producers are beginning to dominate and over-supply the ethical niche markets (Renard, 2005). A central question posed 
in the case of hired labour, is how the ethical concerns of the fair trade movement can function through the integration of corporate producers. The failings to clearly define the ethical purpose of the fair trade movement is, therefore, causing complex debate and confusion (McMurtry, 2009).

While small-scale producers were situated at the core of the fair trade movement, evidence suggests that this group feels increasingly alienated from the movement's governance, representation and focus. It has been stated that the establishment of FLO as an international organisation has further centralised power towards certifiers and away from the producer cooperatives. Existing fair trade research shows that producers tend to be concerned about the lack of certainty in how FLO operates and which actors participate at different levels. These producers have also stated in this existing research, that they receive minimal information about fair trade and have no direct contact with FLO representatives. This can exacerbate the lack of producer knowledge surrounding fair trade. This leaves producers confused and feeling disconnected from the certification (Murray et al., 2003; Pérezgrovas \& Cervantes, 2002). Moreover, FLO has proposed lowering the minimum Fairtrade price paid in order to increase sales. The majority of producers have rejected this proposal and have accused FLO of placing producers second to sales (Renard, 2005). This represents what Fridell $(2007$, p. 87) labelled as 'consumer sovereignty', whereby the needs of small-scale producers and workers in the South, remain submissive to the demands of the consumers in the Global North. Adopting GVC terminology, it appears that fair trade networks are becoming increasingly 'buyer-driven' (Ponte \& Ewert, 2009). Although little similar research has been conducted for alternative fair trade and social certifications such as Fair for Life, it is likely that these certifications suffer from similar problems as FLO.

Economic arguments, particularly by neoliberal authors, have demonstrated important challenges emerging in fair trade. For example, particularly using the example of fair trade coffee, these authors have argued that fair trade certifications distort markets, creating inefficiency while sustaining uncompetitive groups. According to these authors, this has resulted in the growth of low-quality products and global over-production (Bassett, 2010; Griffiths, 2012; Wilson, 2010). Evidence shows that in some cases, these critiques have been valid. For instance, production in a number of fair trade certified commodities, including coffee, is now exceeding the demand for these products (Elliott, 2012). A major challenge faced by the fair trade movement is, therefore, how to respond to the high production growth within a niche market model. This is having very real implications for fair trade certified producers now selling into an over-supplied market. In coffee, for example, it has been documented that on average fair trade co-operatives fail to sell more than $20 \%$ of their coffee to the fair trade market 
(Renard, 2005). This places pressure on the producers who incur the costs and time involved for fair trade certification yet are unable to sell all of their production for the higher fair trade prices (Méndez et al., 2010).

\subsubsection{Gaps in Fair Trade Research}

An interesting knowledge gap identified by Jaffee et al. (2004), is whether fair trade only represents 'far trade'. This statement questions if fair trade should be restricted to the traditional South production - North consumption fair trade model, or if there is potential for fair trade products to be both produced and consumed in the same national markets. This aspect of fair trade remains understudied and this thesis has sought to better understand the potential of national-based fair trade markets and the challenges of fostering these markets within a South American context. In addition, fair trade literature has revealed that there is deficient research which focuses on how producers decide to join a fair trade scheme (Dragusanu et al., 2014). It has become clear that the perspectives and knowledge that these producer groups hold have remain understudied (Méndez et al., 2010). This thesis has endeavoured to somewhat address this research gap through the formation of local level data through interviews with producers in the fair trade wine sector in Chile.

In summary, although the fair trade movement has made some major achievements, the movement is at somewhat of a cross-road and possible crisis. I have also identified some of the key research gaps in fair trade. The following sections will explore origin-based Gl labelling, an alternative EVeN, to examine the potential Gls have to foster localised community development and assist small-scale producers.

\subsection{GEOGRAPHICAL INDICATIONS}

\subsubsection{The Origins and Key Objectives of Geographical Indications}

According to the World Intellectual Property Organization (WIPO) (2013, p. 8): "A geographical indication is a sign used on products that have a specific geographical origin and possess qualities or a reputation that are due to that origin." The place of origin and the linked unique qualities of a product are therefore considered to be the most important factors in a GI (Dagne, 2015; Mancini, 2013; Parasecoli \& Tasaki, 2011). The term itself 'geographical indication' has existed for a very long time, however, it is since the WTO agreement on Trade-Related Aspects of Intellectual Property Rights (TRIPS) was signed in 1994, that the term has been widely used (Giovannucci, 2009). Although Gls were first formed in Southern Europe, examples can now be observed throughout the world. 
The following passage by Bowen (2010a, p. 210) highlights the geographical and product range in the GI market:

"We can find Gls throughout the world, in places such as France (Champagne, Roquefort cheese), Italy (Prosciutto di Parma, Parmigiano Reggiano cheese), Spain (Rioja wine, Manchego cheese), Greece (Feta cheese, Kalamata olives), India (Darjeeling tea, Basmati rice), Sri Lanka (Ceylon tea), Mexico (tequila, mezcal), Brazil (cachaça), and Colombia (Colombian coffee)."

Gls are ultimately connected to the concept of terroir, a French word which translates directly to terrain or soil. The concept originates in the production of French wine (Holland, Smit, \& Jones, 2014). However, in practical application, terroir links the natural (climatic, soil and geographical) and social (historical and cultural) factors which form a product unique to its place of origin. Terroir, therefore, implies an interaction between these natural-social factors. Gls are best observed as the legal representation of this natural-social interaction known as terroir (Josling, 2006; Overton \& Heitger, 2008).

\subsubsection{The Evolution of Geographical Indications}

French wine classification systems beginning in the Nineteenth Century have been regarded as important precursors to Gls. Throughout the Nineteenth Century French wine classification became increasingly institutionalised under the Appellation d'Origine Controlee $(\mathrm{AOC})^{16}$ framework. AOC was the antecedent concept of modern GIs, and like GIs, AOCs governed and protected wine authenticity and quality (Colman, 2008; Stanziani, 2004). In France, the AOC system had various benefits. In particular, it protected consumers and producers from fraud and imitation wines (Overton \& Heitger, 2008). This model spread to other parts of Europe, especially in Italy (Denominazione d'Origine Controllata) and Spain (Denominacion de Origen). It also expanded into other agricultural products, especially cheeses; such as Comté in France and Parmigiano Reggiano in Italy (Van de Kop \& Sautier, 2006). Growth in international trade through the latter part of the Nineteenth Century, however, meant control needed to extend beyond national systems (Parasecoli \& Tasaki, 2011).

Initial moves to protect origin-based production internationally began in 1883 , at the Paris Convention on Intellectual Property, and in 1891 at the Madrid Agreement for the Repression of False or Deceptive Indications of Source of Goods. Efforts were also made in 1958 at Treaty of Lisbon to extend GI control prohibiting the use of words 'kind,' 'type,' 'make,' 'imitation' or the 'like' on product labelling (Parasecoli and Tasaki, 2011). This was only signed by 26

${ }^{16}$ Controlled Designation/Denomination of Origin 
members however and excluded the United States of America (USA) and the European Union (EU) (Bidwell, Murray, \& Overton, 2015; Giovannucci, 2009).

In 1992, The EU issued regulation 2081 on Gls. This regulation was a significant step for GI recognition at the international level. The framework provided three categories for GI protection:

- Protected Designation of Origin (PDO): covers agricultural products and foodstuffs which are produced, processed and prepared in a given geographical area using recognised know-how.

- Protected Geographical Indication (PGI): covers agricultural products and foodstuffs closely linked to the geographical area. At least one of the stages of production, processing or preparation takes place in the area.

- Traditional Speciality Guaranteed (TSG): highlights traditional character, either in the composition or means of production (European Commission, 2015).

As explained by Parasecoli and Tasaki $(2011$, p. 3) "Each category allowed different connections with their place of origin, traditions, and methods of production, with PDO being the most binding category and TSG the loosest."

It is important to note that the term geographical indication (or $\mathrm{Gl}$ ) is used as a general concept of origin-based protection rather focusing on the precise form of protection (WIPO, 2013). In this thesis, the term $\mathrm{Gl}$ is used to include the various origin protection schemes which exist. This research has placed particular focus on the Protected Designation of Origin held by pisco (a distilled grape spirit) from Peru. Protected Designation of Origin has been shorted to DO throughout the thesis. A DO represents the strictest form of protection offered by the different GI schemes, and DOs are reserved for unique and well-known products with significant cultural and economic relevance (Moquillaza, 2011).

The evolution of the European GI framework motivated efforts internationally to protect unique origin products. In 1994, the international TRIPS agreement defined GIs in article 22 as "...indications which identify a good as originating in the territory of a Member, or a region or locality in that territory, where a given quality, reputation or another characteristic of the good is essentially attributable to its geographical origin". The adoption of article 23 of the TRIPS agreement provided stronger GI protection for wines and spirits which prohibits the use of products which use "kind", "type", "style", "imitation" (World Trade Organisation, 1994). The definition used in the TRIPS agreement has however been criticised as it fails to include any reference to the social factors involved in the production of Gls (Martin, 2004). 
Over the last two decades, differing perspectives between the EU and the USA have dominated GI debates internationally. These debates can be separated into two broad camps. The USA represents one camp: where Gl experience has been mostly connected to marketing and brand promotion supported by a system of trademarks. The EU represents the other camp: where Gls have focused more on community development and collective ownership (Giovannucci, 2009). The USA approach to Gls has stressed the involvement of private companies and other organisations with the objectives of fostering innovation, consumer protection, fair competition and intellectual property protection. The European approach conversely, places a more important role on the state in governing Gls while emphasising common benefits and fulfilling a more active role in the protection of local cultures and their traditions (Bidwell et al., 2015).

To critics, Gls fundamentally signify an unfair and unrequired form of protection for producers in a defined area against new competitors. The proponents of Gls in response, assert that Gls provide consumers with accurate information which allows them to select quality products while being protected from misleading information. Although the EU has argued that Gls should be protected from fraud the USA gives more prominence to innovation and creativity. New World ${ }^{17}$ countries have also demonstrated that geographical names, based on their colonial histories, have been used in products unique and profoundly connected to the New World country in question (Parasecoli \& Tasaki, 2011). The differing perspectives around Gls have contributed to a number of trade disagreements and conflicts. Although the tensions are centralised between the EU and the USA, these debates have widespread implications in the global economy. For example, GI frameworks in the EU and the USA have profound implications for producers and exporters of commodities in the Global South, particularly in Latin America and South Africa (Josling, 2006).

\subsubsection{Geographical Indications and the Localisation of Food Production}

As examined, the agro-food sector has become increasingly global in production and distribution. Increasingly, commodities are produced in one part of the world and then pass through complex networks before arriving to distant consumers, who receive minimal information about the product's origin or how this product was made. The expansion of agricultural TNCs and mass-produced agro-foods, have therefore led some to argue that food production has become increasingly 'placeless' (Bowen \& Zapata, 2009). As discussed, consumer concerns over industrial and globalising food production have also heightened over

\footnotetext{
${ }^{17}$ The term New World refers to the countries outside of Europe, Africa and Asia. It refers especially to the Americas but also includes New Zealand and Australia, among other countries.
} 
the same period. Most importantly, consumer fears over food safety and uncertainties surrounding the global agro-food systems has caused greater consumer demand for quality products and transparency (Bowen, 2010b; Goodman, 2004).

Recently, the localisation of food production has become increasingly emphasised as an alternative form of agriculture to the globalised model. While globalised agriculture has been linked to concerns over food safety, environmental destruction and rural poverty, models of agriculture which specify locality have conversely been associated with quality and trustworthy production (Murdoch et al., 2000). This localisation of food has fuelled the economic and cultural significance of GI products which provides reassurance to consumers by highlighting where a product comes from and how it has been produced. Gls represent a form of resistance against the homogenisation of the globalised agro-food system (Bowen \& Zapata, 2009). If managed effectively, Gls and their connection to terroir can, therefore, foster localised production by providing a means to protect and promote distinctive natural and social attributes, which have evolved through a place's history (Bowen, 2010a; Larson, 2007). Thus, GIs have the potential to support the survival of diverse and placed-based foods and their associated cultures, by maintaining local knowledge, traditional methods and ecological resources through legal it protection (Bowen, 2010b).

Existing literature reveals that GIs have enabled local farmers in Europe to counter the negative effects of globalisation by linking production to place and connecting local farmers to global markets (Bowen, 2010a). Gls can thereby, function as a tool for communities to counter the challenges that the globalisation of agriculture is generating for local groups. As discussed, these challenges involve food insecurities, the destruction of biodiversity and cultural homogenisation. Theoretically, Gls should therefore empower local communities to utilise globalisation to maintain their social and natural resources through the provision of external markets for localised production. Similarly, Gls have been observed as an alternative model for rural and community development. The importance of community ownership and broad development goals are easily connected to notions of terroir and localised foods (Bowen, 2010b). Additionally, Gls can incentivise the protection of local ecological resources as GIs should encourage more 'responsibility to place' thereby fostering more sustainable natural resource use (Belletti, Marescotti, Sanz-Cañada, \& Vakoufaris, 2015). This emphasis on place provides greater incentives for sustainable production, as opposed to 'placeless' agro-business operations which are not restricted to one area. Moreover, Gls provide farmers with a possible financial incentive to maintain traditional methods which produce unique products. These traditional methods can preserve biodiversity and commonly have less negative impacts on 
ecological processes when compared to chemical and machinery intensive agriculture usually associated with global agro-food systems (Dagne, 2015).

\subsubsection{Geographical Indications in the Global South}

GI literature often highlights the successes of origin based production, however in a European context (Bramley, Bienabe, \& Kirsten, 2013). A particularly positive outcome Gls have had in the European context is the promotion of community development and preservation of rural ways of life. The connections Gls hold with local cultures, traditional farming and local environments, have been especially supportive of rural communities in Europe. Accordingly, Gls have become a popular avenue for European rural diversification policies. Moreover, Gls have been promoted for fostering growth in the marginalised areas where Gl protected products often originate from (Barham, 2003; Boisvert, 2006). For instance, the natural and cultural environments which make large-scale intensive farming difficult in these marginalised producing areas can be the same conditions which generate the unique qualities of GI products (Murdoch et al., 2000). According to Bowen (2010b), Gls can, therefore, have positive impacts on rural development in the areas which most require these impacts. It has been argued that examples of successful GI products in Europe, can offer some learnings for countries in the Global South (Gerz \& Dupont, 2006). Unsurprisingly, countries outside of Europe, including those in the South, have been drawn to GI schemes as a means to increase the value of traditional production while protecting their industries from imitation and misuse through the protection offered by Gls (Sautier \& van de Kop, 2006).

The exportation of the GI model to countries outside of Europe has evolved from a two-way process. To begin, growing demand for GI protection for agricultural products from the South grew as a response to the successes of these schemes within Europe. Simultaneously, the EU has supported the expansion of the GI model to non-European countries for strategic reasons (Bowen, 2010b). For example, the growth of GI schemes outside of Europe extends the markets for European GI products. It also allows for the 'clawing-back' of European products being produced in non-European countries (Josling, 2006). 'Claw-back' refers to the process where a country attempts to place GI protection on a product which has already become generic in another country. This process has become a central reason for the resistance against GI from countries such as the USA, Chile, and Canada, which have long histories producing products which EU members are now attempting to protect with GI status (Bramley et al., 2013).

Gls can benefit Southern producers by linking production to the origin and thereby creating a tool for market differentiation. This differentiation, and the perceived quality consumers place on localised production can result in increased prices for these products (Bramley et al., 2013). 
Research on European Gls has also demonstrated that these Gls generate higher levels of employment, protect ecological processes, and lead to other agricultural activities such as rural tourism (Gerz \& Dupont, 2006; Réviron \& Paus, 2006). European case studies thus provide valuable insights into the potential positive outcomes Gls could create the Global South (Boisvert, 2006).

Existing research has shown that GIs can create benefits which are particularly valuable in Southern countries. Moreover, Gls are not time-bound and represent inalienable community rights. They are therefore suitable forms of protection from the appropriation of local and traditional knowledge and culture. Finally, Gls can privilege small-scale producers by granting economic incentives for these often marginalised groups to maintain traditional agricultural practices (Boisvert, 2006). In this sense, Gls have been seen as a potential strategy for local development by countering the negative impacts of globalisation, through connecting production to local spaces, while, through the same processes, linking this production with national and international markets (Bowen, 2010b). However, as will be now discussed, GI products can be co-opted and appropriated by powerful, sometimes extra-local, groups thus eroding the potential benefits of GIs (Bowen \& Zapata, 2009).

\subsubsection{Risks of Gls in Global South}

Limited research has examined the challenges for countries outside of Europe when establishing GI systems. Some examples of existing research based on GIs in the South have revealed that these countries experience different, and often more serious, challenges than in Europe when implementing a GI. For example, in different Global South countries, GI implementation has proven to be more difficult as their national institutions are generally less effective than in Europe. This means that these countries encounter challenges in protecting intellectual property, safeguarding against fraud, and managing genetic, biological and natural resources. Accordingly, it has been highlighted that improving the national institutional environment in the Southern countries where a Gl is being established is equally important as the quality of the product for the success of these GIs. It has also been shown that the outcomes of Gl implementation in the South are not as simple or positive as the cases found in Europe. In practice, Gl implementation has often caused unexpected and negative outcomes in the South, as will be discussed (Bowen, 2010a; Larson, 2007). Similarly, the lack of a solid legal GI framework and lacking state willingness to become involved in Gl implementation have been emphasised as major barriers to creating effective Gls in the South (Bowen, 2010b).

Research has shown that another barrier for Gl success in Southern countries has been the general withdrawal of states in these countries from both agricultural and development 
strategies following neoliberal reform, especially in parts of Latin America. This low state support ultimately reduces the ability of these countries to develop a sustainable Gls with the capacity to promote community development (Bowen, 2010b; Bowen \& Zapata, 2009). Promoting conservation and protecting biological and genetic diversity through Gl schemes, also comes with important challenges, particularly in countries with weaker institutional environments. When not effectively established, the incentives to develop Gls can have the opposite effect: causing homogenisation, intensification, and mono-cropping of certain GI products at the expense of natural landscapes and biological diversity, and often creates negative outcomes for traditional farmers (Larson, 2007).

Common challenges in Southern countries such as socio-economic disparities, high levels of corruption and differing interests between local elites and government, can also have negative implications for small-scale farmer participation in establishing and sustaining a GI. Research has highlighted that it is very difficult to foster an equitable and sustainable GI if local farmers are not properly represented or provided with the required support to organise themselves institutionally. Furthermore, it has been shown that there is a risk that the implementation of GIs in Southern countries will result in 'institutional mono-cropping', where the GI frameworks developed over hundreds of years in Europe are inappropriately implemented in Southern countries, with the expectation that these new Gls will create the same outcomes (Evans, 2004; Portes, 2006). Rather than promoting quality rural development this 'institutional monocropping' is more like to worsen local inequalities and benefit local elites and extra-local actors which can co-opt the Gls for their exclusive benefits (Bowen, 2010b). The following sub-section will now highlight these issues through a brief case study of the tequila DO experience in Mexico. This DO represents one of the oldest and most important GI schemes outside of Europe, and provides a particularly important case study for Latin American Gls.

\subsubsection{Tequila Case Study}

Various studies examining the Mexican DO for tequila have stressed that, despite the mainstream rhetoric of purely positive impacts of Gls, that these schemes they can actually be detrimental to community development, cultural preservation, product quality and environmental protection (Bowen \& Zapata, 2009; Chávez, 2007). Tequila is a spirit made from the cooked stems of the agave tequilana plant. It is produced in the delimited regions of origin in the State of Jalisco and the nearby municipalities in the states of Guanajuato, Michoacán and Nayarit, as well as the municipalities in Michoacán and Tamaulipas (Larson, 2007). However, lower-grade tequila can be exported in bulk and bottled outside of these regions. The study of tequila is useful for a number of reasons. To begin with, tequila has been protected with a DO since 1974, making it one of the oldest Gls outside of Europe (Bowen \& Zapata, 
2009). Moreover, the industry has grown rapidly in the last twenty years. The tequila DO has therefore been championed as a successful Gl model to be applied in other countries, especially in Latin America (Bowen, 2010b; Chávez, 2007).

Despite these successes, more detailed studies of the tequila industry have found that the DO has largely failed to foster community development or sustainable resource use in its regions of origin. These studies discovered that the standards of the tequila DO have not succeeded in protecting the quality or authenticity of the product (Bowen, 2010b; Bowen \& Zapata, 2009; Larson, 2007). The rapid growth of the tequila industry over the last two decades has instead, been associated with increased control of the sector by transnational liquor companies, such as Bacardi, Brown-Forman and Diageo, which has driven the concentration of extra-local ownership and the industrialisation of tequila production (Bowen, 2010a).

Therefore, a product which grew from its reputation as a purely Mexican drink, has experienced the increased influence of extra-local interests on the policies and standards of the tequila industry through the concentrated role of foreign liquor companies (Bowen \& Zapata, 2009). The Mexican State has been unable and/or indisposed to have a more active role in governing the tequila DO in order to drive local development and protect the qualities and cultures associated with tequila production (Bowen, 2010b). Instead, many of the benefits of the tequila DO have been concentrated by the largest distilleries and transnational liquor companies, while the small-scale producers and local population have been largely excluded. This has caused the industrialisation and homogenisation of production causing deforestation, increased agrochemical use and widespread plant diseases and plagues (Larson, 2007). The tequila DO can, therefore, serve as a warning for other countries are implementing GI schemes such as DOs (Bowen, 2010a; Chávez, 2007). While it is unfair to assume that GI schemes in all Southern countries will transpire in the same way as the tequila industry it is, however, evident that some of the same challenges of the tequila DO are applicable in other Southern countries, especially in Latin America. This research has sought to ask some similar questions about the evolution of the pisco DO in Peru to those which were utilised to critically explore the case of the tequila DO in Mexico.

\subsubsection{Geographical Indications Research Gaps}

As discussed, most existing GI literature has focused on the potential benefits of exporting the European model of GI protection to Global South countries. However, most of these studies have failed to consider how the local contexts, socio-economic inequalities, and institutional challenges will influence the implementation and outcomes of Gls in Southern countries. In this sense, limited work has focused on the real-world consequences of GI schemes at the local 
level in Southern countries (Bowen, 2010a; Bowen \& Zapata, 2009). This research, through the case study of the pisco DO in Peru has sought to contribute to this limited local level data. In particular, this research has investigated the different claims of localised, ethical and sustainable development which are often established by these Gl sectors, including in the DO pisco sector. The work has therefore evaluated the ways a Gl, through the case study of Pisco DO, can protect local actors from the negative effects of globalisation and has also explored the failings of the Pisco DO. Additionally, through the pisco case study in Peru, this research investigated the assertion that $\mathrm{Gl}$ protection creates more responsibility to place as proposed in European literature (Belletti et al., 2015). In focusing on these research areas, this thesis has partly closed the research gaps surrounding our understandings of the implementation of GI schemes such as DOs, when these are embedded in countries outside of Europe and more specifically in the Global South and South America. All of these contributions will be discussed in later chapters of this thesis.

\subsection{CHAPTER THREE DISCUSSION AND LINK TO CHAPTER FOUR}

This chapter introduced the global and theoretical context in which the studied EVeNs have developed in. First of all, the chapter defined processes of economic globalisation which have caused the accelerated integration of local and national economies into the global economy. It was explained that economic globalisation has been an uneven and exclusionary process. Following this, the chapter explored neoliberalism; a political-economic ideology which promotes free-market policies and state withdrawal from economic and development planning. The chapter also explored the emergence of a NIDL, partly created by neoliberal economic globalisation. It was shown that in order to lower production costs, Northern TNCS have shifted their manufacturing from the Global North into Southern regions of the world. Subsequently, the chapter discussed the evolution of the global agro-food system based on these long and complex global value chains. The chapter then went on to outline the integration of the agricultural sector in the South into the global economy through this NIDL. The sections that followed explored the theorisation of EVeNs by our wider research team. These sections showed that EVeNs have emerged rapidly over the last 30 years, motivated in part by a range of social, health, environmental, and quality concerns in relation to the global agro-food system. The subsequent sections outlined the two EVeNs which have been studied in this thesis; the fair trade and Gls networks. These sections explored the origins and objectives of these two separate networks at a global level and discussed some of the specific successes, benefits, challenges, and risks associated with these two EVeNs. 
The subsequent chapter, Chapter Four 'Grounding Ethical Value One: Historical Evolution of Peruvian Viticulture', will now explore the historical and contemporarily development of Peru through the lens of viticulture. In doing so, this chapter begins to ground the theoretical concepts of this thesis by exploring the evolution of one of the studied viticultural ethical value networks, DO pisco from Peru. 


\section{CHAPTER FOUR. GROUNDING ETHICAL VALUE ONE: HISTORICAL EVOLUTION OF PERUVIAN VITICULTURE}

\subsection{CHAPTER INTRODUCTION}

This chapter starts to ground the larger theories of this research through an exploration of the historical evolution of viticulture in one of the national case studies, Peru. In doing so, the chapter contributes to the first research aim: to complete a comparative exploration of the historical evolution of viticultural sectors in Peru and Chile. While this chapter concentrates on the Peru case study, Chapter Five examines the historical evolution of Chilean viticulture. Existing research shows that a sector does not develop in a vacuum, and instead is affected by the history of the locality where the sector is embedded and the larger social, economic and political shifts in this locality (Dicken, 2007). Considering this, the study of the Peruvian viticulture in this chapter and the study of Chilean viticulture in the following chapter, provide valuable understandings of the important historical changes which have shaped the case studies of this research.

Chapter Four explores the historical evolution of Peruvian viticulture. In doing so, it explores the experiences of viticulture as Peru underwent the transitions from a colony to a republic and through political-economic shifts from classical liberalism, structuralism, neoliberalism and beyond. The chapter closes with a final discussion and a link to Chapter Five.

\subsection{THE ARRIVAL AND EXPANSION OF VITICULTURE IN THE SPANISH AMERICAN COLONIES}

The Spanish and Portuguese explorations and subsequent colonisation of Latin America in the Fifteenth and Sixteenth Centuries, saw the first transportation and planting of European grapevines in the Southern Hemisphere (del Pozo, 1995; del Pozo, 2014). The transportation of large quantities of wine from Spain and Portugal and the subsequent planting of European vitis vinifera grapes for wine production in the Americas provides us with an important insights into the European colonisation of the Americas, and demonstrates the importance the Spanish and Portuguese colonisers placed on wine (Dargent Chamot, 2014; Unwin, 1991). Chapters Four and Five will focus specifically on the experience of Spanish colonisation as this is most relevant to the two national case studies of the research; Peru and Chile. As will be explored throughout this chapter and Chapter Five, the outcomes of colonisation continue to deeply affect the social structure of the rural societies and the viticultural sectors in both Peru and Chile. Chapters Six and Seven will build from the contextual Chapters Four and Five to engage with the primary data from fieldwork interviews and their analysis. 
The colonisation of the 'New World' by the Spanish was driven by complex social, economic and political motives. A central motive, and perhaps justification, underlying the colonisation of Latin America was the perceived noble and ideological belief of the Catholic Monarchs that it was necessary to disseminate the Catholic faith, defeat infidels, and save the souls of the peoples of the New World. In this historical context, religious motives formed important justifications for the conquest of Latin America. Religion also partially explains why the Spanish colonisers sought to secure wine supplies and production in the Americas, as wine was required for Catholic ceremonies (del Pozo, 1995; del Pozo, 2014). Apart from religious uses of wine, other social and economic motives help to explain the transportation of wine and the following spread of wine production across Latin America. During the colonisation of Latin America, the Spanish leaders attempted to symbolically recreate Spain, introducing crops from the Spanish homeland to the Spanish American colonies, including grapevines (Huertas Vallejos, 2004, 2012).

Between 1519 and 1524, the Spanish conquerors invaded the American mainland for the first time, rapidly defeating the Aztec empire. During this period, significant amounts of wine were shipped to the Spanish conquerors in Nueva España centred in modern-day Mexico (Dargent Chamot, 2014). During the 1520s, subsequent to Spanish victories over the Aztecs, the Spanish colonisers planted numerous crops from Spain in the Nueva España colony. These crops included the first European grapevines to be introduced into the Americas. By 1524, the Spanish had entirely dominated the Aztec empire. Most of the Aztec population was shifted to central Mexico, where Spanish colonisers used them as labourers through the encomienda and repartimiento systems. An encomienda was a royal grant which represented a type of reward for meritorious military service (Rice, 2011b). The encomiendas were instruments used by the Spanish to exploit indigenous labour and resources in the American colonies. Although the encomienda was not a land grant, the encomenderos (Those that received the encomiendas) frequently abused the system to establish their personal estates (Lockhart, 1994; Unwin, 1991).

In addition to the encomiendas, the Spanish settlers received access to unpaid indigenous labour under a system known as repartimientos. From the conquest of the Aztec Empire from the 1520s, the encomiendas and repartimientos proved to be important instruments for driving of the expansion of vine planting (Huertas Vallejos, 2012). However, there was limited success in growing grapes and producing wine in Nueva España, as the climate conditions were not suited to wine production. The Spanish conquerors soon looked to the south to expand their empire and, as a result, spread vine cultivation into South America (Mishkin, 1966). By 1545, grapevines were being cultivated following the wake of Spanish colonisation from Mexico, 
through the entire Pacific coast of Peru as far south as the Spanish colonial city of Concepción in southern Chile (Unwin, 1991).

The amount of wine exported from Spain into the Americas also grew rapidly following Spanish conquest. However, due to inadequate early transporting technologies, the wine would frequently spoil during the voyage across the Atlantic. During the Sixteenth Century, wine production shortages in Spain restricted the amount of wine that could be exported to the Spanish American colonies and the wine that did arrive to the Americas was sold at high prices. Through the 1540s and 1550s, as colonial settlements developed and spread through Spanish America, it was practically impossible for the Spanish wine producers to fulfil the growing wine demands in the colonies (Huertas Vallejos, 2012). Wine shortages were experienced in rural areas of Central America and in the remote Viceroyalty of Peru, and church officials and the local populations began to complain. The Spanish crown soon acknowledged the need to develop local wine production in the Spanish American colonies. As a result of Spanish promotion, colonial wine production expanded during the first half of the Sixteenth Century (Lacoste, 2007). This resulted in the rapid development of colonial wine sectors in Spanish America, especially in parts of modern-day Peru, Chile, and Argentina (del Pozo, 2014; Mishkin, 1966; Rice, 2011a; Unwin, 1991).

As the Spanish spread through Central and South America so did colonial encomienda and repartimiento systems. From the 1520s, in España Nueva, and later in the 1540s and 1550s in the Viceroyalty of Peru and the Kingdom of Chile, the use of indigenous populations for labour in the encomiendas, including the vineyards, was widespread (Unwin, 1991). The encomiendas in the Spanish American colonies evolved into an abusive instrument of domination over the indigenous populations (Rice, 2011b).

A combination of exploitation, warfare, and European diseases decimated the indigenous populations over the Fifteenth and Sixteenth Centuries (Lockhart, 1994). In response, the Spanish transported large numbers of African slaves to work in the mines, vineyards and the other activities associated with encomiendas and repartimientos (Rice, 2011b). The flow of African slaves increased dramatically from the 1550s, following the drastic decline of indigenous populations in most of Spanish America (Unwin, 1991). In the colony of España Nueva alone, it is estimated that the indigenous population declined from 22 million in 1519 to around one million in 1620 (Gerhard, 1972).

Wine production continued to grow in the Spanish South American colonies through the Sixteenth and Seventeenth Centuries. African slave labour dominated colonial agricultural activities including in the Spanish American vineyards until the Eighteenth Century when the 
indigenous populations recovered from catastrophic population losses. From the Eighteenth Century, the practice of vineyard slavery was replaced by seasonal waged indigenous workers which became more economically viable than maintaining African slaves (Rice, 1996). The use of seasonal waged workers based on flexible employment continues to play an important role in contemporary South American viticulture, and has grown since neoliberal shifts from the 1980s and 1990s (Caro, 2013). By the second half of the Sixteenth Century, driven by wine shortages and encouraged by policies of the Spanish crown, colonial viticultural expansion was proving to be successful (Mishkin, 1966). Wine production in this period had been concentrated mainly on the Peruvian south coast and in Chile and Argentina (del Pozo, 2014).

In the final decades of the Sixteenth Century, the Spanish wine producers complained about the growing Spanish American wine supplies. In 1569, Spanish King Felipe II issued a directive to ban any planting of new grapevines and on the replacing of old decayed vines in The Viceroyalty of Peru. This ban attempted to stop the export of wine from Peru and Chile into the Caribbean and the España Nueva markets. However, the directive ultimately failed and the expansion of viticulture continue unhindered in Peru and Chile (Mishkin, 1966). In 1595, King Felipe II attempted to extend the ban of the vine planting across all of Spanish America. Over the following two centuries, despite the attempts to ban the growing Spanish American viticultural sectors, the production of wine and aguardiente de $u v a^{18}$ continued to expand (Unwin, 1991). Despite the growth of colonial viticulture, Spanish wine exports into the Americas also grew rapidly and by the mid-Seventeenth Century. At the end of the Seventeenth Century and during the Eighteenth Century, despite directives from Spain to limit American wine production, production and consumption of wine and aguardiente de uva continued to expand across the Americas, as did inter-colonial wine and alcohol trade (Del Pozo, 2014).

\subsection{THE HISTORICAL EVOLUTION OF PERUVIAN VITICULTURE}

\subsubsection{Viticulture and Spanish Colonisation of Peru}

The Viceroyalty of Peru represented the centre of the Spanish Empire in South America from Spanish conquest in 1543. As a viceroyalty, Peru governed all of the South American territories colonised by the Spanish apart from modern-day Venezuela (Davies, Burr, Moore, Pulgar-Vidal, \& Kus, 2018). The Viceroyalty of Peru was at the heart of Spanish wealth extraction, supplying the Spanish Crown with massive quantities of gold and silver. The economy in the viceroyalty was both extractive and highly exploitative. Mining was first based on the use of forced indigenous labour, using a modified form of the Incan mita of labour tribute. The mita system was adapted to function like the repartimiento systems (Friedman, 1984; Stein \& Stein, 1970).

${ }^{18}$ Distilled grape spirit 
The encomienda system proved to be a significant instrument for dominating and controlling the indigenous groups and in maintaining colonial mining and agriculture operations in the Viceroyalty of Peru, and in the rest of the Spanish American colonies (Rice, 2011b; Wiedner, 1960). From the colonial encomiendas and repartimiento systems, feudal socio-economic structures evolved in rural parts of the Spanish American colonies based on classes of a minority landed elite and a dependent mass of peasantry. This saw the evolution of the haciendas; large agricultural estates which monopolised land-ownership, production and labour. This rural socio-economic structure remained virtually unchanged until the midTwentieth Century in most of Latin America (Challies, 2010; Kay, 1980; Stern, 1988).

As the early Spanish towns and cities grew throughout Peru so did the demand for wine and other goods associated with the Spanish diets. The most important silver mine in South America, Potosí, was discovered in 1545 in Alto Perú, now part of modern-day Bolivia. This discovery saw the formation of the mining city Villa Imperial de Potosí. A booming population developed in Potosí which required goods, including large quantities of wine and aguardiente de uva from the haciendas in other Peruvian centres such as Cuzco, Arequipa, Moquegua, Lima and Ica. As discussed, the importation of Spanish wines was unable to fulfil demand in Spanish America, and this encouraged the development of Peru's early vineyards. Population growth in Lima, also encouraged the growth of vineyards in Lima and in Lima's peripheral region, Ica (Dargent Chamot, 2014). Following Spanish conquest, it soon became evident that the natural conditions in Peru were better for vine cultivation and wine production compared to in the earlier colonies in Mexico and Central America. Historical texts highlighted that the colonial grapes adapted well in Peru and with the encouragement of the Spanish Crown, the number of vineyards expanded rapidly. The taxes from local wine production, and later from aguardiente de uva (later known as pisco in Peru), helped to cover the costs of establishing the significant networks created by the growth of the populated centres (Huertas Vallejos, 2012).

From the 1550s, vines and wine production spread through different regions of Peru, particularly along the Pacific coast. However, during the second half of the Sixteenth Century, the most important wine and producers had concentrated in the Arequipa region as well as in the Moquegua Valley in Southern Peru. The producers in Arequipa and Moquegua were relatively close to Potosí and other important mines thereby providing these producers with a significant advantage over their coastal counterparts. In 1600, the Huaynaputina Volcano erupted violently destroying many of the vineyards and the pisco bodegas in Arequipa and Moquegua. Under these circumstances, the Pisco, Ica and Nazca Valleys became the most important viticultural areas in Peru (Huertas Vallejos, 2012; Vázquez-Rowe, Cáceres, TorresGarcía, Quispe, \& Kahhat, 2017). 
At the end of the Sixteenth Century, pisco and Peruvian wines exported through the Pisco Port in Southern Peru to other parts of Spanish America (Huertas Vallejos, 2004; Vázquez-Rowe et al., 2017). The name of pisco the aguardiente de uva originates from the Pisco Port. The spirit was originally transported from this port during Peru's colonial period. The name pisco stems from the word for bird; pishko, in the indigenous language Quechua. The Pisco Port and Pisco Valley received their names from the large seabird populations that inhabited the area. The native populations that lived in the area were also named pishko after these birds, while clay pots used by this population to hold liquids, were also named pishkos (see Figure 15 below). The name pishko, therefore, referred to the geographical area, the port, the people and clay pots. Resulting from the extensive shipments and growing reputation of the aguardiente de uva transported from the Pisco Port, the product adopted the name 'pisco', during the mid1700s (Dargent Chamot, 2014; Huertas Vallejos, 2012). As discussed later in this chapter, pisco would eventually become an emblematic product for Peru and part of the national identity. Moreover, pisco's origin became a significant point of debate between Peru and Chile (Gutiérrez, 2011; Huertas Vallejos, 2012; Mitchell \& Terry, 2011).

During the first decades of the Seventeenth Century, Peruvian wine and pisco production continued to expand, supplying the important market of Potosí and in other mining centres as well as exporting to other Spanish American colonies (Vázquez-Rowe et al., 2017). Over this period, pisco production became an important economic activity for the haciendas. The oldest written record of pisco production discovered in Peru dates back to 1613 (Huertas Vallejos, 2012). In 1641, the King of Spain Felipe IV prohibited the entry of Peruvian wine into Spain and ordered vineyard owners in the Viceroyalty of Peru to replace their wine grapevines with grape varieties for pisco production. From 1641, pisco production intensified and during the early Eighteenth Century pisco production surpassed wine production in Peru (Dargent Chamot, 2014; Huertas Vallejos, 2012). 


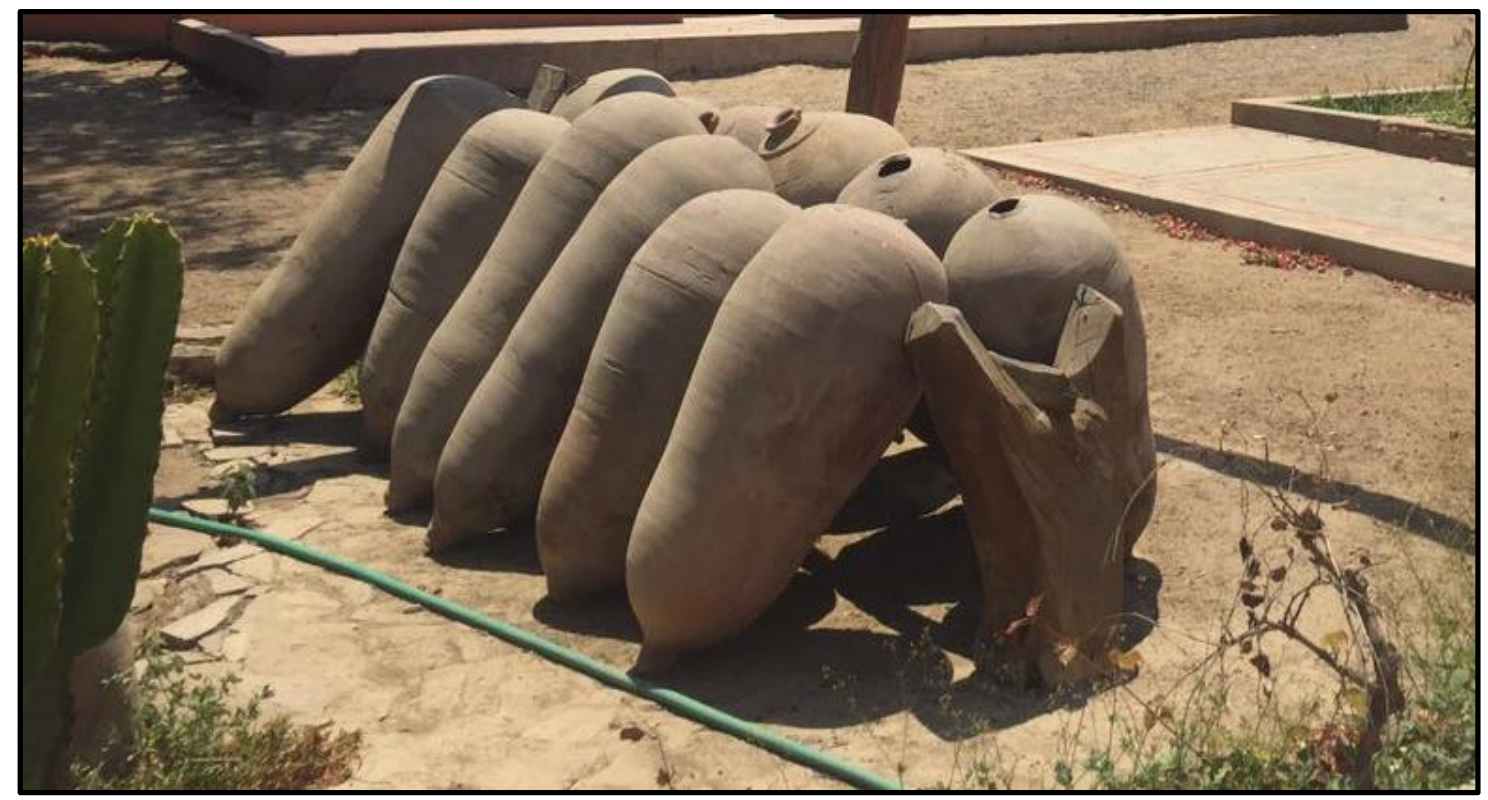

Note. Photo of Pishkos (clay pots) used in Peru since Pre-Hispanic times to store and transport liquids. Since Spanish colonisation, variations of these clay pots have been traditionally used for storing and transporting wine and pisco in Peru. Source: taken by the author.

\subsubsection{Vineyards and Labour Relations in Colonial Peru}

Labour relations in viticultural haciendas of the Viceroyalty of Peru were feudal and based on the exploitation of indigenous tribute labourers and African slaves. By the end of the Sixteenth Century, Peru had been well established as a Spanish centre for mining extraction based on forced-labour, while this centre was supported by the agricultural hacienda estates. The systems of indigenous mita and the encomiendas were very harsh, and many of the indigenous tribute labourers were overexploited and died as a result. As discussed, many more indigenous peoples died due to a number of disease epidemics and indigenous populations plummeted (Friedman, 1984). These exploitative labour relations continued into the post-independence period until the mid-Nineteenth Century on the agricultural haciendas, many of which had evolved from the encomiendas rewarded to Spanish conquerors (Dargent Chamot, 2014). Initially, vines were planted and wine was produced in the estates under the encomiendas or in the mission estates controlled by the Catholic Church, using indigenous tribute labourers or mitayos. As examined, under these systems the indigenous were forced to provide tribute labour to the Spanish conquerors, settlers and catholic officials (Rice, 2011b). Between 1520 and $1620,75 \%$ of the indigenous population had disappeared, and this required the Spanish to replace Andean indigenous tribute labourers with African and other indigenous slaves to work the land (Huertas Vallejos, 2004; Wiedner, 1960). The largest vineyards typically possessed between 10,000 and 40,000 grapevines. Viticulture in the colonial period was not, however, restricted to large estates. Historical records highlight an abundance of medium size vineyards (which possessed between 1,000 and 10,000 grapevines) and smaller vineyards (which 
possessed less than 1,000 grapevines) in the productive viticultural valleys in Peru (Huertas Vallejos, 2012). Viticulture continued to rapidly in expand Peru and production costs remained low due to use of around 20,000 African slaves who laboured in the productive vineyards to the South of Lima (del Pozo, 2014).

\subsubsection{Early Crises in Peruvian Viticulture}

From the 1730s, a combination of social and natural factors caused the significant decline of the wine and pisco production in Peru. A number of serious earthquakes devastated Peru's most important viticultural region of Ica, between 1664 and 1746. In addition, a number of plagues and droughts in the late-Eighteenth Century hindered efforts to recover viticultural production in Peru (Dargent Chamot, 2014). Moreover, the mines experienced declining productivity as it became increasingly difficult to extract the deep deposits of silver and gold. In the most important silver mine, Potosí, resource extraction plummeted between 1780 and 1820. As discussed, these mines had supported the expansion of Peru viticulture. The decrease in mine productivity also signified declines in the wine and pisco consumers working in the mines. Over this period, Peru lost its hegemonic position in South American viticulture and by the second half of the Eighteenth Century wine and pisco exports from Peru declined rapidly (del Pozo, 2014; Huertas Vallejos, 2012).

Between 1719 and 1722, the Spanish Crown created the Viceroyalty of Nueva Granada which removed the Viceroyalty of Peru's jurisdiction of over modern Colombia, Ecuador, Panama, and Venezuela. In 1777 , the crown also created the Viceroyalty of the Río de la Plata which removed the Viceroyalty of Peru's jurisdiction of the over modern Argentina, Bolivia, Paraguay and Uruguay. The establishment of these new viceroyalties removed the political, economic and social hegemony enjoyed by the Viceroyalty of Peru since its creation. This exacerbated Peru's growing economic problems and worsened chances for recovery of viticultural production (Huertas Vallejos, 2012).

In 1821, the Spanish royalists were no longer capable of defending the Viceroyalty against rebel forces led by José de San Martín. By 1824 Peru was declared independent from Spain following the defeat of the last Spanish royalists at the Battle of Ayacucho. Following this, the remaining territories of the Viceroyalty of Peru were divided into modern-day Peru and Chile (Davies et al., 2018). The Peruvian War of Independence also had important consequences for viticultural production. For instance, important numbers of African slaves and indigenous were freed to fight for San Martín who landed his military campaign in the Ica region. The absence of these former slaves, in a time when labour shortages were rife in the vineyards, caused many wineproducing haciendas and smaller wine producers to collapse (Dargent Chamot, 2014; Huertas 
Vallejos, 2012). Following its zenith in the Sixteenth Century and in the first decades of Seventeenth Century, Peruvian hegemony in South American viticulture had therefore been lost by the time Peru was declared independent from Spain in 1824.

\subsection{PERUVIAN VITICULTURE IN POST-INDEPENDENCE}

Long-term economic stagnation resulting from declining mineral extraction from the midEighteenth Century, the Peruvian War of Independence and the 40 years of social instability which followed, had important consequences for Peru's viticultural sector. Following Peruvian Independence, the formerly productive vineyards continued to suffer labour shortages. These shortages were further exacerbated by the deaths and injuries associated with war (Dargent Chamot, 2014). Labour relations in the Peruvian coastal haciendas were modified following independence. These haciendas, including those engaged in wine and pisco production, began to apply more capitalist production and labour relations. The owners of these haciendas directly cultivated most of their land and controlled the majority of the production on their estates. Labour along the coast was increasingly based on waged seasonal labourers and a small number of tenant labourers who received land and other non-wage benefits as payment (Kay, 1980). As a result of long-term economic decline in Peru, most of the vineyards lacked the capital for required fertilisers and new machinery during the early-Nineteenth Century. Vineyards across the newly established Peruvian republic, therefore, suffered declining production and the lack of investment. As a result, grape production reduced to $25 \%$ of earlier levels. By the 1830s, encouraged by growing demands for cotton and sugar due to the English Industrial Revolution, many of the vineyards replaced their vines with cotton plants and sugar cane. As grapevines were replaced, Peruvian wine production continued to decline during the Nineteenth Century. The Peruvian economy did, however, begin to recover from the 1830s, due to an important reactivation of silver exports and significant growth in wool exports funded largely by British capital (Hunt, 1973). Viticulture, however, continued to decline over this period (Huertas Vallejos, 2012).

\subsubsection{Peru Viticulture and Development Post-1850}

Some political and economic stability was achieved in Peru around the mid-Nineteenth Century when Peruvian guano exports boomed. Guano was processed and used for fertiliser in European markets. Peru virtually possessed a monopoly on global guano supplies and by 1847 the product became Peru's most important export. Following neo-colonial trends in the region at the time, the guano industry was however controlled by foreign, mainly British corporations. The taxes on this industry, nonetheless, represented the main source of revenue for Peruvian governments over the subsequent 40 years (Davies et al., 2018; Hunt, 1973). The period 
between 1850-1910 in Peru, and in Latin America in general, is often referred to as the neocolonial period as internal and external relations and structures closely resembled those in the colonial period. For instance, while the elites in Peru and in other parts of Latin America benefited from the export economies, they also yielded important amounts of control to the European and North American industrialising countries. Therefore, like in the colonial period, external groups possessed significant amounts of control in the region. Moreover, most Latin American economies, including in Peru, remained heavily dependent on the exports of lowvalue primary materials and vulnerable to external events similar to the colonial era (BulmerThomas, 2003; Dos Santos, 1970; Frank, 1966).

From the 1850s, like guano, the demand for sugar and cotton also grew significantly in the European markets, especially in England. During the 1850s, the cane sugar plantations in the coastal haciendas expanded and sugar became one of Peru's most important exports in the post-independence era (Dargent Chamot, 2014). Cotton production also grew as demand for cotton similarly increased in European markets (Hunt, 1973). The result was the rapid expansion of cotton and sugar cane crops in Pisco, Ica and other viticultural zones which also caused the decline of land dedicated to viticulture (Huertas Vallejos, 2004). The hacienda owners soon realised that greater profits could be achieved through cotton and sugar production thus providing a viable alternative for the struggling post-independence viticultural sector in Peru. Moreover, pisco production and consumption were largely surpassed by aguardiente de caña (cane sugar spirit). The production of aguardiente de caña exacerbated the decline of the already stagnating pisco industry. Aguardiente de caña represented a cheap alternative to pisco and wine and partially caused the adulteration of both products as viticultural producers searched for ways to survive in an increasingly difficult alcohol market in Peru. This largely ruined the reputation and quality of wine and pisco and alcohol adulteration still remains to be a problem in Peru (Huertas Vallejos, 2012). By 1854, indigenous tribute and African slavery were abolished in Peru. However, owners of the coastal haciendas were allowed to bring thousands of lowly-paid Chinese workers in order to help overcome the existing labour shortages (Davies et al., 2018).

During the second half of the Nineteenth Century, the cotton and sugar-cane cropping continued to expand, replacing areas once cultivated in grapevines. Critical lapses in viticultural production caused by natural events such as flooding, drought, volcanic eruptions, plagues, vine diseases and earthquakes further exasperated the decline in grape cultivation. By 1878, both sugar and cotton became more important export crops than wine and pisco combined 
(see Table 3), while internal alcohol consumption was dominated by aguardiente de caña, beer and chicha ${ }^{19}$ (Huertas Vallejos, 2004, 2012).

Table 3 Production of Cotton, Sugar and Wine and Aguardientes in 1878

\begin{tabular}{|l|l|}
\hline Product & Export Value (in Soles) \\
\hline Sugar & $12,000,000$ \\
\hline Cotton & $1,285,377$ \\
\hline Wines and aguardientes & $1,000,000$ \\
\hline
\end{tabular}

Adapted from (Huertas Vallejos, 2012)

The War of the Pacific, between Chile and the allied Peru and Bolivia, hindered attempts in Peru to create political-economic stability during the second part of the Nineteenth Century. Chile's triumph over Peru and Bolivia in 1883 caused mass destruction in the Peruvian countryside further damaging the already stagnated viticultural sector in Peru (Dargent Chamot, 2014; Huertas Vallejos, 2012).

From 1884 until the 1930s, Peru entered a stage of difficult recovery following the war with Chile. The high spending during the war set Peru on a course of economic ruin. To assist the recovery, the elitist Partido Civilista ${ }^{20}$ government accepted a deal proposed by the Peruvian Corporation of London creditors from 1889. The London-based Peruvian Corporation, gained control of the Peruvian railways for 66 years, access to three million tonnes of guano, and received an additional annual payment of $£ 80,000$ for 33 years. The plan helped to stop the likely national bankruptcy of Peru but was characterised by neo-colonial relations and foreign control (Miller, 1983). During the first decades of the Twentieth Century, the Peruvian economy accelerated as copper exports and agricultural exports in cotton, sugar and wool grew. USA capital became increasingly important in Peru and especially dominated the copper mining and oil sectors (Davies et al., 2018).

In attempts to reactivate viticulture, French and Italian grape varieties were planted in the lateNineteenth Century in order to produce European-style wines. However, most Peruvian viticulturists continued to follow outdated grape growing practices and these introduced vines largely failed until a rejuvenation of Peruvian viticulture in the 1950s (Dargent Chamot, 2014; Huertas Vallejos, 2012). Throughout the first half of the Twentieth Century, the viticultural industry showed little improvement in Peru, continuing to decay following more than a century of decline. In particular, the country's former viticultural centre, Ica, experienced a contraction of wine and pisco production as cotton and sugar crops expanded into land traditionally used

\footnotetext{
${ }^{19}$ Fermented corn drink

${ }^{20}$ Civilian Party.
} 
for vines. In Ica, most of the haciendas flourished during this period due to sugar and cotton exports. Labour in these coastal haciendas continued to consist typically of a small number of tenant labourers who received land and other material benefits and larger numbers of seasonal waged labourers (Kay, 1980).

\subsection{PERU IN THE EARLY TWENTIETH CENTURY}

Peruvian viticulture continued to stagnate in a period largely characterised by economic expansion, neo-colonial relations and classical economic policies. Under the presidencies of aristocrat Augusto Bernardino Leguía y Salcedo, the pro-elite Civilista Party promoted economic growth led by the production and exportation of minerals and agricultural products. Foreign capital, especially from the USA, became increasingly important in Peru and large-scale public works projects were funded by loans financed by US banks (Davies et al., 2018). The benefits of economic growth were however concentrated by the powerful oligarchy and foreign investors while most of the Peruvian population was largely excluded (Hudson, 1992). Two Peruvian political parties were founded in the early-Twentieth Century largely in response to demands for wider political inclusion; the Alianza Popular Revolucionaria Americana ${ }^{21}$, and the Partido Communista Peruano 22 (Caceres Booth, 2013).

During the Great Depression of the 1930s, the Peruvian economy did not suffer like others in the region as it enjoyed a relatively diverse export economy. As the Peruvian economy recovered rapidly from the Great Depression, Peru remained mainly concentrated on a model of export-led growth rather than engaging in the structuralist policies which had become popular in many other countries in Latin America following the depression (Hudson, 1992). During WWII, Peru continued to be heavily influenced by USA capital and the war encouraged additional economic growth through the exportation of petroleum, cotton and minerals to the Allied countries. As a result, Peru was further inserted into the international economy as a resource periphery (Thorp \& Bertram, 1978).

In 1948, hopes of more inclusive democracy in Peru were dashed when General Manuel Odría took power forming a military dictatorship (Davies et al., 2018). Odría led a repressive regime which took harsh measures to suppress the Alianza Popular Revolucionaria Americana and leftwing supporters. Odría was successful in creating a stable political and economic environment as well as strengthening Peru's ties with the regional hegemony, the USA. Between 1950 and 1970 , the economy grew 5\% annually, yet the Peruvian governments also granted increasing political influence to foreign investors. The economic benefits were concentrated by elites on

\footnotetext{
${ }^{21}$ American Popular Revolutionary Alliance Party.

${ }^{22}$ Peruvian Communist Party.
} 
the industrialised Pacific Coast while populations in the highlands were largely ignored, and these populations experienced stagnating or falling living standards in the two decades following 1950. This uneven economic development worsened the historical disparity between the highland and coastal regions and sometimes led to violent protests from landless rural groups and urban workers during the 1950s and 1960s (Hudson, 1992).

\subsection{PERUVIAN VITICULTURE, POST-1940}

Despite moments of political stability and economic growth, Peru's viticultural sector faced multiple challenges during the first 40 years of the Twentieth Century. To begin, the sector continued to grapple with long-term industrial decay and any signs of recovery remained limited (Dargent Chamot, 2014). Although WWII encouraged some economic activities in Peru, it had the opposite outcome for viticulture. The demand for cotton prompted by these wars only exacerbated the expansion of cotton cropping which begun in the 1870s. This caused viticultural production to decline further as landowners continued to convert their vines to the more profitable cotton crops. Moreover, the viticultural sector had suffered from a number of plant diseases and plagues during the first half of the Twentieth Century. The phylloxera plague which had decimated European vineyards during the Nineteenth Century, reached Peru in the 1900 s destroying entire vineyards. Finally, high taxes on the production and commercialisation of alcohol further contributed to the declining wine and pisco industries in Peru (Huertas Vallejos, 2004, 2012).

In 1963, Fernando Belaúnde was elected president, promising solutions to Peru's social and economic challenges. Belaúnde applied some moderate ISI policies which had become popular in South America and initiated the Agrarian Act of 1964 (Wills, 2003). Peruvian agricultural land experienced some of the highest rates of ownership concentration in Latin America leading into the 1960 s. In 1958, $2 \%$ of landowners retained $69 \%$ of Peru's arable land, while small landholders (owning five hectares or less) only controlled 6\% of arable land (Hudson, 1992). The Agrarian Act of 1964 expropriated unused land from the haciendas and by 1966, over 200,000 hectares of rural land had been redistributed (Davies et al., 2018). These agrarian reforms likely damaged the pisco and wine-producing estates that remained (Huertas Vallejos, 2012). The Belaúnde government proposed further reforms in attempts to modernise Peru's rural sector and develop the usually excluded interior regions of the country, however, these reforms were constantly blocked by a conservative congress (Caceres Booth, 2013).

\subsubsection{Limited Viticultural Reactivation}

Despite these aforementioned difficulties faced by vineyards, new grapes were brought from European and North American stocks by Peruvian vineyard owners during the early decades of 
the 1900s, and especially from the 1940s. For instance, the owners of the hacienda Ocucaje, Virgilio Rubini Fuller and Marsiglio Rubini Stocki, transported grapes vines from Europe to Ica from 1904 (Huertas Vallejos, 2004). Despite some difficulties at first, some of these vines later became very productive. By 1945, Ocucaje Estate was successfully growing 300 hectares of Malbec, Cabernet Sauvignon, Merlot, Semillon, Muscatel as well as pisco producing grapes. Other important wine and pisco producers in Peru such as Tabernero, Tacama and Queirolo, added new grapes varieties to their vineyards especially during the 1930s and 1940s, encouraging some minor viticultural recovery (Dargent Chamot, 2014; Huertas Vallejos, 2012).

Growing levels of urbanisation and population growth since the 1940s in Peru helped to create larger markets for both pisco and wine and other agricultural products. Moreover, by the 1960s farmers were recognising the risks involved in monoculture cotton, as synthetic materials started to reduce global for demand cotton. As a reaction to down-turns in the demand for cotton, a significant number of farmers along the Peruvian coast began to revitalise grape, pisco and wine production in the 1960s. In 1967, the Peruvian Government announced that it was planning to invest ten million soles de oro ${ }^{23}$ into the development of viticulture. It also acknowledged the growing crisis in cotton and recommended planting grapevines in areas cultivated with cotton crops. Moreover, the government planned to introduce projects with the objective of improving the production and commercialisation of wine and pisco. However, a new and unexpected set of changes came suddenly with a military coup in 1968 with important implications in Peruvian viticulture (Huertas Vallejos, 2004, 2012).

\subsubsection{Military Coup, Structuralism and Agricultural Reform}

In 1968, the military staged a coup headed by General Velasco Alvarado forcing President Belaúnde to resign. The junta was known as the Peruvian Revolutionary Government of the Armed Forces (Davies et al., 2018). The Revolutionary Government was convinced that Peru's development, political and economic stability, and social equality could only be achieved through significant social and economic reform. The populist Revolutionary Government attempted to dismantle the structural roots of social injustice in Peru, attacking the traditional landed elites and foreign control (Velasco Alvarado, 1970; Wills, 2003).

The Revolutionary Government implemented a set of economic and social reforms which aimed to initiate a 'Peruvian Revolution' which according to the military officials was 'neither capitalist nor communist'. The Velasco government shifted from the formerly dominant classical liberal economic model and encouraged developmentalist state strategies through ISI policies, representing Peru's first extensive structuralist reforms. Moreover, the Velasco

${ }^{23}$ Valued at US\$373,000 in 1967 (Huertas Vallejos, 2012) 
regime imposed strict controls on foreign investments and in central economic activities (Bazán, 2003; Davies et al., 2018). From 1969, the military government implemented one of the most important agrarian reforms in Latin America; close to $40 \%$ of land was distributed by 1982, benefitting $30 \%$ of all rural families. Figure 16 below shows the propaganda used to support these reforms, demonstrating the clear rural populist and anti-elite discourse used. Most of the haciendas were expropriated during these reforms, with over eight million hectares of land redistributed. Most of this land was not reallocated directly to rural families but instead established as Agrarian Production Cooperatives (CAPS) which consisted on the former hacienda workers along the coast, and Social Interest Agricultural Societies (SAIS) which were made up of cattle ranch workers in the highlands. The agrarian reforms altered the sociopolitical structure of Peru; for the first time the landowning elites who had lost their political control through congress and were thus unable to block land reform. The agrarian reforms were therefore successful in uprooting the traditionally powerful landed elites. However, these reforms failed to increase agricultural production, productivity or earnings (Burneo, 2011; Huertas Vallejos, 2012; Wills, 2003).

The military regime attempted to control all critical industries and public services through state nationalisation and through a process of 'Peruvianisation', whereby a majority percentage of stocks in a foreign company were required to be held by Peruvian citizens (Davies et al., 2018). By 1977, less than ten years following the military government coup, the state controlled $50 \%$ of the country's GDP (Wills, 2003).

Figure 16 Propaganda used During Peruvian Agrarian Reforms

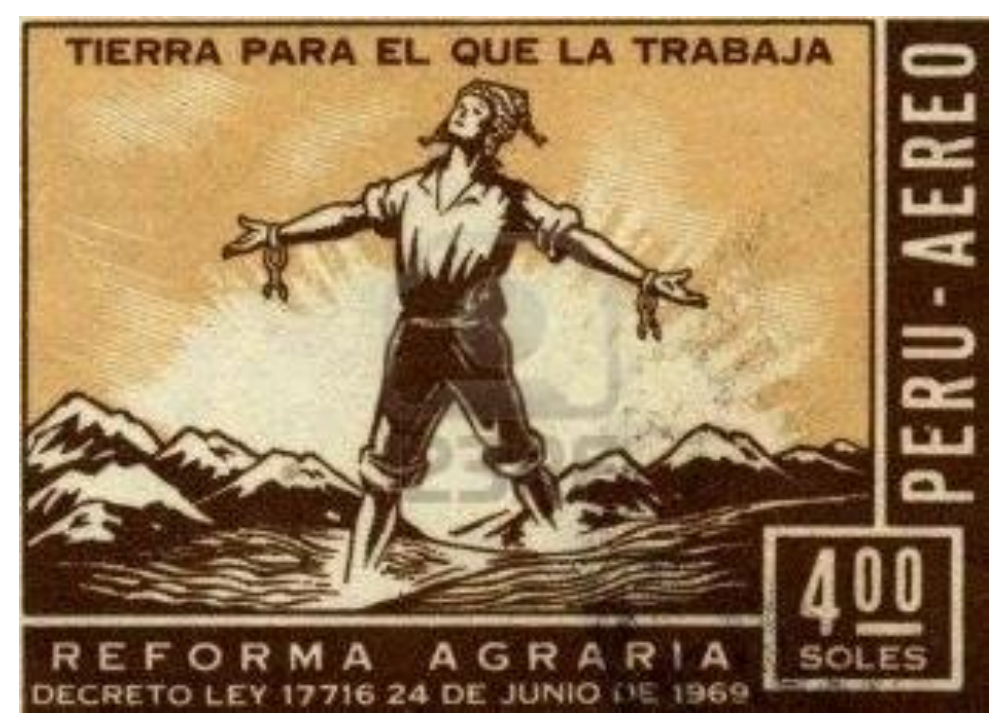

Note. Postal stamps sold during the 1969 agrarian reform. Title; 'Land for those who work it' (Author translation). Source: (Crisóstomo, 2016). 


\subsection{VITICULTURE AFTER THE AGRARIAN REFORMS}

The agrarian reforms eliminated many of haciendas which, since Peru's colonial period, had concentrated viticultural production. Land redistribution was a costly process for the state which attempted to expropriate land from the traditional oligarchy of the landed elite to campesino CAPS and SAIS cooperatives (Caceres Booth, 2013). The challenge for Peruvian viticulture at this time was that a large majority of these cooperatives preferred to produce other more profitable crops. While some of these cooperatives continued to produce wine and pisco grapes to sell to the producers the large majority produced export crops such as cotton (Huertas Vallejos, 2012). These reforms, therefore, had a very negative impact on viticulture; the vineyards and a number of grape varieties were almost completely eliminated, while the campesinos did not receive the technical training required to maintain productivity (Kuramoto \& Bank, 2011) A fieldwork interview with a representative of one of Peru's largest wine and pisco producing companies revealed the difficulties the reforms created for Peru's viticultural haciendas:

"The agrarian reforms had a large impact on [unnamed company], our company had 900 hectares before and was left with only 150, obviously with 900 hectares to produce grapes we could have produced more and entered international markets more strongly."

The reforms resulted in a further viticultural contraction and ended the short-lasting recovery of the 1950s and 1960s. Without available grapes, the wine and pisco sectors virtually disappeared and viticultural exports ceased (Kuramoto \& Bank, 2011). The agrarian reforms, therefore, represented an important challenge for wine and pisco production in general, and more specifically for the large viticultural haciendas which had dominated wine and pisco production since the colonial period (Huertas Vallejos, 2012). The reformist government did, however, strengthen workers' rights and labour laws in Peru and saw the creation of numerous small farmer and worker organisations, and improved land access for rural families (Caceres Booth, 2013; Williams \& Murray, 2018). These reforms eventually led to the establishment of the landholdings owned by the small-scale grape producers interviewed for this research.

\subsubsection{Decline of Military Regime, Second Junta}

Despite the focus on Peruvian economic nationalisation and independence, the Velasco regime had paradoxically relied heavily on foreign loans to fund the state's active role in the economy. Extensive foreign borrowing proved to be unsustainable when Peru's terms of trade suddenly changed in 1974. Fish meal and copper prices dropped globally ending a period of an economic boom in both products, while foreign loans used to fund the agrarian reforms and the large- 
scale copper and petroleum ventures augmented levels of foreign debt. Economic recession began in Peru, accompanied by negative terms of trade, growing inflation rates, declines in real incomes and mounting underemployment. As a result, discontent grew towards the Velasco regime. In August 1975, a second military coup headed by General Francisco Morales Bermúdez Cerrutti, ousted Velasco. This second coup signalled the end of the developmentalist state and Peru's experiment with structuralism. Morales shifted towards moderate right-wing free-market strategies, reversing many of the community ownership strategies in the industrial and agricultural sectors. This second phase of military government control signalled the start of a set of largely unsuccessful economic readjustment strategies which caused a further economic recession, growing levels of unemployment, and declining wages. By the late 1970s, the second junta faced increasing public pressure and elections were planned for May 1980 (Bazán, 2003; Caceres Booth, 2013; Davies et al., 2018).

\subsubsection{Economic Decline in Civilian Governments, 1980-1990}

Belaúnde won the 1980 elections, returning to the role of the president which he held before the military coup. On Election Day, the Maoist guerrilla group Sendero Luminoso ${ }^{24}$ burnt ballot boxes in the highland region of Ayacucho to demonstrate the group's rejection to civil rule based on an oligarchical centre-right government. Belaúnde continued the market-oriented approach initiated by Morales, reducing government economic involvement, promoting privatisation and export-led growth. However, this approach largely failed to resolve the mounting political and economic crisis which was being experienced in Peru at the time (Hudson, 1992). By 1985, the Peruvian economy was on the brink of collapse as inflation rapidly increased by 3,240\% between 1980 and 1985 (Davies et al., 2018). Worsening this dismal economic situation were the increasingly violent guerrilla groups which spread fear among the Peruvian population and forced the government to direct increasing amounts of resources towards containing the insurgents. Widespread human rights violations by the guerrilla groups, the police and military caused over 7,000 deaths and approximately 2,000 disappearances between 1890 and 1985 (Bazán, 2003; Caceres Booth, 2013).

In 1985, Alan García Pérez was elected president. García implemented a populist approach, attempting to reverse economic stagnation and lower high inflation rates, end human rights violations and build unity among the Peruvian population. The García government promoted a greater role of the state in the economy and in protecting national producers. García announced that Peru would not direct more than $10 \%$ of the country's export earnings towards servicing Peru's \$14 billion in foreign debt, creating confrontations with the international

\footnotetext{
${ }^{24}$ Shining Path.
} 
financial institutions (Davies et al., 2018; Hudson, 1992). The García administration experienced some early economic successes: GDP and employment grew and inflation fell between 1986 and 1987. However, from 1987 it became evident that the administration's approach to controlling high inflation was failing. In 1988, Peru entered its worst economic crisis of the Twentieth Century; GDP plummeted 8.8\% in 1988 and a further 14\% in 1989 (Crabtree, 2016). Hyperinflation was out of control, reaching 2,788\% in 1989. Peru's foreign debt was also an overwhelming burden, reaching \$25 billion in 1989. The García government had therefore only exacerbated the growing economic crisis (Rudolph, 1992). As Peru entered economic depression, the country's civil conflict between the government and guerrilla forces grew increasingly violent and human rights were violated by all sides. García ended his presidency in 1990 in the context of social and economic crisis (Bazán, 2003; Caceres Booth, 2013).

\subsection{VITICULTURAL CONTRACTION, 1970-1990}

As mentioned, the wine and pisco sectors practically disappeared following the expropriation of the private vineyards and the replanting of grapevines with other crops by the cooperatives during the reforms from 1968. The second junta failed to avoid a mounting economic crisis (Bazán, 2003; Caceres Booth, 2013). During the 1980s, Peru returned to democracy, however, the elected governments of Belaúnde and García failed to resolve the growing economic problems faced by Peru, and both governments were further challenged by the increasingly violent conflict with guerrilla groups (Crabtree, 2016). The economic crises placed strict restrictions of the credit available for agricultural producers and the markets for viticultural products declined during these troubling times. These events represented significant blows to the viticultural sector and made a viticultural recovery extremely difficult in the context of economic and social turmoil. Resulting from these events, the viticultural sector experienced further contraction between 1970 and 1990, following the short period of restricted recovery leading up to the late 1960s (Huertas Vallejos, 2012). By 1990, Peruvian viticulture had been paralysed for over twenty years.

\subsection{FUJIMORI GOVERNMENT AND NEOLIBERAL REFORMS}

By the 1990 presidential elections, Peru suffered from internal conflict, external debt and economic decline. The two main candidates were Mario Vargas Llosa, a famous Peruvian writer, and Alberto Fujimori, a virtually unknown engineer and university professor. Vargas was associated with the elites in Lima and promoted neoliberal reform. Fujimori conversely, found support from the lower-middle classes and urban poor as well as indigenous groups (Wills, 2003). Fujimori criticised the neoliberal reforms proposed by Vargas, asserting that these 
policies would isolate the country's poor and working classes (Davies et al., 2018; Hudson, 1992). Fujimori defeated Vargas with a large majority, taking advantage of the widespread disapproval of the political parties and the significant social divide which separated the elitist supporters of Vargas and the rest of the Peruvian voters (Hudson, 1992; Mauceri, 1995).

To a large extent, those that voted for Fujimori in 1990 voted against neoliberalism. However, the Fujimori administration began to implement a neoliberal shock programme soon after taking office (Hudson, 1992). Between 1991 and 1998, the Fujimori government raised US\$8,650 million from the sale of publicly-owned enterprises and investments to mainly foreign groups. The policies of the Fujimori government clearly sought to create an important reorganisation of the Peruvian economy rather than mere short-term economic stabilisation. This economic reorganisation attempted to reverse the interventionist role of the state which had become important during the Velasco regime (Mauceri, 1995; Wills, 2003). Fujimori's neoliberal austerity programme, which became known as the Fujishock programme quickly reduced high levels of inflation but also created abrupt hardship, especially among the poor and working classes (Davies et al., 2018).

The neoliberal reforms were accompanied by an increasingly authoritarian Fujimori administration and a general militarisation of Peruvian society. In April 1992, with the support of the military, Fujimori staged an autogolpe (self-administered coup) by closing congress which had opposed presidential decrees designed to defeat the guerrilla groups (Hudson, 1992). Later in 1992, Abimael Guzmán the leader of Sendero Luminoso was captured by the National Police, practically resulting in the fall of the guerrilla group. This significant victory was claimed by President Fujimori. A new legislature headed by Fujimori was elected after the autogolpe, and a new constitution was signed in 1993 (Davies et al., 2018). This new constitution strengthened the neoliberal economic approach and the Fujimori government announced plans for further privatisation of state-owned assets (Wills, 2003). For the next seven years, Fujimori's governance was increasingly authoritarian. During the military's counter-terrorism campaign, the Peruvian State became one of the worst human rights violators in Latin America (Mauceri, 1995). This period has since been labelled by the Peruvian Truth and Reconciliation Commission (2003) as, “...the most intense, extensive and prolonged episode of violence in the entire history of the Republic." An estimated 70,000 people were killed during the conflict, the Peruvian military and government-sponsored paramilitary groups were reportedly responsible for almost half of these deaths (Human Rights Watch, 2003; La Comisión de la Verdad y Reconciliación, 2003). 
Over the Fujimori period, Peru had experienced an important economic transformation, experiencing steady macro-economic through neoliberal readjustment, following twenty years of economic stagnation and decline (Silva, 2011). It is, however, important to also consider the unprecedented increase in the mineral prices which also encouraged Peru's GDP growth over the same period (Loayza \& Rigolini, 2016). However, other serious challenges arose over the same period. Cuts in social spending caused increased suffering, especially for the poorer segments of the population, and social inequalities grew despite macro-economic growth (Bazán, 2003; Crabtree, 2002). Furthermore, wages in the private sector declined while underemployment and unemployment became significant problems. With allegations of corruption and human rights violations mounting, Fujimori fled to Japan and resigned as president in 2000 (Wills, 2003).

\subsubsection{The Legacy of the Fujimori Period}

Fujimori left a mixed legacy with the already weak democratic institutions and state social services in Peru were severely weakened during his presidential terms (Wills, 2003). While the internal conflicts largely ceased, this had come at a high human cost and was associated with widespread human rights' abuses (Mauceri, 1995). The social roots these conflicts of poverty and inequality also remained. The reforms introduced by Fujimori created the conditions to support sustained macro-economic growth, however, this has not been the best indicator of overall human development, and social-economic inequalities have remained stark in Peru (Latin American Center for Rural Development, 2011).

Like in other Latin American countries, the Peruvian governments of the 2000s tended to implement a mix of neoliberal and neostructural policies. Increased government support for lower socio-economic groups through progressive government transfers signalled a shift towards neostructural measures and away from the stricter neoliberal readjustment of the 1980s and 1990s, experienced in Peru and most of Latin America (Grugel \& Riggirozzi, 2012). In 2001, Alejandro Toledo was elected as president. Toledo was the first elected indigenous Quechua president in Peru, and his indigenous background helped him gain support from the poor and working classes. The Toledo government largely continued to consolidate the neoliberal approach introduced by the Fujimori regime. The new government broadened Peru's international free trade agreements and continued to introduce domestic economic liberalisation policies. In 2006, Alan García was elected as president for a second term, first serving between 1985 and 1990. The second García government sought to address social inequalities while continuing the economic growth the country had enjoyed since the 1990s. Like the Toledo administration, the García government generally consolidated the neoliberal approach yet included some neo-structural policies. Overall, the second García government 
implemented additional free trade agreements, including with the USA, and a consolidated neoliberal policy and export-orientated growth (Burneo, 2011; Davies et al., 2018).

\subsection{VITICULTURE AND NEOLIBERAL REFORMS}

As discussed, Peru experienced one of Latin America's most dramatic agrarian reforms between 1969 and 1975, which expropriated the majority of the country's haciendas (Caballero, 1980). Land expropriation devastated Peruvian viticulture sector as the campesino cooperatives replaced grapevines (Huertas Vallejos, 2012). A number of measures were taken during the 1980s to reverse some of the policies implemented during these agrarian reforms. A significant law change was implemented in 1988 when the García government increased the limits on land ownership set in 1969 from 150 hectares to 450 hectares (Burneo, 2011).

After a decade of experimenting with the cooperative model in Peru, the cooperative lands were subdivided amongst the members in a process known as parcelación. The redistribution of these cooperatives resulted in the proliferation of rural smallholdings, which continued to be divided and reduced in size due to inheritance land transferals. By the early 1990s, smallscale farmers became the most important farmer group in Peru. During the expansion of smallholdings in Peru, the viticultural sector remained stagnant, and the production of wine and pisco grapes represented a supplementary activity (Burneo, 2011). However, the 1980s set changes in motion which allowed for the formal division of the cooperative lands and established some of the conditions for a new era of land ownership re-concentration in Peru (Crabtree, 2002; Eguren et al., 2018; Nieto, 2012). For the viticultural sector, these changes created some of the conditions which allowed larger wine and pisco producers to later repurchase land for grape cultivation (Huertas Vallejos, 2012).

The Belaúnde and García governments in the 1980s implemented legal changes which promoted private land ownership. The collectivist objectives of the Revolutionary Government of Valesco had therefore been abandoned for policies which promoted the market in agricultural spaces well before the 1990s. Nonetheless, the liberalisation of Peru's agricultural sector became far more explicit following the election of Fujimori. The Fujimori regime implemented a number of anti-constitutional laws which established the 'reform of the agrarian reform' in the early 1990s (Eguren, 2004; Eguren et al., 2018). In 1993, a new constitution removed the barriers which limited agricultural land, provided incentives for investors to enter the land market, removed campesino communal land ownership rights, and attracted foreign investment (Burneo, 2011; Eguren et al., 2018). Other important changes included the closing of the Agrarian Bank which provided credit to producers, the end of state subsidies, and institutional downsizing (Crabtree, 2002). 
During the Fujimori years, supporting small-scale producers was no longer considered a priority during the neoliberal restructuring of the Peruvian economy (Hopkins, 1998). The state's role in agriculture was reduced overall (Santa Cruz, 1999). For instance, after the Fujimori government was elected the Ministry of Agriculture was reduced by 23,000 employees in 1990 to only 5,000 in 1996 (Crabtree, 2002). This important shift in Peru's agricultural sector had uneven consequences and there were both 'winners and losers' in rural areas. Generally, the neoliberal reforms favoured larger producers who exported to international markets while impacted negatively on the smaller producers who were oriented towards the national markets $^{25}$ (Crabtree, 2002).

Following almost three decades of contraction since the 1970s, Peruvian viticulture was a stagnated and diminished sector of the time the neoliberal reforms in the 1990s. There is therefore limited information on the impacts of economic readjustment in this sector. The liberalisation of agricultural land ownership and investment incentives during the 1990s formed the conditions for the owners of the viticultural estates to re-purchase much of the land that was expropriated in the 1970s. The reactivation of viticulture in Peru proved to be a long and slow process. Following the two blows to the sector caused by the agrarian reforms from the late 1960s and the economic crises of the 1980s, the wine and pisco producers began to re-acquire the lands they formerly owned, hired foreign experts and renovated technology for the first time since the 1940s (Arata \& Vargas, 2007; Huertas Vallejos, 2012).

From the early 2000s, successive governments promoted the growth of the viticultural sector, creating the conditions required for its reactivation (Huertas Vallejos, 2012). As mentioned, the Ministry of Agriculture was downsized dramatically during the Fujimori government which reduced the Ministry's roles in agricultural research and producer support. The main exception has been the expansion of the state organisation National Agrarian Health Service, which had developed as an important programme for the control and eradication of pests along the productive coastal valleys in order to support the expansion of fruit and vegetable exports (Arata \& Vargas, 2007). A study of Peru's Ministry of Industry and Tourism (MITINCI) published in 1999 highlighted the principal challenges facing the viticulture at the end of the 1990s. According to MITINCI (1999), these challenges included;

i. The area of grape cultivations for pisco and wine production had reduced and there was a lack of technology in wine and pisco production;

\footnotetext{
${ }^{25}$ For a comprehensive explanation of the impacts on neoliberal reforms on agriculture in Peru see;
} (Crabtree, 2002). 
ii. There was insufficient genetic material to renovate the grape plantations or expand the cultivation areas;

iii. There were difficulties in the provision of water and high costs in securing regular supplies for grape irrigation;

iv. Research in viticulture had reduced considerably.

Until 2001, the pisco sector was virtually stagnated and was considered to be a complementary activity with wine production. Both wine and pisco were principally oriented towards the Peruvian national market at this time (Mendoza Solari, 2015). It is somewhat difficult to identify exactly how the neoliberal reforms during the 1990s directly impacted the stagnated and restricted viticultural sector. As will be further explored, it is likely that these reforms assisted reinvestment and expansion of the viticulture sector in the 2000s, however, this was also supported by a number of neostructural polices at this time.

\subsection{THE EVOLUTION OF THE PERUVIAN DO FOR PISCO}

Although pisco as a product has evolved over centuries in Peru, the Peruvian designation of origin mark (DO) for pisco is relatively young. This especially true at the international level, as Peru's attempts to protect pisco under international intellectual property laws have been largely motivated by the challenge to the Peruvian origin of pisco from Chile. The origin of pisco has generated a long-standing debate between Peru and Chile. Chile produces a grape spirit, albeit following different methods of production, under the same name and has implemented a DO pisco mark for this product. The debate over the origin of pisco has heightened especially since the 1990s, resulting from the global expansion of DOs and the implications this has had on international trade, as discussed in Chapter Three (Gutiérrez, 2003; Lacoste, Jimenez, Castro, Rendon, \& Soto, 2013). Research has also demonstrated that this DO debate is closely linked with important historical factors, such as nationalism, and disagreements and conflicts between these neighbouring countries (Mitchell \& Terry, 2011). Keeping to the scope of this research, this thesis does not attempt to comprehensively cover this debate and instead concentrates on the evolution of the Peruvian DO for pisco as an EVeN case study.

It is commonly perceived that the efforts to implement the Peruvian DO for pisco were largely abandoned until the aforementioned Peruvian-Chilean debate over pisco's origin intensified in the 1990s. However, a review of the relevant laws and establishment of pisco-related institutions demonstrates that attempts to legally protect the Peruvian origin of pisco and quality of the product began as early as the late-Nineteenth Century. These efforts sought to protect the intellectual property of the producers and local communities, as well as the traditional methods of production and the product's quality (Guerrero, 2004; Gutiérrez, 2003). 
Table 4 below summarises the important laws and institutions associated with the evolution of Peruvian DO for pisco.

Table 4 Legal and Institutional Evolution of Peruvian DO for Pisco

\begin{tabular}{|c|c|c|}
\hline Year & Law, Treaty or Organisation & Description \\
\hline 1896 & Riva Agüero - Wagner Treaty & $\begin{array}{l}\text { Treaty on October 1896, between Peruvian } \\
\text { Foreign Affairs Minister Enrique de la Riva } \\
\text { Agüero and French Plenipotentiary Minister } \\
\text { Raoul Wagner. Mutually committed to } \\
\text { protecting the respective signs and } \\
\text { designations of each country, including } \\
\text { designations of origin and place of fabrication. }\end{array}$ \\
\hline 1925 & Law 5102 of 18.5 .25 & $\begin{array}{l}\text { Ended taxes on wine and grape alcohols } \\
\text { produced in Southern Peru. }\end{array}$ \\
\hline 1940 & Magisterial Reform 5.40 & $\begin{array}{l}\text { Prohibited the expansion of cane sugar } \\
\text { alcohols in Southern Peru. }\end{array}$ \\
\hline 1963 & $\begin{array}{lccc}\text { Supreme } & \text { Decree } & \text { of } & 10.6 .63 \\
\text { Sanitary Code Article. } 731 & \end{array}$ & $\begin{array}{l}\text { Sanitary Code for pisco, the product obtained } \\
\text { from distillation of fermented grape must. }\end{array}$ \\
\hline 1988 & $\begin{array}{l}\text { Legal Regime of the Instituto } \\
\text { Nacional de Cultura del Perú }\end{array}$ & $\begin{array}{l}\text { Pisco declared as national cultural heritage of } \\
\text { Peru. }\end{array}$ \\
\hline 1990 & $\begin{array}{l}\text { Directorial Resolution } 07087 \text { of } \\
\text { 12.12.90 of the ITINTEC (Instituto } \\
\text { de Investigación Tecnológica } \\
\text { Industrial y de Normas Técnicas) }\end{array}$ & $\begin{array}{l}\text { Pisco declared as Peruvian designation of } \\
\text { origin, for products obtained from the } \\
\text { distillation of musts, resulting from the } \\
\text { fermentation of mature grape on the coast of } \\
\text { Lima, Ica, Arequipa, Moquegua and the } \\
\text { valleys of Locumba, Sama and Caplina in } \\
\text { Tacna. }\end{array}$ \\
\hline 1994 & Law 26426 of 29.12 .94 & $\begin{array}{l}\text { Executive Power to protect the recognition of } \\
\text { the Peruvian DO for pisco under all available } \\
\text { avenues of international law }\end{array}$ \\
\hline 2000 & CITEvid established in 2000 & $\begin{array}{l}\text { Centro de Innovación Tecnológica Vitivinicola } \\
\text { (CITEvid) created to support improvements in } \\
\text { the viticultural chain and pisco sector. }\end{array}$ \\
\hline 2002 & $\begin{array}{l}\text { INDECOPI implements Technical } \\
\text { Norm 211.001.2002 }\end{array}$ & $\begin{array}{l}\text { Technical norms for pisco production and } \\
\text { pisco DO implemented }\end{array}$ \\
\hline 2003 & $\begin{array}{l}\text { Comisión Nacional del Pisco } \\
\text { created in } 2003 .\end{array}$ & $\begin{array}{l}\text { Comisión Nacional del Pisco (CONAPISCO) } \\
\text { established as platform for public-private } \\
\text { coordination, bringing together institutions, } \\
\text { associations and producers involved in pisco } \\
\text { sector. }\end{array}$ \\
\hline 2005 & $\begin{array}{l}\text { Lisbon Agreement for the } \\
\text { Protection of Appellations of Origin } \\
\text { and their International Registration }\end{array}$ & $\begin{array}{l}\text { On February } 16,2005 \text {, Peru presented its } \\
\text { accession instrument to the Lisbon } \\
\text { Agreement, which came into force on May } 16 \text {, } \\
2005 \text {, therefore Peru became a member state } \\
\text { to this agreement. }\end{array}$ \\
\hline
\end{tabular}




\begin{tabular}{|l|l|l|}
\hline 2005 & $\begin{array}{l}\text { World Intellectual Property } \\
\text { Organization }\end{array}$ & $\begin{array}{l}\text { On July 14, 2005, the World Intellectual } \\
\text { Property Organization issued the } \\
\text { international registration certificate for the } \\
\text { designation of origin No. 865 pisco, } \\
\text { corresponding to Peru. }\end{array}$ \\
\hline 2006 & $\begin{array}{l}\text { Technical Norm 211.001.2002 } \\
\text { updated with Norma Técnica } \\
\mathbf{2 1 1 . 0 0 1 . 2 0 0 6}\end{array}$ & $\begin{array}{l}\text { More specification about types of pisco, grape } \\
\text { varieties and elaboration processes added to } \\
\text { the technical norm. }\end{array}$ \\
\hline 2011 & $\begin{array}{l}\text { Consejo Regulador de la } \\
\text { Denominación de Origen Pisco } \\
\text { authorised by INDECOPI }\end{array}$ & $\begin{array}{l}\text { El Consejo Regulador de la Denominación de } \\
\text { Origen Pisco (Regulatory Council for Pisco } \\
\text { DO), a non-profit association created. The CR } \\
\text { represents the beneficiaries of the pisco DO. } \\
\text { Its main objective is to administer the pisco } \\
\text { DO and care for and protect the quality of } \\
\text { pisco. }\end{array}$ \\
\hline
\end{tabular}

Sources: Adapted by the author using information from; (Comisión Nacional del Pisco, ND; Gutiérrez,

2003, 2011)

Important efforts to improve and protect the Peruvian DO for pisco at the national and international levels have been implemented (Table 4). This has been particularly evident since the early 1990s, through a range of laws and the establishment of related public and private institutions associated with the pisco DO in Peru. By examining the findings from the research interviews, Chapter Six will further discuss the formation and implementation of the pisco DO in Peru. Furthermore, Chapter Seven will expand upon this discussion to explore the impacts of the pisco DO identified in the interviews.

\subsection{REACTIVATION OF PERUVIAN VITICULTURE, 2000-2010}

Between 2000 and 2010, Peruvian viticulture underwent an important reactivation. For the first time since the challenges posed by the agrarian reforms and the subsequent social and economic crises of the 1980s, Peruvian wine and pisco producers began to reinvest in viticultural production in the late 1990s and early 2000s. Importantly, the Peruvian State started to refocus on the viticultural sector during this period, particularly through the development of the DO for pisco following neostructural ideas (Huertas Vallejos, 2004). As shown in Figures 18-21 on subsequent pages, the phase of viticultural reactivation has been impressive between 2000 and 2010. After two centuries of stagnation and decline, pisco returned to be a flagship Peruvian product while the associated product of wine also expanded (Huertas Vallejos, 2012).

Pisco production quadrupled from 1.6 million litres to 6.3 million litres between 2000 and 2010 (see Figure 17). Pisco exports values also experienced exponential growth in value, growing almost fifteen times from US\$140,530 to US\$2,064,994 between 2000 and 2010 (see Figure 
19). Peru's relatively larger wine industry grew at a slower rate than pisco, expanding from 33 million litres to 52 million litres between 2000 and 2010 (see Figure 18). During this period, the wine industry remained oriented towards the national market. Despite domestic orientation, the value of wine exports did nonetheless grow from US\$99,000 to US\$824,000 between 2000 and 2010 (see Figure 20). It is important to note that informality is widespread in many industries in Peru. The production statistics referred to in this section represent the formal (taxed) viticultural production. It is possible that production could be as much as $50 \%$ higher than the numbers quoted here as large quantities of wines and aguardientes de uva (without pisco DO) are sold informally within Peru (Huertas Vallejos, 2012; Pflucker, 2015).

Figure 17 Pisco Production in Peru, 2000-2010

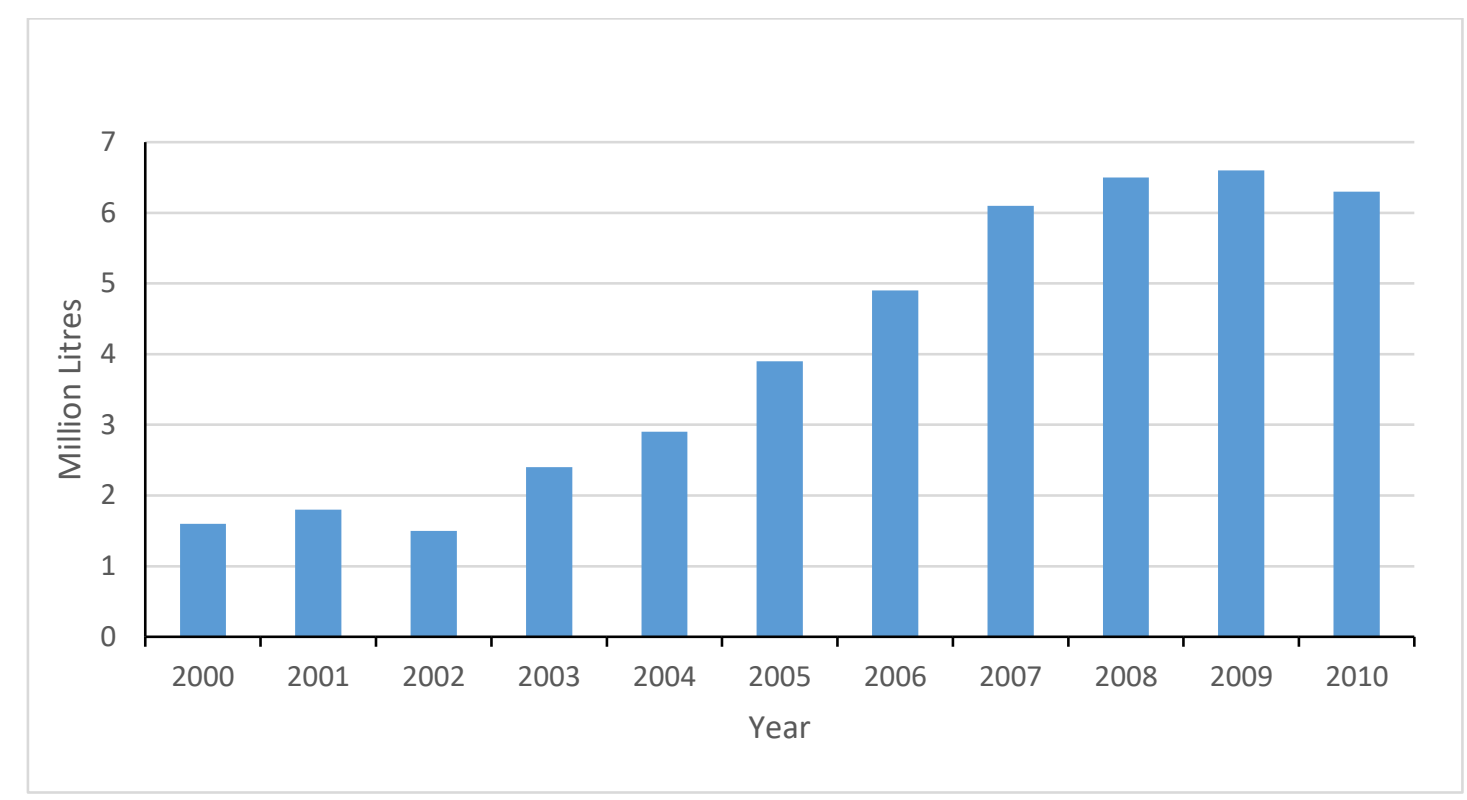

Source: Elaborated by the author using data from (Superintendencia Nacional de Aduanas y de Administración Tributaria, 2016) 
Figure 18 Wine Production in Peru, 2000-2010

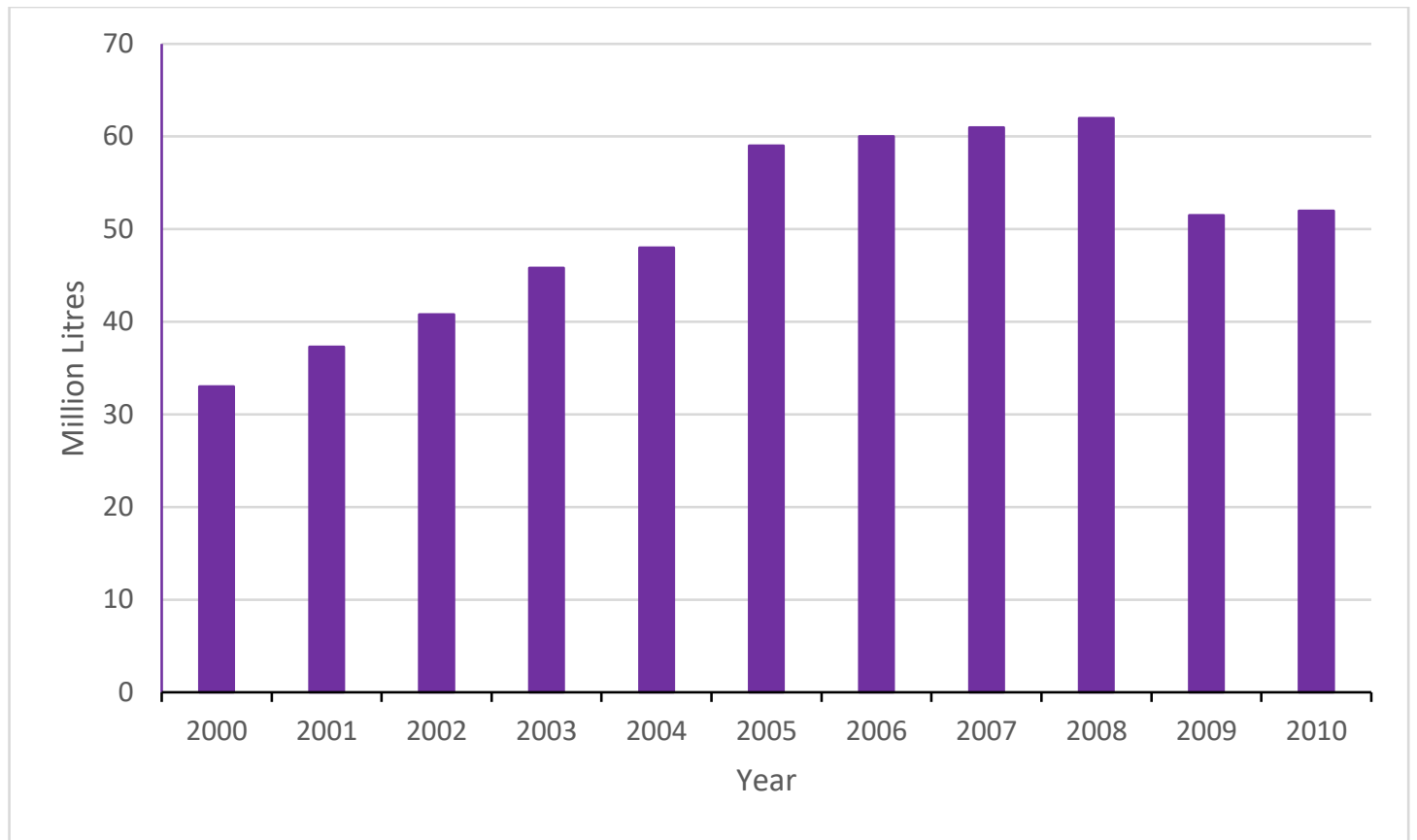

Source: Elaborated by the author using data from (Organisation of Vine and Wine, 2016)

Figure 19 Pisco Export Value from Peru, 2000-2010

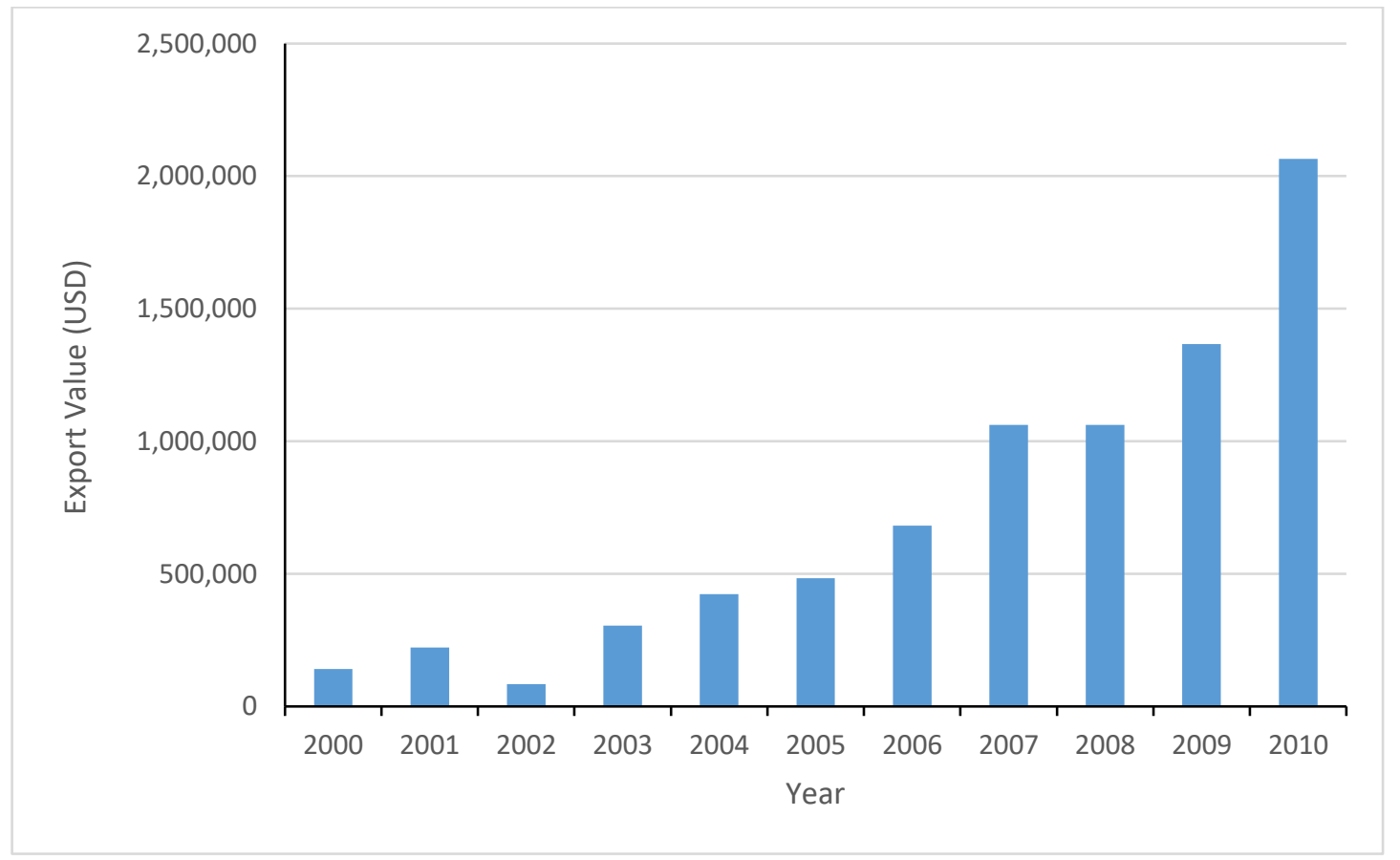

Source: Elaborated by the author using data from (Comisión de Promoción del Perú para la Exportación y el Turismo, 2018) 
Figure 20 Peruvian Wine Export Value, 2000-2010

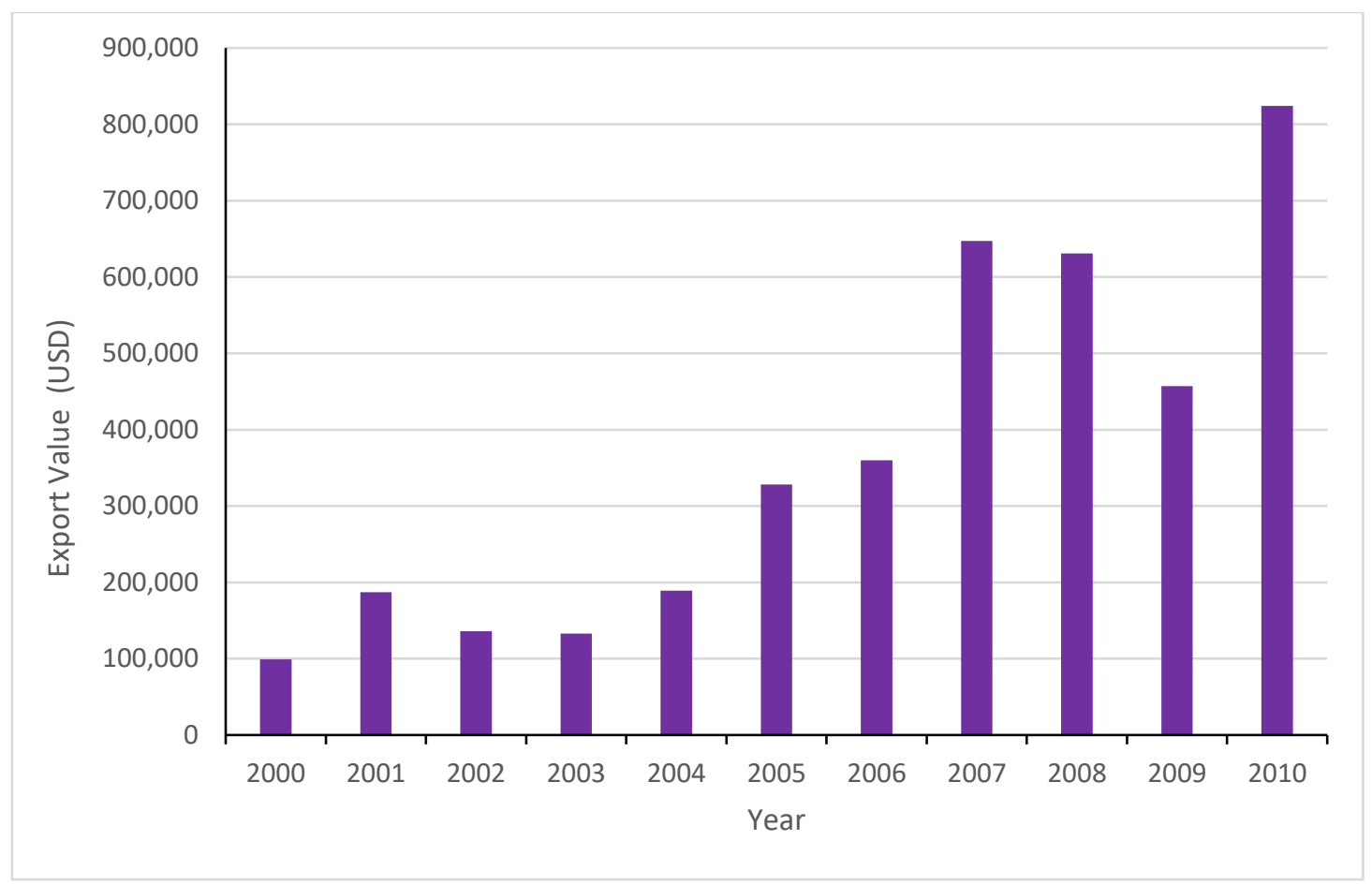

Source: Elaborated by the author using data from (Superintendencia Nacional de Aduanas y de Administración Tributaria, 2016)

\subsubsection{Factors for Post-2000 Reactivation of Peruvian Viticulture}

By examining the figures above, it is evident that Peruvian viticulture experienced a reactivation phase from the 2000s. The Peruvian State's refocus on the viticultural sector since 2000 has been acknowledged as a particularly important factor in the sector's rejuvenation, clearly following neostructural tendencies. The creation of the state-owned Centro de Innovación Tecnológica Vitivinicola ${ }^{26}$ (CITEvid) in 2000 (now CITEagroindustrial) was especially supportive of the industry's growth (Kuramoto \& Bank, 2011). CITEvid has been an instrumental organisation in resolving many of the problems facing viticulture in Peru during the 1990s. Since the organisation's establishment in 2000, the production and exportation of wine and pisco have increased dramatically in Peru. Additionally, since the early 2000s, the Peruvian State has actively supported the consumption of pisco and Peruvian wines through promotional campaigns as a strategy to recover national markets and gain new export markets. In this way, the state has supported the growth of viticultural activity and national consumption (Arata \& Vargas, 2007).

${ }^{26}$ Centre of Innovation and Technology for Viticulture (CITEvid) became Centre of Innovation and Technology for Agro-industry (CITEagroindustrial). 
Huertas Vallejos (2012) lists some of the other important factors which have contributed to the reactivation of Peruvian viticulture:

a) The viticulturist families in Peru continued to produce pisco and wine including during the decades of viticultural contraction. It has been recognised that these families maintained the traditions of Peruvian viticulture.

b) The dispute over the origin of pisco between Peru and Chile since the late 1980s, saw the creation of a number of public and private organisations which defend the Peruvian origin of pisco and promote its production and consumption. For example, the publicprivate Comisión Nacional del Pisco ${ }^{27}$ (CONAPISCO) was created in 2003, and was designed to support the industry's growth. Also in 2003, the Academia Peruana del Pisco $^{28}$ (APP), an academic group was formed to defend the Peruvian origin of pisco and encourage academic research relating to pisco.

c) Researchers and specialists such as oenologists, agrarian engineers and business schools have also made important contributions to reactivation of viticulture in Peru by contributing to relevance studies.

d) In important viticultural zones, such as Ica, the sector has received national and foreign investments. These investors have supported the use of new technologies which have improved wine and pisco production.

e) Important investments in transportation have supported the national distribution and the exportation of Peruvian wines and pisco.

f) Steady population growth and urbanisation have created a steady demand for agricultural products, including pisco and wine.

g) Finally, in what represents an unlikely consequence of globalisation, in wake of the influx of international products and influences, Peruvians are valuing and defending 'what is theirs' thereby revitalising traditional Peruvian products including pisco and local wines.

During the first decade of the Twenty-First Century, Peruvian governments have been instrumental in promoting the recent development of the viticultural sector. The neostructuralist policies of the Toledo and second García administrations have supported the rejuvenation of the pisco sector. Moreover, the linked wine industry benefitted from these efforts (Huertas Vallejos, 2012; Kuramoto \& Bank, 2011). The reactivation of Peruvian viticulture has therefore not been completely neoliberal, as the state has played an important

\footnotetext{
${ }^{27}$ National Pisco Commission.

${ }^{28}$ Peruvian Pisco Academy.
} 
role in the promotion of the sector. However, the neoliberal reforms have incentivised investment in agriculture along the coast and allowed private groups to purchase land for vineyards and invest in the sector.

\subsection{PERUVIAN POLITICS AND ECONOMY, POST-2010}

The period between 2001 and 2016 represented an important democratic period for Peru. This period was the first time in the republic's history that four presidents were democratically elected in succession. Over this stable period, Peru also experienced some of Latin America's strongest economic growth, especially between 2003 and 2008, when Peru's economic growth averaged 6.8\% annually due to a boom in commodity exports (Taft-Morales, 2016). In 2011 at the end of García's second presidential term, left-wing Ollanta Humala defeated the conservative candidate Keiko Fujimori, daughter of former President Alberto Fujimori, in a close presidential run-off. The election of Humala signalled a possible shift from the neoliberal model which had dominated Peru since 1990. Once in office, rather than rejecting neoliberal policies Humala's economic strategy was to extend these policies, while also making attempts to eradicate the large economic-social inequalities in Peru implementing neostructural policies. Despite falling poverty rates between 2011 and 2014, the Humala government lost most of its left-wing support base and faced strong conservative opposition. The government faced serious social unrest as indigenous communities protested against expanding mining projects. The inability to effectively resolve this unrest demonstrated the difficulties of the Humala government in balancing the protection of the country's vulnerable populations while also encouraging economic growth and investment. Despite steady GDP growth of $6 \%$ annually during his first two years in office, Humala's inability to resolve social unrest and a growing number of political scandals saw his approval ratings plummet. Humala continued to struggle as Peru's economic growth slowed to $2.4 \%$ in 2014 as mineral prices declined (Davies et al., 2018). Peru's economy did, however, experience some rebound, experiencing 3.3\% GDP growth in 2015 and 3.9\% GDP growth in 2016 (World Bank, 2018b). In 2016, Pedro Pablo Kuczynski, a former World Bank economist, defeated Keiko Fujimori in a historically close presidential run-off. Both candidates had campaigned on continuing the neoliberal model and implementing hard lines against crime (Taft-Morales, 2016; The Economist Intelligence Unit, 2017). However, Kuczynski became involved in corruption allegations and resigned as president in March 2018. Former First Vice President Martín Vizcarra became president on the $23^{\text {rd }}$ of March, 2018, signalling a likely continuation of the neoliberal model with some neostructural tendencies. 


\subsection{PERU'S PISCO SECTOR, POST-2010}

Pisco production has expanded rapidly in recent years, growing from 1.6 million litres in 2000 to 10.9 million litres in 2017 (see Figure 21). With the inclusion of the significant informal segment of production, overall pisco and aguardiente de uva production could be as high as 22 million litres in 2017. Nonetheless, this informal segment is a controversial topic and without the authorisation to use the pisco DO, the alcoholic products from the informal sector cannot be legally considered as pisco. These products are however commonly called pisco in the local markets despite not having the authorisation to use this name. Growing national consumption is mainly associated with quality improvements and greater levels of state and private promotion (Vázquez-Rowe et al., 2017). Since this revival in production, Peru's pisco sector has also experienced an important expansion in exports. Total pisco exports value grew from US\$141,000 in 2000 to reach US\$8.6 million in 2016, before dropping to US\$6.8 million in 2017 (see Figure 22). This important decline in pisco exports between 2016 and 2017 is mainly explained by the drop of pisco exports entering the Chilean market, following the reactivation of the debate over the pisco DO between Peru and Chile in early $2017^{29}$ (Koo, 2017). The pisco sector in Peru, while still dominated by internal demand, has become increasingly oriented towards international export markets and higher-end niche liquor markets. For example, pisco exports as a percentage of overall sales grew from 6.5\% in 2006 to $15 \%$ in 2014 (Pflucker, 2015). Additionally, the unit price of exported pisco has grown. For instance, between 2000 and 2015, the pisco unit export price grew from US\$4.4 to US\$7.8 per litre (Comisión Nacional del Pisco, ND).

\footnotetext{
${ }^{29}$ The inclusion in official statistics of pisco exports from Peru to Chile is a controversial topic as a product cannot be imported into the Chilean market with under the name pisco due to Chile's pisco DO. Therefore, a significant proportion of products recognised as pisco in the Peruvian official exportation statistics are actually sold as aguardiente de uva in Chile. This is a problem with the official statistics which has been identified.
} 
Figure 21 Pisco Production in Peru, 2000-2017

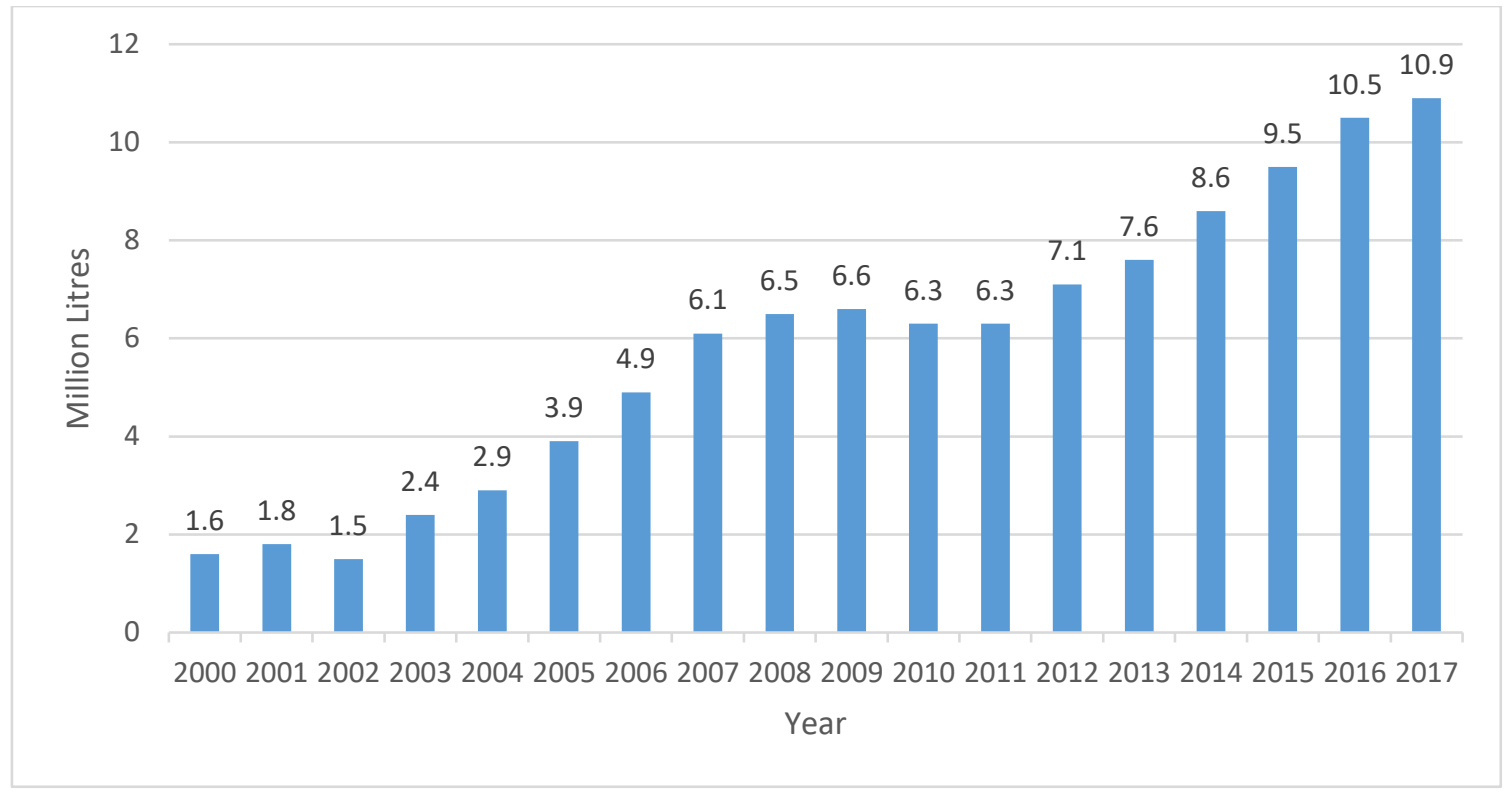

Source: Elaborated by the author with data from (Comisión Nacional del Pisco, ND).

Figure 22 Evolution of Total Pisco Exports from Peru in Value and Weight, 2000-2017

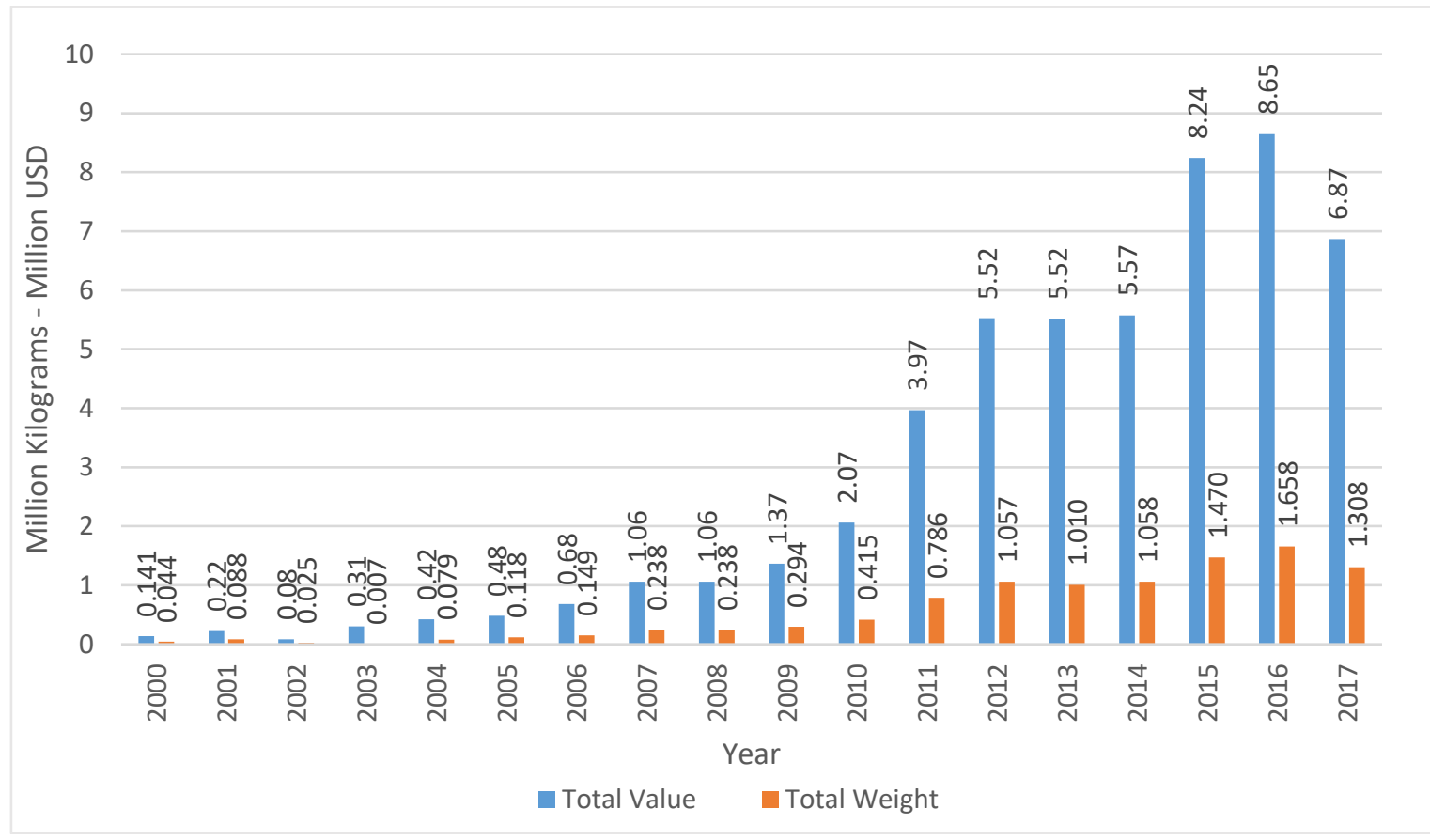

Source: Elaborated by the author, data from (Comisión de Promoción del Perú para la Exportación y el Turismo, 2018).

Although these production and export figures are insignificant when compared with viticultural sectors in other countries, it is important to note that pisco holds a special heritage status in Peru and represents a significant symbol of 'Peruvianess' (Dargent Chamot, 2014; Huertas Vallejos, 2012). Moreover, it is important to note that these figures of growth have been an important change, signalling a revival of the pisco sector following centuries of stagnation. 


\subsubsection{Exclusionary Growth}

Despite the overall growth, not all producers have been included in the reactivation of Peru's viticultural sector since 2000 . The sector, as a result, is characterised by growing inequalities. For instance, many traditional producers lacked the financial capacities to renovate their technologies and have been left behind. Reaching national and international markets is especially challenging for small-scale producers, and a number of studies promote the formation of producer cooperatives to overcome this challenge (Arata \& Vargas, 2007; Huertas Vallejos, 2012). For a number of complex reasons, the creation of producer cooperatives is particularly difficult in the Peruvian context. This is partly due to the failed attempt to promote producer cooperatives during the agrarian reforms (Burneo, 2011). The challenges for the smaller-scale producers identified through fieldwork interviews will be discussed in greater detail in Chapters Six and Seven.

It is worth noting the important contributions small-scale viticulture provide for local communities. For instance, the activities of small-scale producers improve local capture of value and localised rural employment. Moreover, the income generated by these producers and the labourers is generally redistributed in the locality. Despite the benefits of small-scale viticulture in local communities, existing studies show this group of producers has been largely ignored in agricultural promotion programmes in Peru (Arata \& Vargas, 2007; Mendoza Solari, 2015).

\subsection{CHAPTER FOUR DISCUSSION AND LINK TO CHAPTER FIVE}

As demonstrated throughout this chapter, Peru's viticultural sector has not evolved in a vacuum. Instead, the political-economic shifts as Peru transformed from a dependent colony to an independent republic (although under neo-colonial relations) have had important implications for the evolution of Peruvian viticulture. This chapter has illustrated that Peru developed early as the viticultural hegemon of South America during the colonial period, however, a series of events caused centuries of viticultural stagnation and contraction, until the recent reactivation in the pisco and wine sectors from the early 2000s. This chapter demonstrated that colonial and neo-colonial social stratification and structures have operated over more than 500 years since the Spanish colonised Peru. As discussed, the colonial legacies in Peru have generated long-entrenched socio-economic disparities while consolidating Peru's position as a resource periphery in the global economy.

The subsequent chapter, Chapter Five, explores the historical evolution of Chilean viticulture. Chapter Five expands on the ideas presented in this current chapter to examine the shifts in Chile's viticultural history. The final sections of the following chapter compare and contrast the 
Peruvian and Chilean viticultural cases, thereby providing a comparative review of the historical evolutions of viticulture in the two national case studies. The two chapters following Chapter Five will present the research findings from the fieldwork interviews. 


\section{CHAPTER FIVE. GROUNDING ETHICAL VALUE TWO: HISTORICAL EVOLUTION OF CHILEAN VITICULTURE}

\subsection{CHAPTER INTRODUCTION}

This chapter extends from Chapter Four, to explore the historical evolution of viticulture in Chile while continuing to ground the larger theories of the research. Chapter Five, therefore, contributes to the first research aim: to complete a comparative exploration of the historical evolution of viticultural sectors in Chile and Peru. This current chapter better informs the research by examining the Chilean viticultural experience as the country made important political-economic transitions over time.

To begin, Chapter Five explains the establishment and historical evolution of viticulture during the Spanish colonisation. Following this, it discusses the shifts in Chilean viticulture as the country transitioned from a colony to an independent republic characterised by significant economic-political changes which have important implications for viticulture. Like the Peruvian case, this chapter demonstrates that Chile has tended to experience neo-colonial integration into the global economy despite becoming independent in the early-Nineteenth Century. Following this discussion, the chapter presents the key ideas from both Chapters Four and Five, to provide a comparative exploration of the historical evolutions of Peruvian and Chilean viticulture. Finally, the chapter closes with a link to Chapter Six, which explores some of the findings from the primary interview data.

\subsection{VITICULTURE AND SPANISH COLONISATION OF CHILE}

In 1540, Pedro de Valdivia led an expedition into Chile searching for 'another Peru'. However, limited mineral wealth was found in Chile by the early Spanish settlers and the colony was established as a peripheral territory in Spanish America (Bauer, 1975; Johnson, Carmagnani, Drake, \& Caviedes, 2018). From around 1548, grapevines were planted in the northern areas around La Serena and Copiapó by Catholic missionaries and Spanish settlers, for both religious and commercial purposes. The vineyards continued to spread south as the Spanish populations expanded into the fertile Central Valley (Knowles \& Sharples, 2002). In the decades following Spanish settlement, the colonisers faced precarious conditions and lived under the constant threat of the indigenous Mapuche who resisted colonisation. The land in the conquered areas in the Central Valley and the north was divided by the Spanish colonial administration and rewarded to the conquerors under the encomienda systems. This saw the creation of the first large haciendas in Chile, most of these estates planted vines and produced wines (del Pozo, 2014). After a long ten years of conflict with the indigenous Mapuche, Valdivia conquered 
south of the Bío Bío River, and in 1550 the city of Concepción was founded. As the colonisers initially found limited sources of precious minerals in Chile, the Chilean economy became based on agriculture (Bauer, 1975). As a result, the colony remained relatively peripheral throughout the Sixteenth Century, the Spanish population remained low and limited numbers of African slaves were bought into colonial Chile (Johnson et al., 2018). By the Seventeenth Century, minerals were discovered in the northern regions and Chile's early economy developed from its important agricultural base into mining (Collier \& Sater, 1996).

Encomiendas were used to dominate the indigenous populations and support the early development of the agricultural and mining sectors. In the Central Valley and northern regions, indigenous communities lost all sovereignty and these populations declined rapidly due to European diseases and exploitation. Between 1570 and 1600, the indigenous populations that could be used for labour in the encomiendas plunged from 450,000 to 230,000 . The Spanish colonisers began transporting African slaves to work, however, the high prices for these slaves restricted this practice (Bauer, 1975). The Spanish also used 'enemy' indigenous slaves that were defeated in battles; a practiced allowed by the Spanish authorities in the Sixteenth and Seventeenth Centuries (Prado, 2012). Similar to other Spanish colonies, Chile's society followed a colonial social structure, with the Spanish born holding the highest social positions, followed by American born creoles, then mestizos, while the indigenous and African slaves were considered to be inferior (Collier \& Sater, 1996).

\subsubsection{Expansion of Viticulture in Colonial Chile}

By 1554, wine production had spread through most of Chile under the promotion of Valdivia (Mishkin, 1966). As the Spanish conquerors moved further south into Concepción and the Bío Bío River, they faced tough resistance from the indigenous Mapuche, which hindered the early growth of viticulture in the southern area (Knowles \& Sharples, 2002). Despite some setbacks, Chile's early wine industry continued to grow. By 1594, wine production in Chile reached 1.6 million litres. Viticultural production during the Sixteenth and Seventeenth Centuries, was centred both in large wine haciendas and also in small-holdings. Wine production in Concepción and the nearby areas in southern Chile experienced periods of growth and decline due to regular conflicts with the Mapuche. By the end of Sixteenth Century and throughout much of the Seventeenth Century, wine production in the south had diminished due to Mapuche attacks. This, however, changed over time as the region entered into a phase of relative peace. During this period, Mapuche populations became important markets for the Spanish vineyards. Under peaceful conditions, the area around Concepción grew to be Chile's most important viticultural area. Viticulture also developed in Maule Region in the Central Valley during the Seventeenth Century. By the Seventeenth Century, significant amounts of 
wine was produced in Santiago and close to $20 \%$ of the land awarded to the Spanish settlers was planted in vines, however limited access to irrigation and drought restricted production in these central regions. In Colchagua, vines were planted across the region, mostly by the local encomenderos. The northern region of Norte Chico, experienced an important revitalisation in viticulture from the Eighteenth Century, driven by the growing demands for wine and aguardiente de uva due to expanding mining activities (del Pozo, 2014).

As viticulture became an increasingly important economic activity in Chile, the Spanish crown attempted to ban and then restrict the planting of vineyards in the colony. However, these decrees were largely ignored. From the Eighteenth Century, Chile's role as a wine producer and exporter began to grow. From the Eighteenth Century, Chile (which included the Mendoza region until 1776) started to overtake Peru as the South American hegemony in wine production, and by the mid-Eighteenth Century, Chile became the most important South American wine producer (del Pozo, 2014; Mishkin, 1966).

\subsubsection{Colonial Vineyards and Labour Relations in Chile}

The encomienda system was used by the colonial elites to gain control of large landholdings and form enduring feudal based socio-economic structures and exploitative labour relations. This development created the dominant position of the landed elite first over the indigenous population and eventually over the campesinos in Chile (Bauer, 1975; Challies, 2010). During the Sixteenth Century, the Spanish were able to distribute indigenous labourers from the northern and central regions among the vineyards, under the encomiendas. However, by the Seventeenth Century, the toll of European diseases and the harsh practices of indigenous tribute labour caused a drastic decline in the indigenous populations. The elites had two alternative sources of labour; African slaves and enslaved indigenous rebels, both of which were expensive and hard to obtain. This situation changed at the start of the Eighteenth Century, when Chile entered an era of growth as cereals and later mining exports expanded significantly. This new-found prosperity in Chile led to population growth. Under these changing conditions, new sources of labour developed; nomadic mestizos, poor Spanish and freed slaves boosted available labour. Many of these groups entered into forms of peonaje (debt servitude) including inquilinaje (resident workers). The inquilinos workers were paid with access to unused estate land. Inquilinaje came to dominate labour in the Chilean haciendas for over a century and represented a cost-effective practice for the landowners. In addition to inquilinos workers, the estates hired paid seasonal labourers or afuerinos in busy times such as grape harvest (del Pozo, 2014; Kay, 1980). 
In 1810, the Chilean War of Independence began between the Chilean rebels and the Spanish royalists. Despite a number of important victories, the royalists were eventually defeated by Chilean and Argentine rebels led by Bernardo O'Higgins and José de San Martín in the decisive Battle of Maipú in 1818. This saw the end of Spanish colonial rule and Chile was established as a republic (Johnson et al., 2018). The Chilean War of Independence had negative consequences for the country's expanding wine industry as fighting caused significant loss of life as well as damage to the vineyards across the territory. The important southern viticultural zone around Concepción was particularly affected as between 1810 and 1829 the region entered into a period of famine and de-population (del Pozo, 2014).

\subsection{CHILEAN VITICULTURE IN POST-INDEPENDENCE}

Chilean viticulture experienced more continuation than change during the first decades of post-independence. There were, however, some important changes around the 1850s. The removal of Spanish rule saw the increase in imported French and other European wine, which represented significant competition for Chilean wine producers. Contact with these French wines catalysed a major transformation in the ways Chilean wines would eventually be produced (del Pozo, 1995). Labour in the viticultural sector in post-independence Chile also changed. The Chilean Wars for Independence caused labour shortages. Moreover, the slave trade in Chile was abolished in 1823, exacerbating these labour shortages. As a result, the use of inquilinaje workers became increasingly important in the wine haciendas, a practice that remained important into the 1900s (Kay, 1980). A final notable change in Chilean viticulture during the first decades of independence was the completion of important irrigation projects. These projects increased the areas of irrigated land in the region of Santiago, transforming the unproductive land around Santiago into the country's most important wine-producing area from the 1850s (del Pozo, 2014).

There was some political and economic instability during the founding decades of the new Chilean republic. O'Higgins assumed control of the newly formed republic following Chilean Independence, however, he received resistance from the Chilean oligarchy who felt that their privileges were being threatened. The Chilean oligarchy forced O'Higgins from power in 1823. The subsequent years in Chile were plagued by a political divide between the army and the oligarchy (Johnson et al., 2018). The Chilean economy continued to grow supported by the gold, silver and copper mining sectors in the northern regions, which were funded by British capital (Challies, 2010; Collier \& Sater, 2004). 


\subsubsection{Chilean Economic Expansion during the Mid-Nineteenth Century}

Between 1840 and 1850, Chilean agriculture began to expand more rapidly compared to previous decades, thus setting the context for an important renovation of Chilean viticulture (del Pozo, 2014). Mineral exports began to boom from the mid-Nineteenth Century as the industry began to diversify and expand further north. During this period, nitrate exports which were mainly controlled by British investment, extended Chile's early mining growth. Over this period, neoclassical economics and neo-colonial relations dominated Chile, encouraging economic liberalisation, foreign investment and export-led growth. From the 1850s, Chile's economy became increasingly dependent on mineral extraction, international markets and foreign investments. The mining profits that were retained in Chile promoted a relatively stable political and economic environment. However, any attempts to promote inclusive development were limited due to the political influence of the landed oligarchy whose power expanded from 1850 (Challies, 2010; Collier \& Sater, 2004; Kay, 1981).

\subsubsection{Expansion of Wine Sector in Chile, Post-1850}

From the 1850s, Chile's wine sector began to expand in a period of macro-economic growth. This was partly encouraged by the profits made from mining, as elite families searched for new sectors to invest in. Gold rushes in California and Australia represented important new export markets for wheat, driving investment towards Chilean agriculture (Johnson et al., 2018; Morel-Astorga, 2002). The growing international demand of Chilean wheat in Northern America and Australia, and subsequently in England, from the mid-Nineteenth Century, drove the first important insertion of Chilean agriculture into the global capitalist system (Challies, 2010; Kay, 1981). The hacienda owners increased wheat production to meet international demands and concentrated rural land ownership. Many from this landed elite group later invested in wine production (del Pozo, 2014; Knowles \& Sharples, 2002).

From the 1850s, the Chilean vineyards and wineries began to plant French grapes, gradually replacing the colonial grapes and laying the foundations of the large-scale wine production in the Central Valley. These shifts represented the beginnings of a new era of expansion of Chilean viticulture (del Pozo, 2014). Chilean agricultural entrepreneur Silvestre Ochagavía, is usually considered to be the first to have started the importation of French grapes to Chile in $\mathbf{1 8 5 0}$ (Morel-Astorga, 2002). However, French national Nourrichet introduced French Grapes in 1845 and Pierre Poutays also introduced French grapes in 1848 to Chile. Ochagavía also brought a generation of French experts to organise the vineyards, representing a fundamental change in Chilean viticulture. Other Chilean entrepreneurs followed, and wine production expanded significantly from the 1850 s and 1860 s (del Pozo, 1995). 
French wine experts continued to guide Chilean viticulture during the second half of the Nineteenth Century. Many emigrated from France during the phylloxera plague which devastated European viticulture during the Nineteenth Century. Some of these French immigrants became owners of important vineyards in Chile. French expertise pushed an unprecedented process of modernisation and change in Chilean viticulture which continued into the Twentieth Century (del Pozo, 2014; Knowles \& Sharples, 2002).

From 1879 until 1883, Chile was engaged in the costly War of the Pacific against allied Bolivia and Peru. Despite the Chilean victory, the war had weakened the Chilean government's finances. Nonetheless, Chilean viticulture expanded significantly during the decade following the war until the late 1930s. The northern territory gained by Chile during the war increased demand for agricultural products from central Chile, including wine. Similarly, the wealth created by mining in the northern areas fuelled further investment in agriculture in Chile, with capital flowing especially into the wine sector (del Pozo, 1995). By 1869, wine production had reached 23 million litres. 30 years later, wine production had reached 100 million litres. The growth in Chilean wine production, however, had limited impacts on exports, which remained lower than $5 \%$ of overall production over this period. By 1940, at the very end of the era of viticultural expansion in Chile, wine production had reached over 300 million litres. The viticultural frontier in Chile grew as the hectares of grapevines plants rapidly expanded, particularly from late-Nineteenth Century until 1940. Over this period, wine production was associated with the Chilean landed elites. Producing wine had developed as a connotation of social prestige, influence, power and wealth during the end of the Nineteenth Century and through the Twentieth Century in Chile (del Pozo, 2014; Morel-Astorga, 2002).

\subsubsection{Labour Relations in Chilean Viticulture}

The majority of the medium and large-scale wineries and vineyards hired a number of permanent labourers, who lived on the estates and received housing and a low salary which was compensated with other material benefits. These relations were somewhat similar to the inquilinos which existed in the colonial period however there were some important differences. The inquilinos that worked in the vineyard were specifically known as the contratistas, who were involved in the different stages of grape growing and winemaking (del Pozo, 1995). The incomes of these workers came from the salaries they received as well as the material goods such as food stocks they were granted. Men, women and children worked in the vineyards and children were particularly important labour sources in the harvest times. Those that worked in the vineyards in these times experienced a difficult life; they worked long hours for low pay and received low-quality housing. While these labourers could have gained higher salaries working in industries or construction, working in the vineyards provided certain advantages; 
for example, the housing, employment stability and the provisions of consumable goods. Apart from the contratistas labourers, the vineyards also hired temporal labourers who did not live on the estate, known as afuerinos. The afuerinos received slightly higher salaries than their contratistas counterparts but did not enjoy the additional benefits of the contratistas. This modified system based on contratistas or inquilinos and seasonal afuerinos labourers remained important in viticulture and agriculture in Chile until the agrarian reforms which will be discussed later in this chapter (del Pozo, 2014).

\subsection{CHILE IN THE EARLY TWENTIETH CENTURY}

During the first 30 years of the Twentieth Century, Chile experienced a number of significant political and economic shifts, and the period was largely characterised by economic growth. Since Chile's post-independence economic growth continued to be led by mineral and agricultural exportations supported by foreign investments. This followed a neoclassical approach which maintained a highly unequal society in Chile. Wealth distribution, political influence and opportunities were concentrated by the landowning oligarchy and urban upper classes (Kay, 1981).

The start of WWI in 1914 initially restricted Chile's trade economy and exposed its dependence on foreign capital and markets. However, as the war continued the demand for Chilean nitrates and agricultural products increased (Kay, 1981). USA investment into Chilean copper extraction grew remarkably following the end of WWI. However, the period following 1920 was largely characterised by political uncertainty. Growing levels of inflation and the decline of saltpetre sales created discontent among the Chilean working and middle classes. This discontent led to the presidential election of Arturo Alessandri Palma, a reformist president in 1920. The years between 1920 and 1932 were marked by political crises and stalemates as attempts were made to replace the oligarchy with a new political class. A military dictatorship headed by Carlos Ibáñez del Campo, took power from 1927 until 1931. The Ibáñez regime attempted new economic reforms; mines were partly nationalised, public works were initiated, industrialisation was promoted and public education was developed (Hudson, 1994; Johnson et al., 2018). Growth in urban centres and industrialisation in Chile continued to stimulate national demand for agricultural production, thus supporting the growth of the country's agricultural sector including in viticulture (del Pozo, 2014). Chile experienced overall steady economic growth until 1929, supported mainly by the earnings from diverse mining activities and agriculture (Challies, 2010; Collier \& Sater, 2004). Wealth distribution, however, remained highly concentrated (Drake, 1993). 


\subsection{GREAT DEPRESSION AND CRISIS IN CHILE}

Chile's economy eventually crashed following the Great Depression in 1929. Global prices for Chile's most important exports, including copper and saltpetre, plummeted. Between 1929 and 1932, the value of Chilean exports declined by almost 90\% (Blakemore, 1993). At the time, the League of Nations stated that in trade, no other country had suffered more than Chile from the Great Depression. Rates of unemployment almost reached $25 \%$ of the Chilean workforce, while government deficits increased and revenues declined rapidly. During this period, the middle and working classes became increasingly intolerant of the country's longstanding socioeconomic inequalities which resulted in increasing social unrest (Collier \& Sater, 2004; Kay, 2001). The Great Depression exposed Chile's external economic dependence based on primary product exports and foreign capital, especially from the USA (Challies \& Murray, 2008; Kay, 1981). Instead of risking civil war, Ibáñez exiled to Argentina in 1931. In 1932, the Chilean population, now exasperated by economic depression and political instability, eventually restored democratic rule with the re-election of President Alessandri (Hudson, 1994).

\subsection{CHILE AND THE DEVELOPMENTALIST STATE, 1932-1973}

Following the Great Depression, Chile had emerged with a developmentalist state model. Consecutive governments strengthened their roles in directing the economic thus shifting away from the neoclassical economic approach which had dominated Chile since independence (Challies \& Murray, 2008; Kay, 1978). Between 1932 and 1973, structuralism, as well as socialism, influenced the Chilean governments which became progressively inward-looking (Illanes \& Riesco, 2007). Chile's development policies were guided by ISI strategies that attempted to promote national industrialisation and economic diversification (Prebisch, 1962).

From the 1940s, state agricultural strategies sought to encourage the sector's modernisation and promote investment through subsidies (Kay, 2002a). These subsidies, however, tended to exacerbate existing trends of land ownership concentration and consolidate the power and wealth of the landlord class, while lowering living standards of rural worker and campesino classes during the 1950s and 1960s (Bellisario, 2007; Castillo \& Lehmann, 1982). Social reforms during the structuralist period also tended to prioritise the urban classes while ignoring the needs of the rural populations (Challies, 2010; Kay, 1981). By the late 1950s, responding to mounting pressures, agrarian reforms were implemented by three consecutive government during the presidencies of Jorge Alessandri Rodríguez (1958-1964), Eduardo Frei Montalva (1964-1970), and Salvador Allende Gossens (1970-1973) (Kay, 1978). 
President Alessandri attempted to satisfy the demands of the working and middle classes without making major changes to structures of the Chilean economy (Hudson, 1994). The Alessandri government took a technocratic approach to introduce reforms in rural areas, instead of attempting to modify rural class structures, this government sought to address the uneven income distributions in the countryside through ISI policies. While this failed to result in any meaningful reform, the strategies of Alessandri provided the foundations for more extensive agrarian reforms (Collier \& Sater, 1996).

In 1964, Christian Democrat Frei was elected president with support from the right-wing in a coalition. Frei promised a 'Revolution in Liberty', including reforms to improve working-class living standards (Gazmuri, Clavel, \& Escobedo, 1996). In attempts to fulfil this promise, the Frei government implemented a reformist 'Chileanisation' programme and the Chilean State took control of the copper industry which was the country's main export earner. Chileanisation meant that the state acquired $51 \%$ of the shares in the USA copper companies which dominated the sector. Moreover, the Frei government introduced a reformist agrarian reform law in 1967. This new law enabled government expropriation of unused agricultural land and placed limits on land ownership. The implementation of the Frei government's reforms proved, however, to be slow and hindered by the landed elites (Kay, 2002a; Murray, 2002b).

In 1969, Chile's left-wing parties formed the Unidad Popular ${ }^{30}$ coalition, selecting Salvador Allende Gossens, a socialist, as their presidential candidate. Allende was elected president in 1970, initiating the Chilean socialist reforms (Johnson et al., 2018). Socialist reforms of Unidad Popular sought to end the domination of foreign capital in the mining and finance sectors, extend the agrarian reforms, and by establishing more equal income distribution, benefit Chile's poor (Hudson, 1994). Agrarian reform by Unidad Popular attempted to expropriate all rural estates larger than 80 irrigated hectares, reallocate land to campesino cooperatives and remove the landlord class and hacienda system (Challies, 2010; Kay, 1981). In less than three years, more than 6.4 million hectares were expropriated and by $1973,40 \%$ of all agricultural land was administrated by campesino cooperatives (Bellisario, 2007; Kay, 2002a). These reforms would eventually create some of the smallholding owned by the small-scale viticulturists interviewed for this research.

\subsubsection{Years of Limited Wine Production and Agrarian Reforms, 1938-1973}

Chilean viticulture entered a period of restricted production between 1938 and 1973. The fundamental shift was caused by Chile's alcohol law of 1938 which restricted the cultivations used for alcohol production (Knowles \& Sharples, 2002). The 1938 alcohol law restricted new

${ }^{30}$ Popular Unity 
vine producers from legally entering the market for close to four decades. The restrictive alcohol law represented an important shift in Chile's viticultural history. Beginning in 1938 and lasting until 1973, Chilean viticulture evolved within a regulated framework which meant that the areas dedicated to wine grapes and the production developed very little over this period. Wine production grew in the 1960s with government support, reaching a peak in 1972, which is most likely explained by campaigns by Unidad Popular to promote greater national consumption of Chilean wine. Over this period, there were no important changes in the market orientation for Chilean wine, which concentrated on the national markets (del Pozo, 2014). The 1938 alcohol law also coincided with the beginning of structuralist strategies in Chile (MorelAstorga, 2002). Structuralist policies encouraged restrictive legislation on technology and machinery importations between the 1940s and 1960s, impeding the renovation of vineyard technologies.

\subsubsection{Chilean Viticulture, ISI and Agrarian Reform}

From the 1930s and well into the 1970s, Chilean viticulture became characterised by strong protectionist strategies which supported the already established wineries and the newly formed campesino cooperatives. Throughout the 1950s and 1960s, influenced by structuralist strategy, successive governments financed significant improvements in viticulture, including the establishment of new vinification plant in the northern, central and southern regions of Chile. In 1965, an amendment in the 1938 alcohol law permitted vineyards to increase their areas of grape cultivation by ten hectares, signalling the government's objectives to further develop the sector (Morel-Astorga, 2002).

The most important and long-term impact on Chilean agriculture during the period of structuralist policy perhaps came with the implementation of the agrarian reforms. As discussed, the first stage of land reform under Alessandri represented somewhat of an acceptance that reform was required with the adoption of new legal frameworks created for reform. This second stage of reform under the Frei government (1964-1970) was more influenced by structuralist ideas and involved the first expropriation of haciendas and land redistributions. There is no clear evidence that demonstrates negative impacts in the wine sector during these first and second stages of the agrarian reforms (del Pozo, 2014; MorelAstorga, 2002).

\subsubsection{The Vineyards during the Socialist Government}

The election of the Allende government (1970-1973) signalled the most extensive agrarian reforms in Chilean history (Morel-Astorga, 2002). Interestingly, no significant wine estates were expropriated during these agrarian reforms. The largest Chilean wineries were 
considered by the Allende government to be examples of true agro-industries. The large-scale wine-producing companies, a total of fifteen, were better organised than the majority of other Chilean agricultural companies and it was perceived that these wine companies contributed to Chile's development. Nonetheless, these wineries were impacted by agrarian reforms from 1970. While the Allende administration prohibited the expropriation of lands planted in wine grapes, the wine estates had to fulfil certain requirements set by the government. For instance, the vineyard workers had to receive a percentage of the profits. Due to the relative importance of viticulture in Chile, the Allende regime offered vineyards owner's special association with the government. Under this model, the government acquired $51 \%$ of the vineyard's stocks, while the traditional owners were able to retain the remaining $49 \%$ of the stocks. Many owners perceived this to be a step towards full expropriation of their lands by the government (del Pozo, 2014).

Although no vineyards were expropriated, the Allende land reforms represented a threat to private property rights in rural Chile and contributed to the deterioration of a number of Chilean wine estates between 1971 and 1973. During the same period, however, the government invested in viticulture, particularly in small-scale producers and promoted campesino cooperatives in viticulture (Morel-Astorga, 2002)

\subsection{MILITARY COUP AND NEOLIBERAL TRANSITION}

Between 1970 and 1972, the economic situation had grown increasingly difficult as inflation grew and the economy stagnated and the Chilean middle and upper classes became more intolerant of the government and opposition against Chilean socialism grew (Johnson et al., 2018). In September 1973, the armed forces staged a coup ousting the Allende government. Allende died during the attack on Chile's presidential palace and his government was replaced by a military junta which lasted until 1990. The right-wing General Augusto Pinochet Ugarte became Chile's president in 1974 . The military dictatorship shut congress, suspended the constitution, and started to implement extensive neoliberal reforms. National industries were privatised and the agrarian reforms were reversed. According to Murray and Overton (2011a, p. 174); “...the junta soon reversed the structuralist and dependency-inspired policies of Allende and replaced them by 1975 with a series of reforms that converted Chile into the most open economy in the world". The dictatorship was highly repressive, committing a raft of human rights violations. Thousands of Chilean civilians, especially those associated with Unidad Popular, were imprisoned, tortured, murdered, or exiled (Ensalaco, 2000b; Taylor, 2006).

By 1975, the dictatorship shifted its focus on ending the pre-existing order in Chile and began to transform the country. Decades of developmentalist state policies were replaced by a 
neoliberal programme designed by technocrats later known as the 'Chicago boys', influenced by professors at the University of Chicago who advocated neoliberal economics. A radical programme of privatisation, liberalisation and economic shock treatment was implemented. Trade tariffs, state welfare and deficits were slashed between 1975 and 1979. In response, the Chilean economy expanded impressively from 1976 until 1981 in what has been labelled as the 'Chilean miracle' (Taylor, 2006). Economic growth was mostly driven by the influx of foreign capital through external loans until the global debt crisis in the 1980s (Barton, Gwynne, \& Murray, 2008). Non-traditional commodity export sectors in fruits, timber and fisheries, also boomed until 1981, mainly benefiting foreign TNCs (Barton et al., 2008; Kay, 2002b). Despite the economic success, income inequalities grew in Chile and unemployment increased causing hardships in the middle and working classes. Chile's political and social situation became increasingly difficult during the early 1980s, as the international debt crisis worsened (Johnson et al., 2018). In 1983, widespread popular protest spread across Chile, and a number of centreleft political parties formed the Alianza Democrática ${ }^{31}$ coalition opposing the Pinochet dictatorship and gained open support from the Catholic Church (Ensalaco, 2000a, 2000b). In 1984, eleven political parties signed an accord drafted by Archbishop Raúl Cardinal Silva Henríquez, demanding democratic elections before 1989. The political and economic context during the late-1980s continued to be unstable. With pressure towards a return to democracy, protests proliferated, and although the economy showed some recovery, economic stability was hindered by strikes (Hudson, 1994).

\subsubsection{Military Regime and Chilean Viticulture}

When compared to the previous decades of statist economic policies, the dictatorship's 'capitalist revolution' initiated a period which in some aspects favoured the country's agricultural and viticultural sectors (del Pozo, 2014; Kay, 2002b). The overthrow of the Allende government reversed the agrarian reforms and removed the threat of land expropriation while private investments were encouraged. Moreover, the liberalisation of the Chilean economy allowed agricultural producers, to directly purchase technologies and set favourable conditions for Chilean exports. The 'capitalist revolution' therefore had positive consequences in the wine industry, yet these were felt unevenly. In general, the largest-scale producers with the capacities to enter international markets benefited the most, while the smaller-scale producers and cooperatives tended to be negatively impacted (del Pozo, 2014).

\footnotetext{
${ }^{31}$ Democratic Alliance
} 


\subsubsection{The Neoliberal Reforms}

The first objective neoliberal restructuring of Chile's agricultural sector was to reverse the agrarian reforms (Kay, 2002b). However, reversal did not signal a return to the situation prior to the reforms. For instance, while a small percentage of reformed land was returned to the former owners, the large majority of land was resold. This new land market created the emergence of new types of agro-business groups in rural Chile. The second objective was to attract investment, both foreign and national, into the agricultural sector and agro-export crops in fruits and forestry expanded as a result (Morel-Astorga, 2002; Murray \& Overton, 2011a). However, these policies also had negative consequences. For example, they created a large influx of imported agricultural products which increased competition, debts and hardships among local producers (Lear \& Collins, 1995). The small-scale producers which did not have the capacities to export experienced the most negative impacts of liberalisation (del Pozo, 2014; Overton \& Murray, 2011). Furthermore, the neoliberal counter-reforms led to the re-concentration of agricultural land ownership (Murray, 2002b). Many campesino families lost their traditional way of life and land due to these counter-reforms (Bellisario, 2007).

Despite initial growth following the counter-reforms, agricultural production declined by $-2.1 \%$ and $-3.6 \%$ in 1982 and 1983 . The losses experienced by domestic-oriented producers were even higher (Collier \& Sater, 2004). For the first time during the Pinochet period, farmers openly criticised the regime over its farmer-hostile policies. The dictatorship's policies towards the agricultural sector changed somewhat following the economic crisis of 1982 and 1983, and special support was directed towards the national staple productions (Morel-Astorga, 2002). Between 1984 and 1986, agriculture began to recover. However, the benefits were again concentrated by the TNCs which controlled Chile's fruit and forestry export sectors (Murray, 2002b).

\subsubsection{Viticulture during the Counter Reforms}

One of the most important transformations in the Chilean wine industry was initiated when the dictatorship abolished the restrictive 1938 alcohol production law. As a result, wine production increased rapidly during the first years of the dictatorship. In 1983, wine reached peak production of 648 million litres. However, national wine consumption declined over the same period. With no significant market, wine production plummeted by $50 \%$ in 1984 (MorelAstorga, 2002). During the 1980s, wine exports remained modest, the areas under grape cultivation declined and vines were replanted with export fruit crops (Banks \& Overton, 2010). Although there was a slow recovery during the second half of the 1980s, many wine producers, especially small-scale producers, disappeared under these challenging conditions (del Pozo, 2014). By the mid-1980s, most small-scale producers had been out-competed by large-scale 
producers which had acquired properties similar to the pre-reform haciendas (Murray, 2006b). Ownership and production in Chile's wine industry become gradually concentrated from the 1980s (Murray \& Overton, 2011a). Some of these challenges faced by small-scale producers became important topics in the research interviews. These topics will be further examined in Chapters Six and Seven.

\subsection{TRANSFORMATIONS IN CHILEAN VITICULTURE, POST-1973}

\section{New Producers}

Post-1973 saw an important transformation in the types of producers in Chilean viticulture. The neoliberal shift fuelled the consolidation of wealthy groups and the creation of new economic groups in viticulture. For the first time in the history of Chilean viticulture, there was a significant expansion of foreign wine producers in Chile following economic liberalisation. These foreign investors either invested in established Chilean wineries or purchased land and created new wineries. A noteworthy case was the entry of Spanish wine producer Miguel Torres who invested in the Chilean wine sector in 1979. Torres created a winery in Chile and introduced new viticultural technologies which had important impacts for the rest of Chile's viticultural sector. During the 1980s, supported by the foreign and national investments, Chilean viticulture began a process of renovation as new technologies were introduced and attempts were made to improve the quality of Chilean wines (del Pozo, 2014; Morel-Astorga, 2002).

\section{Viticultural Workers}

After 1973, the unions which supported workers, including in viticulture, declined in Chile. The unions were condemned by the dictatorship and union leaders were often fired, or worse detained. Prior to the coup, the unionisation of agricultural workers reached 280,000 in 1973. By 1985 , the number of unionised agricultural workers had dropped to 50,000 . In this new repressive context, workers' strikes became rare and the vineyards preferred to hire workers on precarious short-term contracts. Post-1973 saw the final decline of the inquilinaje system. Workers became solely waged and lost most or all of the benefits involved in the inquilinaje system; including non-monetary benefits such as housing and land access (del Pozo, 2014; Kay, 2002b). Prior to military rule, rural workers were emancipated from the haciendas, and participated in rural unions, eventually joining cooperatives on reformed land. Under the dictatorship, a minority of these rural workers gained small landholdings and managed to become independent producers. The large majority of the rural workers, however, lost access to the farmland and converted into non-landed waged workers in the expanding yet exclusionary Chilean agricultural sector (Bellisario, 2007; Murray, 2002a). 


\subsubsection{Wine Exports during Pinochet Dictatorship}

As discussed, the Chilean wine sector entered into a crisis in the 1980 s when national wine consumption declined. Wine producers, therefore, started to search for new opportunities in international markets. During the early 1980s, a few wineries were able to successfully enter international wine markets but international wine over-production made this difficult. Chilean wine exports only became important at the end of the 1980s. The growth in wine exports from the late 1980s was caused by the aforementioned expansion of new producers, the renovation of the sector, and the general opening of the Chilean economy associated with the neoliberal policies. As explained by Murray and Overton (2011a, p. 174) producers in Chile attempted to fill an important international niche at the time of low-quality wine: "Based on low labour costs, precipitated by deregulation in the labour market, Chilean wine competed based on price in the global market and began to carve a low-quality niche in that regard."

A number of countries boycotted Chilean products in opposition to the dictatorship, having negative implications for Chilean wine exports (del Pozo, 2014). It was not until the return to democracy in the 1990s, that Chilean wine exports really started to boom. This coincided with the end of boycotts on Chilean products (Morel-Astorga, 2002), as well a shift in the neoliberal model to value-adding to the country's exports, including wine (Murray \& Overton, 2011a).

\subsection{RETURN TO DEMOCRACY IN CHILE}

Loss of domestic support, international disapproval, disagreements within the regimes, and growing disaffection against the ruling military groups tended to drive the transitions towards democratically elected governments in Latin America during the 1980s and early 1990s, including in Chile. The return to Chilean democracy was formally initiated with the 1988 plebiscite as the country's population expressed their disapproval of dictatorship and supported the Concertación de los Partidos por la Democracia. The Concertación was a centreleft alliance of political parties and represented the main political challenge to the dictatorship. Chile was governed by four consecutive Concertación governments between 1990 and 2010 . The return to democracy can be divided into two important periods; (1) the Christian Democrat transitional governments of Patricio Aylwin and Eduardo Frei Ruiz-Tagle between 1990 and 2000, and the neostructural socialist governments of Ricardo Lagos and Michelle Bachelet between 2000 and 2010 (Challies \& Murray, 2011).

The Aylwin administration was essentially a transitional government; its main focus was strengthening Chile's electoral institutions while sustaining macro-economic growth. This government had inherited a growing economy and therefore had no clear proposal for implementing an alternative economic approach to neoliberalism (Barton \& Murray, 2002). 
The Frei Ruiz-Tagle government was elected in 1994, during a period macro-economic success. This government promoted export-driven growth showed and little interest in transforming the neoliberal approach. However, despite economic expansion, the Frei Ruiz-Tagle government experienced growing pressures to redress the social costs associated with the legacy of the dictatorship and the continuation of the neoliberalism (Hojman, 1996; Murray, 2002b).

In 2000, Ricardo Lagos, the first socialist president since Allende was elected. This government implemented a number of social reforms while Chile continued to experience economic growth (Challies, 2010). In 2006, Lagos was succeeded by Michelle Bachelet, also a socialist. The Bachelet government soon encountered mass student demonstrations fuelled by frustration over the quality of the country's public education, as well as strikes by disaffected workers in the mining and health sectors. Bachelet's popularity, however, grew when the price of copper increased and her government redirected funds towards social welfare, pension reforms and a new employment stimulus programme (Johnson et al., 2018).

\subsubsection{Chilean Agriculture, Post-1990}

Since the return to democracy, the neoliberal model has continued to dominate agricultural policy despite some neostructural shifts to include equality. Although agriculture made a significant contribution important to the country's economic growth during the 1990s and 2000s, levels of rural inequalities and poverty remained high. The chronic inequalities and poverty in rural areas partly represented the failure of Concertación governments to confront social issues. Through the promotion of export-led growth, agro-businesses gained increased influence and lobbied for the continuation of the neoliberal approach in Chile. While research has demonstrated that small-scale farmers can benefit from the emergence of agro-business (Berdegué, 2001) other studies have shown that the interactions between the agro-business and small-scale producers tend to be exploitive (Challies \& Murray, 2011; Murray, 2002a).

The successive Concertación governments supported the small-scale producers to increase productivity and re-orientate their production towards profitable markets through a strategy of 'reconversión'. Since 2000, agricultural policy of the Lagos and Bachelet governments have sought to integrate small-scale producers into the country's growing agro-export sector. The reconversión programmes have however focused on already productive small-scale producers and have been criticised for largely ignoring the needs of Chile's most vulnerable and smallestscale producers (Challies \& Murray, 2011; Murray, 2002a). Despite implementing some important social reforms in the Chilean countryside, the Lagos and Bachelet governments have 
failed to challenge the underlining neoliberal model which has sustained inequalities in rural areas (Illanes \& Riesco, 2007; Murray, 2002b).

\subsection{THE CHILEAN WINE SECTOR DURING THE TRANSITION TO DEMOCRACY, 1990-2010}

Since 1990, the Concertación governments have influenced the orientation of the wine industry. Internally, these governments have continued to implement pro-business policies with neostructural tendencies. Externally, they have supported trade liberalisation through free trade agreements. Chile's viticultural sector has responded to these internal and external strategies and wine reached unprecedented production and export growth following the 1990s, as shown in Figures 24 and 25 (Morel-Astorga, 2002). Following the return to democracy, Chile shifted its export strategy to one of adding value to the country's wine production. This involved a clear move to distinguish Chilean wine production from other emerging producers and Chile begin to specialise in the exportation of red wine varieties during the 1990s. The growth in global sales of Chile wine has been remarkable in the last 30 years. In 1990 , Chilean wine exports represented only $1 \%$ of total global wine sales. By 2010, Chilean wines exports had grown to represent $12 \%$ of total global wines sales and Chile became the fifth largest wine exporter in the world. Wine exports have clearly been a motor for growth in Chile's viticultural sector since the 1990s and during the 2000s (del Pozo, 2014). This rapid growth in Chilean wine exports can largely be explained by responding to international wine consumer demands for higher quality wines and by adding value to wine exports by improving quality and specialising in specific varieties. This has been labelled as 'upgrading' which took place after the 'easy' phase of the neoliberal phase of producing low-value wines had ended and is associated with neostructural thought (Murray \& Overton, 2011a).

A number of growing Chilean wineries, including some new companies, now participate in international markets. However, the wine industry in Chile has remained dominated by a small number of industrial-scale wineries which control the majority of wine production and exports, the industry has therefore continued to be characterised by an oligopolistic nature into the 2000s (del Pozo, 2014). 
Figure 23 Chilean Wine Production, 1995-2010

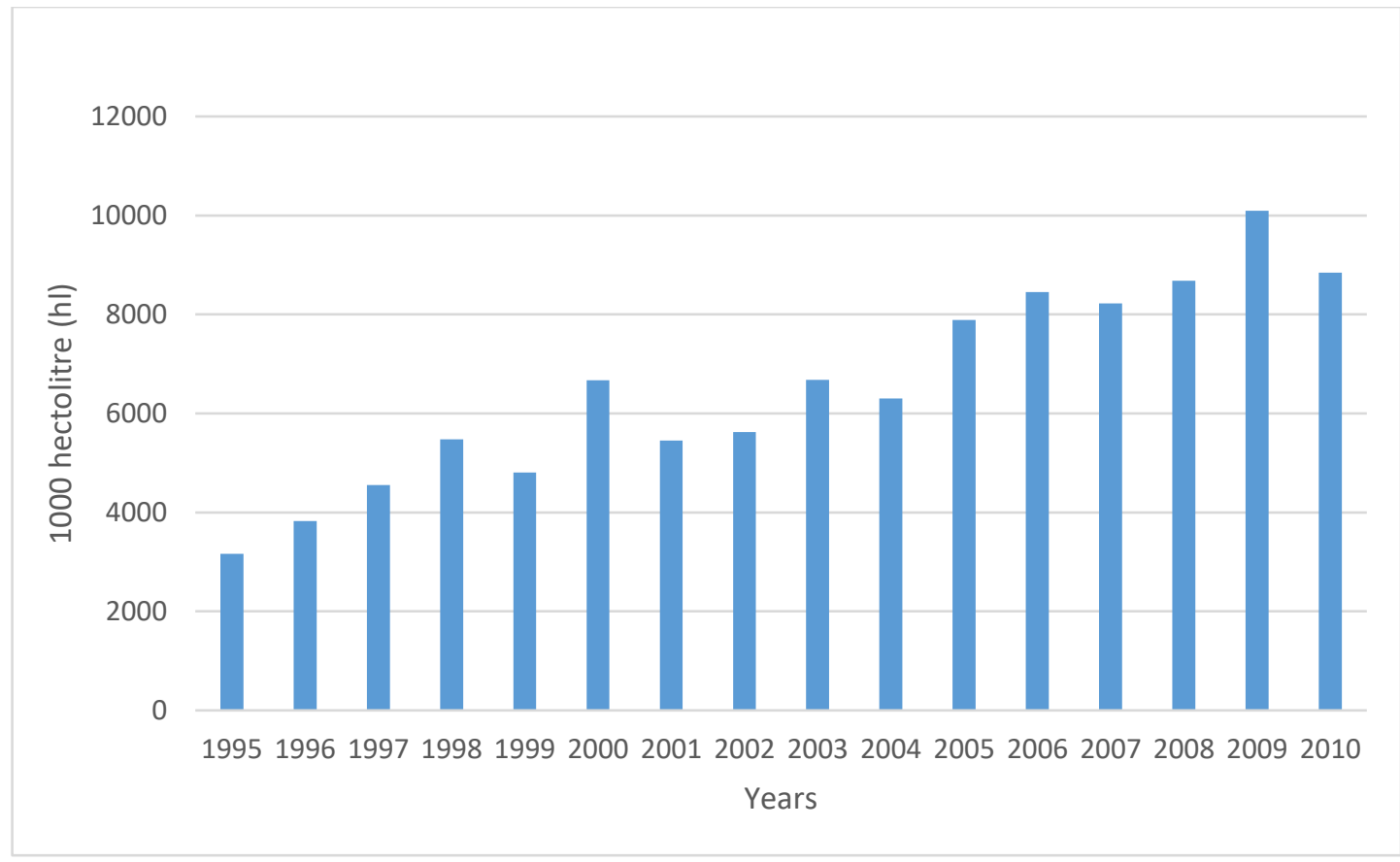

Source: Elaborated by the author using data from (Organisation of Vine and Wine, 2016).

Figure 24 Chilean Wine Exports, 1995-2010

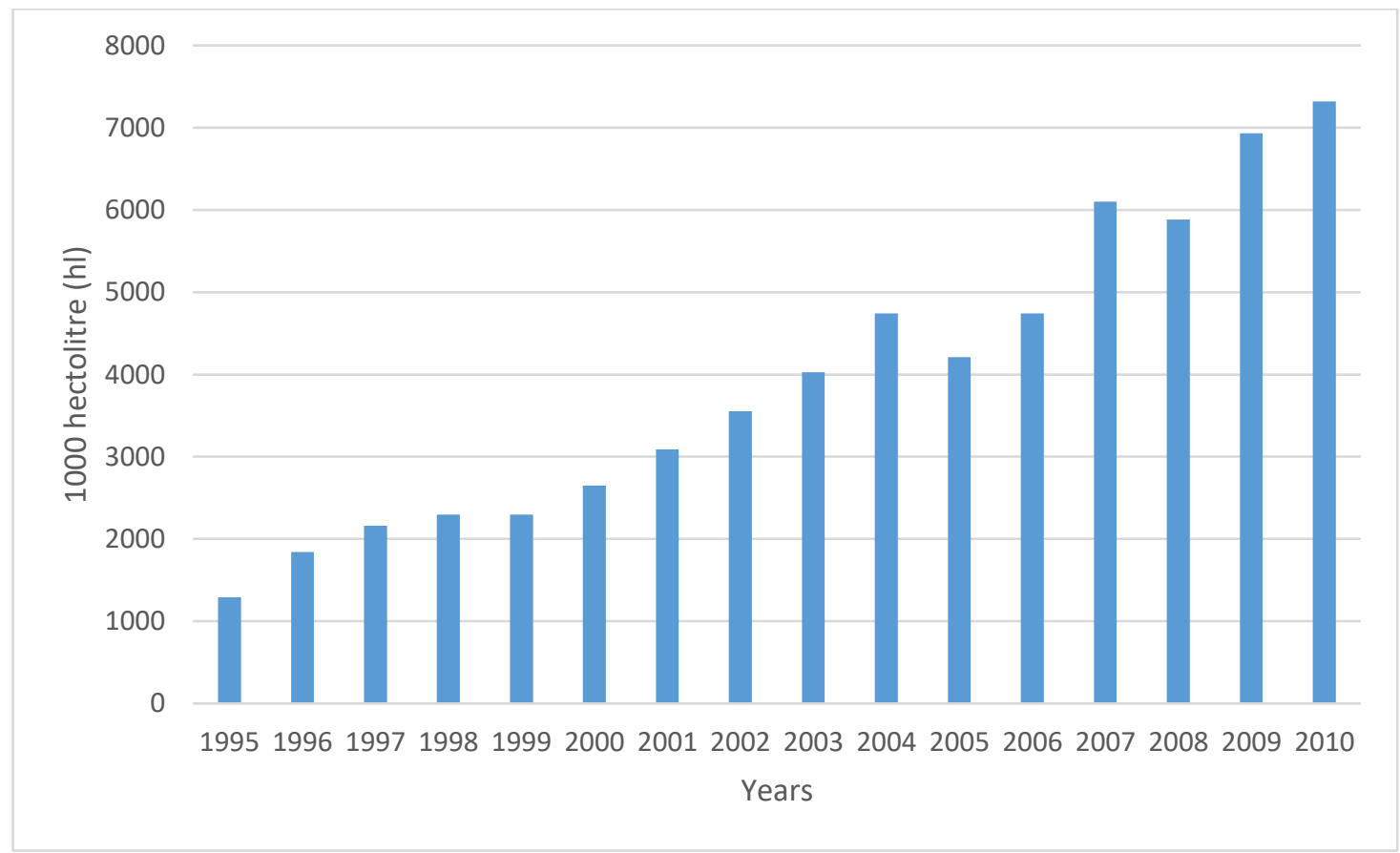

Source: Elaborated by the author using data from (Organisation of Vine and Wine, 2016).

\subsubsection{Chilean Wine Production, 1990-2010}

From the mid-1990s until 2010, wine production experienced sustained growth despite some dips in production, as shown in Figure 24 on the previous page. The number of vineyards, however, declined during the 1990s and 2000s. For example in 1975 , there were 22,000 vineyards by 1997 there was only 11,000 despite the growing levels of production. In 2007, the 
number of vineyards in Chile had only grown to just over 14,000 despite impressive and sustained growth over this ten-year period (see Table 5 below). These trends highlight the trends of concentration in Chile's wine production (del Pozo, 2014; Morel-Astorga, 2002).

Table 5 Number of Vineyards According to Area, 1995-2007

\begin{tabular}{|l|l|l|l|l|l|l|l|}
\hline Year & $\begin{array}{l}\mathbf{0 - 1} \\
\text { ha }\end{array}$ & $\begin{array}{l}\mathbf{1 . 1 - 5} \\
\text { ha }\end{array}$ & $\begin{array}{l}\mathbf{5 . 1 - 1 0} \\
\text { ha }\end{array}$ & $\begin{array}{l}\mathbf{1 0 . 1 - 2 0} \\
\text { ha }\end{array}$ & $\begin{array}{l}\mathbf{2 0 . 1 - 5 0} \\
\text { ha }\end{array}$ & $\begin{array}{l}\mathbf{5 0} \text { or } \\
\text { above ha }\end{array}$ & $\begin{array}{l}\text { Total } \\
\text { ha }\end{array}$ \\
\hline 1997 & 5308 & 3799 & 920 & 585 & 436 & 204 & 11,253 \\
\hline 2003 & 5567 & 4370 & 1428 & 1044 & 819 & 364 & 13,592 \\
\hline 2007 & 5614 & 4485 & 1538 & 1104 & 873 & 398 & 14,012 \\
\hline
\end{tabular}

Source: Adapted from (del Pozo, 2014)

Growth in production has been supported by the expansion of the wine industry into new viticultural valleys (Like Casablanca) as well intensification of wine production the traditional wine-producing areas of the Central Valley (such Curicó and Rancagua) (Overton, Murray, \& Silva, 2012). The expansion into new viticulture valleys is mostly explained by attempts to produce new premium wines with different terroir (Bustos, Torres, \& Willington, 2007). Since the 1990s, Chilean wine producers have sought to take advantage of climatic and soil variations to produce more distinctive premium wines and thus position Chilean wines in higher-end international markets. As discussed, these attempts to increase the value of Chilean wines through new qualities and specialization has been labelled as 'upgrading'. Furthermore, grape varieties which were practically unused before 1990 such as Pinot Noir, Syrah, Chardonnay and Carménère, have expanded impressively during the 1990s and 2000s. Carménère warrants a special mention; the variety was 'rediscovered' in Chile after it was believed to have been eliminated in France, Carménère's country of origin, during the Nineteenth Century phylloxera plague. It was not until genetic testing of phylloxera-free vines in Chile that Carménère was rediscovered in the 1990s. Since its rediscovery in Chile, demand for Carménère grew internationally and Carménère production expanded rapidly in Chile, aiming particularly for high-end red wine markets (del Pozo, 2014; Murray \& Overton, 2011a; Overton, Murray, \& Silva, 2012).

\section{Domination of a Minority of Large-Scale Wine Producers}

Since 1990, Chilean wine has been dominated by a few very large-scale wine producers; Concha y Toro, San Pedro, Santa Rita, Santa Carolina and Undurraga. In 1995, these five companies produced around 160 million litres of wine, over half of all of Chile's wine production that year. By 2010, the domination of a few companies had been further consolidated, only three companies; Concha y Toro, San Pedro, Santa Rita controlled the large majority of total wine 
production and exports. In the history of Chilean viticulture, there has never been a moment when so few yet very large companies have controlled so much of the market (del Pozo, 2014). This means that these companies have substantial influence in the industry and are able to set the prices of the grapes produced by small and medium scale producers. The growth of these companies has been promoted by Chile's neoliberal policies which have encouraged trade liberalisation and exports (Overton \& Murray, 2011, 2013). Within the post-1990 sector, smallscale domestic wine producers oriented towards low-end local markets has almost vanished altogether in the context of sectoral concentration (Morel-Astorga, 2002).

Between 1990 and 2010, the large-scale Chilean wine producers have expanded their vineyards, thus relying less on small-scale producers for the supply of grapes. Vineyard ownership has there become increasingly concentrated since the 1990s, as demonstrated in Table 5 (Morel-Astorga, 2002). In this increasingly concentrated industry, Chile's small-scale grape producers have become increasingly vulnerable to market forces. Many of these smallscale producers have not been able to sustain their viticultural activities and have disappeared due to the very low grape prices offered by the dominant wine producers (del Pozo, 2014; Overton \& Murray, 2013). Sectoral concentration and the challenges this creates for smallscale producers in Chilean viticulture will be further explained using evidence from fieldwork in Chapter Six.

\section{Growth in Foreign Investment}

Following the return of democracy, the number of foreign investors attracted to the Chilean viticulture grew at unprecedented rates (Murray \& Overton, 2011a; Overton \& Murray, 2013). The influx of foreign investment from the early 1990s has generally taken two paths; the creation of joint ventures where foreign groups invest in already established Chilean wine companies or the creation of companies affiliated with foreign wine producers (Bustos et al., 2007; del Pozo, 2014). There has also been the emergence of a third category of boutique highend and export-oriented vineyards. These boutique vineyards are generally small in terms of land but are modern and intensive and often connected to foreign capital (Morel-Astorga, 2002).

\section{The Cooperatives Fail to Recover}

The return to democracy failed to cause any important recovery in the producer cooperative sector. Most of the cooperatives established during the agrarian reforms of the 1960 s and early 1970s had disappeared by the 1990s, while a number of others disappeared during the first years of the 2000s (Morel-Astorga, 2002). Some cooperatives have continued to operate through the waves of neoliberal reform in Chile. Most notable are the Loncomilla and 
Cauquenes viticultural cooperatives which have continued to produce wine predominately for the national markets while also making some breakthroughs into international wine markets during the early 2000s. By 2010, Loncomilla and Cauquenes were the only two remaining wineproducing cooperatives from the agrarian reform era to survive the shifts associated with neoliberalism in Chile. A number of private organisations controlled by collectives of smallscale viticultural producers have also developed in Chile. These organisations operate as cooperatives but are officially private companies (Kleine, 2008). These cooperative companies have had some success in improving access to markets for small-scale producers in the viticultural sector as will be discussed later in this thesis (del Pozo, 2014; Jano, 2016).

\section{Labour Shift in Chilean Viticulture and Expansion in Temporal Labour}

Since 1990, there has been a clear diminishing trend in the numbers of permanent employees in the viticultural sector. Many of the formerly rural populations have been pulled towards urban centres and other industries, such as mining, for higher paid employment. Employment in the viticultural sector is highly seasonal and increasingly precarious in Chile. While there is a relatively small number of well-paid permanent professional staff, since the 1980s and 1990s, there has been an increase in flexible and short-term contracts in Chilean viticulture, particularly for the labour roles. These temporary workers are known as temporeros. Under the neoliberal model in Chile, temporeros play an important role and are hired to complete periodic tasks, especially in the harvest and pruning seasons. As a result, the temporeros experience instable employment and generally do not receive the same benefit as permanent employees (Caro, 2013, ND). Temporary workers are usually hired by contractors and not directly by the vineyards which removes a certain level of company responsibility towards these labourers. It has been recognised that the contractors which hire temporeros regularly engage in illegal labour practices (Caro, 2013; Overton \& Murray, 2013). Despite the important labour role fulfilled by the temporeros, it very difficult for this group to establish unions or stage collective action due to opposition of the contractors and the vineyards. Worker unions within the vineyards, in general, have remained limited since the dictatorship, including following the return to democracy (del Pozo, 2014).

\subsection{CHILEAN POLITICS AND ECONOMY, POST-2010}

In 2010, for the first time since the end of the Pinochet dictatorship, a conservative was elected president through the right-wing businessman Sebastián Piñera. The election of the Piñera government saw the re-consolidation of the neoliberal model in Chile. Piñera soon faced mass student demonstrations protesting the poorly funded public education system. Protests spread into other areas, including workers' rights, environmental issues and consumer rights. Despite 
these challenges, the Chilean economy continued to grow, largely boosted by high international cooper prices at the time. Macro-economic success strengthened support for the neoliberal model, and fiscal restraint and economic stability were prioritised above the growing demands for social spending. In this political-economic environment, the business elites were able to consolidate their power and influence (Gould, Garcia, \& Remes, 2016). Since 2010, in rural areas, for instance, agro-export businesses have expanded their shares of earnings and further concentrated land ownership (Challies \& Murray, 2011). In 2014, Bachelet was elected for her second presidential term, signifying a shift away from the neoliberal model towards a neostructural programme (Barton et al., 2007; Undurraga, 2015). The Bachelet administration implemented tax and education reform and increased public social spending. The Chilean economy continued to experience important growth supported by mineral and agricultural exports, industrial expansion and declining rates of unemployment. However, largely due to declining international prices for copper, GDP contracted from 6.1\% in 2011 to $1.6 \%$ in 2016 (Johnson et al., 2018; World Bank, 2018a). In December 2017, Piñera was re-elected as president, again signally the reconsolidation of neoliberalism.

\subsection{CHILEAN WINE SECTOR, POST-2010}

Following impressive growth in the 1990s and 2000s, Chile is currently the ninth-largest wine producer in the world. Wine production in Chile grow rapidly from 282 million litres in 1991 to 1.2 billion litres in 2015, before declining to 1.0 billion litres in 2016, and 983 million litres in 2017 (See Figure 25 below) (Servicio Agricola y Ganadero, 2018). The sector has also experienced important export growth (in value and volume), only surpassed by the traditional wine exporting countries Spain, Italy and France (Farinelli et al., 2017; Organisation of Vine and Wine, 2016). Between 2000 and 2017, the value of Chilean wine exports grew from US\$569 million to US\$1.9 billion (see Figure 26) (Buzzetti Horta, 2018). 
Figure 25 Total Chilean Wine Production, 1991-2017

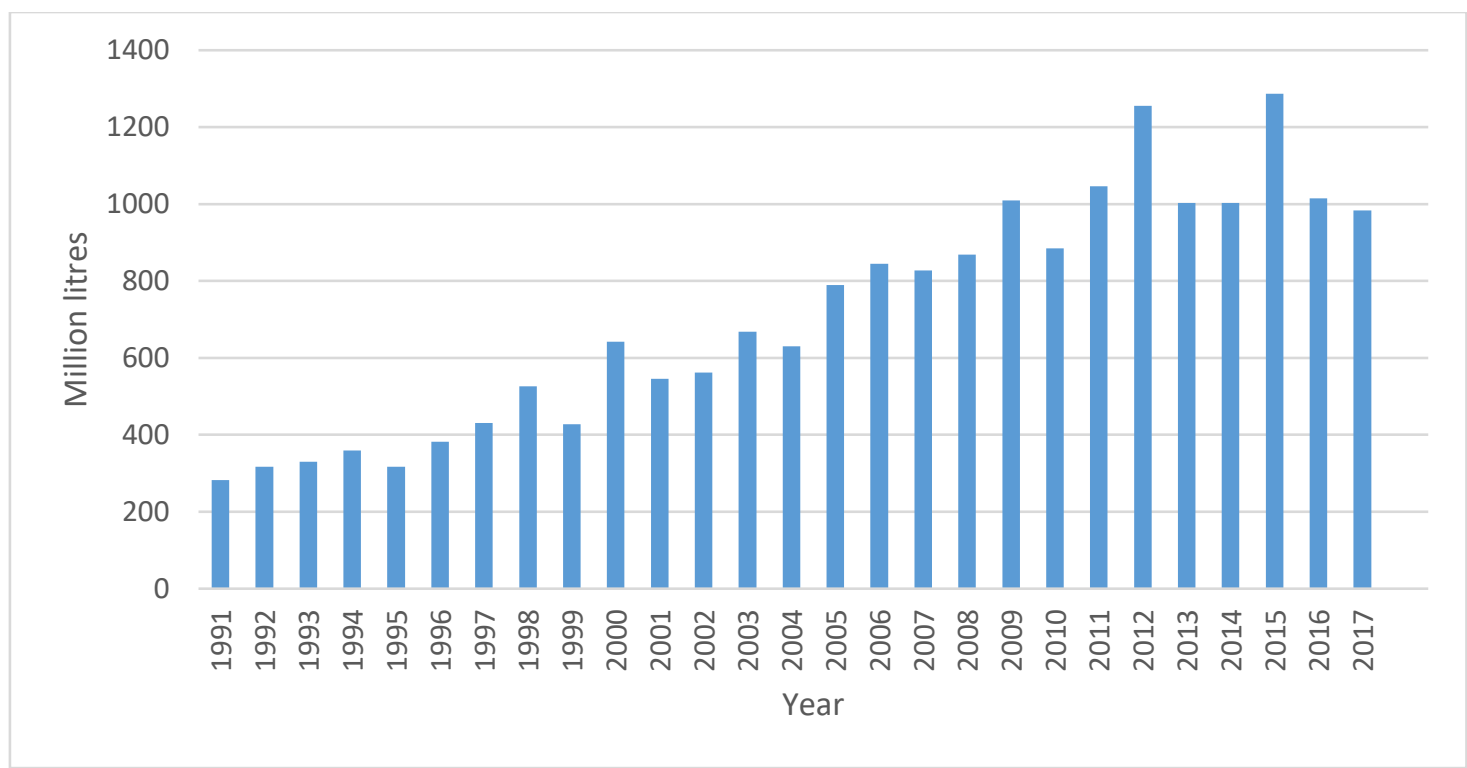

Source: Elaborated by the author using data from the Oficina de Estudios y Políticas Agrarias (ODEPA) (Buzzetti Horta, 2018)

Chile's remarkable viticultural growth over the last three decades has been supported by the upgrading of the sector and the influx of foreign and national investment (Overton, Murray, \& Banks, 2012). Over this period, the Chilean wine sector has developed from a traditional sector oriented towards a relatively stagnant national market into an intensive export-oriented industry, with over $60 \%$ of total wine production exported (Farinelli et al., 2017). There has been a continued transition of upgrading from mass-produced low-value to higher value-added wines through sectoral up-grading (Banks \& Overton, 2010; Murray \& Overton, 2011a; Overton \& Murray, 2013). It is important to note that over the last four-five years wine production and exports have flattened due to a number of factors; including unfavourable climatic events, the conversion of grapevines to export fruit crops and a global over-supply of wine (Buzzetti Horta, 2018; Servicio Agricola y Ganadero, 2018). Furthermore, there has been a growing concentration of sectoral control, production, land-ownership, and market access in the hands of a small group of industrial-scale wine-producing companies in Chile (del Pozo, 2014). 


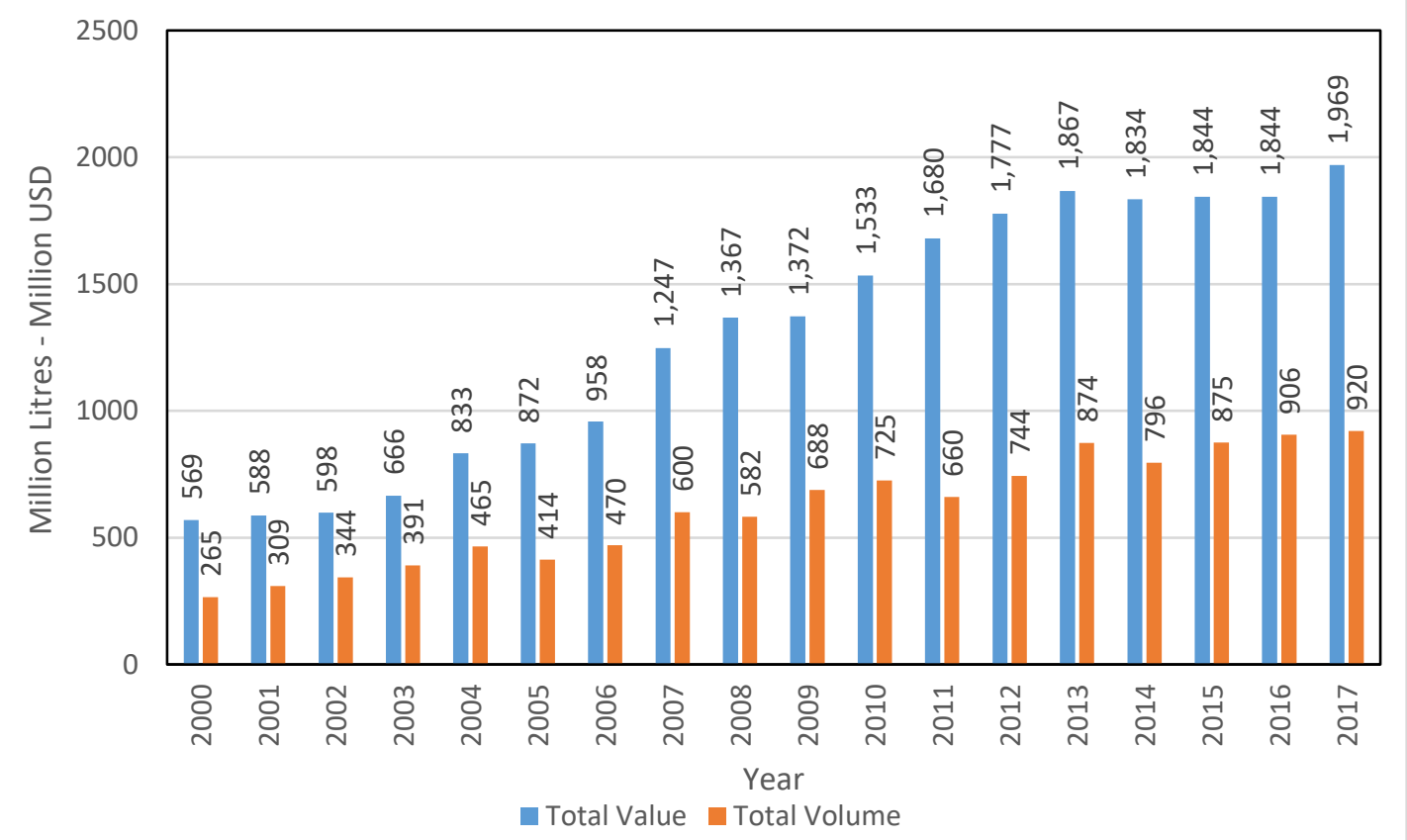

Source: Elaborated by the author using data from ODEPA (Buzzetti Horta, 2018)

\subsection{THE EVOLUTION OF FAIR TRADE WINE IN CHILE}

Over the last twenty years, and especially during the last decade, there has been significant growth in various certifications targeted towards consumers concerned with ethical and sustainable production in Chile's viticultural sector. This has included social concerns about inequalities in Chile's viticultural, and other sectors, demonstrated particularly through the growing use of the fair trade certificate (Kleine, 2008). fair trade certifications were first implemented in Chile in the 1990s. Three organisations, outside of the wine sector, led the initial implementation of fair trade in Chile; la Cooperativa Campesina Apícola Valdivia, Comparte, and la Fundación Solidaridad. These three groups emerged in the difficult social and political context of rural Chile under the Pinochet dictatorship in the 1970s and 1980s. In this context, these groups emerged in Chile to support vulnerable small-scale producers to escape cycles of poverty and promote fairer conditions and markets access for these groups, eventually linking with international fair trade networks in the 1990s (Malo \& Mori, 2003; Wijnant, Raga, \& Ramakers, 2015). Currently, there are 42 Chilean organisations and companies certified with one of the three fair trade certifications (WFTO, FLOCERT and Fair for Life) and many more small-scale producers associated with these fair trade certified organisations and companies (Wijnant et al., 2015). The domestic Chilean market for fair trade products, however, remains limited, and fair trade products are oriented towards external Global North markets. 
fair trade certified wine in Chile has expanded particularly since the late 1990s. In 2015, fair trade certified wine represented $33.4 \%$ of all Chilean products sold under a fair trade label. An important factor for the expansion of fair trade certified wine in Chile has been the purchasing policies of Nordic countries; Denmark, Finland, Sweden and Norway. Under government controlled alcohol purchasing monopolies, these countries have prioritised wines with ethical and sustainable production labels. This has created important markets for fair trade certified wine and has encouraged Chilean wine producers to implement fair trade certifications (Kleine, 2008; Malo \& Mori, 2003; Wijnant et al., 2015). External demand for fair trade wine and the growing use of fair trade certifications on Chilean wine will be further examined in Chapter Six. Fair trade certified grape and wine producers in Chile have entered into either the FLOCERT Fairtrade or IMO Fair for Life systems of certification. Although there are some variations between these certifications both offer two different fair trade models: the cooperative model and the plantation or hired labour model. Under the cooperative model, small-scale grape producers form a cooperative and become certified to receive a fair trade minimum price. This fair trade price covers the costs of production (Fair for Life, n.d.-a;FLO International, n.d.). In addition, the cooperative receives a fair trade premium used to benefit the cooperative members and their families. In February 2019, the fair trade price for non-organic FLOCERT certified wine grapes was $€ 0.28$ per $\mathrm{kg}$, with an additional $€ 0.05$ per kg paid as the fair trade premium. Certified organic and Fairtrade wine grapes received a higher price of $€ 0.33$ per kg plus the additional $€ 0.05$ per $\mathrm{kg}$ in premium (FLOCERT, 2019). Under the plantations or hired labour model, certified companies agree to ensure decent working conditions for their employees and protect their rights following International Labour Organization Conventions. These rights include the right to join a union, the right to a safe and healthy work environment, and prohibits any discrimination or the use of child labour. Employees of certified plantation form fair trade committee and decide how the fair trade premium is used to benefit themselves and their community (Fair for Life, n.d.-a;FLO International, n.d.). This research has identified nine key producer groups which have encouraged the implementation of fair trade in wine in Chile's main viticultural zones of the Central Valley (shown in Table 6). 
Table 6 Key Producer Groups of Fair Trade Certification in Chilean Wine Sector

\begin{tabular}{|c|c|}
\hline $\begin{array}{c}\text { Name of } \\
\text { Actor }\end{array}$ & Description \\
\hline Lautaro & $\begin{array}{l}\text { Vinos Lautaro was formed by a group of } 17 \text { small-scale producers in the } \\
\text { comuna La Sagrada Familia, in Curicó, Maule, in 1997. This group is } \\
\text { considered a leader in fair trade in Chilean wine and begun exporting wine } \\
\text { to Oxfam Belgium under fair trade conditions without certification from } \\
\text { 1997. In 2009, Vinos Lautaro was certified with the FLOCERT. }\end{array}$ \\
\hline $\begin{array}{l}\text { Miguel } \\
\text { Torres }\end{array}$ & $\begin{array}{l}\text { Miguel Torres is a Spanish winery. Torres expanded operations into Chile in } \\
1979 \text {, establishing its base in Curicó. Torres in Chile become fair trade } \\
\text { certified in 2010, under the Fair for Life label. Torres is also considered a } \\
\text { leader in Chile's fair trade wine sector due to its relatively high profile for } \\
\text { promoting the certification. }\end{array}$ \\
\hline $\begin{array}{l}\text { Esperanza } \\
\text { para la Costa }\end{array}$ & $\begin{array}{l}\text { Esperanza para la Costa was formed by } 19 \text { small-scale grape producers and } \\
\text { certified with the FLOCERT after the offshore earthquake which devastated } \\
\text { central Chile in } 2010 \text {. This group produces traditional País grape which are } \\
\text { sold to Miguel Torres under fair trade. }\end{array}$ \\
\hline Red del Vino & $\begin{array}{l}\text { Red del vino was formed in } 2004 \text {, by } 19 \text { small-scale producers in the } \\
\text { Colchagua Valley. The group was certified with FLOCERT in 2010. Red del } \\
\text { Vino has also promoted alternative forms of wine tourism. }\end{array}$ \\
\hline Caupolicán & $\begin{array}{l}\text { Viñas Caupolicán was originally founded by } 23 \text { all women small-scale } \\
\text { producers following grape price crashes in } 2007 \text {. The organisation was } \\
\text { certified with FLOCERT in } 2008 \text {. Its producers are based in the comuna la } \\
\text { Sagrada Familia, Curicó, Maule. }\end{array}$ \\
\hline $\begin{array}{l}\text { Agrícola } \\
\text { Vitivinícola } \\
\text { Loncomilla }\end{array}$ & $\begin{array}{l}\text { Cooperativa Agrícola Vitivinícola Loncomilla was formed in } 1959 \text { with } \\
\text { government support to assist small-scale farmers in Loncomilla, Maule. This } \\
\text { cooperative is certified with FLOCERT, supporting the small-scale grape- } \\
\text { producing members. }\end{array}$ \\
\hline Emiliana & $\begin{array}{l}\text { Viña Emiliana was established as one of Chile's first and largest organic } \\
\text { wineries. In 2011, Emiliana was certified with Fair for Life and in } 2012 \text { with } \\
\text { FLOCERT, these certifications cover the winery's hired labour. Emiliana has } \\
\text { vineyards in diverse regions of Chile, including in Colchagua and Casablanca. }\end{array}$ \\
\hline $\begin{array}{l}\text { Viña La } \\
\text { Fortuna }\end{array}$ & $\begin{array}{l}\text { Viña La Fortuna is located in the comuna la Sagrada Familia, Curicó, Maule. } \\
\text { The winery was one Chile's first wineries to become certified for organic } \\
\text { production. In 2009, La Fortuna became certified with FLOCERT under hired } \\
\text { labour. }\end{array}$ \\
\hline $\begin{array}{l}\text { Casas } \\
\text { Patronales }\end{array}$ & $\begin{array}{l}\text { Casas Patronales is a relatively new winery formed in 2001. It certified in } \\
2013 \text { with Fair for Life under hired labour. It has various vineyards in the } \\
\text { Maule Region. }\end{array}$ \\
\hline
\end{tabular}

Source: Elaborated by the author using primary information 


\subsection{COMPARATIVE DISCUSSION}

Chapters Four and Five have grounded the larger theories of the research by exploring the historical evolution of viticulture in the national case studies of Peru and Chile. These two chapters have therefore contributed to the first research aim by completing a comparative exploration of the historical evolution of the Peruvian and Chilean viticulture. In completing this, these chapters have provided focused historical study of Peru and Chile through the lens of viticulture. This exploration has highlighted the social, political and economic shifts in Peru and Chile and discussed the consequences of these shift for the two studied viticultural sectors. This closing part of this chapter begins with a comparative table which summarises the important transformations in the Peruvian and Chilean viticultural sectors over history (see Table 7 on the following pages). A brief discussion expands on the historical evolutions and transformations outlined in Table 7. 
Table 7 Transformations in the Peruvian and Chilean Viticultural Sectors over History

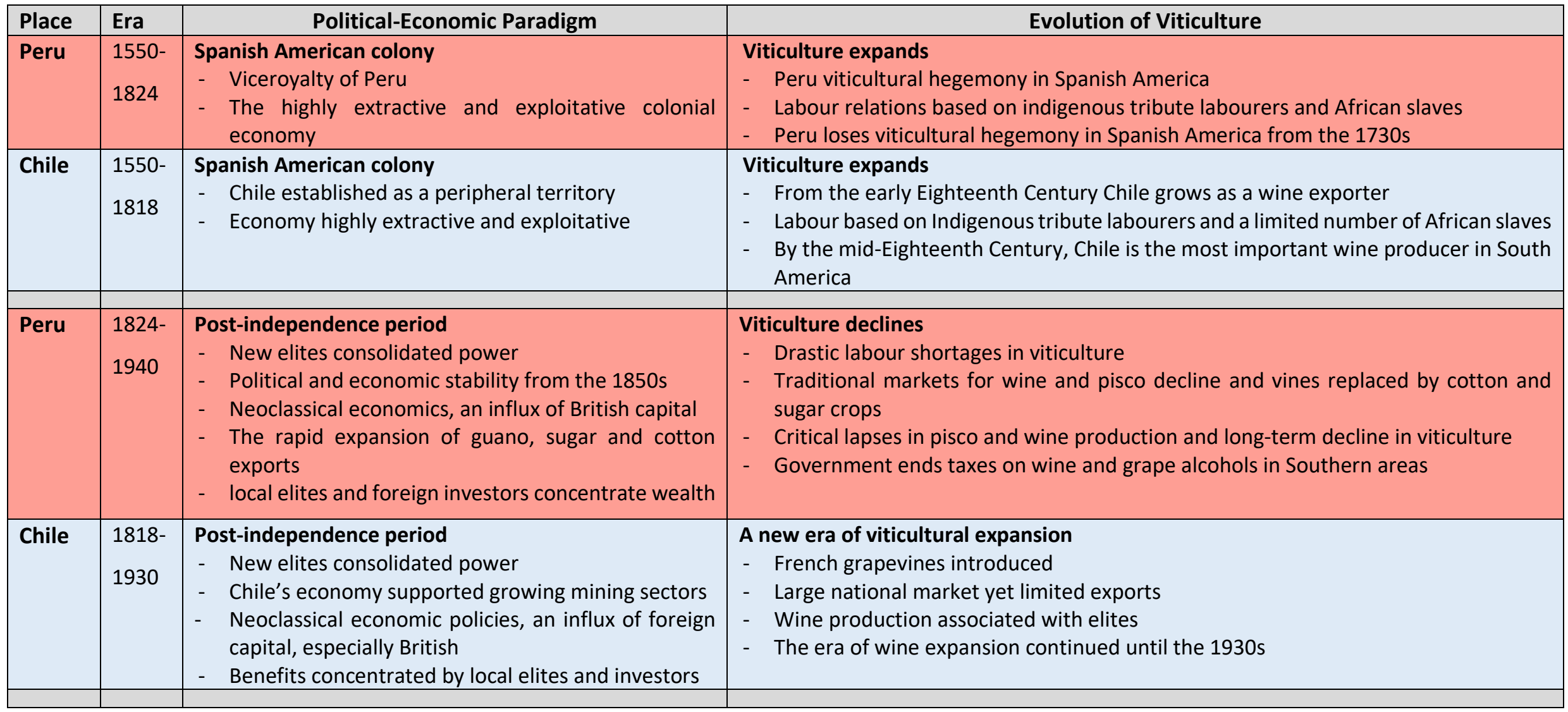




\begin{tabular}{|c|c|c|c|}
\hline Peru & $\begin{array}{l}1940- \\
1960\end{array}$ & 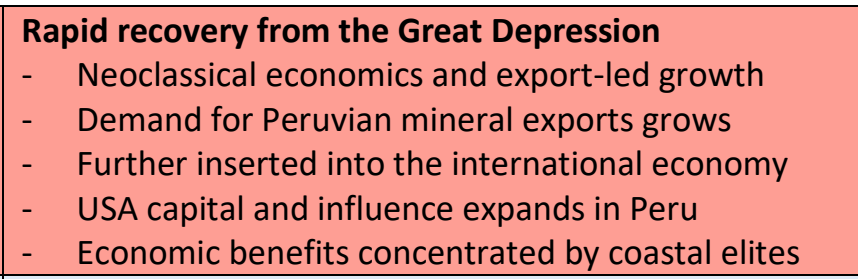 & $\begin{array}{l}\text { Some limited viticultural reactivation } \\
-\quad \text { New grapes from Europe and North America introduced from the } 1940 \mathrm{~s} \\
\text { - } \quad \text { Domestic markets for viticultural production expands } \\
\text { - } \quad \text { Responding to falling cotton prices, the government plans to invest in viticulture in } \\
\text { the mid-1960s } \\
\text { - } \quad \text { The government prohibits the expansion of cane alcohols in Southern Peru }\end{array}$ \\
\hline Chile & $\begin{array}{l}1930- \\
1973\end{array}$ & $\begin{array}{l}\text { Enters economic crisis, enters a period of State } \\
\text { intervention } \\
\text { - A shift from the dominant neoclassical economics } \\
-\quad \text { Structuralism and ISI dominate between } 1932 \text { and } \\
1973 \\
\text { - } \quad \text { Agrarian reforms and industrial nationalisation }\end{array}$ & $\begin{array}{l}\text { Period of limited wine production } \\
\text { - } \quad \text { Alcohol law of } 1938 \text { restricted wine production for almost } 40 \text { years } \\
\text { - } \quad \text { From the 1960s, agriculture impacted by agrarian reforms which redistributed } \\
\text { haciendas } \\
\text { - } \quad \text { Rural groups benefited but agricultural production stagnates } \\
\text { - } \quad \text { No major vineyards expropriated but private property rights threatened } \\
\text { - } \quad \text { Large wine estates deteriorated over this period of uncertainty }\end{array}$ \\
\hline Peru & $\begin{array}{l}1960- \\
1975\end{array}$ & 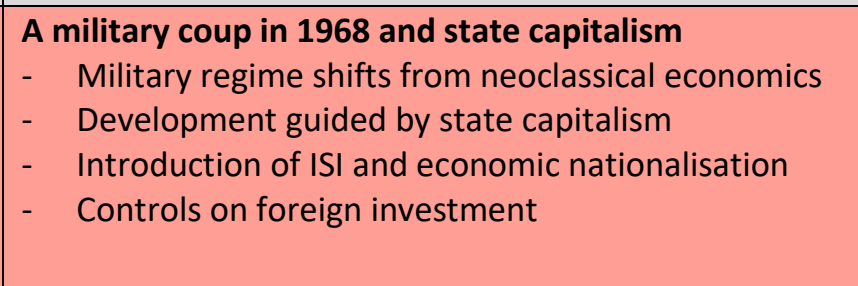 & $\begin{array}{l}\text { Viticulture enters contraction } \\
\text { - Agrarian reforms dismantled system of haciendas and wine and vineyard estates } \\
\text { disappear during reforms } \\
\text { - Producer cooperatives converted vineyards to sugar and cotton } \\
\text { - The wine and pisco industry practically disappeared } \\
\text { - While rural populations benefited from the reforms, agricultural overall stagnated }\end{array}$ \\
\hline
\end{tabular}




\begin{tabular}{|c|c|c|c|}
\hline Peru & $\begin{array}{l}1975- \\
1990\end{array}$ & $\begin{array}{l}\text { End of state capitalism and return to democracy } \\
\text { - Peruvian economy overburdened in debt } \\
\text { - The second coup of 1975, shift to free-market } \\
\text { policies } \\
\text { - Elections in 1980, democratic governments fail to } \\
\text { resolve conflict or economic strife between } 1980 \\
\text { and } 1990\end{array}$ & $\begin{array}{l}\text { Viticulture remains in a period of contraction } \\
\text { - } \quad \text { The sectoral contraction continues from the } 1970 \text { s until late } 1990 \text { s } \\
\text { - } \quad \text { Viticulture unable to recover from the negative impact of agrarian reforms } \\
\text { - } \quad \text { Recovery very difficult during economic stagnation and civil conflict } \\
\text { - } \quad \text { Peru declares pisco as national cultural heritage of Peru }\end{array}$ \\
\hline Chile & $\begin{array}{l}1990- \\
2010\end{array}$ & $\begin{array}{l}\text { Return to democracy } \\
\text { - The victory of Concertación centre-left parties in } \\
1988 \\
\text { - From 1990-2010, four Concertación administrations } \\
\text { govern } \\
\text { - Concertación governments retain the neoliberal } \\
\text { model, yet with an emphasis towards growth with } \\
\text { equality and neostructural policies }\end{array}$ & $\begin{array}{l}\text { Viticultural production and exports expand } \\
\text { - } \quad \text { Pro-business and investment and policies fuel growth in viticulture } \\
\text { - } \quad \text { Chilean wine exports boom following the return to democracy } \\
\text { - } \quad \text { From 1990, export strategy shifts from bulk cheap wine to higher value-added wine } \\
\text { - } \quad \text { Production and exports concentrated by a small minority of very large producers } \\
\text { - }\end{array}$ \\
\hline Peru & $\begin{array}{l}1990- \\
2010\end{array}$ & 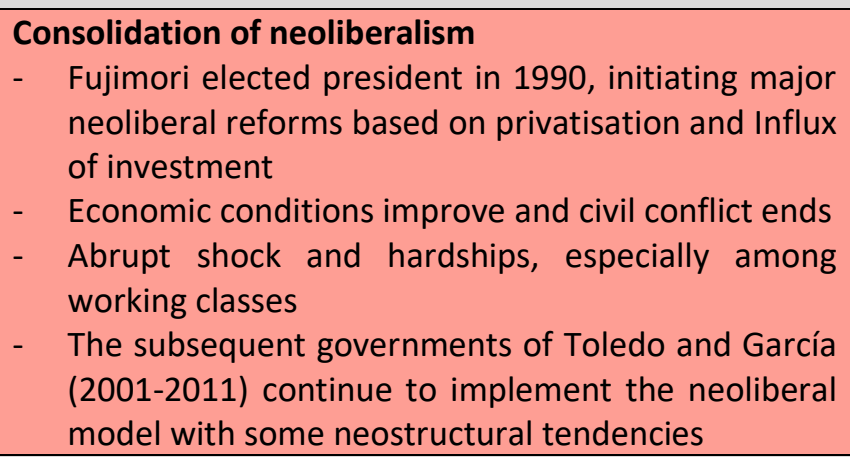 & $\begin{array}{l}\text { Reactivation of viticulture } \\
\text { - } \quad \text { Neoliberal policies created uneven consequences in rural areas } \\
\text { - } \quad \text { Exporters grew while domestic-oriented producers stagnated } \\
\text { - } \text { expoval of land ownership restrictions allows large-scale producers to re-purchase } \\
\text { - Peruvian States declares Peruvian DO for pisco in } 1990 \\
\text { - Peru government implements a number of legal changes and establishes } \\
\text { - } \quad \text { Betwanisations to protect pisco and improve the sector } \\
\text { - } \quad \text { Inequalities as the reactivation of viticulture proves exclusive }\end{array}$ \\
\hline
\end{tabular}




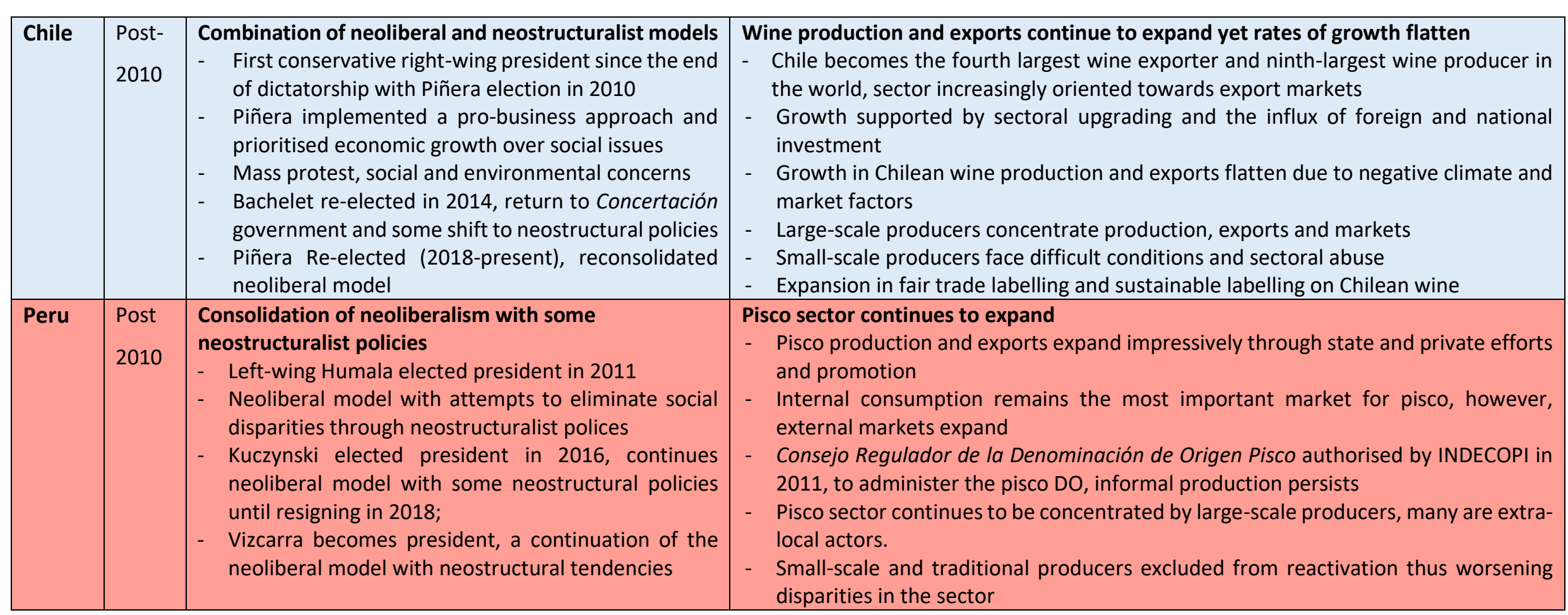

Source: Elaborated by the author 
As presented throughout Chapters Four and Five, the comparative historical exploration has revealed a number of similarities but also important differences between Peruvian and Chilean viticulture. In doing so, these chapters have provided an important lens for comparing the wider histories of both countries which have resulted in rural socio-economic disparities relevant to this study.

A discussed, through the colonial period similar extractive and exploitative economies, were maintained by the Spanish in both Peru and Chile. However, there were also differences as Peru was established as a colonial centre while Chile remained peripheral. Over this period, viticulture expanded through both colonies. Peru became the Spanish American wineproducing hegemon until the 1730s. During the Eighteenth Century, Peruvian viticulture declined and Chile became the region's most important wine producer.

Following independence, Peruvian and Chilean viticulture experienced different transformations. In Peru, viticulture declined in the context of political-economic instability. Similarly, Chile experienced a certain degree of instability, however, this largely subsided due to export growth in minerals and agriculture. In Peru, the political-economic situation improved from the mid-Nineteenth Century under a neoclassical model. During this period, viticulture continued to decline as other export crops expanded. Like in Peru, a neoclassical economic model of export-led growth dominated post-independence Chile. Chilean viticulture entered a period of continual expansion.

Between 1940 and 1969, Peruvian viticulture experienced slight reactivation. Chile conversely, entered into crisis during the Great Depression and emerged in the late-1930s with a developmentalist state. This was largely a challenging period for Chilean viticulture, which entered a 35-year period of limited production. From 1968, Peru shifted towards a similar period of state capitalism following a military coup. Peruvian viticulture entered 30 years of contraction.

In 1973, the Chilean military ousted a socialist government and initiated a period of widespread neoliberal reforms. The neoliberal reforms had some positive outcomes in the wine industry, yet these were felt unevenly; generally favouring the larger-producers oriented towards external markets. Peru's developmentalist state was ended in 1975 through a second military coup. Statist policies were abandoned and moderate free-market strategies were implemented. This second junta failed to alleviate a debt crisis and there was a return to democracy in 1980. The social and economic crisis worsened during the civilian governments between 1980 and 1990, as a violent civil conflict erupted from 1980 and the economy further deteriorated. Over the 1970 s and 1980 s, Peruvian viticulture continued to retract. 
Chile returned to democracy in 1990. Four successive civilian governments from the centre-left alliance Concertación, governed between 1990 and 2010. While these governments placed more emphasis towards equality, the core principles of the neoliberalism remained dominant. Chilean wine experienced unprecedented levels of growth in production and exports following the transition to democracy. During the 1990s, Peru entered a new period of sweeping neoliberal reform, reversing the remaining statist policies. Subsequent governments during the 1990 and 2000s continued to implement a neoliberal approach. Following 30 years of contraction, Peruvian viticulture was a stagnated sector by the time neoliberal policies were implemented. It was not until the early 2000s that Peruvian viticulture began to reactivate with increased government support, creating the conditions for growth under neostructural policies.

In Chile, wine exports and production continued to expand from 2010. From 2010, neoliberal policies with neostructural tendencies have dominated Chile's political-economic environment. Under these conditions, Chile's wine production and exports have continued to expand, despite some levelling of these trends in the last five years. Over this period, Chile's viticultural sector has remained concentrated by a small number of large wine producers. This oligopolistic nature has been unfavourable towards smaller-scale producers and workers and explains some of the reasons for implementing fair trade certification in the wine sector.

Peru's pisco and wine sectors have continued to expand as the country enjoyed a relatively stable political-economic environment since 2010. Successive governments implemented neoliberal policies with varying neostructural tendencies. Under the relatively stable conditions, pisco grew impressively in production, national sales and export value. However, despite an overall recovery, the sector has become characterised by growing inequalities and concentration in production and market access.

\subsection{LINK TO CHAPTER SIX}

The following chapter, Chapter Six; 'Mapping Ethical Value: Motivations, Governance and Power in Chilean and Peruvian Viticulture' will now explore the formation and institutionalisation of the EVeNs surrounding the fair trade certification in Chilean wine and the DO mark on pisco from Peru. Chapter Six mainly draws from the findings from primary interview data, although links to relevant literature and earlier chapters of this thesis are made throughout. 


\section{CHAPTER SIX. MAPPING ETHICAL VALUE: MOTIVATIONS, GOVERNANCE AND POWER IN CHILEAN AND PERUVIAN VITICULTURE}

\subsection{CHAPTER INTRODUCTION}

This chapter explores the formation and institutionalisation of the ethical value networks surrounding the fair trade certification in Chilean wine and the designation of origin (DO) mark in Pisco from Peru. Its purpose is to contribute to research aim two: to critically investigate the construction of, participation in, and governance of EVeNs using examples from the fair trade and DO networks in viniculture in Chile and Peru. This chapter engages with primary data from research interviews and their analysis and applies the first two parts of the FII framework (Formation, Institutionalisation and Idealisation) devised by this research to examine the studied EVeNs. This chapter, therefore, discusses the formation of the studied EVeNs, including the key motivations which led to the evolution of these networks. Correspondingly, the chapter concentrates on the institutionalisation of the two studied EVeNs. The chapter has been structured by the two case studies. First, the chapter explores the formation and institutionalisation of the fair trade wine EVeN in Chile. The chapter then examines the formation and institutionalisation of the DO pisco EVeN in Peru. It closes with a discussion which compares the formation and institutionalisation of each case study and provides a link to Chapter Seven, 'Evaluating Ethical Value: Critical Investigation of Ethical Claims and Local Outcomes' which examines idealisation of the studied EVeNs. Chapter Seven, therefore, expands on the explanations of the formation and institutionalisation of the studied fair trade and DO EVeNs provided in Chapter Six to discuss the impact of these networks in Chile and Peru.

\subsection{FORMATION OF ETHICAL VALUE NETWORKS}

As discussed in Chapter Three, this thesis contributes to the project of a wider research team consisting of Warwick Murray, John Overton, Kelle Howson and I. Our research has theorised that the globalisation of agro-food systems has led to the rapid expansion of diverse EVeNs linked to ethical product labelling. Our research has shown that different EVeNs have expanded in response to growing concerns among Global North consumers over the negative social, health, environmental, and quality impacts that the globalisation of agriculture is causing, particularly when production is embedded the Global South. As explained in Chapter Three, we have defined EVeNs as value networks which emphasise and certify ideas of ethical and high-quality production and consumption such as fair trade labels, organic or sustainable certification, and geographical indication marks. Our research argues that despite the 
expansion of these EVeNs, critical exploration of where these networks are embedded however remains understudied. This research, therefore, attempts to contribute to filling this knowledge gap through two case studies.

This chapter seeks to better explore the formation and institutionalisation of the two case study EVeNs, fair trade wine in Chile and DO pisco in Peru. To complete this, the chapter examines the motivations for, the construction of, and participation within these EVeNs, by drawing from primary data from interviews undertaken in the selected field study areas. Connections with key literature are made throughout the chapter.

\subsection{FORMATION OF FAIR TRADE WINE EVEN IN CHILE}

The formation of the EVeN based on the use of fair trade certification in the Chilean viticultural sector was motivated by seven key factors. These factors appeared across multiple research interviews, including with producer and expert groups. These factors were:

1. Commercial factors and business opportunities for Chilean wine producers

2. The search for new external markets for Chilean wine

3. Growing consumer demand for fair trade wine in Northern markets

4. Responding to inequalities in the Chilean wine sector

5. Contribution to the social responsibility programmes of Chilean wine producers

6. The search for market differentiation and access for small-scale wine and grape producers in Chile

7. Attempt to escape grape market dependence for smaller-scale wine and grape producers in Chile

The subsequent sub-sections will now systematically discuss these seven factors using findings from the research interviews.

\subsubsection{Commercial Factors and Business Opportunities for Chilean Wine Producers}

Interviews with producers, national experts and certifiers have demonstrated that commercial interests have been influential in the construction and expansion of the fair trade EVeN in Chilean wine, especially in the case of medium to larger scale producers which have certified lines of their production. For instance, Alex Fuentealba Commercial Director at Casas Patronales, a large-scale winery with Fair for Life certification stated;

"We received the [Fair for Life] certification four years ago, the truth is that we started this with a commercial vision, we didn't know a lot about this certification but our importers from Scandinavia asked us about possibility of using it [...] after 
we understood what the fair trade certification included we realised that we were very in line with these ideas...."

Similarly, Marietta Montenegro from Vineyard Emiliana, a large-scale wine producer with fair trade lines explained that;

"When we started using these certifications [...] the company did not know about these certifications and we saw them as a business opportunity. We investigated and we learnt about the principles of fair trade [...] and as we are a company which is very concerned about our workers and our social responsibilities, we thought that it all sounded perfect..."

These two examples highlight that fair trade certifications were explored as business opportunities however that there was also some alignment with the principles of these companies and fair trade. These findings are linked to attempts made by Chilean wine producers to upgrade their positions in the international market by searching for higher-end niche markets. This has represented a move away from the neoliberal bulk model and demonstrated a shift to neostructural thinking, as discussed in Chapter Five. However, these commercial factors also highlight a significant risk experienced within EVeNs. This risk is associated with how capital operates within these networks to appropriate the ethical value created. For instance, in the case of fair trade wine in Chile, there has been a clear insertion of larger-scale and high-end wine exporters which have entered the ethical niche market. These corporate actors have entered into the fair trade wine network as the ethical value created in this network represents an opportunity for profits. By exploiting this opportunity for profit, these corporate wine exporters are appropriating the ethical value intended for smaller-scale and more disadvantaged producers in the network.

\subsubsection{The Search for New External Markets for Chilean Wine}

A clear motive for entering the fair trade wine EVeN was the search for new external markets as certifications are generally not used for wine sold in the internal Chilean market. The Northern European markets have been particularly important due to the government monopolies in alcohol imports and distribution. As described by Karene from Fair for Life certifier Institute of Marketology (IMO) in Chile;

“...there are governmental monopolies on imports in Europe, which demand ethical wines and do not import wines that do not have ethical labelling. This includes the Danish, Swedish, and Finnish markets. These monopoly wine buyers have been very 
important markets for wines with ethical characteristics and have pushed the demand for certified wines here."

Gabriela Negrete from Montes Wines (a large-scale winery with a fair trade line) explained this from a wineries view; "We started to certify ourselves with fair trade as it is a good tool to promote our wine in the Nordic countries, this was the push factor to start using this certification..." Entry into Nordic and other European markets were stated to be the main reason for the growing use of fair trade and similar certifications. The national market was perceived by most research participants to neither understand nor demand fair trade certified production. As described by Gerardo Wijnant, sustainability and fair trade consultant from Chile, there is however potential to create local demand for fair trade certified products;

"The demand for fair trade products is stronger particularly in Europe, but also in the USA, Canada, New Zealand, and Australia. There is a greater number of responsible consumers that are worried about the production chain in those regions. In Chile, there is a tendency towards this [...] but this has not been taken advantage of."

Raúl Navarrete, General Manager at the grouping of fair trade certified small-scale producers Vinos Lautaro, highlighted this organisation's early focus on entering external fair trade niche markets;

"We started the company with the aim of exporting, this allowed us to enter an international niche market with better prices and fairer commercial relationships, and we defined our core principles around targeting the fair trade niche market in Europe."

The search for new external markets for Chilean Wine is associated with the growing orientation towards higher-end export markets, as discussed in Chapter Five.

\subsubsection{Growing Consumer Demand for Fair Trade Wine in North Markets}

The interviews in Chile also revealed the important role of the consumer, in the Global North, in driving the $\mathrm{EVeN}$ in fair trade Chilean wine. As mentioned by Marietta Montenegro, “...more consumers have realised that they have massive power when they purchase something and this segment is using this power to choose ethical options." This idea of consumer influence was also explained by Karene from Institute of Marketology;

"...consumers want to buy something that does not include discrimination, bad working conditions, child labour, they want producers and workers to receive a fair 
price [...] the consumer at the end is willing to pay more for something when they know is not harming other people."

Pablo Lacoste, director of American Studies at Universidad de Santiago, linked these ideas to the Chilean wine sector stating that; "Chilean wines will have to increasingly adapt to the ethical demands of the market..."

The growing demand for fair trade certified Chilean wines is associated with the broader changes in consumer preferences, particularly in the Global North, towards ethical products as described in Chapter Three. It is worth noting that certified fair trade wine produced and sold in Chile is usually sold without any fair trade labelling. This demonstrates that fair trade wine continues to represent what Jaffee et al. (2004) identified as 'far trade' despite the growing middle-classes in countries such as Chile which have the financial capacities to purchase ethically labelled products.

\subsubsection{Responding to Inequalities in the Chilean Wine Sector}

Although external demand tended to be cited as the main motivation for the formation of the fair trade EVeN in Chilean wine, internal factors were also identified as contributing to the expansion of this network. For example, Álvaro Muñoz from the cooperative of small-scale producers Cooperativa Vitivinicola Loncomilla explained the need for fair trade in the Chilean wine industry due to the industry's concentration by powerful actors;

"In Chile, there are three very important wine producers which use their size to abuse the smaller producers [...] these three control the prices of the grape market [...] they all continue to pay less and less and have dropped the price to one that is not fair [...] There are a lot of injustices in the sector..."

Similarly, Rodrigo Constandil from Miguel Torres Wines, a large-scale producer with a line of fair trade wine, demonstrated that the internal inequalities of Chile's wine sector justified the need for fair trade certification;

“...there are high levels of inequality that exist in Chile, especially between the large companies and the small-scale primary producers. The primary producers are paid very little for their grapes [...] sometimes these producers are paid as little as 30-50 pesos per kilo, which does not even cover the costs of the harvest [...] Therefore, there is a need for fair trade because the Chilean wine industry is unfair."

Yenny Llanos from the Coalición Nacional de Viñateros de Chile, a union of small-scale grape producers, described the vulnerable position of the grape producers in Chile; "There is no a relationship between the grape producers and the buyer, there is just abuse. The buyer sets a 
low price and the producer has to accept this, they do not have any power to negotiate." Jaime Roselló from Acróbata Wines (medium-scale) made a related observation, connecting the inequalities in Chile with the demands of the international consumer for fair trade certifications;

"Chile is a very uneven country, where few people are owners of almost everything and it very easy for them to abuse the small guys. The roots of fair trade do not come from Chile but from abroad, international consumers know about the problems here and want fair trade to be used in Chile."

In 2015, a group of small-scale grape producers disaffected with the price offered on the grape market decided to give away their grape production to the general public in Chillán, in the Bío Bío Region in protest (see Figure 27).

Figure 27 Small-Scale Grape Producers in Bío Bío Region Protest Low Grape Prices in Chile

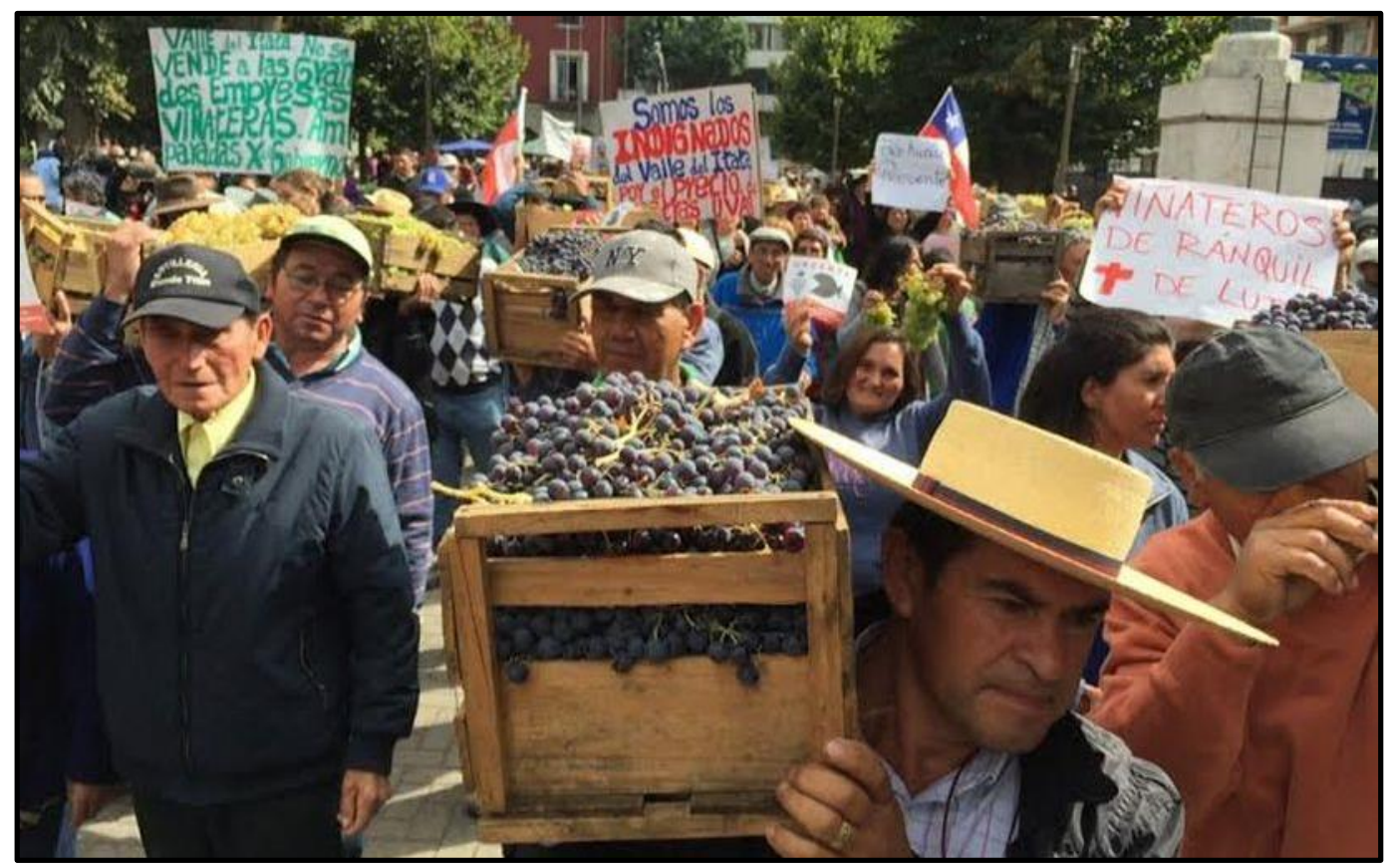

Source: (Tribuna del Bío Bío, 2015)

Lionel Valenzuela, director of the Department of Commercial Engineering at the Universidad Técnica Federico Santa María saw fair trade as a way of responding to some of the abuses in Chile's productive industries; "There are mafia-style abuses in Chile in various industries, therefore fair trade comes as an equilibrium as a way to share the benefits."

The exploitation of the small-scale grapes producers results from the wider socio-economic disparities in Chile's agricultural sector (as described in Chapter Five) and in Latin America in general. The rise of fair trade in Chilean viticulture has therefore, in part, been motivated by growing awareness amongst external consumers of the unfair conditions faced by small-scale 
producers in Chile. In the Chilean context, small-scale grape and wine producers usually experience levels of dependence on larger-scale producers which possess better grape and wine processing technologies and expertise, as well as better access to retail markets. Nonetheless, government programmes in the last 20 years have attempted to ease this dependence by encouraging technology, innovation and expertise sharing with certain groups of small-scale grape and wine producers. This said, the groups involved in these kinds of programmes remain limited and outside of these government programmes, technology and expertise sharing between private large-scale producers and their smaller-scale counterparts tend to be uncommon. As a result, smaller-scale producers continue to depend on powerful larger-scale wine producers and grape buyers. In this context of dependency, it easy to understand how the larger-scale corporate actors, who possess better technologies and expertise, are able to concentrate the value created.

\subsubsection{Contribution to the Social Responsibility Programmes of Chilean Wine Producers}

Interviews also revealed a level of social responsibility in some of the wineries and a commitment to the production areas where the value networks were embedded. Jimena Acuña from the Chilean governmental Instituto de Desarrollo Agropecuario ${ }^{32}$ (INDAP), explained this point, stating that the use of fair trade, "...is also due to the wishes and orientations of the owners of the wine producers [...] this is to say that there is a genuine preoccupation for developing socially sustainable businesses."

Eduardo Aragones a wine aficionado and industry expert, highlighted through the case of Miguel Torres, that the use of fair trade displays more connection and commitment with the locality where wine is produced;

“... it is a very large Spanish company [...] the fact that they buy with fair trade shows me that they highly value the establishment of themselves in the area [...] I believe that the fair trade certification shows their social commitment with this locality. If we compare this with Concha y Toro [...] I do not see this kind of commitment."

A comment from Rodrigo Constandil from Miguel Torres demonstrated that the company's social commitment is used as a point of difference;

“...we searched and decided to certify ourselves because the reality of our company was different to other companies and this made us distinct, but this was something

32 Institute for Agricultural Development. 
we were not displaying [...] our wine has a point of distinction to do with our social and environmental responsibility..."

Other participants from companies made similar statements, for example Germán López from the La Fortuna (fair trade certified large-scale winery), mentioned that the fair trade certification helped to boost recognition for the social projects that the vineyard is involved in; "In many cases this good work is not recognised, the company completed social projects and provided benefits to the workers but no one knew about this and the certification helps to show this."

\subsubsection{Search for Market Differentiation and Access for Small-Scale Wine and Grape Producers} in Chile

When studying the motivations of smaller producers for entering the fair trade wine EVeN there are some obvious cross-cutting ideas but also diversity in comparison with the motivation of larger companies. There has been a clear desire by small-scale producers and producer cooperatives in Chile's wine sector to differentiate their products and enter niche markets. Cooperatives formed by small-scale grape and wine producers were discriminated against and most became bankrupt during the years of the Pinochet regime. The small-scale producers who managed to endure this dictatorship currently suffer from the low grape prices offered in the conventional market. Primary interviews revealed that these low prices often fail to pay the costs of production or generate enough income to support the families of these small-scale producers. Fair trade was often seen to represent the only certification they these producers could use to differentiate their production and support them to escape the cycles of low grape prices and hardship. For instance, Rodrigo Valenzuela from the grouping of fair trade certified small-scale producers Red del Vino in Colchagua summarised this, stating that; "We saw that fair trade was the only way that we could differentiate ourselves." Daniella Gac, PhD researcher in sociology at Universidad De Los Lagos expanded on this point, explaining that;

“... small-scale producers are searching for ways to enter international markets, look at alternatives such as organic production, fair trade [...] The logic behind groups like Red del Vino, is that they cannot compete against large wine producers that are already in international markets [...] instead these smaller producer groups have found opportunities through [...] certifications like fair trade, to insert themselves in alternative commercialisation networks..."

Global value chain (GVC) literature discusses how entering niche markets through standards such as fair trade has improved the participation for some small-scale producers in diverse value chains (Hughes et al., 2008; Humphrey, 2008). 
Daniela Acuña from the governmental agency Oficina de Estudios y Políticas Agrarias ${ }^{33}$ (ODEPA), mentioned that fair trade certification can be used by producer cooperatives to display their campesino production and use this to create a point of differentiation; “...cooperatives see fair trade as a way to expand their business and to benefit the group by differentiating themselves and emphasising that they represent campesino production." This fair trade certification can also be seen as an innovation for smaller-scale producers to allow them to compete and survive in the global market. As explained by Fabiola Argandoña who completed her PhD in Administration Science at the Universidad de Santiago de Chile;

“...the only way for these grape growers and small winemakers to survive and compete against the large companies is by differentiating themselves through innovation [...] fair trade wine has an element of innovation that a conventional wine does not have [...] it is a way to differentiate and [...] to survive in the market."

Upgrading is discussed in GVC literature to refer to the possibilities an actor has to improve their position in the chain to receive better returns on their production (Bolwig et al., 2010). fair trade has therefore been seen as a potential avenue for the upgrading of upstream production actors in the EVeN in Chilean wine. As mentioned, a significant challenge for these small-scale producers involved in the fair trade wine EVeN is the growing participation of larger-scaler producers in this network. This involvement continues to diminish the opportunities for these small-scale producers to differentiate their production and access to fairer markets.

\subsubsection{Attempt to Escape Grape Market Dependence for Smaller-Scale Wine and Grape Producers in Chile}

In the cases of the smaller-scale producers and producer cooperatives, fair trade is being used to ensure the survival of these producers. In these cases, fair trade is perceived as the only option or one of the very few options that these producers have. As explained by Gonzalo Rojas, acting director at Director of Wine Tourism at Universidad de Talca in Colchagua;

"...the motivation for small-scale producers to use fair trade certifications is that if they don't do this they will disappear, they are searching for a way to survive. Fair trade [...] is the only option that the small-scale producers have to survive..."

Interviews with small-scale grape producers found similar results. For instance, Nora, a smallscale grape producer and member of the cooperative Esperanza para la $\operatorname{Costa}^{34}$, noted that:

33 Office for Studies and Agricultural Polices.

${ }^{34}$ Hope for the Coast. 
"fair trade is the best way to sell, in fact, it is the only way to sell [...] there was no alternative for us, the conventional market did not pay us a fair price..." Likewise, Teresa Cañete from the grouping of fair trade certified small-scale producers Viñas Caupolicán repeated this idea "The grape prices in the traditional market in Chile are not sufficient or fair, to be able to receive fair price the producers need to certify themselves..."

Victor Aguilera commercial manager at Vinos Lautaro made a similar point;

"...if they are producing grapes and they are not fair trade certified these producers will not have much of a future [...] there is only so long that grape producers can cope for under the current conditions [...] majority of years the price for the grapes are below the costs of production for the small producers."

Interviews with grape producers showed that they were motivated to use fair trade as it provided them with price stability that they did not experience in the conventional market. José a small-scale grape producer using fair trade certification and partner of Viñas Caupolicán, explained the importance of this stability in his case; "Fair trade regulates the grape price, I believe this is good because it gives us a base price and more security [...] while this price will not go up a lot, it also will not drop..." Luis, another small-scale grape producer and partner of Viñas Caupolicán, discussed his experience with using fair trade certification;

"I am not at the mercy of the grape buyers; as an association we produce [...] wine, and sell this with the security of a fair price. If I was not in the group and I did not have fair trade, I would be at the mercy of the market, one year I may be able to sell for a good price but the next year I could be in trouble [...] the fair trade premium is added to the agreed price, this premium helps us a lot..."

Gerardo Orellana, president and producer from Red del Vino supported these ideas and emphasised the importance of fair trade in helping the development of fairer and more sustainable businesses; "Fair trade is a more sustainable way of doing business, it considers the producers and ensures that they receive a minimal fair price for their product..."

These cases have demonstrated that small-scale producers have entered the fair trade EVeN as a means of escaping the challenges of the conventional viticultural sector in Chile. These challenges included grape price fluctuations and grape price setting by the largest-scale wine producers as discussed in Chapters Three and Five. Therefore, their motives have been based on survival as producers and to receive fairer and more stable prices. The stability and the commitment to the long-term are also very important for the producers working under fair trade. As explained by Gerardo Wijnant; 
"The fair trade price is not much better but the commitment to the long-term and the stability is more valuable for the producers [...] if I am more respected as a producer, I can form a long-term commercial relationship and I can live a more stable life."

Despite these motives for entering fair trade certification, small-scale producers face administrative and financial barriers in receiving these certifications, as described in Box 1 below and discussed in greater detail in the following chapters.

\section{Box 1 Process for Receiving Fair Trade Certification}

Although there are differences between the FLO Fairtrade and IMO Fair for Life certifications implemented in the fair trade Chilean wine case study, the processes for receiving both of these certifications are practically the same. The certification process involves both administrative and financial commitments which can be challenging for some producer groups. The certification process begins with the administrative task of applying for the certification. After applying for certification, all producers, cooperatives and companies must pass an initial independent on-site audit before receiving the Fairtrade or Fair for Life certification. In both cases, an initial audit report is sent after the on-site audit to FLOCERT or IMO, to be evaluated. In some cases, the applicants will need to make some changes to successfully receive the certification. Once the Fairtrade or Fair for Life certification is granted, the cooperative or company will enter a three-year certification cycle. Over this period, two confirmation audits will take place. FLOCERT or IMO monitor routine data through these audits, including the funds received and paid (including the fair trade premium). In addition to the confirmation audits, the certifiers can complete spot audits. An audit before the certification can be renewed is completed during the third year. If the renewal audit is successful, the certifiers issue a new certification and a new three-year certification cycle starts (Fair for Life, n.d.-a; FLO International, n.d.). The certifications are therefore associated with a level of administration and data recording often new and challenging for small-scale producer groups. Although cooperatives pay less than plantations, interviews revealed that the certification represent a significant financial cost and administrative challenge for these producers. The financial costs of certifications are demonstrated in Table 8 below. 
Table 8 Costs of Fair trade Certification (FLOCERT):

\begin{tabular}{|l|l|}
\hline \multicolumn{2}{|c|}{ 1st Year Fairtrade Certification Cost } \\
\hline Cooperative & Plantation/Hired Labour \\
\hline Application Fee (approx.) $€ 550.00$ & Application Fee (approx.) $€ 550.00$ \\
\hline Certification Cost (approx.) $€ 1,505.00$ & Certification Cost (approx.) $€ 2,145.00$ \\
\hline Additional Fees (approx.) NA & Additional Fees (approx.) $€ 1,805.00$ \\
\hline \multicolumn{2}{|c|}{ Fairtrade Certification Cost (Year 2 and following) } \\
\hline Cooperative & Plantation/Hired Labour \\
\hline Certification Cost (approx.) $€ 1,230.00$ & Certification Cost (approx.) $€ 1,690.00$ \\
\hline Additional Fees (approx.) NA & Additional Fees (approx.) $€ 1,325.00$ \\
\hline
\end{tabular}

Source: Elaborated by the author using data from (FLOCERT, n.d.). Note: The costs for Fair for Life certification vary widely depending on the size and complexity of the applicant's operations, the location, and if the applicant already holds an organic or similar certification with IMO (Fair for Life, n.d.b).

\subsection{INSTITUTIONALISATION OF ETHICAL VALUE NETWORKS}

To explore the institutionalisation of the studied EVeNs this chapter applies a combination of both GVC and GPN analysis. As discussed in Chapter Two, both GVC and GPN analysis apply 'maps' which can be used to understand the complexities of the global value production networks (Gereffi et al., 2005). However, this research argues that new methods are required for GVC and GPN mapping. These original diagrams have been created in this thesis to explore the institutionalisation of the studied EVeNs; these have been labelled as 'EVeN maps', which contribute to new methods in GVC and GPN mapping.

The EVeN maps developed in this chapter start by following the value chain structure of studied networks, thus identifying the different segments of each value chain as the single products (wine and pisco) move through their trajectories from conception (grape production) through to the end-use (the consumption of wine or pisco). These value chains are used to reveal the key firms and the linkages at each stage of the products' trajectory (Gereffi \& Fernandez-Stark, 2011).

The EVeN maps presented here have extended from this initial exploration of the studied EVeNs through GVC analysis, including ideas from GPN analysis. As discussed in Chapter Two, GPN follows from ideas of GVC to include contributions from actor network theory, thus placing more importance on non-firm actors and their decisions (Henderson et al., 2002). Consequently, the EVeN maps include the non-firm actors, such as local communities, government organisations and private groups that are involved with the studied EVeNs (Coe et al., 2008). By referring to the maps, these sections seek to explore the governance and power in the studied EVeNs. Governance according to Gereffi and Lee (2012, p. 25); 
“.... is the centerpiece of GVC analysis. It shows how corporate power can actively shape the distribution of profits and risk in an industry, and the actors who exercise such power through their activities. Within the chain, power is exerted by lead firms."

Figure 28 Five Types of Global Value Chain Governance

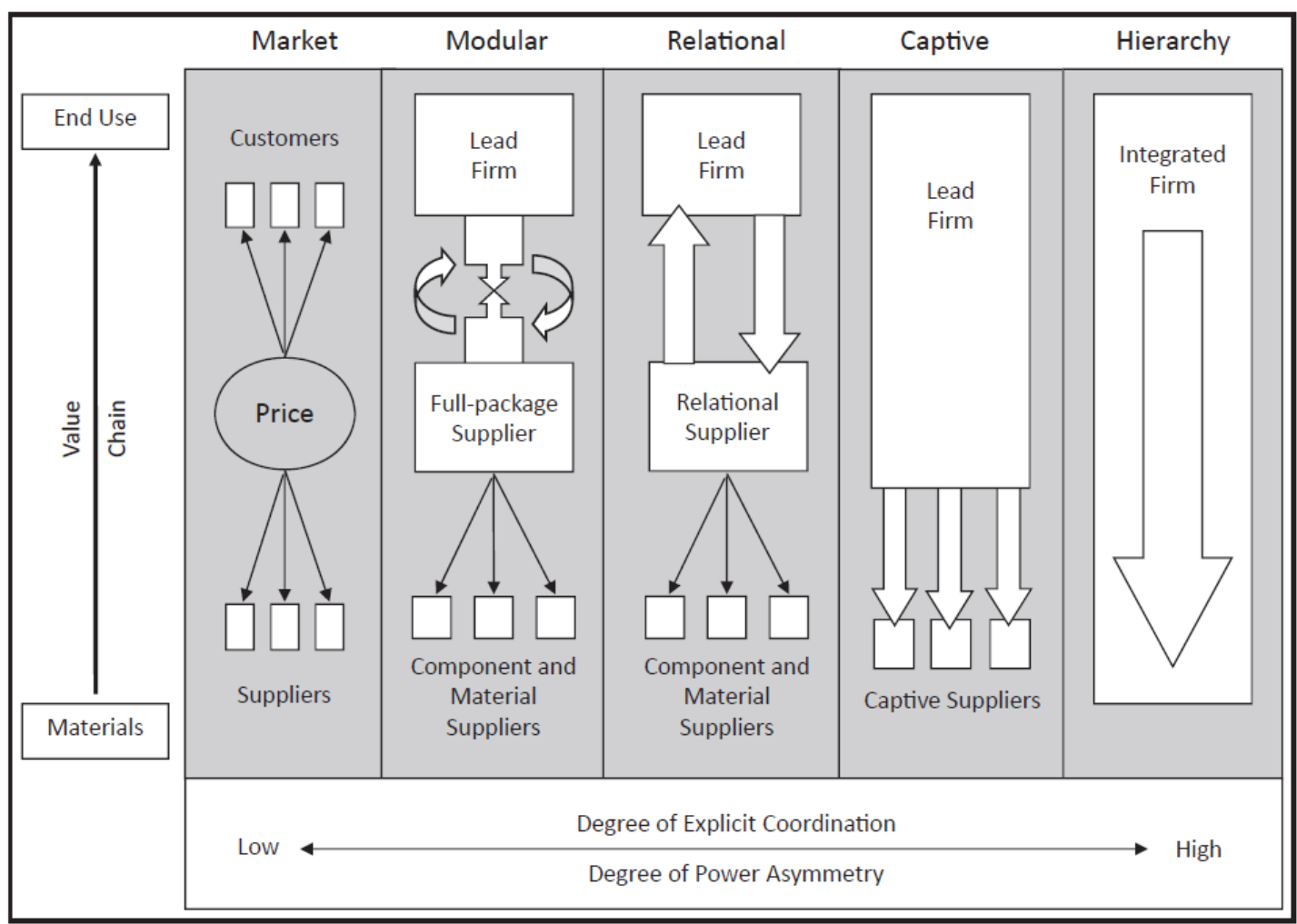

Source: (Gereffi et al., 2005).

Five forms of global value chain governance have been outlined in GVC literature; market, modular, relational, captive and hierarchy (Gereffi \& Fernandez-Stark, 2011). As demonstrated in Figure 28 above, these five forms of governance share power differently. In the following section, the forms governance of the studied EVeNs will be identified. These sections will also include contributions from GPN by focusing on the importance of non-firm actors and the larger networks surrounding ethical labels and production (Coe et al., 2008). Re-engaging with the dependency and world-systems theories, as well as GVC/GPN approaches, these sections will also demonstrate the ways in which powerful actors have been able to capture the ethical value created in the studied EVeNs.

\subsection{INSTITUTIONALISATION OF FAIR TRADE WINE EVEN IN CHILE}

This section applies EVeN maps as described above and presents key findings from the research interviews to explore the institutionalisation of the fair trade wine EVeN in Chile. After the completion of this sector, the chapter will shift the focus onto the formation and 
institutionalisation of the DO pisco EVeN in Peru. Subsequently, the chapter will include a comparative discussion which will compare and contrast the two case studies and link to broader themes of the thesis. 
Figure 29 Fair Trade Ethical Value Wine Network in Chile

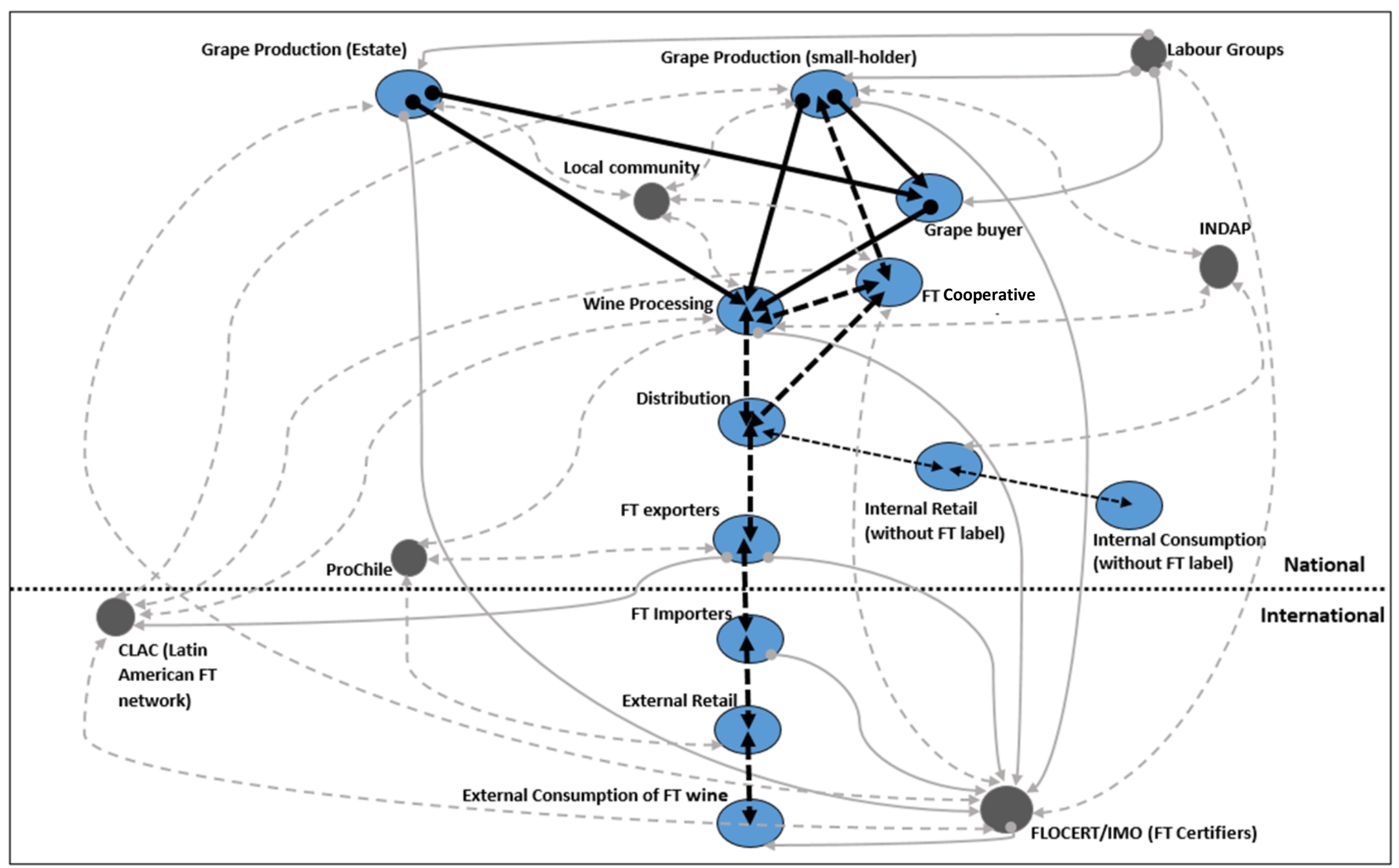




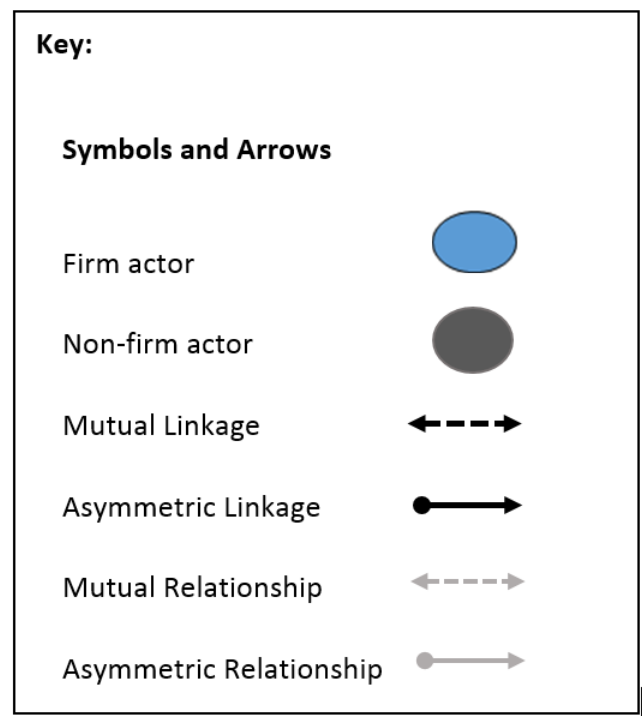

Source: Elaborated by the author

\subsubsection{Governance in the Chilean Fair Trade Wine Network}

By creating maps of the studied EVeNs we are able to gain a better understanding of the institutionalisation of these networks. The maps have been elaborated using information taken from the interviews with different participants involved in the studied networks. These EVeN maps demonstrate the different actors which participate in these networks. As shown through the EVeN map of the fair trade network in Chilean wine (Figure 29), the 'firms' actors are represented by the blue spheres while the linkages between these actors are presented by the black arrows, which demonstrate how power and value are shared or concentrated by these actors. A two-way dashed arrow shows a mutual linkage or relationship and the one-way undashed arrow highlights an asymmetric relationship. A link or relationship is considered to be mutual when the power, value created and risk are distributed more equally between the actors in the networks. An asymmetric relationship, conversely, is represented by the concentration of power and value by some of the actors and in, some cases, the less powerful actors experience greater levels of risk. As shown by the weight of these black arrows, the consumption of wine with fair trade labelling is almost exclusively reserved for international consumers, due to the limited market for fair trade products in Chile. As presented in the EVeN map, the value chain of fair trade Chilean wine has been extended to include ideas of global production networks through the inclusion of key 'non-firm' actors such as fair trade certifiers, labour groups, communities and government agencies (Yeung \& Coe, 2015). The non-firm actors are represented by grey spheres. The network connections between the firm and nonfirm actors are shown through grey arrows. Mutual and asymmetric connections or relationship are represented through these arrows which demonstrate how they interact and how power is shared. A two-way dashed arrow shows a mutual relationship and a one-way undashed arrow represents an asymmetric relationship. Using an EVeN map, it is possible to 
identify the main actors who participate in the Chilean fair trade wine network. The EVeN Map clearly demonstrates that fair trade wine in Chile is associated with a value chain consisting of firm actors, such as the grape producers, buyers, fair trade cooperatives, processors, distributors, retailers and exporters. However, the EVeN Map also highlights the roles of the non-firm actors, as explored in GPN literature, associated with the value network. These nonfirm actors included labour groups, government agencies, fair trade related organisations and certifiers. To critically explore the governance of the different actors in the network presented in the EVeN map, it is useful to examine some of the ideas the research participants provided about the conventional Chilean wine value network and compare this to how the participants perceived and experienced the fair trade EVeN in Chilean wine.

\subsubsection{Governance in the Conventional Wine Value Network in Chile}

Interviews with local industry experts and small-scale producers revealed that the conventional wine value network in Chile was largely controlled by a few powerful wine-producing companies, or firms, with strong links with national and international distribution and retail. In general, these wine-producing firms control the wine processing and commercialisation stages of production. While the conception stage of production, grape growing, was predominately undertaken by small-scale producers who were mainly excluded from the downstream stages of production closer to consumption.

PhD Researcher, Daniella Gac described the conventional Chilean wine network as;

“...very traditional and managed by specific conglomerates; Santa Rita, Concha y Toro, San Pedro, these very large wine producers control almost all of Chilean wine market [...] there are also grape producers that are very small, campesino, family farmers..."

The power held by these main companies in the wine network is explained by Fabiola Argandoña from Universidad de Santiago de Chile;

"Four Chilean companies control 70-90\% of the national wine production [...] unfortunately these monopolistic practices have not really been investigated. The small producers sell in a disadvantaged position in relation to the large companies which set the grape and wine prices..."

The most common form of governance in the conventional wine network in Chile appears to fit the captive value chain governance structure. In this conventional wine network, the grape producers represent captive suppliers while the wine-producing conglomerates are the lead firms. As described by Gereffi and Lee (2012, p. 25) “Captive governance is characterized by a 
group of small suppliers that are dependent on one or a few buyers..." As explained by Eduardo Aragones, the largest producers in the conventional wine network in Chile hold significant power not only due to their ability to set the grape prices but also through their capacities to produce and sell wine;

"...the production chain is controlled by the large wine producers such as Concha y Toro, San Pedro, Santa Rita, who [...] hold a lot of power in the industry due to their capacities to produce wine and through their strong sales and export channels..."

Research participants also discussed examples of vertical integration where smaller actors are excluded from the wine network. For instance, Gonzalo Rojas acting director of Wine Tourism at the Universidad de Talca described how;

“...the largest and most powerful wineries have generated vertical integration, they fulfil the roles of grape producers and they process these grapes into wine and commercialise without interacting with other groups. Therefore, these large-scale producers capture all the value of the chain."

In the cases of vertical integration, the small-scale actors are further excluded from the network which, applying the concepts developed in GVC literature, is clearly characterised by hierarchical governance structures. As defined by Gereffi and Lee (2012, p. 25), “Hierarchical governance describes chains characterized by vertical integration and managerial control within lead firms..."

As a result of hierarchical-captive value chain governance of the conventional wine network in Chile, the majority of the value created in the wine network in Chile is captured by powerful large-scale producers or lead firms while the small-scale grape producers, or suppliers, are largely excluded from the value created. The disadvantaged position of small-scale grape producers in Chile was first introduced in Chapter Five. Pablo Lacoste from Universidad de Santiago summarised this problem, "...in Chile there are thousands of campesinos which work in the wine sector, they are the ones that grow the grapes, but the great majority of them are excluded from the value created in the market..." Gonzalo Rojas described how the value is captured in the conventional wine network in Chile;

“...approximately $15 \%$ of the final price goes to the grape producers [...] the commercialisation captures $45-50 \%$ of the value [...] 35\% goes to the group that transforms the grapes into wine [...] The smaller the actor, the less value they capture..." 
José Alvarez from the small-scale grape producer Asociación de Viñateros de Itata ${ }^{35}$ explained this challenge from a producer's standpoint; "Grape growers across Chile face the same problem, that the industry abuses those that are lower down the wine production chain, they cheat the small producers out of the value of their production..." This problem was referred to as 'social dumping' by various research participants.

Yenny llanos from the Coalición Nacional de Viñateros explained the practice of social dumping;

"The large companies engage in social dumping by buying below the costs of the grape producers [...] the small-scale producers are actually subsiding the larger ones as we sell to them below the true costs, this allows them to compete against wine producers in other countries [...] they gain an advantage at our expense..."

It is important to mention that cooperative models are also part of the conventional wine network in Chile, although these cases are limited. This model is described by a representative from the governmental Agencia de Sustentabilidad y Cambio Climático ${ }^{36}$;

"...the cooperative model is better and more organised compared to the traditional chain, the producers know the grapes price and can enter niche markets for campesino production..."

Entering into cooperatives which produce wine and sell in niche markets for small-scale producers represent channels of upgrading for these producers. As mentioned, upgrading refers to the different strategies used by actors to improve their positions in the value chain (Gereffi \& Fernandez-Stark, 2011). However, it is common for the powerful actors in Chile's wine network to displace smaller producers. This was explained by Professor Philippo Pszczolkowski from the Department of Fruit and Oenology Pontificia Universidad Católica de Chile;

"There has been the creation of smaller wineries but as the structure of the chain has been formed to benefit the large producers and when the larger producers see that the other smaller wineries are doing well, they buy them or they buy into their niche market..."

This demonstrates a level of exclusivity in the network, whereby the lead firms work to exclude smaller actors from improving their position. By examining the perceptions of the research participants it has become evident that the conventional wine network in Chile is

\footnotetext{
${ }^{35}$ Viticulturist Association of Itata.

${ }^{36}$ Agency of Sustainability and Climate Change.
} 
characterised by hierarchy-captive governance and largely exclusive (Gibbon et al., 2008). This structure is visualised in Figure 30 on the following page, which demonstrates how value capture and governance power has been concentrated at the wine processing stage and at the later commercialisation stages of the value network. The smaller-scale grape producers have been integrated into the network as captive suppliers with very little power or ability to upgrade. Moreover, the value created in the conventional network appears to be concentrated by the larger and more powerful wine-producing firms. In some cases, the smallscale grape producers are been further excluded from the value network as the lead wineproducing firms are integrating vertically into the grape production stage. In these cases, governance has become increasingly hierarchical. In both the captive and hierarchy forms of governance in the conventional wine networks in Chile, the large-scale wine processing companies exert different forms of power to concentrate the value created in the network at the expense of other actors such as the small-scale grape producers and labourers through asymmetric relationships. 
Figure 30 Visualisation of Governance in Chilean Conventional Wine Network

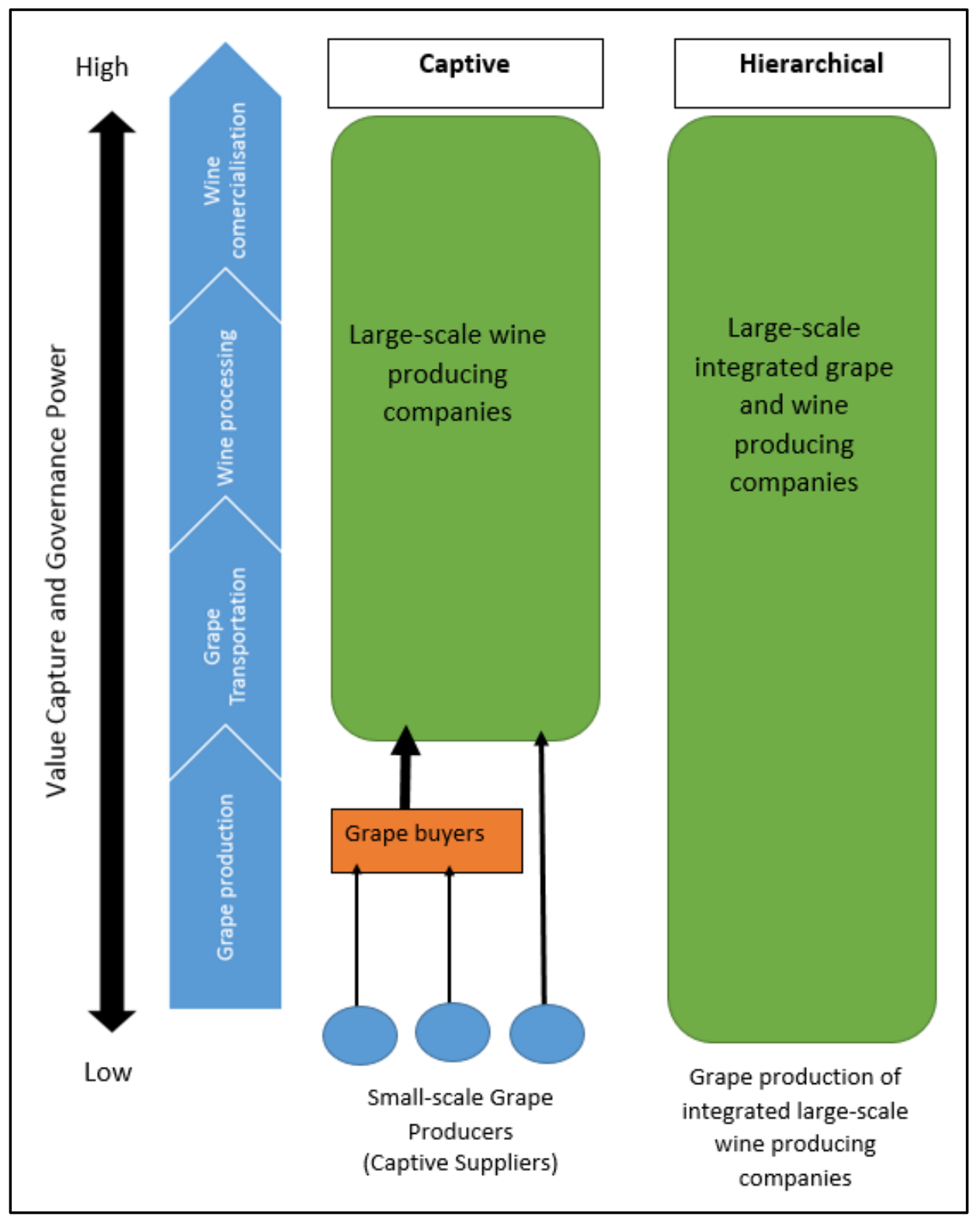

Source: Elaborated by the author using ideas from GVC literature (Gereffi, 1994; Gereffi et al., 2005) and primary data.

\subsection{FAIR TRADE AND GOVERNANCE IN CHILEAN WINE NETWORK}

In comparing the wine networks with and without fair trade certification in Chile, the research participants can be mainly placed into two camps: those that believed that the fair trade network was only slightly different to the conventional wine network, and those that perceived significant differences between the fair trade and conventional networks.

\subsubsection{Minor Changes to Chilean Network created by Fair Trade Certification}

To begin, a minority of participants believed that there were virtually no differences between the fair trade wine network and the conventional counterpart. For instance, Jaime Roselló from Acróbata Wines explained that; 
"I don't believe the wine productive chains with some kind of ethical trade certification are any different [...] the wine producers that use these certifications are the commercial ones which have the money to certify [...] The production chain works the same with or without certification..."

From this point of view, the actors in the production network virtually remain the same. This continuity of the main actors, or firms, was described by an unnamed academic from Universidad de Chile;

"The production chains with certifications are no different, they are the same producers [...] therefore there is no change to the structure of the production chain, what changes is the production practices in the localities..."

This demonstrates a recognition that there are some changes in the processes in the value network, however, there is the clear understanding the main actors remain the same in the conventional and fair trade wine networks. Rodrigo Constandil from Miguel Torres Wines highlighted the roles of different actors in the wine network in Chile and the difficulty in removing some of these intermediary actors to create shortened value networks following the principles of fair trade;

"...normally in Chile the primary producers use the 'corredores' which are intermediaries between grape producers and the wineries [...] It is difficult to remove the corredores for fair trade as this group has become part of the industry [...] the grape producers use them as a reference on price."

From this viewpoint, the fair trade wine network operates in the same way as the conventional wine network. According to Gabriela Negrete from Montes Wines, the differences that do exist are based on the regulations and shifts in the practices in the fair trade network;

"...the only difference is that [...] the certifier has to verify that the product fulfils the fair trade requirements and separate the premium so that this goes to the workers, these are the differences in the chain. It is therefore perhaps more regulated but the chain passes through the same processes."

In these cases, network governance shifts slightly from captive governance to include elements of relational governance, due to the changes in practices following fair trade certification and the regulations of this certification. 


\subsubsection{Significant Changes to Chilean Wine Network generated by Fair Trade Certifications}

Fieldwork, did nonetheless, reveal possibly more important differences between the conventional and fair trade wine network. In particular, over three-quarters of research participants highlighted shifts in the way the different actors interacted and changes in the governance of the fair trade wine network in Chile. These interviews highlighted a shift from the hierarchical-captive governance frameworks common in Chile's conventional wine network to possibly more relational governance, as visualised in Figure 31. Work by Gereffi and Lee $(2012$, p. 25) shows that relational governance is characterised by "Frequent interactions and knowledge sharing based on mutual trust and social ties between parties..." Power and value are also shared more evenly in relational governed chains (Gereffi \& Lee, 2012). Fair trade consultant in Chile, Gerardo Wijnant, explained this important shift between the fair trade wine network and the conventional one;

“...one of the fair trade principles is long-term commitment, which means as a company or cooperative you identify with the primary producers [...] The conventional wine production chain in Chile is based on searching for cheap grapes [...] there is no long-term commitment to the grape producers and this is the large difference with the fair trade network, where this commitment is very important..."

The links and relationships in the fair trade network were also noted to differ from those in the conventional wine network. For example, Lionel Valenzuela from the Universidad Técnica Federico Santa María emphasised that mutual and stronger relationships between the different actors have been created in the fair trade wine network;

"The certifications build mutual and stronger relationships between the wine producers, the communities, the suppliers and traders and this creates a win-win situation, it is cooperation [...] where all of the stakeholders can be happier."

There is also the view that the fair trade wine network is more inclusive, allowing the upgrading for upstream (production-end) actors such as small-scale grape and wine producers, and provides more space for producer cooperatives. This was explained by Daniela Acuña from ODEPA;

“...the chain's structure changes in fair trade wine [...] the chain is more based on cooperatives or small-scale producers groups [...] there is not the dependence on a large company which buys from these small-scale producers [...] instead these producers are part of the winemaking process and the sales which generate higher added-value" 
The fair trade wine network was seen to be more transparent and producers involved in fair trade certified wine felt that they had a good level of access to information about the network and how value was being shared. This supported by fair trade literature which highlighted improved transparency in fair trade networks in comparison to conventional trade (Dragusanu et al., 2014). Gerardo Orellana president and producer at Red del Vino supported this stating that;

"...there is transparency around the sale values at each part of the commercial chain and FLO includes each part of the chain in the value generated [...] we can see what our association, Red del Vino, does and also what traders and companies do as well. Therefore, the work of FLOCERT is very transparent."

Most of the research participants stated that the fair trade wine network in Chile is more inclusive than the conventional wine network. In other words, it is more likely that the leading firms in the fair trade network encourage the upgrading of the smaller-scale grape and wine suppliers in the network, and fair trade represents a social and economic form of upgrading for these producers. Additionally, the interviews revealed a potential shift away from the hierarchy-captive governance which dominate the conventional value network. Participants highlighted characteristics in the fair trade wine network in Chile based on mutual trust and social ties between the different actors more consistent with relational governance (Gereffi \& Lee, 2012). Figure 31 below, visualises the improvements to the Chilean wine network under the producer cooperative model of fair trade certification. It is important to note that Figure 32 visualises the ideal possible outcomes of using fair trade in Chile's wine network. In this visualisation, we can see that small-scale grape producers are involved in more stages of the value network through the fair trade cooperatives they form. Through this improved involvement, these producers are able to upgrade their positions from captive grape suppliers to fair trade certified wine producers, thus capturing more of the value created. As discussed, fieldwork revealed that in practice, these outcomes tended to vary. For instance, the interviews also indicated that the differences between the conventional and fair trade wine networks were more debated as participants often argued that the fair trade wine network followed the same processes and involved many of the same actors as the conventional wine network. Moreover, it needs to be noted that Figure 31 represents the small-scale producer cooperative fair trade model. The hired labour model is more likely to follow the same types of governance which characterise the conventional Chilean wine network, although under fair trade hired labourers should enjoy improved working conditions and benefits as reported in a number of the primary interviews. The interviews, therefore, demonstrated that small-scale producers and workers in the fair trade network enjoyed improved participation, transparency, 
commercial relationships and market stability, in comparison to the conditions of the conventional wine network in Chile. It is important to note that a significant number of smallscale producers and cooperatives representatives reported that they felt increasingly disconnected from the fair trade governance. These participants mentioned that the certifications had centralised power with the certifiers while removing producers from important decisions. This producer exclusion from various fair trade certifications has also been highlighted in the wider literature on fair trade (Murray et al., 2003; Pérezgrovas \& Cervantes, 2002).

Figure 31 Visualisation of More Evenly Distributed Value Capture and Governance in Chilean Fair Trade Wine Network (Producer Cooperative Model)

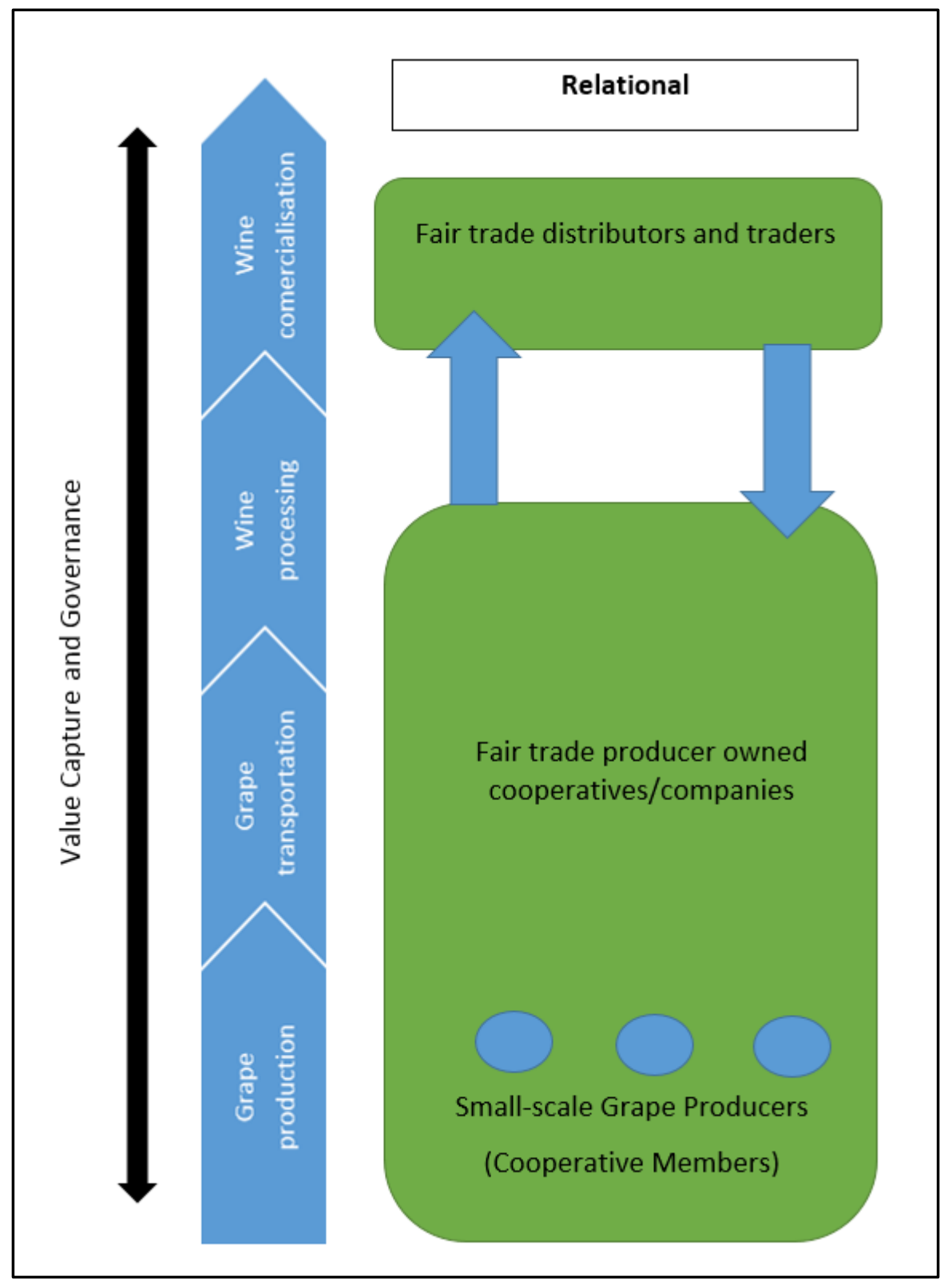

Source: Elaborated by the author using ideas from GVC literature (Gereffi, 1994; Gereffi et al., 2005) and primary data. 


\subsection{FORMATION OF DESIGNATION OF ORIGIN PISCO EVEN IN PERU}

The second half of this chapter will explore the formation and institutionalisation of the DO pisco EVeN in Peru. To do so, the subsequent sections will apply the same structure and methods used to study the formation and institutionalisation of the fair trade wine EVeN in Chile presented above. The next section will discuss the formation of the DO pisco network in Peru. Following this, the chapter will explore the institutionalisation of this same network.

By coding the interviews by key themes in NVivo I was able to ascertain seven central factors which motivated the formation of the DO pisco EVeN in Peru. These were;

1. Commercial factors and business opportunities for pisco producers in Peru

2. Attempts to improve the market competitiveness of pisco

3. Tool for the international promotion and diffusion of pisco

4. Protecting pisco producers and consumers from imitation products

5. Attempts to support pisco and grape producers and local community development

6. Creating protection of cultural value and national identity linked to pisco

7. Supporting Peru's defence for the origin of pisco

The subsequent sub-sections will examine each of these factors using evidence from the fieldwork interviews.

\subsubsection{Commercial Factors and Business Opportunities for Pisco Producers in Peru}

Similar to the fair trade EVeN in Chilean wine, interviews with different actors linked to the DO pisco EVeN revealed that the network's formation had been largely driven by commercial motivations and a desire to differentiate and promote pisco while protecting its unique qualities internationally. These factors are associated with the growing implementation of geographical indication marks globally, as discussed in Chapter Three. For example, Alan Watkin a small-scale pisco producer and representative of producing area Nazca explained what the pisco DO attempts to achieve;

“...DO marks try to build respect for the specific conditions and traditions in the elaboration of a unique product, in our case pisco [...] the pisco DO is necessary, it helps us to differentiate ourselves from other spirits in international markets..."

An important motivation for the formation of a DO has been to link and protect the product's special qualities to its origin and mode of production, as explained in Chapter Four. As described by Peruvian Diplomat Gonzalo Gutiérrez involved in the international defence of the Peruvian origin of pisco; 
"DO products have a specific and determined mode of production that includes two elements; the natural elements [...] and human participation [...] All of this forms a very unique specificity of the product that differentiates it from other products. This specificity is normally connected to high-quality."

In the case of pisco, the formation of the DO has been based on the uniqueness of the product, the high-quality it possesses, and the link to the human and natural factors which have developed pisco. Guillermo Vera, a historian and member of the Academia Peruana del Pisco (APP), explained these unique qualities;

"...nothing can be added to pisco, production does not include the use of wooden barrels which would change the flavours [...] Due to this elaboration and the uniqueness of the product, the DO has been applied to protect this unique product and distinguish it from other spirits. This product has the elements unique to Peru [...] the local climates and the specific cultures that have developed [...] that do not reflect viticulture internationally."

These ideas were supported by the president of the Consejo Regulador de la Denominación de Origen Pisco (CR) at the time of the interview, Jaime Marimon who stated that, "The designation of origin mark provides international legal protection for this traditional Peruvian product with a long history and very special characteristics."

A clear motivation for implementing the pisco DO mark, and for formulating the EVeN based on the $\mathrm{DO}$, has been the requirement to certify and protect the uniqueness and high-quality of the product, while also developing a means to differentiate. As summarised by alcohol marketing specialist Bruno Fistrovic, "DOs work as certifications of quality, [...] it is an element to differentiate and promote the product."

\subsubsection{Attempts to Improve the Market Competitiveness of Pisco}

The use of the DO in pisco has also been identified as a business tool to increase the competitiveness of pisco in different markets. For instance, a governmental representative from INDECOPI explained that;

“...DOs are not just about protecting traditional products in Peru, but also about making them more competitive in diverse markets [...] a DO is used as a business tool to better place special products in markets [...] a DO sends a message to the consumer of standardisation, of quality, of control..."

The development of the pisco DO was also perceived as a method of improving and maintaining the quality and value of the product. For example, president of the research body APP, Eduardo 
Dargent stated that, "The control that comes from the DO is improving the quality standards of pisco by making the production process more uniform [...] it is a good way to regulate products like pisco..." Likewise, an important motivation for the DO has been to increase the value placed on pisco. Alfredo San Martín from industrial institution Sociedad Nacional de Industrias ${ }^{37}$, explained;

"Rather than protecting, DOs are concerned with maintaining the quality and placing value on a product [...] if the DO is managed well, the consumer will feel they are consuming something unique, with a high-quality and history [...] which will increase the product's price."

These factors are associated with the broader expansion of DOs outside of Europe, as explained in Chapter Three.

\subsubsection{Tool for the International Promotion and Diffusion of Pisco}

Similarly, the international diffusion and attracting consumers to the product, have been important motivations for using a DO in pisco. Gonzalo Gutiérrez summarises this, "...one of the important concepts incorporated into the protection of the DOs is the international diffusion and the inclusion of these products in the international market." The pisco DO has been formulated to attract consumers, especially from those in the Global North. Therefore, the pisco DO has also been influenced by changing consumer preferences in the Global North towards product quality and authenticity, as introduced in Chapter Three. This can be seen as a form of upgrading whereby the producers using the DO on their product are able to improve their position in national and international markets and add value to their product (Bolwig et al., 2010; Ponte \& Ewert, 2009). As explained by José Carlos Falconí from innovation and technological centre CITEagroindustrial;

"...when a consumer sees that a product is controlled with a DO they know that it is something unique and exclusive. The DO is particularly important for consumers in other markets such as in Europe and the North American, these groups understand that the DO is a sign of quality."

Therefore, the formation of the pisco DO and the EVeN which surrounds it, has been largely motivated in promoting and protecting the product in external markets. Nevertheless, increasing the product's value, maintaining pisco's special and high-qualities, while opposing unfair competition in both external and internal markets, have also been important motivations for the creation of the DO. As explained by small-scale pisco producer Manuel

\footnotetext{
${ }^{37}$ National Society of Industries.
} 
Bernales from the Bodega El Carmelo, "The DO is designed to protect the authenticity of the product [...] and to combat the unfair competition in the sector."

Continuing with the perspectives of pisco producers, Jhon León, president of a small-scale pisco producer cooperative Asociación de Pequeños Vitivinicultores Bodega el Palto Pachacutec ${ }^{38}$ (APEVIBOPA), explained that;

"The DO is a title given by the state through INDECOPI which shows that we produce high quality and standardised pisco [...] with the authorisation to use the DO for pisco, we have the obligation to produce this high standard of pisco."

\subsubsection{Protecting Pisco Producers and Consumers from Imitation Products}

Although the interviews revealed a clear set of motives for developing the pisco DO based on commercial factors, interviews also demonstrated a concern for assisting local producers and protecting consumers. The DO has therefore been established to protect both the consumers and the producers, and to separate the formal and informal sectors. This is explained by Carlos Romero from the Pisco Campo de Encanto (medium-scale producer);

"...the DO is a guarantee for the public and protection for the producer. For someone who wants to consume an authentic drink [...], a DO means that the state guarantees that the production is genuine. And for a producer, they have the security that their product won't be imitated [...] this means that low-quality imitation products cannot be sold in the pisco market. It is a protection against this unfair competition."

Johnny Schuler, General Manager at bodega La Caravedo, explained the need to create the pisco DO; "I really pushed for a pisco DO [...] when I entered the world of pisco 30 years ago, I realised that there was a lot of disorder [...] anything could be sold as pisco and this was a serious problem."

César Costa a cultural expert in pisco, emphasised that the concept of DO originates from Europe and was first used by producers to protect the traditions and 'know-how' of certain products;

"The DOs were first developed in Europe as producers there sought to protect their traditional products and the know-how involved in producing them [...] The traditions have to come first and these should be protected by a DO."

${ }^{38}$ Association of Small-Scale Viticulturists of Palto Pachacutec. 
Ismael Anicama, from small-scale Bodega San Inocente, explained the need for the pisco DO from a small-scale producer's standpoint, "pisco needs this DO because there are those that are not making pisco correctly and the government needs to protect the high-quality pisco that exists."

Pisco producer, José Falconí from small-scale Falconí Bodega mentioned how the DO has helped to counter imitation products;

"As a result of the DO, we as pisco producers feel more secure [...] others groups cannot produce inferior products and use the name pisco [...] this helps to resolve the adulteration of pisco and the unfair competition."

However, as described by José Moquillaza owner of Pisco Inquebrantable and ambassador of the pisco DO mark for the Peruvian Ministry of Trade and Tourism;

"The informal sector in pisco remains a large problem [...] the informal groups have higher profit margins as their production costs are a lot lower [...] the informal sector, unfortunately, grows with the formal sector."

The informal sector refers to those that produce spirits and use the name pisco without receiving the authorisation to use the $\mathrm{DO}$. In these cases, the informal groups are not bound by the same regulations as the formal pisco producers who receive the authorisation for the DO. Separating the formal producers from the informal ones has been shown to be an important motivation for the evolution of the pisco DO EVeN in Peru. However, similar to the fair trade certification case study, the process for receiving the authorisation to use the pisco DO involves financial and administrative obligations. These obligations often represent significant barriers for some of the smallest-scale pisco producers. As will be discussed in later chapters, these financial and administrative barriers can lock small-scale producers into informal markets or push them out of the pisco network. Moreover, the protection offered to authorised producers through the DO system has failed to protect local traditional producers from an influx of extra-local actors. These extra-local actors represent an important risk in the network as this group has begun to appropriate the value associated with the pisco DO. This value appropriation will be discussed in more detail throughout this chapter and in the following chapters. The process for receiving the authorisation to use the pisco DO is summarised in Box 2 on the following page. 
Box 2 Process for Receiving the Authorisation to Use the Pisco DO Mark

The title-owner of the pisco DO is the Peruvian State. Therefore the different role of protection, defence, promotion, supervision and oversight is completed by different state agencies with support from the producer-controlled private Regulatory Council for the Pisco DO, whose role is to oversee the production and quality of pisco (Dirección de Signos Distintivos, 2017).

To receive the authorisation to use the pisco DO mark, a producer or company must lodge an application to the Peruvian State through the Distinctive Marks Division of the National Institute for the Defence of the Competition and the Protection of Intellectual Property (INDECOPI). The applicant is required to present evidence demonstrating that their product meets the requirements of the National Pisco Regulations; including results of physical, chemical and organoleptic testing. These tests are to show that the product is within the technical parameters, been using the designated pisco grape varieties and traditional methods, and evidence that the production takes place within the designated production zones (in the regions of Lima, Ica, Arequipa, Moquegua and the Locumba, Sama and Caplina Valles in the Tanca region). Furthermore, to apply for the pisco DO, the applicant must by a member of the Regulatory Council. Once received, INDECOPI evaluates the application, if all the requirements are meet INDECOPI grants the authorisation to use the DO pisco mark. The authorisation lasts for 10 years from the date it is granted and the renewal process is the same as the original application. A product cannot be sold legally as pisco until this authorisation to use the DO is granted. The Peruvian State, through INDECOPI, can cancel the authorisation or implement sanctions in cases where the DO mark is used incorrectly (Dirección de Signos Distintivos, 2017).

The cost of the application is 117.50 soles while the testing and documentation required to support the application costs over 500 soles (Dirección de Signos Distintivos, 2017; Instituto Tecnológico de la Producción, n.d.). All applicants pay the same fees creating a clear disadvantage for the small-scale producers who do not enjoy the same financial resources as their larger-scale counterparts. Moreover, field interviews revealed that the administration involved in the application process represents a challenge for the smallscale producers and that these producers faced a list of additional costs no mentioned in official information. 


\subsubsection{Attempts to Support Pisco and Grape Producers and Local Community Development}

The DO has also been constructed as a way of supporting local producers and the communities in the producing areas. This follows the notions from the literature on European case studies which link DOs to local development as explored in Chapter Three. It is important to mention that the motives of supporting community development were not as explicit in the case of the Pisco DO when compared with the fair trade certification in the Chilean wine case study. This important difference between the two case studies will be expanded on at later stages of this chapter and in the following chapter.

Lorenzo Huertas, a historian at the Universidad Ricardo Palma, explained that the DO provides local pisco producers with an opportunity;

"I believe that the DO helps the producers, [...] it works as a base so that they can encourage their businesses to expand. I do not believe the DO is an obstacle, it is a launching point but we need to continue to improve the DO..."

The DO has been partly been established to improve the conditions of the pisco producers in different markets by protecting the intellectual property which they have developed over centuries. As summarised by David Espinoza an official pisco connoisseur, "The DO is an important tool which can help the producer to raise the profile and marketing of their product through the protection of their intellectual property." Homero Herrera, an adviser of cooperative Asociación de Pequeños Vitivinicultores Bodega el Palto Pachacutec (APEVIBOPA), described the benefits and support the DO provides from the perspective of a smaller producer;

"We protect the production of our high-quality pisco by using the DO. This represents a kind of support for us [...] we have learnt the importance of using the DO which means that we can commercialise our pisco directly and we no longer depend on middle-men who offer us low prices [...] we are in a better position than most smaller producers."

As discussed in early stages of this thesis, DOs have been promoted as a strategy for broad community development in marginal areas where unique products are often produced (Bolwig et al., 2010; Bowen, 2010a). Karl Mendoza, an agricultural engineer and consultant in pisco production explained how the pisco DO was formed to include these concepts of local community development;

“...Pisco has contributed to the development of the viticultural sector in depressed localities in Peru [...] The Peruvian state has established laws so that pisco [...] 
contributes to the social and economic development of the communities in the production areas."

Jorge Aparcana, a social activist from Ica, explains that the pisco DO EVeN should create benefits for the local communities in the production areas; "The DO should improve the economy of the small producers which obviously improves the economy of the local community, it brings benefits like tourism and improves other services." These ideas were supported by Manuel Morón, director at CITEagrolndustrial, "There are direct and indirect benefits [...] like the Pisco Trail, and important events and festivals based around pisco [...] this brings people and tourism which has many benefits for the community." However, according to traditional medium-scale pisco producer Matías Grados, from Cholo Matías Pisco the impact in the community depends heavily on the type of producer, "The smaller producers have a more positive impact in the community, what they earn they spend here, but the large producers do not live here and their money leaves this area."

The DO mark on pisco has also been developed as a strategy of creating social and cultural benefits rather than been exclusively concentrating on the economic benefits of entering markets and promotion as already discussed. Patricia Gamboa, a legal expert in DOs in Peru, discussed this idea stating that the DO; "...is a tool to improve the self-worth in the production localities and build more connection between these towns and this economic activity. If a DO is used well it can also create other indirect benefits..."

\subsubsection{Creating Protection of Cultural Value and National Identity Linked to Pisco}

A central motivation for constructing the DO pisco EVeN has been a recognition of pisco's cultural importance and the product's role in Peru's national identity, patrimony and heritage. Close to all interview participants mentioned important connections between pisco and the national Peruvian identity. A significant component of the pisco DO has therefore been motivated by an aspiration to protect, celebrate and promote pisco's cultural value. Rodolfo Vasconi from Vista Alegre, a large-scale wine and pisco producer in Ica, linked the Peruvian people with the evolution of the product pisco;

“...the pisco represents the Peruvian people, we can see that the Quebranta grape which adapted and suffered is just like the Peruvian people [...] a Quebranta pisco has this strength which reminds of us of the Peruvian people who have worked, and suffered and hardened, this is part of the identity of the people here [...] This is what we need to care for and protect through the DO."

The historical value was acknowledged by Jorge Llanos from the Instituto del Vino y del Pisco 
at the Universidad de San Martín de Porres, who mentioned a duty to protect the cultural and historical importance of pisco as a motive for forming the DO;

"The first motive for protecting pisco with a DO is that it is not a spirit that has been made over the last twenty years or so, it is a product that was first made 400 years ago [...] we have this cultural and historical richness that dates back longer than 400 years, it is our duty to protect this."

Likewise, the pisco DO and the EVeN that has formed have been partly motivated by a desire to protect the traditional methods and the cultural connections with pisco which represent an important part of the DO. The DO needs to protect the traditions of pisco and this can only be achieved through supervision over pisco production. Moreover, the social and cultural connections with pisco play important roles in the sector. The importance of the social and cultural links to pisco was described by the José Moquillaza;

"The DO regulations attempt to protect the traditional methods [...] but there also needs to be an orientation towards protecting these traditions through effective supervision. The people who are born and raised in the production areas have a special connection with the grapes, pisco and wine [...] the pisco production is based on this cultural connection, a connection which is just as important as the climatic conditions and soil."

\subsubsection{Supporting Defence of Peruvian Origin of Pisco}

The DO has been created to defend and protect the aforementioned historical and cultural values while supporting Peru's claims over pisco's origin. The drive to protect pisco's origin in Peru has mainly come from the DO challenge from Chile which also produces an aguardiente de uva under the same name. Although it is not in the scope of this thesis to discuss the Chilean DO for pisco in detail, it is important to note that, like in the case of the Peruvian claim over pisco's origin, there is also historical evidence which supports the Chilean claims of the product's origin (Lacoste, 2016). Furthermore, there have been problems with other groups as in countries as diverse as Argentina, the USA, and Australia, among others, which have illegally marketed products with names based on Peru's pisco making traditions. This importance of defending the Peruvian origin of pisco is explained by pisco producer Victor Santhome, from Bellavista Bodega;

“...the pisco DO is something of pride for Peru [...] but unfortunately, we have problems with Chile which claims that pisco has a Chilean origin. For me, it is 
extremely important that we focus on the high-quality of our pisco [...] we also have historical and geographical factors which support the Peruvian origin of pisco..."

Interviews in Peru highlighted that formation of the pisco DO was partially a reaction to the Chilean pisco DO. This was explained by José Carrasco, from the medium-scale Bodega EI Catador; "Chile formed a pisco DO first [...] in Peru we had to react to be able to continue to produce and sell our pisco in international markets." The relatively late push to protect pisco with a DO in Peru is sometimes explained by the waves of different social and economic crises which Peru faced between the 1970s and 1990s as discussed in Chapter Four. José Moquillaza summarised this situation; "The DO for pisco was established relatively late, in 1994, following the end of political and economic instability in Peru. There were other priorities for a country which faced serious problems."

A concern from the pisco sector in Peru is that the product from Chile can confuse the consumer and causes the name pisco to lose its value as a unique product from Peru. As explained by Jaime Marimon;

"Pisco in Peru is not comparable with the Chilean product which follows different processes and is a different product. The existence of the Chilean product puts pisco at risk of becoming a genetic product, this would ruin our DO."

However, there has also been recognition that the competition from external actors, from Chile in particular, has contributed to the development of the pisco DO in Peru. For instance, Gonzalo Gutiérrez stated that;

"...the importance Peru has placed on pisco has likely been encouraged by Chile's desire to claim its origin [...] this competition from the Chileans has helped the development of DO in Peru [...] this competition drove the creation of good quality regulations which have been transferred into a good quality product."

\subsection{INSTITUTIONALISATION OF DESIGNATION OF ORIGIN PISCO EVEN IN PERU}

The following section will apply an EVeN map and demonstrate the central findings from the research interviews to explore the institutionalisation of the DO pisco EVeN in Peru. 
Figure 32 EVeN Map for DO Pisco in Peru

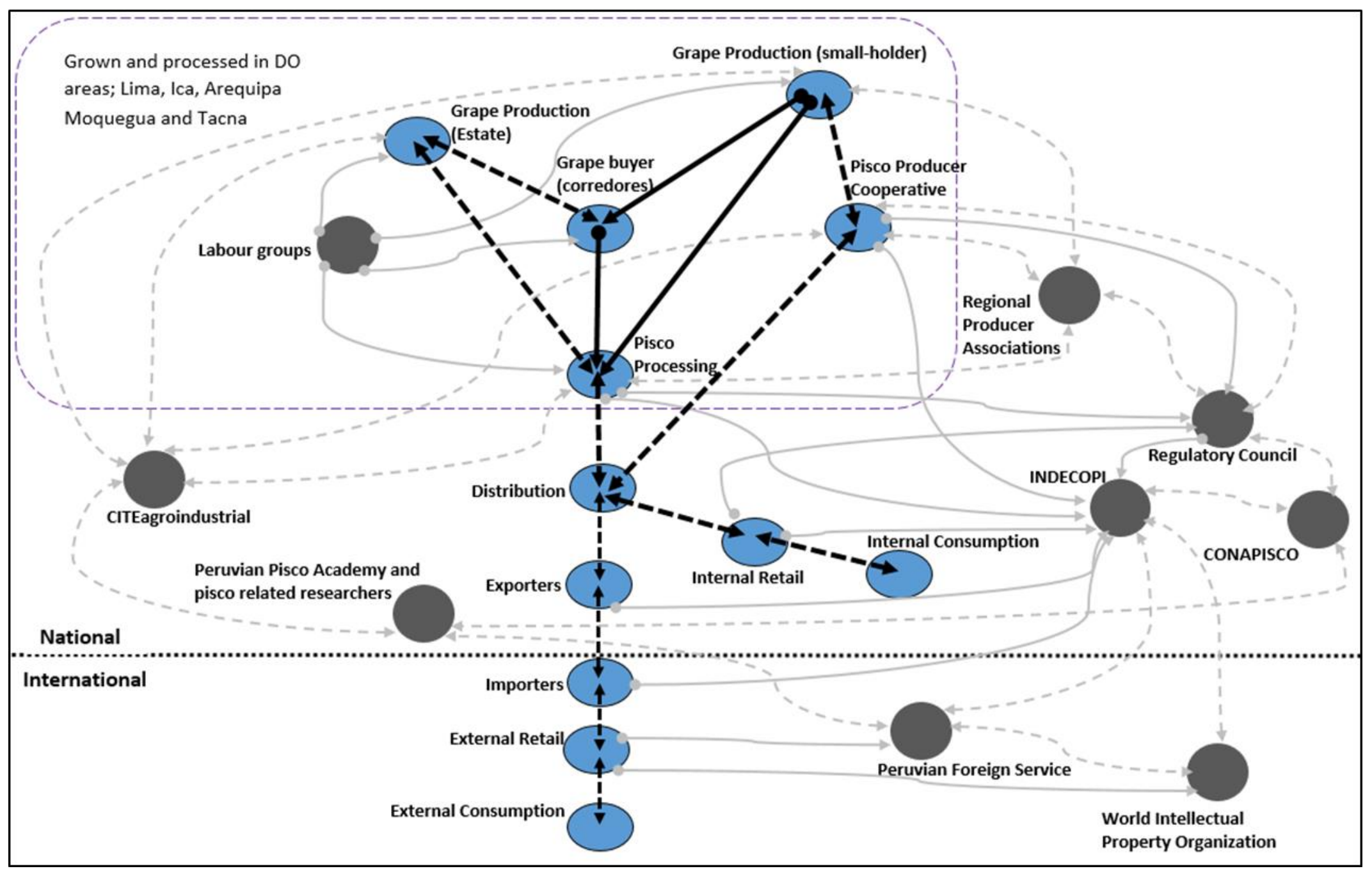




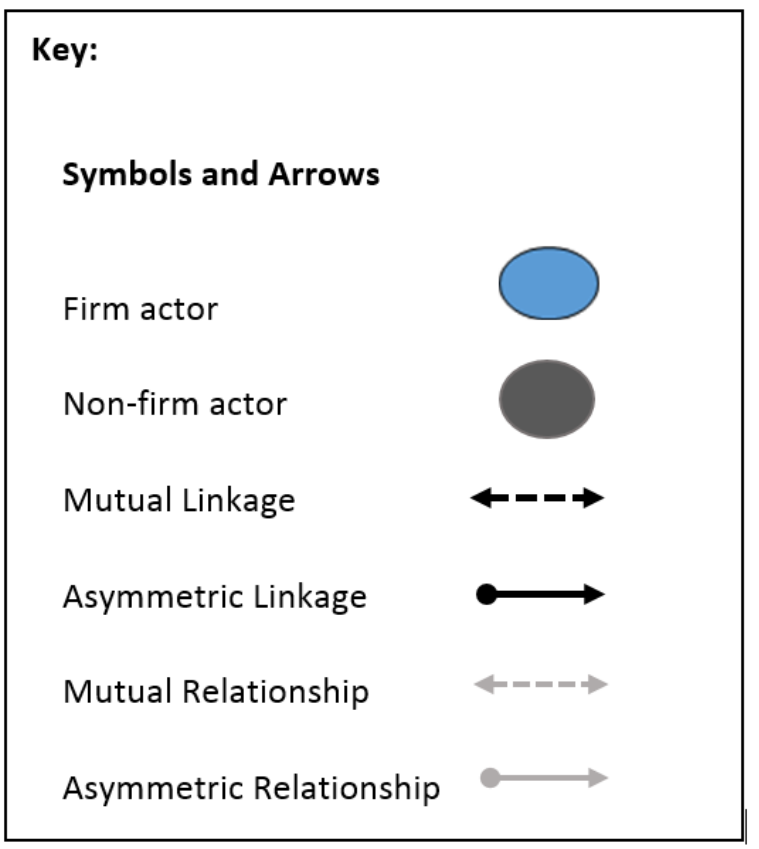

Source: Elaborated by the author.

\subsection{GOVERNANCE IN THE DESIGNATION OF ORIGIN PISCO EVEN IN PERU}

The EVeN map for the DO pisco in Peru (Figure 32) has used the same format as the map created for the fair trade EVeN in Chilean wine. The main 'firm actors' in the pisco network in Peru are shown with blue sphere and the linkages between these firms are represented by the black arrows, with dashed and undashed arrows to showing mutual and asymmetrical firm linkages. The more significant flows are shown through the thicker arrows and demonstrate that DO pisco is mainly sold in the internal national market, although pisco exports have grown over the last decade. Although promoting and protecting pisco in external markets has been highlighted as important motivations for creating the DO for pisco, the pisco EVeN map shows that greater quantities are sold in the national market, as presented through the thicker arrows towards internal retail and consumption. Ideas of global production networks have been included in the DO pisco EVeN maps with the adding of important 'non-firm' actors such as the $\mathrm{CR}$, labour groups, INDECOPI and other related public and private actors. These 'non-firm' actors are presented through grey spheres. The network linkages between these non-firm actors and the firm actors have been shown through grey arrows, with dashed and undashed arrows to showing mutual and asymmetrical relationships. By creating the EVeN map of the DO pisco sector it has been possible to demonstrate the participation of key network actors. It can be observed that the network of non-firm actors is larger in the case of DO protected pisco in Peru when compared with the fair trade wine network in Chile. This is likely due to the significant interactions between public and private sectors involved in the implementation of a DO mark. However, the similarities between the case studies can also be observed through 
the value chain elements of the studied networks, which are very similar although fair trade wine had a stronger export focus compared to overall internal market focus of DO protected pisco. The following sections will examine perceptions surrounding the governance and structure of the pisco DO EVeN in Peru taken from the research interviews.

\subsubsection{Firm Actors in the Pisco Network in Peru}

Pisco is a highly competitive network dominated by a handful of industrial-scale ${ }^{39}$ pisco producing firms. These companies control most of the processing and commercialisation stages of the pisco value network and have strong links with national retail and exports. Smaller-scale actors are mainly concentrated in the conception stage in the grape production and in artisanal-scale pisco production, usually selling in local markets or in bulk to larger pisco companies for re-sale. Many of the smaller-scale producers remain in the informal market due to the barriers they face in receiving the DO. Therefore, as discussed in Chapter Four, the expansion of the pisco sector since 2000 has been exclusionary.

In theory, the pisco value network should be more controlled and regulated due to the $\mathrm{DO}$, as explained in Chapters Three and Four. However, fieldwork found that in practice, the DO pisco value network operated like a conventional viticultural value network. For example, research participants frequently explained that the pisco value network operated like the wine value network in Peru; it was recognised that the processes, the firm actors and linkages remained the same in the pisco network when compared to the production of wine despite the DO. This structure is demonstrated in the EVeN map. Pisco producer Carlos Romero summarised the pisco value chain highlighting the different 'firm' actors involved;

"Small-scale producers grow the grapes which is the first step in the value chain [...] these producers sell to the bodegas which process the pisco, the second step in the chain [...] In other cases, there are producers that make pisco from start to finish, they begin and close the entire production chain as they have everything, the grapes, the bodega and access to markets..."

As shown in the EVeN map, there are other firm actors in the pisco value network such as distributors, retailers and exporters which are involved in the product's trajectory following the processing stage. Agricultural engineer Karl Mendoza described the complex nature of the pisco network;

\footnotetext{
${ }^{39}$ In the pisco sector industrial or large-scale producers refers to those that produce more than 50,000 litres of pisco annually or owned 51 hectares or more. Source: INEI (2012).
} 
"...there are the more traditional producers which are involved in all stages of production as they have grapes, bodega and commercialisation. [...] There are the producers that have a bodega and commercialise pisco but buy their grapes from small-scale farmers. There are others that produce grapes and rent bodegas to produce pisco [...] there are businessmen that buy grapes and rent bodegas [...] there are also middlemen who buy grapes and sell them to bodegas; these tend to take advantage of the grape producers..."

These quotes showed some of the complexities of the DO pisco network as multiple actors are involved through the different stages. Fieldwork also revealed that the DO has failed to control the expansion of newer extra-local pisco producers from entering the pisco DO network, in search of opportunities for profits which has resulted in the appropriation of the ethical value associated with the pisco DO. This has diminished the value captured by the small-scale grape and pisco producers as the value created in the network tended to be unevenly distributed amongst the other actors. Some of these different actors are highlighted on the EVeN map above.

\subsubsection{Non-Firm Actors in the Pisco Network in Peru}

The implementation of the pisco DO indicates that there is a number of non-firm actors in the network connected to the regulation of the DO. President of the APP, Eduardo Dargent explained the two main regulatory groups;

"Two main organisations govern the pisco DO. First of all, there is the state institution INDECOPI. Next, there is the Regulatory Council for the Pisco DO, a private organisation which represents the pisco producers."

Historian Guillermo Vera from the APP, however, explained that the current structure of the CR leaves some important groups out;

"The Regulatory Council regulates the sector [...] which only includes the producers. This leaves people like myself out of the conversation, I am not a producer but I am someone who researches the subject, obviously the producers are very important [...] but I feel there are other important groups too."

As demonstrated in the EVeN map, there are a number of other institutions and actors outside of the CR and INDECOPI involved in the governance of the pisco DO. These include the privatepublic private Comisión Nacional del Pisco (CONAPISCO), regional producer associations, the Peruvian Foreign Service and the World Intellectual Property Organization. The network is also supported by groups of researchers and academics, especially through the APP. The 
Peruvian State's support role in developing the Pisco DO and the range of public-private institutions involved highlights the neostructural tendencies which have supported the implementation of the DO and encouraged the network's growth.

\subsubsection{Dominance of Large-scale Producers in Pisco Network in Peru}

As discussed in Chapter Three, existing research has highlighted the potential benefits of DOs in supporting traditional small-scale producers by connecting them to national and international markets and thereby providing them with an economic incentive to maintain their traditional agriculture (Bowen, 2010b). However, over half of the interviews participants mentioned that the governance of the pisco DO and the network surrounding the DO have largely failed to achieve these benefits. For example, César Costa explained the large grape buyers dominate the sector while the primary producers, the grape growers, are unsupported captive suppliers;

"The grape producers receive low prices set by the buyers, and the large producers apply unfair practices when buying the grapes. The DO at the moment does not support the pisco grape producers in any way [...] The DO would help the small grape producers if there was an institution which regulated all stages of the pisco production, however, the various institutions that exist do not do this..."

It is clear that despite the DO which should represent a possible opportunity to support local primary producers (Boisvert, 2006), this group has been excluded from the governance of the DO in the pisco network. This supports the assertion made by existing research which demonstrates that the capacity of DO protection to encourage development and support local producers depends on the DO regulation and the local social, political and economic context where the DO is embedded (Bowen, 2010a; Mancini, 2013). For instance, local contexts mean that small-scale producers are likely to suffer from exploitative rural structures and socioeconomic inequalities, as discussed in Chapter Four for the Peruvian case. This means that despite playing a critical role in the sector, the grape producers are being largely excluded from the capture of the value created in the pisco network. Although they are an important part of the DO product they have been integrated into the network as captive suppliers. The industrial pisco producing companies, as well as the distributors and retailers, represent the dominant lead firms of the pisco network (Gereffi \& Lee, 2012). This is a clear risk faced when implementing a DO in uneven local social, economic and political contexts, such as those commonly experienced in Latin America. Clear parallels between the pisco DO study and the failings of the DO for tequila in Mexico to protect small-scale local producers from global liquor companies can be observed (Bowen, 2010a, 2010b; Bowen \& Zapata, 2009). 
Viewpoints from interviewed grape producers demonstrated the perceptions of being excluded from the value captured and abused by the companies that buy grapes. Pablo Alvites president of the small-scale producer Asociación de Productores en Ocucaje ${ }^{40}$ (Ica) and grape producer, highlighted that the grape producers are forced to accept the prices offered in the market, including when they fail to cover the costs of production;

"We sell our grapes to large bodegas that send their people to buy to them, but they pay very little and sometimes what they pay does not cover the investment we put into producing the grapes. We are forced to sell to them as we don't have any other options."

Luz Ramos a small-scale grape producer from Ica also mentioned this problem; "We sell our grapes to middlemen who buy grapes for the bodegas, but they pay very little [...] it doesn't even cover the production costs." Similarly, a number of small-scale pisco producers voiced their concerns around their limited representation in the DO. Small-scale producers tended to feel under-represented by the governing institutions and the important decisions taken in the network. For instance, Dennis Grimaldo a small-scale pisco producer from Pueblo Nuevo stated; “...the small producers are not listened to during the processes of the DO and pisco regulation, they just talk to the largest producers. They ignore us..."

José Carrasco, from the Bodega El Catador in Ica, explained how the growth of the large producers is eliminating the smaller ones from the sector;

“...there are companies that are producing too much pisco now and they are using all of the grapes [...] many artisanal bodegas have disappeared in last the ten years as they suffer from grapes shortages and limited market access [...] the large producers are eliminating the small producers."

Interviews revealed that there has also been some vertical integration into grape production by the industrial-scale producers. For example, José Carlos Falconí from CITEagroindustrial explained that, "Many companies are moving away from buying from grapes from producers and are seeking to control the entire production chain by producing their own grapes." Jorge Queirolo from one of the largest-scale pisco producers and exporters justified this shift from the perspective of a larger producer;

"We have always had problems with the grape producers, there is no loyalty in the sale of grapes, the producers sell to who pays more. For this reason, our company

\footnotetext{
40 Producers' Association of Ocucaje.
} 
has tried to cover the bulk of its grape production [...] we cannot trust in third parties for our production."

This type of vertical integration could displace the grape producers from the sector and create a pisco value network governed by an increasingly hierarchical structure (Gereffi \& Lee, 2012). It is important to note that the research found five examples of more relational governance based on mutual trust and the sharing of power and long-term and positive commercial relationships in the pisco network. For example, medium-scale pisco producer Julio Sotelo in Ica described the relationship his company has with the grape suppliers;

“...We have established a minimal price with our producers of at least one sol per kilo, including in years when the grape price has dropped below 70 cents [...] The relationships with our grape suppliers are long-term and very strong, we understand their importance in producing the raw materials for our production."

\subsubsection{Sector Competition and Extra-Local Actors in the Pisco Network in Peru}

As mentioned in Chapter Three, DO schemes have been promoted as a potential way to protect local producers from the competition and exploitation of local products by extra-local actors (Bowen, 2010a). In the case of pisco, the DO has instead attracted extra-local actors into the sector. The growth in the competition was explained by Bruno Fistrovic; "...there are over 400 pisco brands now. This is a very high number [...] pisco has a limited raw material in delimited production areas. This means that the producers suffer from a lot of competition..." José Carlos Falconí from CITEagroindustrial described how the growing competition and the involvement of extra-local actors has helped push improvements in the sector but has also created new pressures for the traditional local producers;

“...modern producers from Lima are moving into Ica's pisco sector [...] These business people come to Ica with business knowledge, vision and work formally [...] those who have really supported the sector's improvement are these different pisco businesses which have started to produce pisco in the last five or so years, although this has hurt the traditional producers. The smallest producers are generally not adapting to these changes..."

Accordingly, while the DO may have created some improvements in the sector, it is also evident that the greater competition and increase in extra-local actors has threatened rather than protected some of the traditional pisco producers. Nonetheless, the DO has also been seen as a possible opportunity for small-scale pisco producers to upgrade (Bowen, 2010b; Ponte \& Ewert, 2009). David Espinoza explained this; 
"A DO should support small producers, it should work as a tool so that producers can enter new markets, add value to their product and inform consumers that their product is produced under supervision and meet high-quality standards..."

There are cases where the DO has assisted smaller-scale pisco producers to upgrade their position in the sector. This was described by Homero Herrera;

"When a producer has the authorisation to use the DO they can commercialise direct and even export their pisco [...] Other small local producers that don't work with the DO and sell their low-quality piscos locally in bulk to middle-men [...] without higher value-added. [...] Receiving the DO has supported us as small-scale producers..."

These cases, however, do not represent the common trend and often have involved support from external groups such as national and international NGOs and government agencies. Interviews with different groups highlighted the challenges and barriers faced by small-scale producers in receiving the authorisation to use the pisco DO. Alan Watkin discussed some of these important barriers;

"The DO supports the producers to a certain degree, but there are small producers who cannot receive the authorisation to use the DO due to the costs and the administration involved [...] The DO should support small producers more, it is a tool that most are not using yet."

An important problem within the DO network has been the exclusion of the grape producers in the regulation of the pisco. As explained by José Moquillaza this is because an interprofessional regulatory organisation has not yet been developed;

"The supervision takes place at the Regulatory Council which is made up of private organisations. However, its vision is overly industrial and the grape producers are not represented. The council is not truly inter-professional like in other countries with DOs. [...] As the council is not inter-professional, the different actors in pisco compete, argue and fail to work together, while only the second half the value chain is included."

This research did find that many producers and experts acknowledged that the DO regulation has created positive changes to the quality and production of pisco. Additionally, a number of participants also believed that the regulations of DO had been successful in protecting traditional production methods while allowing technological advancement. However, the governance in Peru's pisco network is largely captive with lead pisco producing firms 
concentrated at processing and commercialisation stages of the network. These firms were seen to capture most of the value created in the network. These larger producers were also seen to be better linked to the regulation of the pisco DO. On the other hand, the small-scale grape producers and small-scale pisco producers, fulfilled the role of captive suppliers in the network with little representation at the regulation level. These captive suppliers were largely disconnected from important markets and received a restrictive amount of the value created in the network. In some cases, vertical integration by the industrial-scale pisco producers has led to hierarchical governance by removing the grape producers from the network (Gereffi \& Lee, 2012). These patterns are displayed in Figure 33 below which visualises the governance and value capture in the DO pisco network in Peru.

As demonstrated, the DO has provided opportunities for upgrading and inclusion of upstream actors in the production areas, however, a number of barriers and challenges have restricted these opportunities. Instead, the grape producers have been largely left unsupported in a low paying grape market and excluded from the regulatory institutions. Similarly, the small-scale pisco producers have struggled with barriers in receiving the authorisation to use the pisco DO and face strong competition against the industrial producers. While there have been cases where small and medium scale producers have been able to use the DO to upgrade their positions in the network, this has not been a common trend. There were some examples of more relational governance based on mutual trust and the sharing of power as well as longterm and positive commercial relationships in the pisco network. However, the overall trend appeared to a captive governance structure controlled by a limited number of large-scale and sometimes extra-local producers. 
Figure 33 Visualisation of Governance in DO Pisco Network in Peru

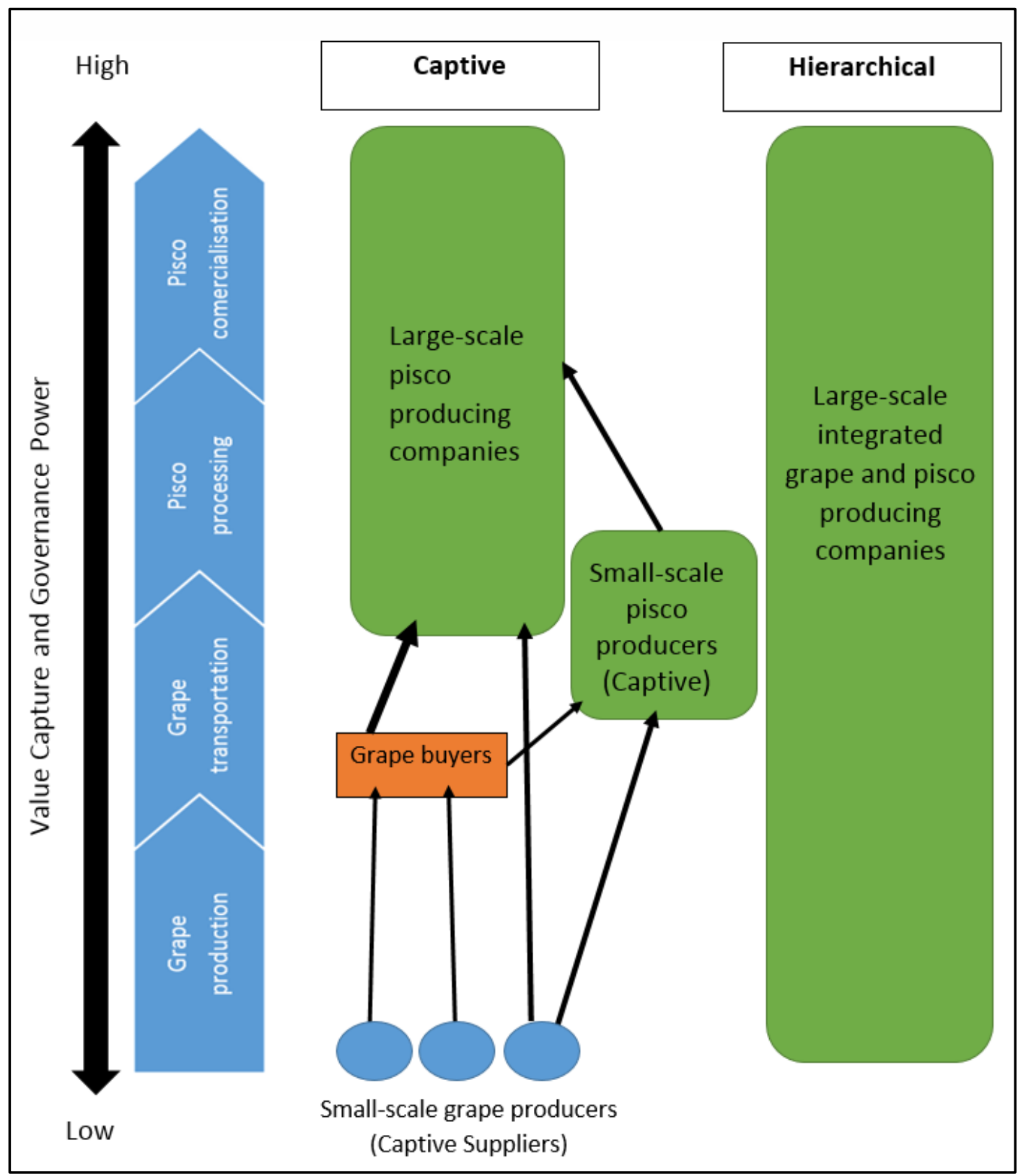

Source: Elaborated by the author using ideas from GVC literature (Gereffi, 1994; Gereffi et al., 2005) and primary data.

\subsection{COMPARATIVE DISCUSSION}

The purpose of this comparative section is to compare and contrast the findings associated with the formation and institutionalisation of the studied EVeNs, presented in this chapter. In doing so, this comparative section asks broader questions which cross the boundaries of the two case studies. This discussion will begin by comparing and contrasting the formation of the two studied networks. Following this, the discussion will compare and contrast the institutionalisation of both cases studies. Where relevant, the section will engage with the 
underlying theories of dependency, world-systems and structuralism as well as the global value chain (GVC) and global production network (GPN) approaches.

\section{Formation: Similarities Between Studied EVeNs}

As demonstrated in this chapter, the EVeNs associated with the pisco DO mark in Peru and fair trade wine in Chile were formed to provide consumers with certain guarantees about how each product was produced (guaranteeing food quality and authenticity in the DO case and equality and social justice in the case of fair trade). Similarly, it was illustrated that both networks have been formed through the objectives of expanding the studied sectors internationally through the use of product labels and certification. Therefore, this research has revealed that both cases studies were associated with growing consumer concerns about global agro-food networks and the increasingly 'placelessness' of food, as discussed in Chapter Three and in the wider literature on ethical trade (Bowen \& Mutersbaugh, 2014; Murdoch et al., 2000). Likewise, the studied EVeNs have both formed following commercial factors and business motives, such as securing new ethical niche markets. This research highlighted common risks in the two case studies, including the appropriation of the ethical value created by more powerful corporate actors. As discussed, these powerful actors were able to use their advantaged positions in the EVeNs to dominant these ethical niche markets, thereby closing opportunities for vulnerable groups which continue to suffer from unequal exchanges, similar to those discussed in dependency and world-systems theories (Halperin, 2013a; Wallerstein, 2004). In many ways, both the fair trade wine in Chile and DO pisco in Peru EVeNs have expanded through the capital of larger-scale conventional companies which have invested in these niche markets which represent new opportunities for profit. Therefore, it has been demonstrated that both networks are open to ethical value appropriation.

\section{Formation: Differences Between Studied EVeNs}

A key difference between the studied EVeNs is that the fair trade wine network in Chile was formed with more explicit social equality and community development objectives compared to key objectives of the pisco DO in Peru to protect the authenticity and quality of the product. As will be discussed, these different objectives meant that the institutionalisation and outcomes of the two EVeNs diverged significantly. This chapter illustrated that another important difference between the case studies was that fair trade wine in Chile formed as a response to an external market demand which already existed for ethically certified wines, especially in Northern European countries. The pisco DO mark in Peru, conversely, was formed as an attempt to create new demand for a niche product at the global scale. The similarity in this instance is that both EVeNs are based in products which are recognised in Northern 
markets, fair trade being recognised for social justice, while DOs are recognised for quality in Europe. Another clear difference in the formation of the studied EVeNs is that the participation of small-scale producers was more obvious in the fair trade wine case study. For instance, the origins of the implementation of fair trade in Chilean wine was partly driven by small-scale producer cooperatives which sought differentiation in difficult conventional markets. In the case of DO pisco, rather than participating actively in the formation of the EVeN, small-scale producers have tended to merely respond to the requirements set by the Peruvian Government. Again, this is linked to the different motivations behind the formation of the studied fair trade and DO EVeNs. Finally, the two studied networks have followed different policy tendencies. For instance, this research demonstrates that fair trade wine has formed following neoliberal tendencies, whereby private groups and organisations have responded to market demands for ethical products. DO pisco on the other hand, has formed under neostructural policies as successive Peruvian governments and public-private partnerships have supported the implementation and promotion of the pisco DO nationally and internationally.

\section{Institutionalisation: Similarities Between Studied EVeNs}

By applying ideas from GVC and GPN literature, this research has demonstrated that the governance of both EVeNs has been dominated, to different degrees, by powerful corporate producers, while small-scale producer groups have faced similar barriers in entering these networks and encountered exclusion from network governance in both studies. The findings also showed that EVeNs are more likely to be associated with complex governance structures as more actors are involved in these networks compared to conventional sectors. This complexity can create institutional overlap and competition between the different actors engaged in the networks, as will be discussed in the following chapter. Both cases demonstrated failings in network governance to hinder the influx of extra-local actors in the case of the pisco DO in Peru and to restrict the expansion of conventional large-scale producers in the case of fair trade wine in Chile. This research has therefore highlighted some of the challenges in ensuring even and representative governance of EVeNs by studying across two diverse networks.

\section{Institutionalisation: Differences Between Studied EVeNs}

The most visible difference between the institutionalisation of the two EVeNs is that the pisco DO network is associated with a larger number of non-firm actors compared to the fair trade wine network in Chile. This is likely a consequence of the neostructural tendencies of the pisco DO which means that there is a significant number of public and private actors associated with 
this network. Although there are some actors associated with fair trade, the fair trade wine actor network in Chile is relatively limited. This is perhaps a result of one of fair trade's objectives of making the value network shorter and fairer. A key difference between the institutionalisation of the studied EVeNs was that governance in the fair trade wine network was clearly more inclusive than in the pisco DO network. For example, while small-scale grape and wine producers were able to improve their positions and influence regulation in the fair trade wine network in Chile, small-scale grape and pisco producers were largely excluded from pisco DO governance in Peru. This is likely associated with the explicit focus on equality in fair trade, while the exclusion of small-scale producers from DO governance and the dominance of larger corporate actors is not atypical for DOs and other geographical indication schemes. The pisco case shares some clear similarities with the problems encountered by the small-scale producers in the tequila sector in Mexico, where global liquor companies have come to dominate the industry (Bowen, 2010a; Bowen \& Zapata, 2009).

\subsection{LINK TO CHAPTER SEVEN}

This chapter has contributed to research aim two; to critically investigate the construction of, participation in, and governance of EVeNs using examples from the fair trade and DO networks in viniculture in Chile and Peru. In order to complete this, the chapter explored the formation of the EVeNs surrounding the use of fair trade in Chilean wine and the DO for pisco in Peru. It revealed that the formation of fair trade wine EVeN in Chile has been motivated by a range of factors including; commercial reasons, demands from external markets, consumer influences, social responsibility, inequalities in the sector, the search for differentiation by small and medium producers. The main driving factors were most likely the commercial opportunities particularly in growing markets for fair trade wine in Nordic countries. The formation of the DO pisco EVeN in Peru has been provoked by a set of different factors including; product differentiation and protection in international and national markets, international diffusion of the product, a way to protect producers and consumers from the informal sector, a support for producers and local communities and finally to promote and protect the cultural, historical and national importance of pisco. Again, commercialisation and creating new markets in the external market have most likely been the driving factor in this case.

Subsequently, the chapter explored the institutionalisation of the studied EVeNs. In doing this, the chapter applied an intersection of GVC and GPN analysis to understand the studied networks through EVeN maps. These EVeN maps were applied to better illustrate actor participation in the studied networks. Furthermore, this chapter has included visualisations of 
the governance types and value capture of the studied networks. Adopting GVC ideas, this chapter showed that both of the networks can be characterised by captive and hierarchy forms governance, with power to set the prices for base materials held by a small number of dominant lead firms in Chile and Peru. fair trade appears to have encouraged more even and relational governance in the case of wine in Chile. The DO has largely failed to create more even governance in the pisco network, at least between the lead firms (industrial pisco producers) and the grape suppliers. fair trade wine was seen to be a more inclusive network which allowed upstream producers to improve their positions, although there were a number of important problems. DO was seen to be exclusive overall as the regulations and markets acted as barriers to the upgrading of the upstream producers. Although there were positive, albeit outlying, case of relational governance and power sharing between the suppliers and certain pisco processing and commercialisation firms as well as small producer upgrading. Finally, the chapter provided a comparative discussion which compared and contrasted the formation and institutionalisation of the studied EVeNs, while asking a number of questions which cross the boundaries of the two case studies. This section reengaged with the underlying theories where possible and demonstrated some of the important similarities and differences between the two case studies, therefore forming broader findings about EVeNs.

The following chapter, Chapter Seven 'Evaluating Ethical Value: Critical Investigation of Ethical Narratives and Local Impacts' extends from this current chapter to examine the idealisation and realisation of the ethical narratives used within the studied EVeNs in Chile and Peru. The subsequent chapter will therefore further explore the impact of the fair trade and DO networks using findings from the research interviews. In completing this, the chapter contributes to the final research aim; to identify the ethical claims utilised to promote these fair trade and DO networks and evaluate how these claims are realised through the detailed investigation in the localities where the selected EVeNs are embedded. 


\section{CHAPTER SEVEN. EVALUATING ETHICAL VALUE: CRITICAL INVESTIGATION OF ETHICAL CLAIMS AND LOCAL IMPACTS}

\subsection{CHAPTER INTRODUCTION}

This chapter builds upon the findings presented in Chapter Six to critically explore the idealisation and realisation of the ethical claims used to promote the studied EVeNs in Chile and Peru. This contributes to the third research aim; to identify the ethical claims utilised to promote these fair trade and DO networks and evaluate how these claims have been realised. In this research, an ethical claim is defined as an assertion, without evidence, that the implementation of an ethical label has created a positive social impact. The realisation is linked to the evidence or lack of evidence which either supports or challenges an ethical claim. The most important ethical claims in the fair trade wine and DO pisco networks were identified by coding and analysing the fieldwork interviews in Nvivo, as well as reviewing the relevant literature. The chapter has applied thematic analysis to organise the primary data from semistructured interviews from both EVeNs case studies. Thematic analysis focuses on what is said over how it is said and has been vital in identifying and organising the key themes across the different research interviews by finding shared thematic characteristics mentioned by the participants (Riessman \& Quinney, 2005). Overall, this chapter seeks to assess EVeNs to better understand if the expansion of these networks has been linked to ethics and positive social impacts or if this expansion, in practice, just represents strategies by corporate actors to market ethics and secure new niche markets.

The first half of this chapter investigates the idealisation and realisation within the fair trade wine EVeN in Chile, by exploring the key ethical claims used to promote this EVeN and the successful and unsuccessful outcomes linked to these claims. The second half of this chapter studies the DO pisco EVeN in Peru, following the same analysis and structure as the first half of the chapter. Subsequently, the chapter provides a comparative discussion which compares and contrasts the ethical claims associated with the two case studies and the realisation of these claims. Finally, the chapter closes with a link to the concluding chapter of this thesis.

\subsection{IDEALISATION AND REALISATION OF FAIR TRADE WINE IN CHILE}

The following sections will explore the idealisation of the fair trade wine EVeN in Chile by identifying some of the key ethical claims used to promote this network. Additionally, these sections will evaluate the realisation of these claims by discussing the different outcomes identified by the research participants. These sections draw from wider literature as well as the semi-structured interviews conducted with grape and wine producers and experts in Chile. 
Coding themes through NVivo demonstrated that the following ethical claims were repeated across multiple interviews:

1. Fair trade supports small-scale producers

2. Company engagement in fair trade creates a broader positive impact by reaching more vulnerable producers and workers

3. Fair trade creates broad community benefits

\subsubsection{Ethical Claim One: Fair Trade Supports Small-Scale Producers in Chilean Viticulture}

As discussed in Chapter Three, at the global level the core ethical claim of the various fair trade certificates is that they improve the livelihoods of small-scale producers in the Global South. The provision of a stable minimum price, known as the 'fair trade price' which protects producers from market fluctuations and covers more than the costs of production is said to improve the livelihoods of these producers. Furthermore, fair trade certified small-scale producers receive a 'fair trade premium' in addition to the fair trade price. The premium is used to encourage community level development through a range of social projects (Jaffee et al., 2004).

In Chile, over half of interviews demonstrated that fair trade wine EVeN was promoted through the same ethical claim that these certificates supported small-scale grape and wine producers. For instance, it was frequently stated during fieldwork that fair trade provided benefits for groupings of small-scale producers. For instance, Ingrid Allende from Fairtrade International (FLO) in Chile explained that;

"For small-scale producers [...] the main motivation to become involved in fair trade is that it guarantees them more stability, as the fair trade price covers the costs of production. The fair trade prices for wine grapes and wine are a lot better than the market prices, moreover, there is the premium which generates development projects..."

Likewise, Karene Volpato, from Institute of Marketology Chile, the Fair for Life certifier, stated that fair trade certification had helped small-scale producers to reach niche ethical markets abroad;

"Fair trade has also helped small-scale producers to export and this has been helped by international niche markets where consumers want to buy from smallscale producers who care for their people and for their local environments, and the certification helps a lot with this." 
The majority of participants also supported the ethical claim that fair trade created more stability for small-scale producers which meant that they felt more respected in the fair trade market. For example, Gerardo Wijnant, Sustainability and Fair Trade Consultant in Chile stated that;

“...Producers also become certified so that they feel respected in their work [...] in many cases the fair trade price is not much better than the traditional price, but the commitment to the long-term and the stability is more valuable for these producers."

The interviews revealed that representatives from small-scale producer associations tended to perceive that fair trade as a movement aligned well with their organisation's social principles. In these cases, fair trade was integrated into the social statements and principles used to support and promote these producer groups. For example, Álvaro Muñoz from Cooperativa Vitivinicola Loncomilla, stated that fair trade had extended from the social vision of the cooperative;

"The fair trade certification extends on our vision and takes this a step further to search for more direct commercial channels so there are fewer middlemen, and so that the consumer is conscious that a large percentage of what they are paying is going to the producers of the raw material."

Similarly, participants from small-scale producer associations claimed that fair trade supports the grape producers and their families. For instance, Teresa Cañete from Viñas Caupolicán in Curicó explained that; "...fair trade creates benefits for all of the families involved and means that the viticulturists can improve their vineyards, it helps with their health and with the education of their children."

\subsubsection{Successful Outcomes of Ethical Claim One in Fair Trade in Chilean Viticulture}

Detailed fieldwork in Chile revealed cases where ethical claim one has been realised through a number of positive outcomes. The successful realisation of ethical claim one can be separated into the two groups of outcomes:

- Stable and fairer prices

- Other benefits for producers

\section{Stable and Fairer Prices for Small-Scale Grape Producers in Chile}

Research participants tended to mention that the main positive outcome of fair trade was the stable and fairer grape prices fair trade provided in comparison to the unstable prices offered 
in the conventional market in Chile. For instance, José a small-scale grape grower at the producer association Red del Vino in Colchagua explained the difficulties in making a profit in the conventional grape market and highlighted the positive impact the fair trade certification has had on grape prices;

“...the grape prices are not fair in Chile. The production costs for each kilo of grapes are between 150-180 pesos, but sometimes we are forced to sell our grapes for 70 130 pesos. [...] we suffer large losses with these prices. Fair trade has had an impact here, it pays more than these market prices."

The fair trade prices surpass the production costs quoted by José and other grape producers while providing a profit margin. Moreover, there is an additional value for producer and community social development known as the premium. Ingrid Allende from FLO described the positive impact fair trade has on the grape prices in Chile;

"The minimum prices for wine grapes certified with fair trade is 0.28 euros (210 pesos) per kilo and additional to this, there is the fair trade premium which is 0.05 euros (37 pesos) per kilo [...] The largest grape buyers [...] sometimes pay less than the production costs of grapes [...] fair trade provides the grape producers with an alternative..."

Participants also mentioned the positive outcome fair trade had created in protecting the small-scale producers in moments of low grape prices. For example, Claudio Jorquera General Manager at fair trade certified small-scale producer association Viñas Caupolicán in Curicó discussed how the fair trade price had protected Caupolicán's producers over years of low grape prices in Chile;

"The fair trade price has been higher for our producers over the years compared to what they would have received outside of our organisation. Our fair trade prices have protected them over the last two to three years where the market prices have been very difficult and unstable."

Various small-scale grape producers interviewed expressed similar ideas. For instance, Rafael Espinoza small-scale producer and partner of Vinos Lautaro also in Curicó, supported these ideas from a producer's viewpoint and demonstrated some of the non-commercial value of fair trade;

"The main benefit of fair trade is knowing that someone is paying a fair price for my work rather than basically robbing me [...] Fair trade has this commercial value 
of course, but it has a value that we cannot put a price on; the fair trade system means I did not need to sell the land that I received from my father..."

This research, therefore, found cases where the different fair trade certifications have provided fairer and more stable prices thus supporting small-scale grape producers and wine producer groups. The fair trade market has therefore provided an ethical niche market which represents an alternative to the unstable low-paid conventional wine grape market in Chile. This research has shown that fair trade certifications in Chilean wine have therefore been at least partly associated with ethics and supporting small-scale producers.

\section{Other Benefits for Small-Scale Producers in Chilean Viticulture}

Research participants also discussed broader benefits fair trade has created for groups of smallscale producers in viticulture in Chile. These benefits have been attributed to the higher and stable prices, the use of the fair trade premium as well as the linked benefits of working in association with other producers. As explained by Victor Aguilera Commercial Manager at Vinos Lautaro, since certifying with fair trade in 1997 there have been positive changes for the organisation's grape-producing partners which extend beyond better prices;

"...we have seen a complete change in the quality of life of the partners, there have been large improvements which do not only relate to the better incomes. Our producers have stated that they have experienced significant changes in themselves [...] they have moved from being small-scale producers to owners of an exporting company. The changes for the families have also been very important..."

A number of small-scale producers described how fair trade had been an important support for them and their families. For example, Luis a small-scale grape producer and partner at Viña Caupolicán, explained how fair trade had supported him and improved the quality of life of his family;

"I have noticed changes in my life since entering fair trade, life was a lot harder before fair trade [...] Now with fair trade [...] our children have the opportunities to study, this is paid by the fair trade premium."

Other participants demonstrated how fair trade has created broad changes for producers and their communities. For instance, Rodrigo Valenzuela, General Manager at Red del Vino in Colchagua, explained some of the wider and positive changes that fair trade can have for these groups;

"It is important to understand that fair trade is not purely economic [...] it is not a mechanism to convert poor people into rich people. It is a mechanism to convert 
poor people into sustainable people, and by converting them into sustainable people this allows them to help their families and communities..."

From the interviews, it became evident that ethical claim one; fair trade supports small-scale producers, had been realised in a number of cases in the Chilean viticultural sector. These positive or successful outcomes included fairer and more stable prices as well as broader benefits for producers and their communities. In this sense, it can be observed through the interviews that the fair trade wine network is associated with several ethical concerns.

\subsubsection{Failed Outcomes of Ethical Claim One in Fair Trade Chilean Wine}

Despite some of the positive outcomes discussed above, the interviews also demonstrated three broad areas where ethical claim one has not been largely unrealised. These categories were;

- Positive impact is limited

- Barriers for small-producers

- Fair trade unlikely to solve larger problems sector

\section{Fair Trade has Limited Positive Impact}

The interviews demonstrated a number of limitations and failures of fair trade in supporting small-scale producers in the wine network in Chile. For instance, Philippo Pszczolkowski, a senior academic at Pontificia Universidad Católica de Chile highlighted that although fair trade has had some positive impact in the network he recognised that this impact has been narrow;

"Yes, the certification can help the smaller producers but the problem of the concentration of the wine sector remains [...] Vinos Lautaro have managed to export wines which indicates that fair trade has helped small-scale producers to access new markets, however, these cases are very limited."

Likewise, participants discussed the restrictive options for small-scale producers when attempting to enter the fair trade certification. For example, Yenny Llanos from the Coalición Nacional de Viñateros, described the difficulties for small-scale grape producers in accessing fair trade markets and certifying their production;

"I was told by a fair trade certifier that if we don't have someone to buy our fair trade certified grapes then the certification won't help us. The barrier is that smallscale producers have to find the demand [...] It is difficult for smaller producers to find clients to buy fair trade production [...] they campesino farmers, what options do they have to find clients?" 
Participants, particularly those representing the certifiers discussed some of the problems in finding the demand for niche fair trade products. For example, Ingrid Allende from FLO, explained some of the challenges in finding opportunities in the fair trade market which largely remains niche;

"...there is not the same growth in demand for fair trade as before and this why we have told producers to check that there is demand for their products before certifying. The fair trade market is a niche market and sometimes the commercial opportunities do not exist..."

\section{Barriers for Small-Producers in Entering the Fair Trade Wine Network in Chile}

The field interviews also highlighted a range of barriers which limited the possibilities of smallscale producers in becoming fair trade certified. Ingrid Allende from FLO explained that the costs of certifying can represent an important barrier for producers;

"An important barrier is the cost of the certification, it is around 2,000 Euros which is 1,500,700 Chilean pesos for the first year. This is a barrier because there are associations which are just starting or very small and they do not have a lot of access to finance."

Some participants stated that this cost barrier, which was seen to disproportionately exclude small-scale producers from fair trade certification, to diminish the core principle of fair trade as an instrument to support vulnerable producers. For example, Gabriel Edwards a small-scale winemaker stated that;

"I believe the main problem with fair trade is the cost of certifying, this takes away from the essence of fair trade as it is a high cost for smaller producers. There are many smaller producers which are fairer than the larger ones, but don't they cannot afford these certifications."

This is a clear failing of the fair trade EVeN, by excluding the most vulnerable small-scale producers it is unclear how fair trade is able to address some of the ethical concerns among Northern consumers about these types of producer groups, as discussed in Chapter Three. Similarly, Gerardo Wijnant Sustainability and Fair Trade Consultant in Chile, explained that financial support so that producers can access certifications simply does not exist and that the state has not shown enough interest in supporting the expansion of fair trade in Chile;

"There is a shortage of available finance, this impedes the producers from fully taking advantage of the certifications. Also, there is low public sector recognition 
of fair trade which means that public agencies are failing to generate more projects [...] to help develop fair trade here."

Without State involvement, fair trade wine, therefore, continues to be facilitated by private groups and capital. There are also other barriers which restrict small-scale producers from becoming fair trade certified thereby limiting the realisation of ethical claim one. In particular, participants discussed the importance of creating producer associations so that producers can share the costs and administration involved in fair trade certification. However, as described by Raúl Navarrete General Manager at Vinos Lautaro there are important challenges of forming producers associations in Chile;

"In Chile, a challenge is that the producers are nervous about working in associations, this came before the Pinochet era but was worsened during the dictatorship [...] This has made it very difficult to encourage producer associations, which has made it more difficult for small-scale producers to certify with fair trade."

In other cases, producer groups lacked knowledge about the fair trade certifications which created an evident barrier to becoming certified. PhD researcher Daniella Gac from Universidad De Los Lagos, explained this obstacle;

“...there are some producers that don't know about these certifications, including in the cases where it would make a lot of sense that they use these certificates. This is an area where the public sector could help a lot by informing the producers through the institutions that support small-scale producers."

Therefore, without State support, small-scale producers and cooperatives face significant barriers in entering the fair trade wine network. This raises questions around the ethical foundations of creating a network to support vulnerable groups if many of these actors are not included in this network.

\section{Fair Trade Unlikely to Solve Larger Problems in Chilean Wine Network}

The interviews also found that some participants believed that fair trade had failed to improve the overall quality of life of the certified producers while failing to solve the larger problems that these producers faced in Chile's wine sector. For example, Gerardo Orellana grape producer and president at the Red del Vino, explained that the overall positive impacts of fair trade had been slow to develop;

“...there has not been the needed constant sale of our fair trade certified products to really have a large positive impact in our lives as producers [...] We hoped for more long-term sales through fair trade to be able to achieve the stability that we 
want. This stability would flow-over to more important impacts and create positive changes in our lives."

An unnamed academic from the Universidad de Chile, explained that there are limitations to how ethical certifications can solve the larger problems faced by small-scale producers in Chile's viticultural sector;

"I am not sure if the certifications can help with the problems we have discussed [...] my impression is that the problems are created by monopolist power in the wine sector, and this cannot be resolved with a certification."

In this sense, it appears that fair trade wine in Chile remains too limited in scope to be able to address the larger problems experienced by small-scale grape producers in Chile, caused by the dominant positions of a select few powerful wine producers which control the grape markets and enforce low prices. Therefore, although the interviews showed cases where fair trade has realised the ethical claim of supporting small-scale producers in a number of cases, the interviews also demonstrated a number of failures and limitations in realising this ethical claim. It is important to note the contradictory nature of the interview responses. While some participants discussed the successes of fair trade in supporting small-scale producers, others discussed the failings of fair trade. This is mostly explained by the diversity of the experiences of the research participants. For instance, the producers who have received positive outcomes of fair trade are more likely to discuss its successes and benefits, compared to producers who continue to be excluded from the network through the barriers mentioned.

\subsubsection{Ethical Claim Two: Company Engagement Creates Broader Positive Impact in Chile's fair trade Wine Network by Reaching More Vulnerable Producers and Workers}

As explained in Chapter Three, over the last decade, the different international fair trade certifiers Fairtrade International, Institute of Marketology and Fair Trade USA, have integrated larger companies into the fair trade movement under the plantation or hired labour model. The growing involvement of these larger companies and hired labour has sparked global debates about fair trade, including in Chile's fair trade wine sector. As discussed in more detail in Chapter Three, those that supported this shift that fair trade is having a 'larger impact' by reaching more vulnerable workers and producers in the Global South (Fair Trade USA, 2012). Those against the inclusion of larger companies have argued that this shift has removed smallscale producers from the central focus of fair trade (Equal Exchange, 2012; Renard, 2005).

Interviews in Chile discovered an important ethical claim that the engagement of larger wine producers in Chile's fair trade wine network has created a broader positive impact by 
benefiting workers and small-scale grape and wine producers. For example, Robin Ramakers from IMO Fair for Life certifier in Chile supported the ethical claim that fair trade supports employees in certified wineries;

"...some larger wineries are now fair trade certified, in these cases, the workers receive benefits as the companies have to follow fair trade standards which means the workers receive good working conditions and decent pay among other benefits."

Likewise, Ingrid Allende from FLO in Chile supported the ethical claim that fair trade provides benefits for employees at companies that are fair trade certified, especially through the premium;

"All of the companies that are fair trade certified provide benefits to their workers, the main way they do this is through the premium [...] this allows workers to generate development projects, these projects usually cover social and environmental areas."

Participants from the medium and larger scale wineries involved in fair trade tended to explain how the use of fair trade had benefited their workers as well as the companies. For example, Rodrigo Constandil from Miguel Torres in Curicó stated the fair trade had had a positive impact on the workers at this winery;

"I believe that the largest change we have seen is with our workers, they are more committed to their work and more enthusiastic. They know that they have the premium to be used for social development projects which is something that benefits them."

These participants also tended to support the ethical claim that fair trade certification has been used to demonstrate some of the positive work at wineries in supporting their employees through their social responsibility programmes. For example, Germán López from the winery La Fortuna also in Curicó mentioned that;

"We decided to certify ourselves with fair trade because as a company we are very connected with our workers [...] maintaining fair trade is expensive [...] but the owners are interested in maintaining this certification because it helps to show our fair treatment with our staff."

Additionally, there is an ethical claim that the integration of larger wine-producing companies into fair trade wine in Chile has support small-scale producers. It is claimed that this integration 
has created opportunities for small-scale producers to sell their grapes under the improved conditions of the fair trade market. Rodrigo Constandil from Miguel Torres explained this positive impact; "Obviously the producers that have entered fair trade have seen improvements in their livelihoods, it has provided them with a fair market for their grapes and in some cases their wine."

Some small-scale producers supported these ideas. For example, Secundina Vasquez from Esperanza para la Costa, a group of small-scale producers with fair trade certified grapes, supported the notion that the involvement of the larger wineries in fair trade has been a positive development for fair trade certified small-scale producers; "I believe the integration of the large wineries in fair trade is something positive for us, if these large wineries did not make fair trade wine then we wouldn't have these better markets to sell our grapes."

Similarly, Gerardo Orellana from Red del Vino in Colchagua, mentioned that there are important benefits for small-scale producers which have resulted from the involvement of larger wineries in fair trade in Chile. However, Gerardo explained that this integration means that the small-scale grape producers remain in a supplier role;

"There are good and bad things which come from the integration of large wineries into fair trade. They provide an alternative market for our production [...]. This, however, means that the producers and the associations do not advance in the chain, they continue to be suppliers but under better conditions."

\subsubsection{Successful Outcomes of Ethical Claim Two in Fair Trade in Chilean Viticulture}

Field research in the Curicó and Colchagua valleys demonstrated that the realisation of ethical claim two. These interviews revealed cases where company engagement in fair trade has created a broader positive impact in Chile by benefiting workers and small-scale producers through positive outcomes based on the following;

- Benefits for workers

- Benefits for small-scale producers

\section{Benefits for Workers in Chilean Fair Trade Wine Network}

A range of research participants mentioned the positive outcomes fair trade had created for the employees at larger-scale wineries with lines of fair trade certified wine. These positive outcomes were usually linked to the premium raised through fair trade. For instance, Belen Ruz from Wines of Chile (association for Chilean wine producers), explained that fair trade had 
generated positive outcomes for employees at a number of large-scale wineries involved in fair trade;

"Workers receive benefits from fair trade in some of the industrial wineries [...] there are large wineries which, as part of their fair trade programmes, have established spaces in their vineyards where the workers can plant vegetables to sell [...] These workers also have access to medical services funded through fair trade."

Various participants from larger-scale wineries involved in fair trade discussed the benefits their employees have received through fair trade. For instance, Marietta Montenegro, from Emiliana, a large-scale winery, explained how they have used fair trade to realise a number of positive benefits for their employees and highlighted the employees' ownership of the fair trade premium;

"...our workers manage the fair trade premium through a workers committee, the committee directive is elected through workers' elections. This committee has organised projects to improve the workers housing, there is a health fund, a solidary fund to help in the cases where a worker faces a serious problem..."

Other participants explained that fair trade had positive outcomes for employees in the viticultural network when there was a clear commitment to fair trade by the larger companies. For example, Gabriel Edwards a winemaker, supported the idea that fair trade has had positive consequences for the employees of the larger wineries involved in fair trade;

"I believe that fair trade's growth, including in the larger vineyards, is something positive as long as it is not merely used as marketing to sell more [...] For example, in Emiliana, I know that they have policies to provide land for their workers to produce their own products, it seems that this is a true fair trade policy in this case."

A number of interviewed employees from fair trade certified wineries felt that the certification had been something positive for them and their colleagues. For example, Roberto from the fair trade committee at winery La Fortuna (fair trade certified large-scale winery) explained that fair trade had been successful in realising a range of positive outcomes for the employee there;

"For us workers, the certification has been very important, the premiums have generated a great impact for us [...] we are taking very good advantage of the premium through different projects; from repairing bikes, to fixing teeth, to the solidary fund which helps workers [...] It is difficult to measure the changes that fair trade has caused in our lives, but it has helped us a lot." 


\section{Benefits for Small-Scale Producers in Fair Trade Chilean Wine Network}

The research also demonstrated that there has been some positive outcomes for small-scale grape producers resulting from the integration of larger wineries into the fair trade wine network in Chile. For instance, Secundina Vasquez from Esperanza para la Costa explained that the integration of large wineries into fair trade has created benefits for herself and other fair trade certified grape producers. Secundina highlighted the positive relationship between the association Esperanza para la Costa and Miguel Torres Wines;

"Our relationship with Miguel Torres is very good, we are not numbers to them we are people [...] they involve us in their events about the products that we supply grapes for, and they introduce us to the clients [...] because of fair trade we receive a better price for our grapes, which means a better a quality of life..."

Through fieldwork, it became evident that ethical claim two; that company engagement in fair trade has created a broader positive impact by reaching more vulnerable Producers and workers in Chile had been realised in certain cases.

\subsubsection{Failed Outcomes of Ethical Claim Two in Fair Trade Chilean Wine}

Despite the positive outcomes due to the engagement of larger companies in fair trade wine, fieldwork in Chile also revealed a number of failed and negative outcomes related to this second ethical claim. These failed and negative outcomes were related to the following:

- Niche fair trade market dominated by larger companies

- No distinction between hired labour and producer fair trade

- Larger wineries concentrate the benefits of fair trade

- Temporary workers do not benefit from fair trade

\section{Niche Fair Trade Market Dominated by Larger Companies in Chilean Viticulture}

Although the interviews demonstrated cases where ethical claim two had been realised by creating positive outcomes for employees and grape suppliers, research participants also discussed a number of negative or failed outcomes associated with the involvement of larger companies in Chile's fair trade wine sector. For instance, Álvaro Muñoz from Cooperativa Vitivinicola Loncomilla explained how the participation of larger wineries in fair trade signified a shift from its original purpose of supporting small-scale primary producers;

"I believe that in some cases there are wineries that shouldn't be fair trade certified, especially the larger wineries. I feel they use the certification as a marketing tool more than a real conviction to improving the living conditions of their workers [...] the benefits of fair trade are meant to go to the raw material producers..." 
Expanding on these ideas, a number of research participants explained how larger wineries have come to dominate the fair trade wine network which is excluding small-scale producer groups from these niche markets. This suggests that the involvement of the larger wineries in fair trade is failing to have a broader positive impact by supporting small-scale grape producers. Gerardo Orellana from Red del Vino, described these problems;

"I don't understand why a company should certify itself so that their workers receive minimal benefits, these benefits are the basic responsibilities of the company [...]. For us, the most negative change is that the large companies arrive with all of their resources and occupy a niche that was started to support smallscale producers."

The interviews, especially with small-scale producers and representatives from the producer associations, revealed that participants from these groups largely believed that allowing the engagement of larger companies in fair trade has been an error. It was frequently stated by these participants that company integration had converted the certification into an unfair system. Raúl Navarrete General Manager at Vinos Lautaro for instance, discussed the involvement of the larger companies in fair trade and explained how this engagement has failed to contribute to social justice and equality goals of fair trade. Instead, Raúl described how fair trade is now largely been used as a marketing tool which has removed smaller-scale producers from the fair trade ethical niche market;

"It is not fair when larger wineries use fair trade because small-scale producer organisations like ours cannot compete with transnational wineries [...] the inclusion of the large companies into fair trade does not contribute to social justice or equality..."

\section{No Distinction between Hired Labour and Producer Fair Trade on Chilean Wines}

A number of participants identified the lack of distinction between fair trade certification for small-scale producers and hired labour as an important failure of fair trade. This creates challenges for small-scale producers who are forced to compete in the same markets as the larger wineries under the identical fair trade certification. As explained by Rodrigo Valenzuela General Manager at Red del Vino, this creates confusion in the fair trade markets as there is ambiguity about who the certification is supporting;

"...it is unfair that our wine made by small-scale producers uses the same fair trade certification as the wines of the large producers [...] I believe there is manipulation 
of information by the certifiers [...] it is unfair that the consumer does not have the clarity of what kind of fair trade they are supporting."

Participants mentioned that the inclusion of larger wineries has failed to create a broader positive impact in the producer communities. For example, Victor Aguilera from Vinos Lautaro summarised these failings;

"...the large producers with fair trade certified lines of wine have minimal impact in the producer communities [...] the consumer wants to buy something that makes a positive impact but they cannot see the difference between a small-scale producer organisation and a transnational company through the fair trade label."

These comments from participants in the case study in Chile support a larger critique of the plantation model in the Fairtrade and Fair for Life certifications. While the fair trade movement was created to support small-scale producer groups to access markets and escape cycles of poverty, there are cases, as demonstrated in the Chilean case study, where these certifications are used to secure profits for larger-scale producers. The expansion of corporate groups in fair trade certifications places the higher fair trade prices and the long-term stability of fair markets at risk, and excludes the entry of some small-scale producers as can be observed in the fair trade wine case study in Chile.

\section{Larger-Scale Wineries Concentrate the Benefits of Fair Trade in Chile}

A number of participants described cases where larger wineries with lines of fair trade wine have engaged in abuses practices, such as paying grape suppliers below the production costs for their non-fair trade lines of wine. For instance, wine producer Gabriel Edwards explained this problem;

"There are also issues with some of the fair trade certified companies that are also involved in abusive practices for their non-fair trade wines. For example, a winery with a fair trade certified wine line can pay the other grape producers outside of this fair trade line very little and there are no repercussions for this."

Similarly, participants criticised the growing involvement of the larger wineries in fair trade in Chile. For example, Yenny Llanos from the Coalición Nacional de Viñateros discussed some of the negative outcomes for grape producers and wine consumers resulting from the involvement of larger companies the fair trade wine sector;

"The wineries, for example, Miguel Torres, pays their grape suppliers a little more when their grapes are fair trade certified, but Torres then sells these fair trade 
wines for a lot more. In this way, they are cheating the consumers as the intermediary receives most of the benefits."

The growing roles of corporate actors in fair trade are explored in the wider literature. These authors criticise this shift as it erodes the movement's ability to critique conventional forms of trade and highlight the unethical practices of some of these corporate actors, as fair trade now relies on these groups as producers, distributors and sellers. This literature also highlights that due to their marketing power, corporate producers find it easy to expand their fair trade product lines, therefore displacing small-scale producers involved in fair trade (Fridell, 2007; McMurtry, 2009). The expansion of larger-scale actors in the fair trade case study in Chilean wine as discussed above confirmed the validity of these concerns and critiques as evidence illustrated that these large-scale producers tend to concentrate the benefits of fair trade certifications in Chile.

\section{Temporary Workers Unlikely to Benefit from Fair Trade in Chilean Viticulture}

As discussed, temporary employment has expanded in Chile's wine network in recent decades, however, it is not clear if these temporal employees benefit from fair trade. $\mathrm{PhD}$ researcher Daniella Gac, explained this possible limitation in the case of the fair trade hired labour model in wine in Chile;

"...the majority of the workers are temporal and work in particular seasons [...]

These workers don't work directly for the wineries as they are sub-contracted and it is unlikely that these workers receive benefits from the certifications."

The realisation of ethical claim two, that company engagement in fair trade has created a broader positive impact in the wine network in Chile by benefiting workers and small-scale producers has clearly been varied. Despite creating some benefits for a select number of hired workers and small-scale producers, the involvement of larger wineries in the fair trade wine network in Chile has been associated with a range of failings and negative outcomes for the groups fair trade claims to support. These failings raise important questions about the ethicality of the insertion of corporate producers into the fair trade wine network under the hired labour model. This research has revealed that the entry of these companies into this EVeN has been largely driven by the search for new commercial opportunities. As a result, the ethical niche market for fair trade Chilean wine is being dominated by larger-scale producers which are appropriating the ethical value of the network while ignoring the costs for smaller-scale actors, which depend on these same ethical markets. 


\subsubsection{Ethical Claim Three: Fair Trade Creates Broad Community Benefits in Chile}

As explored in Chapter Three, broader literature claims that fair trade encourages benefits for the communities in the production areas. These benefits are said to be generated through the social premium raised through fair trade which is designated towards projects for community social development (Méndez et al., 2010). The various fair trade certifications used by both small-scale producer groups and companies with hired labour generate this premium to be used in projects such as schools health clinics, transport and infrastructure, which should encourage broad benefits in the local communities (Dragusanu et al., 2014; Jaffee et al., 2004).

Ethical claim three, that fair trade creates broad community benefits was frequently made by research participants in Chile. For example, Ingrid Allende from FLO in Chile, stated that the fair trade premium had been used in Chile to support community development;

"The initial projects generally cover basic necessities for the producers or workers and their families. Once these basic needs are covered, the second vision is how to support the community [...] There is a social vision that the premium has to be used to support social projects in the communities..."

A number of participants from small-scale producer groups also highlighted the importance of the fair trade premium in helping the local communities. For example, Gerardo Orellana from Red del Vino, explained what the premium signifies from the viewpoint of a small-scale grape producer and partner of a fair trade association; "...There is also a social impact through the social premium [...] Our association, for example, seeks opportunities to support the community in the Colchagua Valley."

\subsubsection{Successful Outcomes of Ethical Claim Three in Fair Trade in Chilean Viticulture}

Interviews showed that the realisation of the third ethical claim, that fair trade supports broad community, tended to be based on the positive outcomes associated with the community development projects realised through the fair trade premium generated.

\section{Community Development Projects Realised Through Fair Trade Premium in Chile}

Research interviews with participants found successful examples where fair trade premium generated by different companies and associations were being used to support community development projects. Claudio Jorquera, General Manager of fair trade certified small-scale producer association Viñas Caupolicán, explained how this group had used the premium to support the wider community in diverse projects; 
"The producers understand that the premium has real benefits. There has been a lot of focus in our organisation on health and education in the local towns [...] the premium is having a benefit for the wider community."

Participants from larger producers also discussed the important impacts the premium can have for the local communities. For instance, Rodrigo Constandil, Miguel Torres Wines, discussed this from the perspective of a larger winery involved in fair trade;

"We have funded many projects that benefit the community through the premium [...] we have constructed school facilities, provided services for vulnerable children, we constructed a bridge, a solidary dining hall, and a lot more [...] This year, we will reach US\$1 million distributed in premium since starting with this in 2010, it is a lot of money."

Therefore, in a limited number of cases, the fair trade premium resulted in positive spill-over impacts in the local communities in the wine-producing case study areas in Chile. This thereby confirmed some of the positive community outcomes mentioned in wider literature related to fair trade (Dragusanu et al., 2014; Méndez et al., 2010), as discussed in Chapter Three.

\subsubsection{Failed Outcomes of Ethical Claim Three in Fair Trade in Chilean Viticulture}

A number of participants expressed their doubts about the realisation of ethical claim three, stating that fair trade has not created the claimed broad positive impacts in the communities. According to these participants, the failings of ethical claim three was based on the following two factors;

- Community impact depended on producers

- Impact in community remained limited

\section{Community Impact of Fair Trade in Chile Depended on Producers}

Some participants stated that the impacts of wine-producing groups in the local communities do not depend on the certifications they use, and instead depends on the producer. For example, Jaime Roselló from Acróbata Wines, criticised the notion that certifications determine a winery's impact in the community and explained that the way a winery operates is more important;

"I would say implementing ethical forms of trade has positive impacts in the communities while using the certifications doesn't ensure a positive impact [...] Certifications do not guarantee any positive outcome for the communities, while real ethical trade does." 
Other participants supported this line of criticism. For instance, wine producer Gabriel Edwards, stated that the impacts a company has in the community is determined by the policies of the company rather than the use of a certification;

"Good practices of a company translates to positive impacts in the community. I am not sure if the certifications can have a positive impact if the company in question does not follow a real desire to do 'good' in the communities..."

\section{Impact of Fair Trade in Chilean Communities Remains Limited}

Other participants acknowledged that although fair trade has the ability to generate positive impacts for the local community, they felt that this impact has remained limited due to the small-scale of fair trade in the wine sector. Sven Bruchfield, from medium-scale winery Polkura Wines described this limitation: "...fair trade wine has had positive impacts in the communities but these impacts are barely noticed because fair trade is very small [...]. For now, the positive impact is very localised and small-scale."

Similarly, participants from small-scale producer associations expressed the difficulties in creating community level outcomes. For example, Secundina Vasquez from the producer association Esperanza para la Costa, described how the premium raised by this group is only enough to support the producers who form the association;

“...we do not receive enough funds from the premium to help the community. The premium remains low because our product is small-scale, therefore the premium doesn't cover anything for the wider community..."

As discussed, ethical claim three that fair trade creates broad community benefits, to some degree has been successfully realised in Chile's fair trade wine network through the generation of the fair trade premium. However, as also illustrated fair trade has not ensured positive outcomes in the communities and these outcomes depend more on the way the wineries operate. Furthermore, it was argued that while fair trade has supported social development in the communities, it was acknowledged that this impact remains limited due to the small-scale of fair trade wine in Chile.

\subsection{SUMMARY: IDEALISATION AND REALISATION OF EVEN IN FAIR TRADE WINE IN CHILE}

This first part of the chapter has therefore applied a critical and detailed exploration of the idealisation and realisation of the fair trade wine EVeN in Chile. In doing so, this chapter has presented three key ethical claims used to idealise and promote this network. These claims were identified using interview coding in NVivo. The ethical claims identified were; 
1. Fair trade supports small-scale producers

2. Company engagement in fair trade creates a broader positive impact by reaching more vulnerable producers and workers

3. Fair trade creates broad community benefits

Figure 34 Ethical Footprint: Fair Trade Wine in Chile

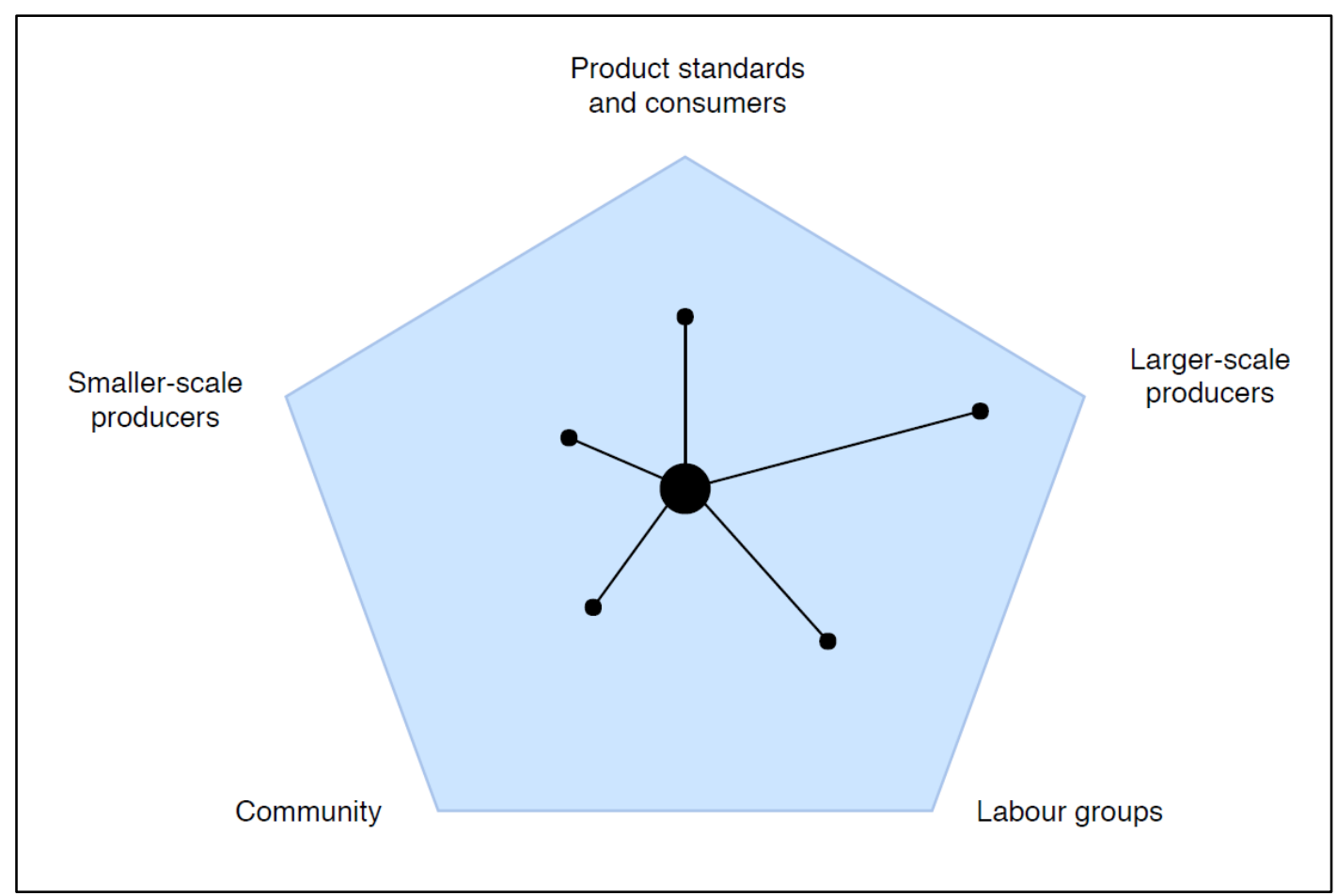

Source: Elaborated by the author and supervisor Professor Warwick Murray

It was revealed that each of these ethical claims have been realised with positive, failed and negative outcomes as discussed in this chapter so far. Figure 34, above provides a qualitative diagram of the ethical footprint of fair trade wine in Chile based on interview responses coded in NVivo software. It is important to emphasise that the ethical footprint is a qualitative estimate of the weak, moderate and strong realisation of the ethical claims. The black centre of the diagram represents an absolute failure to realise the ethical claims of the network. The further the black lines move away from the centre and towards a group, the more this group has benefited from the realisation of the ethical claims. From the ethical footprint for fair trade Chilean wine, it can be observed that larger-scale producers have benefited that most from the realisation of the ethical claims associated with the use of fair trade certification in Chilean wine. Following the larger-scale producers, labour groups and consumers have experienced moderate benefits from the realisation of the ethical claims in this EVeN. Small-scale producers and local communities, on the other hand, have experienced weaker benefits through the realisation of these ethical claims. As demonstrated in the first part of the chapter, the 
realisation these claims has been complex. A summary of these multifaceted outcomes is also provided near the end of this chapter in Table 9.

\subsection{IDEALISATION AND REALISATION OF EVEN IN DO PISCO FROM PERU}

The second part of this chapter will continue the same structure as the first part in order to investigate the idealisation of the EVeN of pisco DO in Peru. To complete this, the subsequent sections will explore the key ethical claims used to promote this network and evaluate the realisation of these claims. I revealed these claims by using NVivo to code key themes across the interviews.

The identified ethical claims were:

1. The pisco DO supports local small-scale producers

2. The DO supports local community development and the preservation of local culture

3. The DO safeguards product authenticity and quality

\subsubsection{Ethical Claim One: Pisco DO Supports Local Small-Scale Producers in Peruvian Viticulture}

As explained in Chapter Three, wider literature about geographical indications, and more specifically around DOs, make the central ethical claim that these networks can protect local producers from the negative outcomes of globalisation while connecting these producers to global markets (Bowen, 2010b; Gerz \& Dupont, 2006). The legal protection provided by these DO marks is said to have benefits for producer communities by providing economic returns from the maintenance of their localised and traditional agricultural practices, while also safeguarding their local cultures and products from the extra-local appropriation (Boisvert, 2006).

In Peru, research participants used the ethical claim that the DO pisco EVeN had supported local producers, including small-scale pisco and grape producers. It was claimed that the pisco DO had created important returns for different producers groups and that the DO mark had been inclusive, thus supporting smaller-scale producers. For instance, Peruvian diplomat Gonzalo Gutiérrez, explained how the specificity of a DO creates economic returns for different groups involved in the pisco network: "DO products are associated with high-quality and this association should create a good economic return for the producers, the grape growers, and the others involved..."

The claim that the DO had supported producers was extended by a number of participants which stated that the DO was able to support small-scale producers in particular. For example, 
a representative from the state institution INDECOPI, claimed that the DO added-value to the pisco made by small-scale producers and improved the market access of these producers;

"The DO supports small-scale producers by providing them with opportunities to enter markets with a value-added product, and thus providing them with an economic benefit. They can, therefore, benefit from the recognition that the DO offers, which shows that pisco meets qualities standards."

Moreover, the claim that the DO has supported the producers was not limited to those that produced pisco, but also included the pisco grape producers. For instance, Patricia Gamboa an expert in DOs in Peru, claimed that the pisco DO has been designed to include the pisco grape producers;

"The DO is designed to benefit all of those involved in the chain, not just the pisco producers but also the grape producers [...] there have been important attempts to include these different producers..."

Furthermore, participants stated that the growth in sales and demand for pisco often associated with the DO, has created benefits for the pisco grape producers. Marketing specialist, Bruno Fistrovic explained this; “...Grape prices must have increased in value due to the growing demand for grapes to make pisco as pisco markets continue to grow..." Additionally, it was claimed that the pisco DO mark had supported local producers by protecting them against the falsification and extra-local appropriation of their traditional product. A representative from a large-scale pisco producing company in Ica explained this;

"The DO was needed to protect pisco both in national and international markets. There are many grape liquors in the world and the only way to protect pisco and its distinct qualities is through a DO mark."

\subsubsection{Successful Outcomes of Ethical Claim One in Designation of Origin for Pisco in Peru}

The interview revealed a number of examples whereby ethical claim one in the pisco DO study had been realised. In these cases, small-scale local producers had been supported by the DO mark. These positive outcomes can be divided into the following themes;

- Growth in network and added-value supports producers

- Protection and recognition supports local producers

- Grape producers supported 


\section{Growth and Added-Value Supports Grape and Pisco Producers in Peru}

A number of research participants, including producers and other experts, demonstrated that the DO had increased the value of pisco and assisted with other improvements in the sector. These improvements included contributing to growing demand and exports and improving attitudes towards pisco. These improvements associated with the pisco DO were frequently mentioned to have supported local producers thus contributing to the realisation ethical claim one. For example, Manuel Morón director at CITEagroindustrial highlighted some of the successes of the pisco DO and explained how these successes have support small-scale producers;

"In relation to the reputation, exportations and national sales, we can see the benefits of the DO [...] I look behind these statistics to see more important changes [...] I also see the changes for small-scale producers who have not only survived but expanded their production and are able to provide for their families..."

A number of small-scale producers discussed the benefits using the pisco DO mark had created for them. For example, Homero Herrera, partner and adviser at small-scale pisco producer cooperative APEVIBOPA explained how the DO had added-value to their product and created more opportunities for them as small-scale pisco producers; "The DO does support the producers because it adds value to our product, this makes us more competitive and the origin mark provides us with more opportunities, the DO therefore supports us."

Likewise, Jorge Aparcana a social activist from Ica, demonstrated some realisation of ethical claim one by highlighting the positive outcomes the DO has had for local and small-scale producers in the pisco sector;

"The DO has been very positive in relation to the reputation, exports and national sales of pisco [...] these changes have supported different actors in the pisco sector, including small-scale pisco producers."

\section{Protection and Recognition for Pisco DO Supports Local Producers in Peru}

A number of research participants also mentioned the support local producers have received through the protection and recognition that the pisco DO mark has established, thus contributing to the realisation of ethical claim one. For instance, small-scale pisco producer José Falconí described how the DO system for pisco has protected producers from the unfair competition created by the falsification and adulteration of pisco;

"Through the DO, we feel better because others cannot produce different liquors and unjustly use the name and reputation of pisco [...] the DO guarantees the 
genuine pisco producer that they are not being cheated in the market, while also protecting the consumer."

The notion that the pisco DO mark has supported the traditional ways of producing pisco while benefiting small-scale producers was supported by a number of producers. For example, Luz Ramos a grape and small-scale pisco producer and partner at the APEVIBOPA stated that;

"I believe that the regulations of pisco are something positive for the traditions of making pisco [...] this DO is an advantage for us producers because it allows us to use the name of a respected product and sell our product with a guarantee."

\section{Peruvian Grape Producers Supported by Pisco DO}

The interviews also found some evidence that the implementation of the DO mark in the pisco network had supported the pisco grape producers. For instance, Alan Watkin a pisco and grape producer explained that the DO has supported these producers;

"We have seen benefits created by DO as this has pushed more demand for pisco which has resulted in more demand for pisco grapes. The regulations have also forced us to produce high-quality grapes which gain a higher price..."

Homero Herrera, reinforced these points yet explained that the support the grape producers have received from the DO has been limited; "The grape producers receive benefits from the $D O$, the growth in demand for pisco connected with the DO has driven up the price for pisco grapes, but only a little.

\subsubsection{Failed Outcomes of Ethical Claim One in DO for Pisco from Peru}

Despite a number of examples which highlighted some realisation of ethical claim one, that the pisco DO has supported local producers, this research also revealed various failings and negative outcomes of the DO for local producers. These failings and negative outcomes demonstrated some of the limitations of ethical claim one in the pisco DO study. The subsequent section will discuss these limitations under these broad titles;

- Barriers and exclusion of small-scale producers

- The concentration of positive outcomes by larger producers

- Expansion of extra-local producers

- Exclusion of grape producers

\section{Barriers and Exclusion of Small-Scale Producers in Peruvian Pisco Network}

Research participants from diverse groups repeatedly mentioned the important barriers faced by smaller-scale producers in receiving the authorisation to use the pisco DO mark and 
explained how as a result, these producers have been excluded from the system. For example, Historian Guillermo Vera from the APP, discussed some of the challenges for small-scale producers in receiving the authorisation to use the pisco DO and explained the exclusion from wider markets these producer encounter;

"I believe that the DO mark helps small-scale producers when they can use it, but if they don't receive the authorisation to use it then they are excluded from sales. I don't believe there is special support for this group through the DO, instead, it is a challenge for them [...] the costs and administration involved are barriers for many of these smaller-scale producers"

Participants mentioned that small-scale producers face a range of additional challenges in receiving the authorisation to use the pisco DO. For instance, a cultural expert in pisco César Costa described some of the important barriers small-scale producers encounter;

“...there are geographic barriers; INDECOPI is in Lima and this sometimes far away for producers [...] there are barriers in education and information, it is hard how to receive something you don't know much about [...] and of course there are the costs involved."

The misinformation and lack of understanding about the pisco DO mark among producers was described by the president of the CR for the Pisco DO at the time of the interview, Jaime Marimon;

"The producers don't have a good understanding of the DO system [...] The DO formation has been a purely political decision [...] The problem is no one explained what the DO means with the producers [...] There has been a lack of planning and strategy."

A number of producers interviewed explained that they felt unsupported in the process of receiving the authorisation to use the pisco DO. Moreover, many of these producers stated that the DO process was difficult, time consuming and costly for them. For instance, small-scale pisco producer Dennis Grimaldo described the challenges of receiving the authorisation to use the DO and the lack of support for small-scale producers;

“We haven't received any support to receive the DO, everything must be done by ourselves. The certifiers hardly ever come out to the countryside [...] The DO should be easier to use, they require us to have this mark but there are still many producers that don't have the resources to become involved." 
Although DOs can privilege small-scale producers by granting economic incentives for these groups to maintain traditional agricultural practices and link them to wider markets (Boisvert, 2006), a significant number of interviews demonstrated that this has not occurred in the pisco DO case study. Instead, the implementation of the pisco DO has favoured larger-scale and extra-local actors who do not suffer from the same financial and administrative challenges in receiving the authorisation to use the pisco DO. This has opened the DO to co-optation and appropriation which has seriously limited the pisco DO mark's ability to encourage local development and assist small-scale producers to counter the negative impacts of globalisation in Peru.

\section{Concentration of Positive Outcomes by Larger-Scale Producers in Peruvian Pisco Network}

Detailed fieldwork in the Ica Valley also demonstrated that participants from diverse groups perceived that many of the positive outcomes associated with the pisco DO had been concentrated by the larger-scale producers while the smaller-scale producers had been largely excluded. César Costa summarised this problem;

"The small-scale producers sometimes makes better quality piscos but they often do not have commercial channels or the rights to use the pisco DO. The large-scale producers, on the other hand, has larger budgets and more sales opportunities. Therefore, the benefits are limited for the smaller producers who do not enjoy the same opportunities..."

Likewise, traditional pisco producer Matías Grados, illustrated how the markets and the DO pisco system overall place smaller-scale producers in disadvantaged positions, thereby failing to support these producers;

"...the DO discriminates against the small-scale producers while favouring the large ones [...] to sell through the supermarkets a producer has to pay for shelf-space and the small-scale producers cannot afford this [...] the producers who have not received the DO yet have not done so out of fear or lack of resources [...] the big guys that have the money can easily buy their way into the sector."

Therefore, fieldwork revealed some of the failed outcomes in realising ethical claim one, as small-scale local producers have been largely excluded from benefits associated with the DO pisco mark. As discussed, these benefits have usually been concentrated by the larger producers.

The fieldwork also discovered that the largest-scale producers have been able to dominate decisions made linked to the regulation of the pisco DO. José Carlos Falconí from 
CITEagroindustrial for instance explained the concentration of power in the regulation of the pisco DO;

"I have been involved in the meetings about changes of the pisco DO and regulation [...] there are around five or six companies the control around $90 \%$ of pisco production, therefore it is obvious that these five or six companies have more control and say than the 500 producers that account for other $10 \%$ of the production..."

The exclusion of small-scale producers from the regulatory bodies of pisco was identified as an important failing. For example, Jhon León, president at the APEVIBOPA, described how many small-scale pisco producers feel completely ignored by the regulatory groups;

"...the problem is that these regulatory institutions are for the larger producers. [...] the national regulatory groups don't even know that us small-scale producers exist [...] these institutions are not well organised and the small-scale producer is marginalised..."

\section{Expansion of Extra-local Producers in Peruvian Pisco Network}

The research interviews demonstrated that the pisco DO had largely failed to protect the local traditional producers from an influx of new extra-local producers which have taken advantage of the growing markets for pisco. This has displaced smaller-scale producers which had traditionally produced pisco in the Ica Valley. For instance, pisco producer and ambassador of the pisco DO mark José Moquillaza described the failings of the DO to protect these traditional producers;

"The traditional small-scale producers have struggled to survive in the current market. This is a problem and the DO should be used to revive these traditional producers [...]. Most pisco producers who are selling in the supermarkets are new to the sector."

A number of participants from traditional pisco producing groups from Ica described the problems they now face in the national market. These participants explained that the growing competition in this market has been driven by the expansion of usually extra-local actors which have entered into Ica's pisco sector. For instance, Manuel Bernales a producer from a traditional pisco producing family described what many traditional producers now face:

"The competition in Peru is now very strong, not just from other bodegas but also from the 'piqueros'. The piqueros are groups that come from outside of Ica and use 
third parties to make piscos [...] it is very difficult to sell pisco in Peru as there are these new actors in the sector [...] have entered with a lot of force..."

Similarly, Jorge Llanos from the Instituto del Vino y del Pisco at the Universidad de San Martín de Porres, explained that the expansion of extra-local actors in the pisco network means that the most of the profits created through pisco in Ica do not stay in the area; "...the sector and markets for pisco have changed a lot [...] now, the profits made in Ica don't stay there, they go to Lima and are concentrated by middlemen, not the producers."

Like in other parts of the Global South, the implementation of the DO has been difficult partly due to the Peruvian national institutions, which are generally less effective than those in Europe where DOs originate. This challenge has been highlighted in wider literature and discussed in greater detail in Chapter Three (Bowen, 2010a; Larson, 2007). This research illustrated that further improvements to the national institutions in Peru are required to protect intellectual property, safeguard against fraud, and manage the genetic, biological and natural resources associated with the pisco DO. Without institutional protection, the appropriation of pisco by extra-local actors is likely to continue.

\section{Exclusion of Grape Producers from Improvements of Pisco DO in Peru}

Interviews with pisco grape producers and other experts showed that the ethical claim that the DO had supported local producers has not been realised in the case of the grape producers. Interviews showed that most of the benefits created by the DO and the associated improvements in the pisco markets had not been passed on to the small-scale grape suppliers. For instance, agricultural engineer Karl Mendoza explained that the DO had failed to support these grape producers or affect the value of their product;

"The pisco DO has not supported the small-scale grape producers a lot. These grape producers depend on the bodegas who buy their grapes. [...] many bodegas offer low prices for the grapes despite the growing demand for the final product."

These views were supported by different grape producers who were interviewed. For example, Mr. Tarqui, a small-scale grape producer in Ica described the dropping prices for pisco grapes despite the growing demand for pisco;

"Over time, selling grapes is no longer profitable so we are trying to produce some pisco which gets a better price [...] before, the price for our grapes was around two soles per kilo, this has now dropped to around one sol in the last few years."

Therefore, despite some of the positive outcomes the DO has had for local small-scale producers discussed earlier, this research has also revealed failings in the realisation of this 
ethical claim. These failings of the DO were based on the concentration of the benefits by larger producers and extra-local actors and the exclusion of small-scale local grape and pisco producers.

\subsubsection{Ethical Claim Two: Pisco Do Supports Local Community Development and the Preservation of Local Culture}

As discussed in Chapter Three in global literature, origin-based production marks such as DOs, have been promoted as potential means to create a broad local community. For example, wider literature has shown the DOs can be used by communities to counter some of the challenges associated with the globalisation of agriculture such as; international competition, food insecurities and cultural homogenisation (Dagne, 2015). It has been noted that DO marks have been used by local communities to preserve local social and natural resources while promoting alternatives for broad community development through the notions of terroir and localised production (Bowen, 2010b; Gerz \& Dupont, 2006; Sautier \& van de Kop, 2006).

The DO pisco EVeN in Peru was promoted through similar ethical claims that this system was able to encourage community development in rural Ica and create other benefits for the local communities, such as the preservation of rural cultures and ways of life. For example, agricultural engineer Karl Mendoza discussed this second ethical claim that the pisco DO supports the protection of local cultures and traditions;

"A DO protected product has to fulfil a number of quality requirements which ensure it is genuine and that it respects the local cultures and traditions [...] the pisco DO therefore has helped rescue the local traditions and cultures connected to pisco production..."

Similarly, Patricia Gamboa expert in DOs in Peru, claimed that the DO contributes to the valuing of traditional local products and fosters benefits not just for the producers but also for the local communities;

"The DO is an intellectual property tool which contributes to the valuing of traditional local products and provides benefits, not just for the producers but also the local communities [...] the DO is a tool which improves the self-esteem of the communities and supports the connection they have with their locality and this economic activity."

Moreover, participants also claimed that pisco and other DOs make important contributions to the identities of the communities embedded in the production areas. For example, Manuel 
Morón Director at innovation and technological centre CITEagroindustrial explained how people from Ica identified with pisco;

"The pisco DO is very important [...] the people from Ica identify a lot with their product $[. .$.$] In the important events here, this identification with pisco is obvious$ as our local product is always consumed."

The interviews also found similar claims that the pisco DO and network had supported the local community in Ica due to the employment that it has created. For example, Johnny Schuler, General Manager at La Caravedo bodega explained the employment created;

"Pisco is labour intensive, Ica an area with zero unemployment. Grapes and pisco are labour intensive in different moments of the year. When we are in harvest time, we need a lot of people. This benefits the community through the employment it creates."

Participants also stated that the pisco DO had created wider economic benefits for the community in Ica due to the tourism this sector attracts. Half of the participants mentioned Ica's 'Pisco Route' a tour of bodegas where tourists can see how pisco is made and try pisco, local wines and local liquors. Marketing specialist Bruno Fistrovic, explained that a DO product can create an interesting element for tourists and therefore boost tourists number in rural areas such as Ica: "The DO supports tourism as it is more interesting to go to an area of origin of a DO product, it creates an attraction such as the Pisco Route..."

Three-quarters of the participants claimed that the pisco network has created important impacts for other actors involved directly and indirectly with the associated tourism sector. For instance, pisco producer Manuel Bernales stated that;

"...the pisco sector has benefits for the community. [...] The harvest festival and the Pisco Route bring tourists to the area and this helps the hotels, the restaurants [...] there a lot of activities that move around the pisco sector."

\subsubsection{Successful Outcomes of Ethical Claim Two in Designation of Origin for Pisco in Peru}

As discussed, the second ethical claim in the pisco study was that the pisco DO supports local community development and the preservation of local culture. As demonstrated, this ethical claim followed two strands;

- Preservation of local culture, identity and traditions

- Economic outcomes and employment 


\section{Pisco DO and Preservation of Local Culture, Identity and Traditions in Peru}

While it is somewhat difficult to measure, a number of participants discussed how the pisco DO had had positive outcomes relating to local culture preservation. For instance, Homero Herrera from APEVIBOPA demonstrated how the ethical claim two, that the DO for pisco has support local communities in Ica through the preservation of local culture and traditions had been realised;

"The pisco DO contributes to traditional methods and local cultures because this regulation means that producers can only use the traditional pisco grapes [...] We also conserved the traditional way of making pisco, through ancestral techniques [...] this contributes to Ica's local culture as a historical pisco production zone and helps us as a community..."

The majority of participants mentioned how the DO has functioned as a guide for producers to ensure that their operations contribute to the traditions of the sector and of the local area. For example, small-scale pisco producer Jhon León mentioned how the DO had supported local traditions in Ica; "The DO helps to protect the local traditions in Ica because they are part of the standards of the DO. As producers, the DO is our guide so we contribute to and participate in these local traditions correctly." These ideas were supported by different experts who tended to link these cultural benefits with the economic outcomes in the local communities. For instance, Alfredo San Martín from the Sociedad Nacional de Industrias stated that; "Pisco strengthens the identities of the local communities and this increases the prestige of these places [...] and there are many positive spillover impacts that come from this..."

Most participants acknowledged that the pisco network has had mainly positive outcomes for the local communities in Ica and described how it has promoted and protected the culture of the area. Medium-scale pisco producer in Ica Julio Sotelo summarised these ideas; "Pisco has few negative impacts for the community. The impacts are more positive. The sector creates festivals and protects the local cultures which have developed over the centuries in Ica..."

\section{Pisco DO and Economic Outcomes and Employment in Peru}

The majority number of research participants discussed the positive economic and employment outcomes driven by the pisco network and often linked these outcomes to the DO and the associated expansion of the sector. These economic outcomes demonstrated some realisation of ethical claim two that the pisco DO had supported the local community. Agricultural engineer Karl Mendoza, linked the DO and the growth of the pisco network to important benefits in the often otherwise depressed communities in viticultural areas; 
"Pisco is the oldest DO in Peru and it has had a strong impact in the country. In the last fifteen years, the production and exports of pisco have grown significantly [...] although the pisco sector is relatively small in earnings, it is very important in terms of creating employment in the communities of depressed viticulture zones."

During fieldwork, both small-scale and larger-scale producers mentioned these positive economic outcomes in the communities Ica. For instance, Mr. Tarqui a small-scale grape producer in Ica explained that; "The pisco sector has many benefits for the community here, it creates work in the times of pruning and the harvest..." At the other end of the production scale, a representative from one of Ica's oldest and largest pisco producers described the positive impact that the producers have in their communities;

"Like any producer, we need labourers which means work for the community. We have an average of 400 people working here [...] we also hire additional temporary staff in busy moments [...] This all creates a positive impact for the local community around us."

Finally, a range of participants mentioned the indirect economic benefits from the pisco DO and network thereby illustrating other examples where ethical claim two that the pisco DO supports the local community had been realised. In particular, these indirect benefits related to the indirect employment and economic benefits created through the tourism industry associated with pisco. Jorge Llanos from the Instituto del Vino y del Pisco, summarised these indirect benefits associated with the pisco DO; “...In Ica, a Pisco Tourist Route has been developed [...] which brings in tourists and has some benefits for the communities, such as opportunities for hotels and restaurants [...] there are indirect benefits."

\subsubsection{Failed Outcomes of Ethical Claim Two in DO for Pisco from Peru}

Findings from the interviews however also demonstrated a number of failings in the realisation of ethical claim two, whereby the pisco DO mark and network had not created positive outcomes for the communities in the production areas. These failings can be broadly placed into the three following failed or negative outcomes in these communities;

- The pisco DO has failed to broadly support the local communities

- The DO has failed to protect the culture of pisco

- The network has negative local environmental impacts

\section{Pisco DO has Failed to Broadly Support the Local Communities in Peru}

The interviews revealed that a number of participants believed that the DO for pisco had not been used as much as it could have to support the communities. Moreover, the fieldwork for 
this research showed that although the pisco network created employment, this employment was largely seasonal which also caused hardship in the local towns. David Espinoza an official pisco connoisseur described how the DO and the network have not been fully taken advantage of to support community development;

“...the producers are not well informed and do not understand the importance that the DO has on their product and the development of their communities [...] the connected benefits of the DO [...] should not only benefit the producers but also those that live in areas."

Despite the ethical claims which concentrated on the employment and economic benefits created by the pisco DO, various participants discussed the temporal nature of these benefits and describe the hardship also caused. For instance, agricultural engineer Karl Mendoza described some of the challenges and precarity of the employment created by the pisco sector: "The sector also has negative impacts. For example, the employment the sector offers is only seasonal, and there are moments that the population doesn't have work." This was seen by different participants to cause hardship rather than support in the local community. This failing of the pisco network to support the wider community was explained by Homero Herrera; "The large bodegas only hire staff for short time periods which creates hardship for these people as they do not have stable employment."

As asserted by Bowen (2010b) and Bowen \& Zapata (2009), without proper state support it unlikely that a DO will encourage sustainable community development. As discussed in Chapter Four, Peru has experienced an important withdrawal of the state in agriculture and rural communities associated with neoliberal reform since the 1990s. While the Peruvian State has supported the development of the pisco DO it is evident that in this case study that the state has failed to effectively encourage broader community development through the pisco DO. As a result, without sufficient state support, the implementation of the pisco DO has resulted in limited and often uneven development outcomes in the local communities in the production areas.

\section{The DO has Failed to Protect Culture of Pisco in Peru}

Although there were many claims that the DO has been successful in preserving the culture of pisco in the production communities, detailed research in Ica discovered failings in achieving this. Participants stated that the DO had prioritised the sector's growth over the protection of local pisco culture. For example, medium-scale grape producer Moises explained how pisco had failed to support local cultures and traditions of pisco; 
"The pisco DO has focused on expanding production but there was not a greater concern for culture. The DO regulations for pisco [...] should do more to preserve the cultures of artisanal production [...] if the sector becomes completely industrial there are many cultural aspects and value that we will lose..."

Other participants criticised the increasingly industrial nature of the network and stated that the DO was failing to support local cultures associated with pisco. For example, small-scale grape producer Walter Cahua mentioned that;

"Inside the larger pisco bodegas they sometimes display old artefacts showing the historical ways of producing pisco, but they use industrialised techniques and hire foreign experts, they do not really maintain the old cultures of pisco."

Similarly, the interviews showed that the pisco DO has largely failed to regulate newer actors in the network from buying into the cultures and histories of pisco. Historian Lorenzo Huertas described this problem;

“...in marketing and labels, I have seen new companies use dates such 1868, which is when someone unconnected to the company bought the hacienda. These groups are just using dates to make their company seem old, and old portrays tradition and quality to the consumer. As a result, the histories of pisco are being bought..."

\section{Pisco Network has Negative Local Environmental Impacts in Peru}

Finally, despite the ethical claim that the pisco DO supports local communities, research participants frequently mentioned that negative local environmental impacts linked to pisco production which create problems for the communities in the production areas. For example, pisco producer and ambassador of the pisco DO mark José Moquillaza described these problems;

"There are two negative impacts on local communities. First, there is the use of wood for the fire for the distilling process while there is no reforestation. And secondly, there is the dispersal of waste-water used in the pisco processing, this has a very bad smell and there are no faculties provided by the state to deal with this problem."

Agricultural engineer Karl Mendoza expanded on these points and highlighted that these negatives impacts may worsen as production expands; "...these negative impacts on the environment are detrimental for those living in the production areas. As pisco production increases, these impacts need to be better managed to avoid greater problems." 
In the case of the pisco DO mark, the negative impacts on the local environment places doubt on the claimed link between origin-based marks and sustainable resource use and responsibility to place cited in wider literature (Belletti et al., 2015). As highlighted above, DO can also create negative outcomes for the communities in the production areas. This is because, when not established effectively, the incentives to implement a DO can cause homogenisation, intensification, and mono-cropping of certain DO products at the expense of natural landscapes and biological diversity, and often creates negative outcomes for traditional farmers, as discussed in Larson (2007).

\subsubsection{Ethical Claim Three: DO Safeguards Product Authenticity and Quality of Pisco from Peru}

As explored in Chapter Three, DO marks have expanded recently largely as a reaction to consumer concerns around food safety, quality and authenticity following the increasing 'placelessness' and industrialisation of the globalised agro-food systems (Goodman, 2004). Conversely, DO marks and the localisation of agriculture have been linked with trust, quality and safety among global consumers (Murdoch et al., 2000). In the context of the globalisation of agro-food systems, DO marks provide consumers with reinsurance by demonstrating where a product originates from, and how it was produced. Wider literature on DOs promotes their use to safeguard product quality and authenticity (Colman, 2008; Parasecoli \& Tasaki, 2011; Stanziani, 2004). It is claimed that DO marks protect consumers by providing them with accurate information to select high-quality authenticity products while protecting these consumers from deceptive product information (Josling, 2006). Additionally, DOs protect legitimate producers by governing and regulating high-quality agro-foods while eliminating false production (Bowen \& Zapata, 2009; van de Kop et al., 2006).

Fieldwork in Peru found that the pisco DO EVeN was promoted through similar ethical claims that pisco's DO protects the product's authenticity and quality, thereby having positive outcomes for both consumers and producers. This represented the third ethical claim from the pisco study, that the DO safeguards pisco's authenticity and high quality. A number of participants stated that the DO was critical in protecting the high-quality of pisco and ensuring consumers that they were consuming an authentic DO protected product. For instance, smallscale pisco producer in Ica José Falconí claimed that; "The DO is fundamental to product authenticity, with this mark we are guaranteeing that our pisco is high-quality and we ensure the consumers of this quality, this a very important part of the DO." It has been claimed that the DO creates a certain level of control and verification which supports the maintenance of the high-qualities of pisco. For example, a representative from one of the largest and oldest pisco producing companies in Ica made the claim that; "The DO has helped improved the overall 
quality of pisco as the sector is a lot more formal now. The DO gives a standard of quality that registered bodegas must follow as it is controlled and certified."

Moreover, participants tended to claim that the DO had been supportive in regulating the false production of pisco which has represented a long-lasting challenge in the sector. For instance, a large-scale pisco producer Jorge Queirolo claimed that the DO had been an important factor to eliminate the false production of pisco;

"Before the DO mark, different groups were making cheap, sometimes unsafe products and naming them pisco. This ruined the reputation of our high-quality product. The DO has been something beneficial, as it places a guarantee on our pisco and stops the falsification..."

\subsubsection{Successful Outcomes of Ethical Claim Three in Designation of Origin for Pisco in Peru}

The research participants identified different examples where ethical claim three was realised. In these cases, the quality and authenticity of pisco had been safeguarded through the DO thus protecting consumers and producers. These examples can be separated into three broad interrelated positive outcomes where;

- The DO has supported the recovery and improvement of the product's quality

- The DO has created more control in the network

- The DO has contributed to the acceptance of pisco

\section{The Pisco DO has supported the Recovery and Improvement of the Product's Quality in Peru} Three quarters research participants noted examples where the pisco DO had supported the recovery and improvement of the product's high quality. These positive outcomes demonstrated the realisation of ethical claim three, whereby the DO had safeguarded the product's authenticity and quality. For instance, Peruvian diplomat Gonzalo Gutiérrez explained the improvements in pisco's quality associated with the DO;

"30 years ago, the quality standards in pisco were much lower than now, we can clearly see that there have been improvements since the implementation of the DO [...] the Pisco DO establishes very clear regulations so that this DO product is guaranteed to be produced [...] following the strict technical norms..."

Other participants discussed similar trends showing improvements in the pisco sector, and linked these improvements to the creation of the pisco DO. For example, Johnny Schuler General Manager at the large-scale La Caravedo bodega, supported the notion that DO had realised positive outcomes for the quality of pisco; "The DO has contributed to the quality of 
pisco, in the last twenty years there has been a marvellous change, now in the market there are around twenty extremely good pisco brands."

\section{The Pisco DO Created More Control in the Network in Peru}

Interviews with different pisco producers demonstrated that the pisco DO had created some positive outcomes associated with control and regulation in the sector. These participants felt that this control had placed limits on the false production of pisco and impeded groups from continuing to harm the reputation of the legitimate pisco production. Victor Santhome, a smallscale producer from Bellavista bodega explained that the DO has resulted in more control in the pisco sector;

"Since the creation of the $D O$, you have to receive the authorisation to use the name pisco, which was a great idea and this has helped place more control in the market [...] This is great for us genuine producers"

Similarly, a number of participants noted the important role the pisco DO regulation has had in limiting the false production and the adulteration of pisco. For instance, pisco producer Julio Sotelo recognised the significant positive change the DO and technical norms have had in controlling the adulteration of pisco;

"Peru is a country with a lot of product adulteration and pisco would be in a worse situation without the DO and the technical norms. The DO is still not perfect, but it has contributed to an important change [...] Before the DO, there was a lot of adulteration of pisco and poor-quality piscos which weren't be controlled [...] the situation has completely changed."

A number of participants also discussed the positive outcomes of the DO in conserving the high-quality and the reputation that pisco has developed. For example, small-scale pisco producer José Falconí discussed the contributions of the DO in the conservation of the traditional methods, high-quality and authenticity of pisco;

“... without the restrictions created by DO, the producers could be tempted into changing their production methods towards quantity over quality and pisco would lose its high-quality [...] which would damage the authenticity of the product."

\section{The Pisco DO has Contributed to Acceptation of Pisco}

Moreover, various participants discussed the positive outcomes that the DO has had in the public acceptation of pisco in Peru, as well as abroad. In these interviews, the public acceptation and growing demand for pisco was frequently linked to the improvements in the product's quality associated with the DO. For instance, DO expert Patricia Gamboa described 
how the DO had placed new value on pisco and assisted the product's transformation from a largely niche traditional product to one which is consumed by different groups;

"Pisco has gone from a traditional product that was not really consumed to something that is now consumed by different socio-economic groups in Peru [...] without doubt the DO has helped this process. Pisco exports have also grown and there has been more international market acceptance of the product [...] the fact that pisco has a DO has helped in international markets."

Eduardo Dargent, president of the APP, also discussed the changing perspectives around pisco and linked these changes to the improvements in the product's quality which he associated with the DO regulations;

"Perspectives around pisco have changed drastically in Peru. People are now proud to bring a special bottle of pisco to social gatherings, something unheard of before. These changes have been encouraged by the improving quality of pisco, supported by the DO..."

\subsubsection{Failed Outcomes of Ethical Claim Three in DO for Pisco from Peru}

Despite the examples above which illustrated the various ways the pisco DO has successfully realised ethical claim three by safeguarding the product's authenticity and quality, the interviews have also revealed important failings in realising this claim. The key failings identified by the participants can be divided into three categories where this third ethical claim has not been realised due to:

- A lack of supervision and control in the pisco DO

- A persistent informal network de-values legitimate pisco

\section{A Lack of Supervision and Control in the Pisco DO system in Peru}

A number of diverse research participants discussed the failings of the DO regulatory institutions to establish the supervision and control required to protect the authenticity and high-quality of the product. Agricultural engineer Karl Mendoza summarised this failing;

"The DO has had an important impact on pisco production, which has grown fivefold in the last fifteen years [...] but this growth has been unorganised, there are products that don't fulfil the minimal regulations which have received the pisco DO mark [...]. There needs to be more work to control the processes."

The fieldwork found that a significant failing of the DO in guaranteeing the authenticity and quality of pisco was related to the problems encountered by the producer-controlled CR for 
the Pisco DO. In general, participants stated that this organisation was not functioning well and as a result, there was not enough supervision and control the in the DO pisco sector. For instance, David Espinoza an official pisco connoisseur described this problem;

“...the problem with the pisco DO is that we don't have a well-structured Regulatory Council [...] people trust that our product is effectively regulated through the DO but this is not that case. [...] the Regulatory Council has not worked as it should [...] we don't have control in the sector and we can't say that the DO has been successful in establishing this control."

Likewise, a number of participants explained that the DO is failing due to a lack of enforcement of the regulatory norms which exist. The problems associated with the lack of enforcement of the pisco DO regulations were explained by pisco producer and ambassador of the pisco DO mark José Moquillaza;

"...there is no strong institution to enforce the DO. The focus is wrong [...] the system is based on private groups supervising other private groups and this has not been successful. [...] Gaining the authorisation of DO is difficult, the problem is that once a producer is within the DO they are able to play with the regulations as there is no enforcement."

This research found that CR for the Pisco DO has largely failed to fulfil its functions of supervision and control due to budget deficiencies. Moreover, this organisation has had some of its core functions suspended by the state which means that it has been unable to operate. Without an effective regulatory institution, the realisation of ethical claim three (that the DO safeguards the authenticity and quality of pisco) has mostly been uncompleted. President of the CR for the Pisco DO at the time of the interview, Jaime Marimon described these challenges;

"Our role at the Regulatory Council is to verify to quality of pisco and to make sure every bottle with the name pisco on it is actually pisco. [...] we have not been able to do a lot as we don't have any way to gain funding to complete our functions..."

A number of participants linked the failings of the DO to protect pisco, to the lack of resourcing of the CR. For instance, president of the APP, Eduardo Dargent discussed the problems faced by the $\mathrm{CR}$ in raising the funding needed to regulate the pisco DO; "...it is not a requirement for the producers to be members of the Regulatory Council, this means most producers do not support the Regulatory Council financially." 


\section{A Persistent Informal Sector in Peru De-Values Legitimate DO Pisco}

Partly resulting from the failings to establish a functioning system of supervision and control, there has been a persistent informal sector involved in the false production and adulteration of pisco. Interviews demonstrated that this informal sector damages the reputation of the legitimate production, and left unregulated this could ruin the authenticity and quality of pisco. Traditional medium-scale pisco producer Matías Grados summarised the challenges of the false production and adulteration of pisco has generated for legitimate producers;

"The population is drinking more pisco than before, the problem is that the price has remained low due to the adulteration [...] If not controlled, the adulteration will destroy the authentic piscos. Fake pisco can be sold much cheaper making it harder for those who are making pisco correctly to survive..."

Similarly, a number of participants discussed how the false production and adulteration of pisco removes the authenticity and quality of the product thereby also deceiving the consumers who want to purchase a high-quality DO protected product. César Costa explained this problem;

"....there are groups that use incorrect grapes and sell their piscos for very cheap, like nineteen soles, which abuses the traditions of pisco and also the public who purchase these products thinking they are purchasing real pisco."

Most participants linked the failings to protect the quality and authenticity of pisco to the low levels of enforcement of the DO. For instance, Peruvian diplomat Gonzalo Gutiérrez described how the lack of enforcement of the DO has meant that false production of pisco exists in Peru and other countries;

"...the problem is the lack of enforcement by the institutions that regulate the DO for pisco. They have failed to fulfil their roles in protecting the DO and sanction the groups that falsify pisco [...] There are examples of falsified piscos in other countries as well..."

Therefore, the majority of the interviews highlighted that the pisco DO had at least partly failed to ensure one of the core objectives of a Gl, to provide consumers with accurate information to allow them to select quality products while being protected from misleading information, as discussed in Josling (2006). In the pisco DO case study, the supervision, control and enforcement of the regulations have failed to ensure that all of the products currently sold as pisco have fulfilled all of the necessary requirements under the DO. Without implementing the required level of supervision, control and 
enforcement, it is not likely that the pisco DO will be able to protect consumers or the unique natural and social attributes which have evolved over the product's history.

\subsection{SUMMARY: IDEALISATION AND REALISATION OF THE DO FOR PISCO FROM PERU}

The second part of this chapter applied the same critical and detailed assessment used to study the case of fair trade wine in Chile, in order to explore the idealisation and realisation of the DO for pisco from Peru. Interviewing coding identified three key ethical claims which had developed to idealise and promote the DO pisco network.

In this case, these ethical claims were:

1. The pisco DO supports local small-scale producers

2. The DO supports local community development and the preservation of local culture

3. The DO safeguards product authenticity and quality

Figure 35 Ethical Footprint: Designation of Origin Pisco in Peru

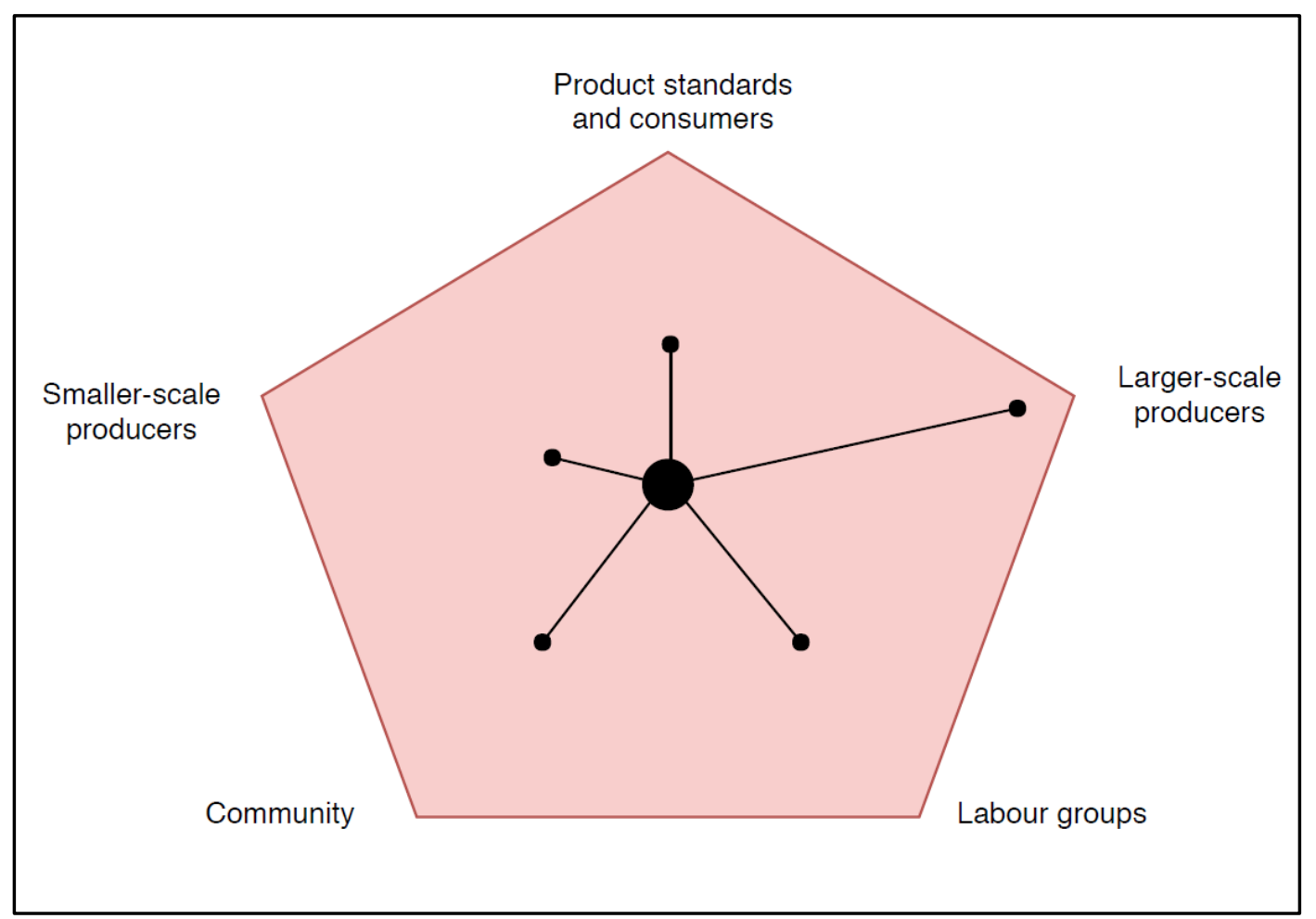

Source: Elaborated by the author and supervisor Professor Warwick Murray

Figure 35, above shows the ethical footprint of the DO pisco network in Peru using NVivo coded findings from the interview responses. The black centre represents an absolute failure to realise the ethical claims made to promote the network while the lines moving away from the centre represent the degrees these ethical claims have been realised. The closers the black lines get to a category the more this category has benefited from the DO. Again, as in the 
Chilean fair trade wine case study, it is important to emphasise that these ethical footprints represent qualitative estimates of weak, moderate and strong realisation of the ethical claims. By observing the ethical footprint for DO pisco in Peru, it is clear that larger-scale producers have received the greatest benefits from realisation of the ethical claims associated with this DO mark. After the larger-scale producers, labour groups and local communities have experienced moderate benefits from the realisation of the ethical claims in this EVeN. Smallscale producers and consumers have however experienced fewer benefits from the realisation of these ethical claims. The exploration of the idealisation and realisation of the EVeN in DO for pisco from Peru indicated that these ethical claims had been realised with diverse outcomes with cases of successful, failed and negative results. Therefore, similar to the fair trade wine network study in Chile, the DO network study for pisco in Peru showed that the realisation of the ethical claims was complex. These results are also demonstrated in Table 9. 
Table 9 Summary of Ethical Claims and Outcomes

\begin{tabular}{|c|c|}
\hline \multicolumn{2}{|c|}{ Ethical Claim 1: Fair Trade Supports Small-Scale Producers } \\
\hline Successful outcomes: & Failed outcomes \\
\hline $\begin{array}{l}\text { - Stable and fairer price for small-scale } \\
\text { producers } \\
\text { - Reported improvements in quality of } \\
\text { life of small-scale producers }\end{array}$ & $\begin{array}{l}\text { - } \quad \text { Positive impact remains limited } \\
\text { - Barriers for small-scale producers } \\
\text { - Does not solve larger problems in the } \\
\text { sector }\end{array}$ \\
\hline \multicolumn{2}{|c|}{ Ethical Claim 2: Company Engagement in Fair Trade creates Broader Positive Impact } \\
\hline Successful outcomes: & Failed outcomes: \\
\hline $\begin{array}{l}\text { - } \text { Benefits for workers } \\
\text { - } \text { Benefits for small-scale producers }\end{array}$ & $\begin{array}{l}\text { - Niche fair trade market becoming } \\
\text { dominated by larger companies } \\
\text { displacing smaller actors } \\
\text { - No distinction between hired labour } \\
\text { and small-scale producer in fair trade } \\
\text { certification } \\
\text { - Larger wineries concentrating benefits } \\
\text { - Unclear how temporary workers } \\
\text { benefit }\end{array}$ \\
\hline \multicolumn{2}{|c|}{ Ethical Claim 3: Fair Trade Creates Broad Community Benefits } \\
\hline Successful outcomes: & Failed outcomes: \\
\hline $\begin{array}{l}\text { - Community development projects } \\
\text { have been funded by fair trade } \\
\text { premium }\end{array}$ & $\begin{array}{l}\text { - Impact in the community remains } \\
\text { limited due to small-scale of fair trade } \\
\text { sales }\end{array}$ \\
\hline \multicolumn{2}{|c|}{ Ethical Claim 1: DO Supports Local Small-Scale Producers } \\
\hline Successful outcomes: & Failed outcomes: \\
\hline $\begin{array}{l}\text { - Sector growth and added-value } \\
\text { associated with DO system supports } \\
\text { producers } \\
\text { - Protection and recognition supports } \\
\text { local producers } \\
\text { - Grape producers being supported by } \\
\text { growing demand for pisco grapes }\end{array}$ & $\begin{array}{l}\text { Barriers and exclusion of small-scale } \\
\text { producers } \\
\text { - } \quad \text { Larger-scale producers concentrating } \\
\text { positive outcomes } \\
\text { - } \text { displacing traditional producers } \\
\text { - Grape producers largely excluded }\end{array}$ \\
\hline \multicolumn{2}{|c|}{$\begin{array}{l}\text { Ethical Claim 2: Pisco DO Supports Local Community Development and the } \\
\text { Preservation of Local Culture }\end{array}$} \\
\hline Successful outcomes: & Failed outcomes: \\
\hline $\begin{array}{l}\text { - Identified examples of the } \\
\text { preservation of local culture, identity } \\
\text { and traditions } \\
\text { - Economic outcomes and employment } \\
\text { creation in local areas }\end{array}$ & $\begin{array}{l}\text { - The pisco DO has not supported broad } \\
\text { community development } \\
\text { - The DO failing to protect the } \\
\text { traditional producers or culture } \\
\text { - The sector has negative local } \\
\text { environmental impacts }\end{array}$ \\
\hline \multicolumn{2}{|c|}{ Ethical Claim 3: DO Safeguards Product Authenticity and Quality } \\
\hline Successful outcomes: & Failed outcomes: \\
\hline $\begin{array}{l}\text { - The DO has supported the product's } \\
\text { quality } \\
\text { - The DO has created more control } \\
\text { - The DO has assisted the public } \\
\text { acceptation }\end{array}$ & $\begin{array}{l}\text { - DO failing in supervision, control and } \\
\text { enforcement } \\
\text { - A persistent informal sector }\end{array}$ \\
\hline
\end{tabular}

Source: Elaborated by the author 


\subsection{COMPARATIVE DISCUSSION}

This comparative section compares and contrasts the findings presented in this chapter related to the idealisation and realisation of the ethical claims which surround the two EVeN case studies. In doing so, the section explores a number of questions and findings which traverse the boundaries of the pisco DO case study in Peru and the fair trade wine case study in Chile. This discussion will begin by comparing and contrasting the idealisation or ethical claims of two studied networks. Subsequently, the discussion will compare and contrast the realisation of the ethical claims in these case studies. Where possible, the section will engage with the underlying theories of the thesis and broader literature.

\section{The Idealisation of Ethical Claims: Similarities Between Studied EVeNs}

As demonstrated in this chapter, the two studied EVeNs employed ethical claims based on supporting small-scale producers and contributing to broader community development. By crossing the lines between the two case studies, we can see that EVeNs tend to be associated with ethical claims which link consumers with the positive impacts of the ethical label in question in the production areas. The promotion of these networks is based on the common ethical claims that purchasing products with ethical labels will support vulnerable producers and their communities to face the negative impacts of conventional trade and globalisation. Moreover, the two case studies showed the important links between global EVeNs and the localisation of production. The studied networks have therefore illustrated how the ethical claims have evolved to match consumer concerns for small-scale producers and rural labourers, food quality and authenticity, and localised and less intensive forms of production, as discussed wider literature and explored in detail in Chapter Three (Barrientos \& Dolan, 2006b; Bowen, 2010b; Reardon \& Barrett, 2000; Swinnen \& Maertens, 2007). Therefore, the two studied networks have demonstrated how actors in EVeNs have evolved and utilised ethical claims to insert themselves into ethical niche markets based on diverse yet interconnected concerns associated with conventional trade and the globalisation of agriculture by consumers.

\section{The Idealisation of Ethical Claims: Differences Between Studied EVeNs}

The case studies however also highlighted the diversity experienced across EVeNs and the ways in which they are promoted. For instance, in the fair trade Chilean wine case study, there was an explicit ethical claim for community development and for supporting small-scale producers and rural workers. Conversely, in the DO pisco case study this claim was not made explicitly, 
and instead, the ethical claims of the DO were associated with the protection of the pisco's authenticity, quality and the preservation of local cultures and traditions. The broad implication of these findings is that it is important to consider the diversity of the different EVeNs and acknowledge that despite the communalities between these networks, they are motivated by different objectives and promoted through diverse ethical claims. The commonalities and diversity of ethical claims have important implications for the realisation of the ethical claims in EVeNs and the overall impacts of these networks as will now be discussed.

\section{The Realisation of Ethical Claims: Similarities Between Studied EVeNs}

This chapter highlighted revealed some of the key similarities in how the ethical claims were realised or failed to be realised, across the two case studies. For instance, this chapter demonstrated that although some of the ethical claims associated with fair trade wine in Chile and DO pisco in Peru were realised successfully, many of the claims failed to be realised or were realised with limited success in both case studies. Therefore, a broader implication which can be extended from both case studies, is that EVeN face important challenges in the realisation of the ethical claims, especially when implemented in the Global South. As discussed, these challenges are created by the uneven and contested local social, political and economic contexts, as well as the competition between different actors within the networks. These contexts and conditions clearly open EVeNs to ethical value appropriation by larger and more powerful actors and the exclusion of smaller-scale and weaker actors. Furthermore, both case studies revealed the complexities and diversity of the experiences of the different actors within EVeNs. This was highlighted by the range of responses across the interviews in each case study. The successful realisation of the ethical claims made in the two case studies did, however, demonstrate that EVeNs and the associated ethical labels were capable of creating additional ethical value. Despite this, a more even distribution of this additional ethical value has remained an important challenge in both case studies, and is most likely a challenge for other EVeNs.

Similarly, the positive impacts associated with both case studies remained limited, and as currently implemented, the studied EVeNs have been unable to face the wider problems experienced in the two networks. These case studies, therefore, highlighted some of the limitations of EVeN in resolving some of the difficulties for vulnerable small-scale producer groups created by unequal national economies and the uneven impacts associated with the globalisation of agriculture. The common failures and challenges in realising the ethical claims the Peruvian and Chilean cases demonstrated some of the wider challenges of EVeNs in general. In both case studies, failures to successfully realise ethical claims meant these EVeNs 
failed to benefit the most vulnerable actors while privileging more connected groups. In fair trade wine in Chile, larger-scale producers have been able to dominate the network, while in DO pisco in Peru, extra-local actors are displacing smaller-scale local producers. As supported by wider literature, it is probable that similar EVeNs face comparable challenges created by ethical value appropriation, the domination of ethical markets by corporate actors, deficient state support, and financial and administrative barriers which exclude the small-scale producers from EVeNs (Bowen \& Zapata, 2009; Fridell, 2007; Mancini, 2013; Raynolds, 2012).

\section{The Realisation of Ethical Claims: Differences Between Studied EVeNs}

Despite the similarities, the realisation of ethical claims of the two case studies demonstrated important differences between the studied EVeNs. For example, as mentioned the positive effects on local community development is a more explicit rationale of fair trade certifications compared to DO mark. It is therefore unsurprising that the fair trade wine case study is associated with more inclusive governance and positive, albeit limited, outcomes for smallscale producers, while the DO pisco case study is linked to mainly exclusive governance and minor benefits for small-scale producers. As discussed, the exclusion of small-scale producers is not uncommon with other DO experiences, where the majority of the power and the shares of the ethical premium have been concentrated by larger-scale corporate actors, as explored in other studies (Bowen, 2010a; Larson, 2007).

Similarly, the realisation of the ethical claims which promoted fair trade certifications in Chilean wine had more positive impacts on the small-scale grape producers and winery workers compared to the pisco DO. It is clear that this is because the fair trade certifications directly targeted these groups as beneficiaries, while the DO did not. On the other hand, the pisco grape producers and workers involved in this sector were not targeted directly by the DO mark and, as a result, tended to be excluded from the scheme's benefits, or at best only receive some positive overflow impacts through improvements in the sector linked to DO. This demonstrates that the EVeNs which target social impact are more likely to have positive community, worker and producer development outcomes. The pisco DO alternatively, was more targeted towards protecting the product's quality and local traditions and, as a result, the realisation of the ethical claims of the DO mark have supported pisco's authenticity and the preservation of local traditions, to varying degrees of success. Conversely, fair trade wine certification concentrated less on local traditions and quality was dictated more by the external demand for fair trade wine. A broader implication of these findings is that although this research has defined EVeNs by the commonalities across these networks, it is also important 
to recognise the different objectives of the networks which have concrete impacts on how EVeNs are implemented, realised and the outcomes they have on local groups.

\subsection{LINK TO CHAPTER EIGHT}

This chapter has contributed to research aim three; to identify the ethical claims utilised to promote the fair trade and DO networks and evaluate how these claims are realised through detailed investigation in the localities where the selected EVeNs are embedded. In order to make this contribution, this chapter applied a thematic analysis approach to identify and organise the key ethical claims used to promote the two studied EVeNs which were discussed across the different interviews. As summarised above, the key ethical claims and the realisation and failed realisation of these claims highlighted a number of cross-cutting themes but also showed the importance of local context and differentiation between the two studied EVeNs. Figure 36 compares the ethical footprints of the two studied EVeNs. The two ethical footprints have been compiled into one diagram. The blue lines demonstrate the realisation of the ethical claims in the fair trade wine EVeN in Chile while the red lines indicate the same but for the pisco DO EVeN in Peru. The ethical claims in the EVeN in fair trade wine in Chile focused on the positive impacts the network has had on small-scale wine and grape producers, workers in the viticultural sector, as well as the broader communities. As demonstrated, each of the ethical claims surrounding the fair trade wine $\mathrm{EVeN}$ in Chile were realised to some degree but had also failed in other aspects. Similarly, the DO EVeN in pisco from Peru was promoted by a set of key ethical claims which asserted the ways in which this EVeN supported local small-scale producers, local communities and their cultures, as well as safeguarding the product's authenticity and quality thus protecting consumers and producers. The EVeN in pisco from Peru revealed differing degrees of realisation and failing of these ethical claims. This chapter, therefore, recognises the contradictory nature of the studied EVeNs which demonstrates the complexity in evaluating these networks. 
Figure 36 Comparative Ethical Footprint: Designation of Origin Pisco in Peru and Fair Trade Wine in Chile

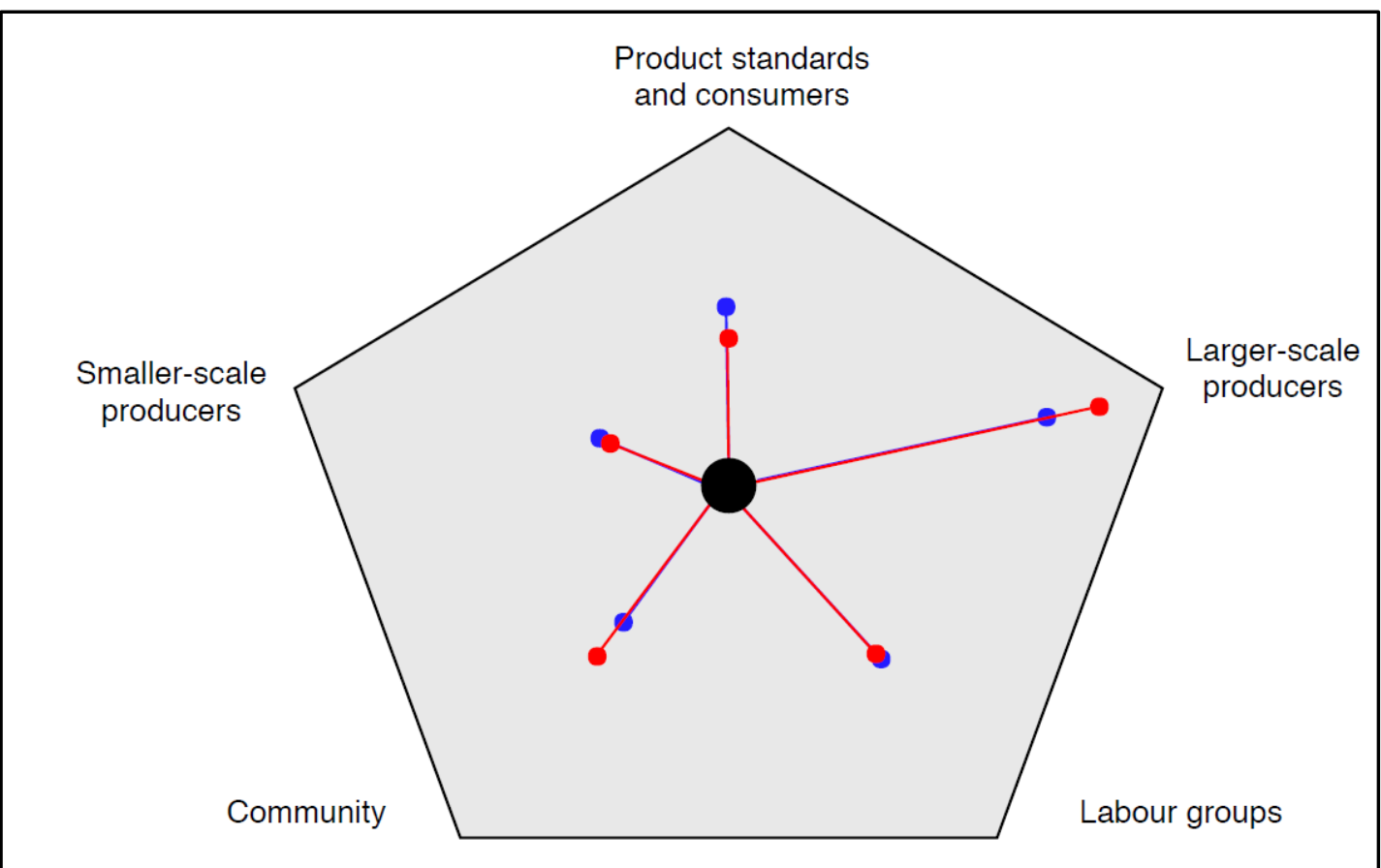

Note. Qualitative visualisation of ethical footprints for pisco DO from Peru shown in red and fair trade Chilean wine shown in blue. Source: Elaborated by the author and supervisor Professor Warwick Murray, based on analysis from fieldwork interviews.

Chapter Eight; 'Conclusions: Discussing Ethical Value' closes this thesis. This final chapter discusses the research aims and question which guided this research. Moreover, Chapter Eight evaluates this research by examining its theoretical contributions, practical recommendations while also highlighting the limitations of the study and areas for further research. Furthermore, the final chapter discusses some of the broader possibilities and limitations of EVeNs based on the key findings of this research. 


\section{CHAPTER EIGHT. CONCLUSIONS: DISCUSSING ETHICAL VALUE}

\subsection{CHAPTER INTRODUCTION}

As explored throughout this thesis, EVeNs have emerged in response to the negative outcomes associated with the globalisation of agricultural production. This thesis has demonstrated that the globalisation of agro-food networks has had a range of negative social, economic and environmental outcomes particularly across the Global South, including in Latin America. Impacted by shifts, campesino groups in rural Latin America face local colonial legacies, global neo-colonial economic and political structures, lowering levels of state support and increasing international competition. As discussed in Chapters Four and Four, these factors have created negative outcomes for these groups who have tended to experience market exclusion and precarious livelihoods.

As explained, the globalisation of agriculture has corresponded with growing concerns of Northern consumers in the last 30 years over social justice, food authenticity and safety, and environmental sustainability. This has led to the rise of what our research group has theorised as EVeNs; networks which certify ethical production and create a kind of ethical value. This thesis has critically explored the emergence of EVeNs in Peruvian and Chilean viticulture, to better understand the local outcomes of these networks.

This chapter closes this thesis. To begin, it discusses the central research aims which have guided this project. Subsequently, the chapter will explore the broad research findings extended from both the fair trade wine and pisco DO case studies. Following this, the chapter evaluates this research by discussing its contributions, recommendations, and areas identified for further research. Finally, the thesis closes with some concluding remarks on the possibilities and limitations of EVeNs based on the research findings.

\subsection{FINAL DISCUSSION OF RESEARCH AIMS}

The following sections summarise the completion of the three central research aims initially discussed in Chapter One and examined in detail through Chapters Four to Seven.

\subsubsection{Research Aim One:}

\section{Complete a Comparative Exploration of the Historical Evolution of the Viticultural Sectors in} Chile and Peru

This aim sought to provide a more informed research context. The main contributions to this aim were made in Chapters Four and Five. As discussed in these contextual chapters, viticulture in both Peru and Chile was introduced through Spanish colonisation. The colonial era was 
associated with social stratification and the exploitation of indigenous groups and African slaves, including in the viticultural sectors. It was illustrated that during this period, rural social inequalities were created through systems of forced labour known as the encomiendas and the establishment of large agricultural haciendas by the colonial elites (del Pozo, 2014; Huertas Vallejos, 2004). In the post-independence era, viticulture continued to expand in Chile and decline in Peru. Social stratification was maintained informally as the new mestizo elites concentrated power and wealth in Peru and Chile, as discussed in Chapters Four and Five. Socio-economic inequalities were maintained especially in rural areas, where haciendas owned by the mestizo elites dominated in both case study countries well into the Twentieth Century. Following an economic crisis in Chile during the 1930s, Chile implemented a developmentalist strategy. Agrarian reforms implemented by successive developmentalist governments over the next 35 years signalled the first significant attempts to eliminate the hacienda class and close the wide socio-economic inequalities in rural Chile. Similarly, Peru implemented a developmentalist strategy following a military coup in 1968, implementing comprehensive agrarian reforms. These reforms benefited campesino groups in Chile and Peru by redistributing the haciendas, however, the reforms caused declines in agricultural production and employment, in both countries. In Chile, viticulture stagnated between 1938 and 1973, while in Peru, viticulture practically disappeared between 1970 and 1990.

In Chile in 1973, a military coup reversed the statist model and eventually saw the implementation of neoliberal counter-reforms. In rural Chile, large-scale producers, including in viticulture, mainly benefited from these reforms, while campesinos struggled with the challenges of a liberalising economy. As discussed in Chapter Five, rural inequalities grew in Chile over this period. In Peru, a growing debt crisis during the 1970s caused a second coup and a gradual shift from statist policies to free market strategies from 1975. A return to democracy in 1980 was met with violent civil conflict and economic deterioration. Under these circumstances, rural poverty increased and Peruvian viticulture continued to retract between during the 1980s, as discussed in Chapter Four.

In 1990, Chile returned to democracy and wine exports began to grow impressively. Nonetheless, Chilean viticulture became increasing concentrated by a handful of large-scale exporters. This concentration created difficult conditions for smaller-scale producers in the sector. As explained in Chapters Five and Six, these conditions in part motivated the expansion of fair trade certifications in Chilean wine. From the early-1990s, Peru emerged from civil conflict and entered an era of sweeping neoliberal reforms. These reforms partly drove economic recovery while also causing economic shock and hardship among Peru's vulnerable 
groups. The neoliberal policies favoured private land ownership and investment, creating the conditions for large pisco and wine producers to repurchase land from the 1990s. However, it was not until the early 2000s, when the Peruvian State actively supported the growth of the pisco and wine industries, that viticulture began to reactivate. However, like in the case of Chile, this reactivation has been associated with sectoral concentration and rural inequalities. As discussed in Chapters Four and Six, this formed some of the motivations for implementing the pisco DO, as a potential avenue for broader development.

Therefore, completion of research aim one through the comparative historical reviews of Chilean and Peruvian viticulture demonstrated the connections between uneven rural development in South America and colonial legacies and neo-colonial structures. In both case studies, these legacies and structures have maintained socio-economic inequalities. Moreover, the completion of research aim one demonstrated the longue durée trajectories of Chilean and Peruvian viticulture and the important changes associated with the social, political and economic shifts over time in each country. In doing so, Chapters Four and Five highlighted the complexities and diversities of these historical trajectories and illustrated the persistent elements of continuity in both cases. This informed the context of studied viticultural sectors which are characterised by striking disparities between the campesinos and large-scale producers. Understanding these historical contexts informed the evolution of the studied EVeNs in Chile and Peru.

\subsubsection{Research Aim Two:}

\section{Critically Investigate the Construction of, Participation in, and Governance of EVeNs using} examples from the fair trade and DO Networks in Viticulture in Chile and Peru

This aim expanded from the contextual and historical knowledge achieved through the completion of research aim one, to investigate the formation and institutionalisation of the studied EVeNs. The main contributions of this aim were presented in Chapter Six.

This research identified that the expansion of fair trade wine network in Chile was motivated by diverse factors. These factors included; commercial interests by participating groups, external demands for ethical wines from international markets, growing social responsibility programmes, concerns over socio-economic inequalities in Chile's wine sector, the search for differentiation by small and medium scale producers, and support for rural communities, producers and workers. Similarly, the expansion of the pisco DO network in Peru was encouraged by a range of factors. These were linked to differentiating pisco in international and domestic markets, encouraging the international diffusion of the product, protecting consumers and producers, supporting producer communities and promoting the cultural 
importance of pisco. The motivating factors for the expansion of both studied EVeNs were discussed comprehensively in Chapter Six.

As illustrated in Chapter Six, the research highlighted some of the commonalities and differences between the formation of diverse EVeNs. For instance, Chapter Six demonstrated that both of the EVeNs of pisco DO in Peru and fair trade in Chile, were partly formed in response to global consumer concerns over how agricultural products are produced and to what standards. Similarly, through dependency and world-systems perspectives, this research emphasised some common risks involved with EVeNs. These risks were associated with the appropriation of the ethical value by corporate actors. It was illustrated that these corporate actors were able to apply their advantaged positions in the studied networks to dominant these niche markets, thus excluding smaller-scale and less powerful groups from the ethical value created. In many ways, both studied EVeNs expanded through the capital of larger-scale corporate actors which, seeking new opportunities for profits, have entered ethical markets. This research, therefore, demonstrated some of the common ways that EVeNs are exposed to ethical value appropriation.

Nonetheless, the research also revealed a number of key differences between the formations of the two studied EVeNs. As discussed in Chapter Six, the main difference between the evolution of the fair trade wine network in Chile and the DO pisco network in Peru, was that the Chilean case study was formed with more explicit social equality and community objectives in comparison to the Peruvian case study. The pisco DO was created with the objectives of protecting the authenticity and quality of the product, while community and social development objectives were not prioritised. Related to the point above, small-scale producers had more important roles in the formation of the studied fair trade network than in the DO case study. As explored in Chapter Six, the use of fair trade certifications in Chilean wine was partially driven by small-scale producer cooperatives which sought market differentiation. In the DO pisco case study in Peru, instead of representing active participants in the formation of this network, small-scale producers tended to only respond to the requirements imposed by the government. These differences had important implications for the institutionalisation, governance, and finally the impacts of each network. Lastly, the formations of the two studied EVeNs have been associated with different policy tendencies. The research demonstrated that fair trade wine network has formed following mainly neoliberal tendencies, where private groups have responded to global markets for ethically labelled products which are certified by private certifiers, such as FLOCERT and IMO. Conversely, the pisco DO has formed through neostructural policies by successive Peruvian Governments and public-private partnerships have encouraged the implementation of the pisco DO. However, as mentioned, government 
engagement has tended to prioritise commercial interests over community development in the DO pisco case study in Peru.

The research critically explored the institutionalisation of the EVeN in fair trade wine in Chile and DO pisco in Peru to complete research aim two. To complete this, the research developed EVeN maps based on wider concepts from GVC and GPN literature. Chapter Six demonstrated that both studied EVeNs were characterised by captive and hierarchical forms of network governance, whereby the minority of large-scale producers were able to set the prices for the base material and concentrate the value created in each network. As explored in Chapter Six, this research revealed that the EVeN in fair trade wine in Chile tended to be more inclusive in comparison to the country's conventional wine network. For instance, it was shown that there were more possibilities for the small-scale grape and wine producers to improve their positions in the network by using fair trade certification as a tool for upgrading. However, the research also demonstrated that the differences between the conventional and fair trade wine networks in Chile were contested as both networks consisted of many of the same actors and the larger producers appeared to continue to capture most of the value created in the fair trade wine network.

In Peru, the research found that the DO had largely failed to include small-scale producers in the governance of the pisco network. Instead, it was demonstrated that despite the implementation of the pisco DO, the value created in this network was usually captured by a number of large-scale pisco producing firms. It was illustrated that the small-scale grape and pisco producers were concentrated in captive supplier roles with minimal support from the DO or meaningful representation in the regulatory bodies. As discussed in Chapter Six, exclusive forms of governance which favour corporate actors over local small-scale producers are not uncommon for DOs, and clear comparisons with the pisco and tequila DOs can be observed. Although not a common trend, the research did identify cases where smaller and medium scale producers have been able to use the DO as a tool to improve their positions in the network. While there are examples of more relational forms of governance in the pisco DO network, the common form of network governance was captive under the control of a number of largescale, sometimes extra-local, producers. Therefore, the completion of research aim two demonstrated that although the formation of these EVeNs has been partly driven by ethical concerns and the possibilities of improving the positions of small-scale producers, these improvements have been limited in both case studies.

By applying GVC and GPN perspectives, this research successfully compared and contrasted the institutionalisation and governance of the studied EVeNs. For example, governance in both 
case studies was concentrated in the hands of powerful large-scale actors, while small-scale producers have faced important barriers in entering these networks and the governance of these networks, as discussed in Chapter Six. The findings also illustrated that EVeNs can be associated with complex governance structures, as additional actors are involved in these networks compared to their conventional counterparts. This complexity can create institutional overlaps and competition between the different actors in the EVeNs. The two studied networks highlighted similar failings of governance to restrict the entry of extra-local groups in the pisco DO case study, and to limit the expansion of conventional large-scale producers in fair trade wine case study. This research has consequently emphasised the key challenges in ensuring representative and fair governance of EVeNs.

The research also demonstrated some important differences between the institutionalisation of the two studied EVeNs. The clearest observable difference between the institutionalisation of the two case studies was that the pisco DO network is linked to a greater number of actors than the fair trade wine network in Chile. As discussed in Chapter Six, this has most likely been caused by the neostructural tendencies of the DO case, which has resulted in a significant grouping of public and private actors in this network. The network of the fair trade study is relatively limited, which likely results from fair trade's objectives of making this network shorter and fairer. The most central difference between the governance of both case studies is that the fair trade network was more inclusive of small-scale producers. Again, this was most likely linked to the social equality objectives of fair trade certifications. Governance of the DO case study was instead linked to the exclusion of small-scale producers. As explored, smallscale producer exclusion from governance and the dominance of corporate actors is not uncommon for DOs and the pisco case shares some clear similarities with the issues faced by small-scale tequila producers in Mexico, where global liquor companies virtually control this DO.

\subsubsection{Research Aim Three:}

\section{Identify the Ethical Claims utilised to Promote these fair trade and DO Networks and Evaluate how these Claims are Realised}

The final research aim examined the idealisation and realisation of the studied EVeNs through detailed investigation in the localities where these networks are embedded. The third research aim was mainly completed through Chapter Seven.

This research identified three central ethical claims which were used to idealise and promote the fair trade wine EVeN in Chile. These ethical claims were; 
1. Fair trade supports small-scale producers in Chilean viticulture

2. Company engagement in fair trade wine in Chile creates broader positive impact by reaching more vulnerable producers and workers

3. Fair trade creates broad community benefits in viticulture areas in Chile

The research found that the realisation of these claims was complex, with each claim resulting in positive, failed and negative outcomes, as described in Chapter Seven. Fieldwork demonstrated that the fair trade wine EVeN in Chile had some positive outcomes for smallscale grape and wine producers, viticultural labourers, and the broader communities in the production areas. However, fieldwork also revealed that the implementation of fair trade wine has had a range of failed and negative outcomes for these same groups. While recognising the positive outcomes that fair trade has had for different groups in the studied viticultural areas, the local socio-economic inequalities, exclusion of small-scale producers and other marginalised rural groups, the appropriation of fair trade by powerful actors, and limited scale of fair trade for community development, has meant that the positive realisation of the ethical claims in fair trade in Chile have encountered important barriers.

Similarly, this project identified three key ethical claims used to idealise and promote the DO pisco EVeN in Peru. These ethical claims were;

1. The pisco DO supports local small-scale producers in Peru

2. The pisco DO supports local community development and the preservation of local culture

3. The pisco DO safeguards product authenticity and quality

As discussed in Chapter Seven, it was revealed that the realisation of the ethical claims in the DO pisco network in Peru were also complex. Fieldwork found evidence that the pisco DO and the associated regulations had been successful in supporting traditional small-scale pisco and grape producers, creating local community development, while safeguarding the product's authenticity and quality and thereby protecting consumers and authentic producers. However, it was also revealed that the realisation of these outcomes had often failed. This study demonstrated that the local socio-economic inequalities, the exclusion of the most marginalised rural groups from the receiving the $\mathrm{DO}$ or being represented in its regulation, the appropriation of the DO by powerful extra-local actors, and limited focus on community development, have all signified that the ethical claims in the pisco DO network have been mostly unrealised. These unequal social contexts in rural areas of Peru and Chile were first discussed in Chapters Four and Five. 
The research revealed a number of similarities and differences in how the ethical claims were idealised and realised across the two case studies, as explored in detail in Chapter Seven. The research highlighted that both EVeNs were based on the idealisation of ethical claims associated with supporting small-scale producers and local community development to a differing degree. This showed that EVeNs are usually associated with an ethical claim which links consumption to positive social impacts in the local production areas. Furthermore, both case studies were linked to the localisation of production and countering the negative impacts of globalisation by supporting local producers. Therefore, the two cases studies illustrated the ways in EVeNs have expanded using ethical claims which target the concerns of global consumers over small-scale producers and rural labourers, food quality and authenticity, and the placelessness and intensification of production, in order to insert themselves into ethical niche markets. As discussed in Chapters Three, Six and Seven, these ethical niche markets are usually linked to the diverse yet interrelated consumer concerns associated with the globalisation of agriculture.

The two case studies however also illustrated the diversity across EVeNs and the differences in how these networks are promoted. For example, as explored the ethical claims in the fair trade wine case study were more explicitly linked to social equality and community development objectives. The DO case study conversely was linked to ethical claims which prioritised product quality, authenticity and traditional methods. This reveals the significant diversity across the different EVeNs which signifies that, despite the communalities between these networks, EVeNs are motivated by a range of objectives and promoted through diverse ethical claims, as discussed in Chapter Seven.

This research also revealed some of the important difference and similarities in the ways in which the ethical claims were realised or failed to be realised in the case studies. Across both case studies, this research confirmed that while several of the ethical claims were realised successfully, many of these claims failed to be realised or were realised in a restrictive sense. A broad implication which can be extended from the case studies is that they have illustrated some of the key issues EVeNs encounter in the realisation of the ethical claims, particularly when EVeNs are embedded in the Global South. As discussed in Chapter Seven, these important issues tend to be caused by the uneven and contested social, political and economic contexts and the competition between network actors. Through the case studies, this research demonstrated that under these contexts there are risks that the ethical value created in EVeN can easily be appropriated by corporate and extra-local actors, thereby causing local smallscale producer exclusion from the value created. The case studies did, nonetheless, demonstrate that EVeNs linked to ethical product labelling were able to encourage an 
additional value which can be observed as an ethical value. As mentioned in Chapter Seven, it was clear that distributing this ethical value fairly remained a challenge from the two case studies and most likely for other EVeNs. Likewise, the positive outcomes associated with the case studies continued to be restricted as the studied ethical labels were unable to counter the broader problems experienced by small-scale producers in the two networks. Both of the case studies thereby illustrated the limitations of EVeNs in addressing the challenges and hardships for vulnerable rural groups created by uneven social, political and economic national contexts and uneven economic globalisation. The commonalities between the failed realisation of ethical claims across the Chilean and Peruvian case studies stressed the broader challenges of EVeNs more generally. Literature has shown that other EVeNs also experienced similar obstacles to realising ethical claims. These broader challenges include value appropriation, deficient state support, the growing dominance of corporate and extra-local actors and significant barriers for small-scale producers (Bowen \& Zapata, 2009; Fridell, 2007; Mancini, 2013; Raynolds, 2012).

The research also discovered a number of differences in the realisation of the ethical claims associated with the EVeN case studies. For instance, as the studied fair trade network had more explicit community development and social equality objectives, it was not unsurprising that this network had more positive outcomes for small-scale producers and workers in comparison to the small-scale producers and workers in the DO case study. The pisco DO conversely, was oriented more towards safeguarding the product's quality, authenticity and traditional production, and the DO mark has had success in these areas to varying degrees, as discussed in Chapter Seven. In a broad sense, this research has, therefore, demonstrated that while EVeNs have been defined by the common aspects across different networks, it is vital to acknowledge the diverse objectives of these networks which have very real outcomes in how EVeNs and realised and the impacts they have on local actors and communities.

Therefore, the completion of research aim three discovered a range of cross-cutting themes in the idealisation and realisation of the two studied EVeNs. However, completing this aim has also demonstrated the importance of local context and the differentiation between the two case studies. Moreover, Chapter Seven highlighted the contradictions of the studied networks of the fair trade and DO labels in Chile and Peru which have has resulted in mixed outcomes for the different actors in these networks. As demonstrated in Chapters Six and Seven, there were complexities and diversity in how the research participants experienced and perceived the studied ethical labels. For instance, this research revealed contradictions between the research participants, and in some cases, there were contradictions within the same interviews. This diversity and complexity can be explained by the range of different experiences 
and outcomes associated with the studied networks. It is clear that a producer who has experienced positive outcomes with an ethical label is more likely to support this label and discuss its benefits. Conversely, a producer who has not experienced benefits of an ethical label or has faced significant barriers and has not been able to access this label is unlikely to support it or discuss its benefits. As mentioned, there were cases in which producer participants contradicted themselves. These contradictions and diversity tend to be explained by cases where these producers have experienced both successes and failings with the ethical label discussed.

\subsection{FINAL DISCUSSION OF RESEARCH QUESTIONS}

As explained in Chapter One, the three aforementioned research aims were supported by a set of research questions at the global, regional/national, and local scales. This section revisits these research questions.

\section{Global Level}

1.1 What has motivated the evolution of EVeNs in fair trade and DO globally?

1.2 What actors participate in the construction and regulation of these global EVeNs?

1.3 What ethical claims are applied to promote these networks, and do they represent valid alternatives to conventional trade?

It was illustrated that the globalisation of agro-food systems, and the integration of parts of the Global South into these systems, has fuelled growing concerns in Northern markets. These concerns have motivated the evolution of what we have labelled as EVeNs, as explained in Chapters One and Three. As discussed in Chapter Three, the fair trade EVeN has been motivated globally by social justice concerns and attempts to regulate global agro-food systems to promote fairer trade for small-scale producers, labourers and their communities in the South (Raynolds, 2012). As also discussed in Chapter Three, EVeNs based on DOs and other types of geographical indications, have recently arisen globally as a reaction to homogenisation of food production caused by globalising agriculture and in response to consumer concerns over food quality and safety (Bowen \& Zapata, 2009).

Both the fair trade and DO networks have been partly constructed by global actors. In the case of fair trade, international certifiers have played important roles in the development and expansion of these networks. Two international certifiers have been particularly important for the construction of the fair trade wine network in Chile; Fairtrade International which implemented a common fair trade certification in 2002 under the FLOCERT label, and IMO, which implemented the 'Fair for Life' label in 2006. Both these labels have been particularly 
important in Chilean wine. As discussed, although fair trade certifications seek to criticise conventional trade, these certification systems are associated with neoliberal tendencies. For instance, fair trade certifications have expanded as a response to market demand for products which contributes to social justice. Moreover, these fair trade certifications rose with limited state support and instead have been pushed by the interests of different private groups and certifiers. Arguably, fair trade, therefore, represents the neoliberalisation of ethical trade. In the case of the DO network, the World Intellectual Property Organization has been a particularly important actor in the construction of geographical indications EVeNs globally as the international regulator (including for DOs). Governments also possess important roles in protecting their DO products. Southern European countries; France, Italy and Spain with long histories in origin-based products have also been influential in the global diffusion of these networks (Parasecoli \& Tasaki, 2011). As also discussed in this thesis, the expansion of DO over the last few decades has been associated with neostructural tendencies in inter-governmental organisations such as the World Intellectual Property Organization as well as neostructural policies of national governments. In this sense, DOs have expanded globally through the support of governmental agencies, public-private interactions and groups and inter-state organisations. DOs therefore clearly represent a neostructural approach to ethical trade.

At the global level, fair trade has been promoted through the ethical claims that the network supports the livelihoods of small-scale producers, and more recently hired labourers, in the Global South through the provision of fairer prices and conditions. As explained in more detail Chapter Three, fair trade is also promoted globally through the ethical claims that it can reregulate the global market to empower Southern groups through trade. Globally, DO and other GIs have been linked to the localisation of agriculture which has been promoted as an alternative to the globalised agro-food systems as discussed in Chapter Three. DOs have been promoted globally to support local producers and their communities in countering the negative outcomes of globalisation by connecting production to place and local producers to international markets (Bowen, 2010a). It has also been claimed that DO networks provide global consumers with safer and more authentic food options. It is important to note that DOs, particularly when implemented outside of Europe, are usually applied to promote consumer security and this has tended to be prioritised over objectives of supporting local producers and communities. While providing avenues for rural community development have been established as key motives for implementing DOs in European countries, this is usually considered to be an indirect benefit of DOs outside of Europe. The validity of global fair trade and DO networks as alternatives to conventional agro-food have however faced challenges and come under contestation, as explored in Chapter Three. 


\section{Regional/National Level}

2.1 What historical and contemporary factors have caused the expansion of EVeNs in viticulture in Peru and Chile?

2.2 What actors participate in these DO pisco and fair trade wine networks nationally, and how is the 'ethical value' distributed between these actors?

2.3 What ethical claims have been applied to promote these networks at the national level?

As mentioned in the final discussion of research aim three and in Chapters Four and Five, socioeconomic inequalities in rural Chile and Peru have been caused by long histories of colonial legacies and neo-colonial structures in Latin America. These factors have resulted in the longterm marginalisation of campesinos including viticulturists, which have faced unfair conditions and market exclusion. These historical factors, therefore, created some of the motivations for the implementation of EVeNs in both the viticultural case studies, particularly in the fair trade cases study as these certifications are clearly linked to social objectives. Similarly, a number of contemporary factors caused the expansion of these studied EVeNs. As discussed in Chapters Four to Seven, the studied fair trade and DO EVeNs have expanded as responses to the negative outcomes of neoliberalism for campesinos in both Chile and Peru. As discussed throughout these chapters, neoliberal globalisation has led a concentration of production, market access and land ownership by a minority of large-scale producers. Therefore, the fair trade wine and DO pisco EVeNs have partly expanded to offer potential niche markets for small-scale producers disadvantaged first by colonial and neo-colonial structures, and more recently by neoliberal globalisation. Nonetheless, as demonstrated in both case studies, these niche markets are vulnerable to appropriation by larger corporate and extra-local actors, which has caused the exclusion of small-scale producers from the ethical markets. The participation of the different actors in the fair trade wine network in Chile and the DO pisco network in Peru is examined in the final discussion of research aim two in this chapter and in Chapter Six. Likewise, the ethical claims applied in the studied EVeNs at the national levels were summarised in the final discussion of research aim three, and discussed in greater detail in Chapter Seven.

\section{Local Level}

3.1 What has encouraged small-scale producer and rural labourer engagement in the pisco and wine EVeNs in the local case study areas?

3.2 To what extent have local actors been included and excluded in the expansion of these EVeNs in the production areas?

3.3 Are the ethical claims used to promote wine and pisco EVeNs being realised in the communities where these networks are embedded? 
The motivations which encouraged the engagement of small-scale producers and rural labourers in the local case study areas were clearer in the case of fair trade wine in Chile compared to the DO pisco case study in Peru. This was because these groups tended to have been more engaged in the fair trade network. As discussed in Chapter Six, disparities within Chile's viticultural sector and the aspirations of small-scale producers to find niche ethical markets were seen as key reasons for this group's engagement in fair trade. Small-scale viticultural producers have therefore engaged in fair trade in Chile as the label represented a form of upgrading as explored in GVC literature. fair trade was observed as a possible method to improve the returns and positions of these producers in the value network. Nonetheless, as discussed in detail throughout Chapter Seven, small-scale producers faced important financial and administrative barriers in entering and engaging in fair trade certification. Similarly, it has been illustrated that the pisco DO was partially created to assist local producers while protecting consumers. Therefore, this project found that the DO in some ways has been implemented to improve the livelihoods of producers in the pisco sector while safeguarding the intellectual property these producers have developed. However, as explained in detail in Chapter Seven, engagement of smallest-scale local producers in the DO network has been limited as these groups have been excluded from the DO regulation and face challenges in receiving the authorisation to use the pisco DO.

It has been demonstrated that there are cases of both inclusion and exclusion in the two studied EVeNs. In the fair trade wine case study in Chile, it was illustrated that the fair trade network was more inclusive compared to the conventional wine network. Local small-scale wine and grape producers were seen to be included in the fair trade wine network. However, the research in Chile also demonstrated that the inclusive nature of the fair trade wine network was contested it was shown that the smallest-scale local producers faced serious barriers in entering the fair trade network and tended to be excluded from participating, as examined in Chapters Six and Seven. In the pisco DO case study in Peru, local small-scale producers have been mainly excluded from the DO system and either fulfil roles as captive suppliers or as participants in informal low-value markets. The realisation of ethical claims in the local communities was examined in the final discussion of aim three in this chapter, and discussed in detail in Chapter Seven.

\subsection{BROAD RESEARCH FINDINGS}

This research successfully brought two diverse EVeN case studies together and address a number of broader issues regarding the appropriation of ethical value and control in EVeNs. The research demonstrated that there were broad governance and regulation issues across 
EVeNs. For instance, Chapter Six demonstrated that standards were set and monitored in ways which excluded the groups which are usually seen to benefit the most for ethical product labels, the small-scale producers, in both case studies. Although small-scale actors did enjoy a certain level of representation in governance and regulation of fair trade networks, this study and wider research, demonstrated that producer voices are becoming increasingly marginalised in this network. In the DO case study, small-scale pisco grape and pisco producers have been largely excluded from the governance and the setting of standards as this network has been dominated by the interests of larger commercial actors. The research did illustrate that although small-scale producers faced barriers in both case studies, governance in the fair trade EVeN was more inclusive than in the pisco DO EVeN overall. Both case studies revealed the potential roles of the states to support more inclusive forms of governance and regulation. States should play important roles in supporting small-scale producers to enter these networks and by advocating for their representation in the governance frameworks of these networks.

Further, both case studies revealed important findings about the role of capital in EVeNs. For instance, the case studies demonstrated that capital was attracted to the opportunities in ethical niche markets when these markets were deemed to be significant or expanding. Therefore, capital became more active when commercial opportunities became more obvious. This was linked to growing consumer markets for these labelled products. This observation was clearer in the fair trade wine case study as the expansion of this network in Chile was obviously linked to the growing demand for wine with ethical and sustainable product labels. In the DO case study, the pisco DO was more linked to attempts to create new external markets and to improve and control the product's quality. Across both case studies, it was clear that corporate and extra-local investors entered the EVeNs including when they did not fit the profiles of these networks. These investors have demonstrated their abilities to apply their influence to change the regulations of ethical labels to better fit their commercial interests. Furthermore, the case studies illustrated that investors will also change their profiles to fit the labels as an alternative means to enter an EVeNs. In the fair trade case study, this included setting-up smaller-scale companies, buying from certified producers or making changes to their labour relations. While in the DO case study, this included establishing production in the destinated productions zones or buying from local producers and using their authorisation to use the pisco DO. A broad implication of these findings is that as the markets for specific ethical products expand, investors become more hands-on and apply their influence in different areas. Likewise, as capital is drawn to these networks, it is likely that the risk for the appropriation of these networks by corporate and/or extra-local actors will increase. This thesis has demonstrated that as this investment grows, EVeNs are likely to be transformed to concentrate increasingly 
on securing niche markets over promoting ethical outcomes. Overall, by forming these findings, this research has provided critical insights into how EVeNs tend to perpetuate and reinforce many pre-existing social and economic inequalities. Moreover, the research findings also revealed the challenges in implementing EVeNs in contested and uneven political, economic and social contexts.

\subsection{EVALUATION OF RESEARCH}

These final sections evaluate this research by discussing its theoretical contributions, practical recommendations of the study and areas for further research. Following the completion of these sections, the thesis closes with some concluding remarks.

\subsubsection{Theoretical Contribution One:}

\section{Dependency, World-Systems and Neostructural Theories}

As explained in Chapter Two, dependency, world-systems and neostructural theories have provided important theoretical underpinnings. This section will demonstrate how this project has illustrated the modern relevance of these theories while making important contributions to them.

In particular, this research has exemplified the modern application of these theoretical perspectives in critiquing global capitalism and its uneven consequences. Although dependency and world-systems theories emerged in the 1960s and 1970s, this thesis has demonstrated that their varying criticisms of free market economics and modernisation still provide important lenses for studying neoliberal globalisation and development. Moreover, this research has illustrated the valid contributions neostructural thought has made in responding to, and critiquing, neoliberal shifts in these countries. These theories demonstrate the importance of understanding that the integration of countries in the Global South into the international economy, initially through colonisation and later through forms of neocolonialism, has caused uneven development outcomes (Dos Santos, 1970; Wallerstein, 2004; Gwynne \& Kay, 2000). Through the South American case studies of Peru and Chile, this work has demonstrated the important contributions of these theories in understanding the challenging integration of these countries into the global economy and the socio-economic disparities which were established and maintained in these two countries. Therefore, these theories have proven to be central in critically exploring the use of ethical labels and the rise of EVeNs in the neoliberal era, and more specifically in the national South American cases studies; Peru and Chile. 
In particular, this research has contributed to dependency, world-system, and neostructural theories by demonstrating the main failings these studied EVeNs have had in countering the uneven trade relations and socio-economic inequalities in the areas where these networks are embedded in Chile and Peru. Likewise, the research has contributed to these theories by illustrating how these EVeNs have generally failed to respond to the larger issues which cause underdevelopment, external dependency, unequal exchange and socio-economic disparity in Latin America explained by dependency, structuralist and world-system theories. For instance, the success of these networks appears to depend on expansion into Northern markets, which signifies that the positive outcomes of these networks are conditioned by the integration of ethically labelled products into Northern markets and by Northern consumer demand. Similarly, this research supports the neostructural argument that selective state invention is required in peripheral and semi-peripheral economies to encourage a shift from neoliberal policies based on comparative advantage in natural resources, to measures which encourage value-adding and upgrading. As discussed, EVeNs represent attempts to add value and upgrading by targeting ethical markets, in line with neostructural ideas. Furthermore, this research has contributed to neostructural thought by stressing the important role of the state in ensuring that all actors, including small-scale producers, are represented in the governance of EVeNs and that ethical value created in these networks is distributed evenly.

\subsubsection{Theoretical Contribution Three:}

\section{Extending Global Value Chain and Global Production Network Approaches by Theorising}

\section{Ethical Value Networks}

As introduced in Chapter Two, GVC and GPN approaches have contributed to this project by providing useful methods for investigating economic globalisation. Both approaches have proven to be valuable in exploring the studied EVeNs in Chile and Peru. As explained in Chapters Two and Six, the GVC approach concentrates on firm linkages, chain governance and power dynamics between firms (Gereffi et al., 2005). GVC analysis has contributed to this thesis by simplifying the complex intangible elements of this study, such as the global economy, by examining two tangible products; wine and pisco, as they progressed through the different stages of their respective value networks (Kleine, 2008). As discussed in Chapter Two, the GPN approach has critiqued the central focus of the GVC on firms, and endeavoured to include notions of human agency and the interactions of non-firm actors (Coe et al., 2008). The GPN approach has therefore provided an important lens for researching the complexities of the studied pisco and wine networks in Peru and Chile, by also concentrating on human elements which have influenced the evolution of these studied EVeNs. 
As evident in the name (ethical value networks), our research group has selectively incorporated elements of these two approaches to create a new approach for studying the value networks based on ethical labelling. As demonstrated in Chapter Six, this thesis and larger project this work feeds into, have consequently contributed to the GVC and GPN approaches by developing the innovative EVeNs approach. In doing so, this work has extended from these original two approaches to include an analysis of the ethical value created and distributed within the studied networks. In particular, it contributes to growing literature using GVC and GPN approaches to explore international development and social and environmental outcomes of global trade (Challies \& Murray, 2011; Hughes et al., 2008). Furthermore, the EVeNs approach could be applied to other examples of ethical labelling in diverse sectors. As discussed, the concept of EVeNs has been developed explicitly by the wider research team to which this thesis contributes to.

\subsection{RECOMMENDATIONS AND POLICY CONTRIBUTIONS}

The following sections provide recommendations for the fair trade wine network in Chile and pisco DO network in Peru, based on the research findings. These recommendations do not ignore the positive outcomes that these two studied networks have created, but instead, summarise some of the practical and policy contributions of this project. These sections have been separated into recommendations for fair trade wine in Chile and recommendations for DO pisco in Peru, although there are some cross-cutting themes. It is important to note that these sections do not claim to present an exhaustible list of recommendations, as there are other recommendations outside the scope of this study.

\section{Recommendations for Fair Trade Wine in Chile}

This research has demonstrated that small-scale producers in Chile's viticultural sector require more financial and administrative support to help with the fair trade certification process. The state should play a more important role in directly supporting small-scale producers to receive fair trade certification. Moreover, it was revealed that fair trade certifiers should lower the costs of certification for small-scale producers and support these producers to make international commercial connections once certified. Similarly, the state should expand its programmes to incentivise the formation of small-scale producer cooperatives to assist these producers in sharing the costs and administration associated with fair trade. This project has illustrated that efforts need to be made to expand markets for fair trade products by increasing promotion. Again, the certifiers and possibly the public sector should play larger roles in this process. Promotion should include expanding the existing Northern fair trade markets, but could also include the promotion of South-South fair trade by targeting the growing middle- 
classes in Southern regions. For example, existing research has highlighted the potential markets for fair trade Chilean wines in large Latin American markets such as Brazil and Colombia (Wijnant et al., 2015). Likewise, there needs to be more educational programmes in fair trade to facilitate the growth of a national consumer base in Chile where a growing middleclass is consuming more sustainable and organic production, demonstrating potential demand for fair trade production. Furthermore, additional educational programmes should be implemented to improve understandings about fair trade certification among the smallestscale producers who could benefit from certification.

Additionally, this thesis argues that fair trade requires a re-orientation towards the movement's original objectives of supporting scale-scale producer groups. Fieldwork highlighted that fair trade has become increasingly focused towards consumer demands in Northern supermarkets rather than responding to producers' needs. Similarly, it was revealed through the wine case study in Chile, that more differentiation between the use of fair trade certifications for small-scale farmer products and the products certified under the hired labour plantation systems is required. It was demonstrated that the current fair trade certifications appear to misinform the consumer by failing to display these differences, thereby denying consumers the option of selecting between small-scale farmer products or products made with hired labour. As discussed, the lack of differentiation has unfairly placed fair trade certified small-scale producers in direct competition with the fair trade lines of the larger-scale and more resourced companies. However, care must be taken in creating differentiation as the multiplication of diverse labels tends to create consumer confusion. Therefore, a balance needs to be found, however, it is clear that there needs to be differentiation in fair trade.

\section{Recommendations for Designation of Origin for Pisco in Peru}

It was shown that the regulatory institutions surrounding the pisco DO need to be reorganised to clarify the functions of each institution. Currently, there is organisational confusion and overlap, and the Peruvian State should work with the different institutions to resolve this issue. Most importantly, an effective Regulatory Council (CR) for the pisco DO needs to be established, with appropriate funding mechanisms. This study has demonstrated that this organisation is critical in verifying the legitimacy of products sold as pisco and in the enforcement of the DO regulations. Without this organisation, it is impossible to control the falsification of pisco or the unfair competition this creates for producers. Likewise, without a functioning $C R$, there is no valid guarantee for consumers that the products labelled as pisco follow the regulations for high-quality and authenticity. The creation of an effective $C R$ requires the support of the state as well as the producers. Likewise, the CR should better represent all producers which form the pisco network. This should include the small-scale pisco and grape 
producers which have been largely excluded. Moreover, the CR should integrate other actors in the network, such as researchers and other actors which contribute to the development of the pisco DO. This research has found that currently, the CR does not represent an interprofessional organisation, which means that grape producers and other groups tend to be excluded from benefits generated by the DO.

Additionally, small-scale pisco producers require financial and administrative assistance to receive the authorisation to use the pisco DO. The state should play a more important role in integrating these small-scale producers into formal DO sector. Moreover, the state should expand programmes to incentivise producer cooperatives in order to support small-scale pisco producers to adopt DO and improve their economies of scale. Additionally, this thesis recommends stricter DO regulation to counter the extra-local appropriation of pisco. This could include implementing stricter regulation so only groups that own grapevines and/or pisco processing facilities in the designated pisco areas are able to receive the authorisation to use the DO. This would also assist in controlling the falsification of pisco. Finally, there should be additional educational programmes about the DO, so producers and consumers value and support this system in Peru. Finally, the state should continue to expand its direct support towards promoting pisco and the pisco DO in high-end international niche markets.

\subsection{AREAS FOR FURTHER RESEARCH}

This innovative research has explored two EVeNs, in two viticultural products, across two South American countries. The multifaceted nature of the research has opened areas for further research while also adding value to this project. The complex nature of the research generated a high level of research value. While most studies in ethical labelling have tended to examine one label in one country, this study has instead endeavoured to compare and contrast two EVeNs across two labels in two countries, thus resulting in ground-breaking findings.

Due to the multifaceted nature of this research, this project has centred largely at the production end, in the local areas where the EVeNs are embedded. In order to keep within scope, this project did not concentrate in detail on the consumption end of the studied EVeNs. However, this has created an interesting area for further research. For example, further research could explore in greater detail the evolution of these same EVeNs in retail and at the consumer base to better understand the rise of the studied EVeNs from the consumption end. Moreover, further research could extend from the concepts and approaches created in this project to study EVeNs in different networks and countries. In particular, further research could contribute to our knowledge on the implementation and validity of EVeNs surrounding sustainability or organic labels. Similarly, valuable further research could explore the 
development and possible shifts in the fair trade wine EVeN in Chile and the DO pisco EVeN in Peru in five to ten years.

Furthermore, this study has extended global value chains and production networks approaches for studying economic globalisation. The extension of these existing methodologies through the EVeN approach provides a valuable starting point for further research which applies EVeN methodologies. Moreover, the presentation of ethical footprints as a method to visualise the outcomes of EVeNs could be developed further and applied to other networks and product labelling.

\subsection{CONCLUDING REMARKS}

Overall, by critically exploring two case studies, this thesis argues that in the era of neoliberal globalisation, progressive states and social-oriented civil society organisations are required to ensure the creation of ethical trade while addressing the wider factors which have driven exclusive and uneven development in most of Latin America and in other parts of the Global South. Moreover, this doctoral research extends from critical literature on the rise of DOs and fair trade in the South, and more specifically Latin America. Detailed fieldwork and analysis have supported these bodies of literature which emphasised the importance of local contexts in the formation and outcomes of ethical labels (Bowen, 2010b; Fridell, 2007; Overton, Murray, \& Banks, 2012). Moreover, it supports literature which suggests that the ethical value created through product labelling is vulnerable to extra-local and larger corporative appropriation which has eventually marginalised the groups that are seen to benefit from the EVeNs (Barrientos \& Dolan, 2006b; Bowen \& Zapata, 2009). The networks case studies in fair trade and DO have evolved in contexts of historically entrenched social, economic and political inequalities, especially for small-scale producers and rural labourers. These uneven social, economic and political contexts in both Peru and Chile, have created significant barriers to creating meaningful ethical outcomes. In a number of ways, the fair trade and DO networks have worsened local rural inequalities by excluding the most vulnerable groups of the smallscale producers and temporal labourers, while supporting larger-scale and newer producers to enter niche markets based in ethical labelling. Nonetheless, this research has also highlighted that despite the commonalities across EVeNs, the critical exploration of the two cases studies has revealed the diversity between the formation, institutionalisation, and realisation of different EVeNs. Therefore, although the case studies revealed significant diversity, the broader implications of this research is that it has illustrated the potential of EVeNs in creating positive social outcomes through ethical labels, however, it has also demonstrated the 
significant limitations of EVeNs, as they are currently implemented, in encouraging local development outcomes in Chile, Peru and beyond. 


\section{REFERENCES}

Ackroyd, S., \& Fleetwood, S. (2005). Critical Realist Applications in Organisation and Management Studies (1 ed.). London: Routledge.

Allen, P., \& Wilson, A. B. (2008). Agrifood Inequalities: Globalization and Localization. Development, 51(4), 534-540.

Andrews, N., \& Bawa, S. (2014). A Post-development Hoax? (Re)-examining the Past, Present and Future of Development Studies. Third World Quarterly, 35(6), 922-938.

Arata, A., \& Vargas, S. (2007). Cautivos en su mercado. Pequeños productores de pisco y vino Perú Hoy, mercados globales y (des)articulaciones internas (pp. 226-244). Lima: Centro de Estudios y Promoción del Desarrollo (Desco).

Auty, R. M. (1994). Industrial Policy Reform in Six Large Newly Industrializing Countries: The Resource Curse Thesis. World Development, 22(1), 11-26.

Banks, G., \& Overton, J. (2010). Old World, New World, Third World? Reconceptualising the Worlds of Wine. Journal of Wine Research, 21(1), 57-75.

Barbier, E. B. (2000). Links between Economic Liberalization and Rural Resource Degradation in the Developing Regions. Agricultural Economics, 23(3), 299-310.

Bárcena, A., \& Prado, A. (2016). Neo-structuralism and Heterodox Currents in Latin America and the Caribbean at the Beginning of the XXI Century. Santiago: Economic Commission for Latin America and the Caribbean.

Barham, B. L., \& Weber, J. G. (2012). The Economic Sustainability of Certified Coffee: Recent Evidence from Mexico and Peru. World Development, 40(6), 1269-1279.

Barham, E. (2003). Translating Terroir: the Global Challenge of French AOC Labeling. Journal of Rural Studies, 19(1), 127-138.

Barrientos, S., \& Dolan, C. (2006b). Transformation of Global Food: Opportunities and Challenges for Fair and Ethical Trade. In S. Barrientos \& C. Dolan (Eds.), Ethical Sourcing in the Global Food System (pp. 1-33). London: Earthscan.

Barton, J. R., Gwynne, R. N., \& Murray, W. E. (2007). Competition and co-operation in the semiperiphery: closer economic partnership and sectoral transformations in Chile and New Zealand. Geographical Journal, 173(3), 224-241.

Barton, J. R., Gwynne, R. N., \& Murray, W. E. (2008). Transformations in resource peripheries: an analysis of the Chilean experience. Area, 40(1), 24-33.

Barton, J. R., \& Murray, W. E. (2002). The End of Transition? Chile 1990-2000. Bulletin of Latin American Research, 21(3), 329-338.

Bassett, T. J. (2010). Slim Pickings: Fairtrade Cotton in West Africa. Geoforum, 41(1), 44-55.

Bauer, A. (1975). Chilean Rural Society from the Spanish Conquest to 1930. Cambridge: Cambridge University Press.

Bazán, C. V. (2003). Autocratic Neoliberalism and the Peruvian Dilemma: the Political Economy of the Fujimori Decade. (Doctor of Philosophy), University of Denver, Denver.

Belletti, G., Marescotti, A., Sanz-Cañada, J., \& Vakoufaris, H. (2015). Linking protection of geographical indications to the environment: Evidence from the European Union oliveoil sector. Land Use Policy, 48, 94-106.

Bellisario, A. (2007). The Chilean Agrarian Transformation: Agrarian Reform and Capitalist 'Partial' Counter-Agrarian Reform, 1964-1980. Journal of Agrarian Change, 7(1), 1-34.

Berdegué, J. (2001). Cooperating to Compete. Peasant Associative Business Firms in Chile. Wageningen: Wageningen University.

Bidwell, S., Murray, W. E., \& Overton, J. (2015). The Rise of Ethical Value Chains in a Globalising World: An Overview of Fair Trade, Organics and Geographical Indications with an Emphasis on Latin America. Ethical Value Networks Working Paper Series. Victoria University of Wellington. Wellington. 
Biénabe, E., \& Marie-Vivien, D. (2015). Institutionalizing Geographical Indications in Southern Countries: Lessons Learned from Basmati and Rooibos. World Development, 98, 58-67.

Blakemore, H. (1993). From the War of the Pacific to 1930. In L. Bethell (Ed.), Chile Since Independence (pp. 33-85). Cambridge: Cambridge University Press.

Boisvert, V. (2006). From the Conservation of Genetic Diversity to the Promotion of Quality Foodstuff: Can the French Model of 'Appellation d'Origine Contrôlée' be Exported? . CAPRI Working Paper. No. 49. International Food Policy Research Institute. Washington, D.C.

Bolwig, S., Ponte, S., Du Toit, A., Riisgaard, L., \& Halberg, N. (2010). Integrating Poverty and Environmental Concerns into Value-Chain Analysis: A Conceptual Framework. Development Policy Review, 28(2), 173-194.

Bonanno, A., Busch, L., Friedland, W., Goveia, L., \& Migione, E. (1994). From Columbus to ConAgra: The Globalization of Agriculture and Food. Lawrence: University Press of Kansas.

Bowen, S. (2010a). Embedding Local Places in Global Spaces: Geographical Indications as a Territorial Development Strategy. Rural Sociology, 75(2), 209-243.

Bowen, S. (2010b). Development from Within? The Potential for Geographical Indications in the Global South. The Journal of World Intellectual Property, 13(2), 231-252.

Bowen, S., \& Mutersbaugh, T. (2014). Local or localized? Exploring the contributions of FrancoMediterranean agrifood theory to alternative food research. Agriculture and Human Values, 31(2), 201-213.

Bowen, S., \& Zapata, A. V. (2009). Geographical indications, terroir, and socioeconomic and ecological sustainability: The case of tequila. Journal of Rural Studies, 25(1), 108-119.

Bramley, C., Bienabe, E., \& Kirsten, J. (2013). Developing Geographical Indications in the South: The Southern African Experience: Springer Netherlands.

Bryant, R. L., \& Goodman, M. K. (2004). Consuming Narratives: the Political Ecology of 'Alternative' Consumption. Transactions of the Institute of British Geographers, 29(3), 344-366.

Bulmer-Thomas, V. (2003). The Economic History of Latin America Since Independence (Vol. 77). Cambridge: Cambridge University Press.

Burneo, Z. (2011). The Process of Land Concentration in Peru. CEPES Contribution to ILC Collaborative Research Project on Commercial Pressures on Land. Rome: Centro Peruano de Estudios Sociales (CEPES).

Bustos, J., Torres, J. P., \& Willington, M. (2007). Propiedad extranjera y especialización productiva en la industria del vino en Chile: Georgetown University; Universidad Alberto Hurtado.

Buzzetti Horta, C. (2018). Boletín del vino: producción, precios y comercio exterior. Avance a diciembre de 2017. Santiago: Oficina de Estudios y Políticas Agrarias (ODEPA), Ministerio de Agricultura (Chile).

Caballero, J. M. (1980). Agricultura, reforma agraria y pobreza campesina. Lima: Instituto de Estudios Peruanos.

Caceres Booth, J. (2013). The Persistence of the Fujimori Legacy in Peru. (Honours Program in History), University of British Columbia, Okanagan.

Cantin, É. (2010). New International Division of Labor. In B. Warf (Ed.), Encyclopedia of Geography (pp. 2020-2021). Thousand Oaks: SAGE Publications.

Caro, P. (2013). Contratos de género en temporeros/as del vino de Casablanca, Chile. Cuadernos de Desarrollo Rural, 10(72).

Caro, P. (ND). Procesos de migración transfronteriza e interna de trabajadores/as temporeros/as del vino en Argentina y Chile: Familia, pareja y género: Centro Investigación y Estudios Familia, Trabajo y Ciudadanía (CIELO).

Castillo, L., \& Lehmann, D. (1982). Chile's Three Agrarian Reforms: The Inheritors. Bulletin of Latin American Research, 1(2), 21-43. 
Cellar Tours. (ND). Chilean Wine Regions Map. Retrieved 1 September 2018, from https://www.cellartours.com/chile/wine-maps

Cesano, D., \& Gustafsson, J.-E. (2000). Impact of Economic Globalisation on Water Resources: A Source of Technical, Social and Environmental Challenges for the Next Decade. Water Policy, 2(3), 213-227.

Chacko, E. (2004). Positionality and Praxis: Fieldwork Experiences in Rural India. Singapore Journal of Tropical Geography, 25(1), 51-63.

Challies, E. (2010). Agri-Food Globalisation and Rural Transformation in Chile: Smallholder in the Global Value Chain for Raspberries. (Doctor of Philosophy in Geography), Victoria University of Wellington.

Challies, E. R., \& Murray, W. E. (2008). Towards Post-neoliberalism? The Comparative PoliticoEconomic Transition of New Zealand and Chile. Asia Pacific Viewpoint, 49(2), 228-243.

Challies, E. R. T. (2008). Commodity Chains, Rural Development and the Global Agri-food System. Geography Compass, 2(2), 375-394.

Challies, E. R. T., \& Murray, W. E. (2011). The Interaction of Global Value Chains and Rural Livelihoods: The Case of Smallholder Raspberry Growers in Chile. Journal of Agrarian Change, 11(1), 29-59.

Chambers, R. (1997). Responsible Well-being - A Personal Agenda for Development. World Development, 25(11), 1743-1754.

Chambers, R. (2007). Poverty Research: Methodologies, Mindsets and Multidimensionality. IDS Working Paper, 293. East Sussex: Institute of Development Studies.

Chambers, R. (2012). Revolutions in Development Inquiry. London: Taylor \& Francis.

Chase-Dunn, C., \& Hall, T. D. (2012a). Global Scale Analysis in Human History. In D. Northrop (Ed.), A Companion to World History (pp. 185-200). Malden: Wiley-Blackwell.

Chase-Dunn, C., \& Hall, T. D. (2012b). Global scale analysis in human history. A Companion to World History, 185-200.

Chávez, D. (2007). Globalizing Tequila: Mexican Television's Representations of the Neoliberal Reconversion of Land and Labor. Arizona journal of hispanic cultural studies, 10(1), 187-203.

Coe, N. M., Dicken, P., \& Hess, M. (2008). Introduction: Global Production Networks-Debates and Challenges. Journal of Economic Geography, 8(3), 267-269.

Collier, S., \& Sater, W. F. (1996). A History of Chile, 1808-1994. Cambridge: Cambridge University Press.

Collier, S., \& Sater, W. F. (2004). A History of Chile, 1808-2002 (Vol. 82). Cambridge: Cambridge University Press.

Colman, T. (2008). Wine Politics: How Governments, Environmentalists, Mobsters, and Critics Influence the Wines We Drink: University of California Press.

Comisión de Promoción del Perú para la Exportación y el Turismo. (2018). Exportaciones de pisco y similares. Lima: Comisión de Promoción del Perú para la Exportación y el Turismo (PromPerú).

Comisión Nacional del Pisco. (ND). Estadísticas. Retrieved 18 May 2018, from http://www.conapisco.org.pe/estadisticas.html

Crabtree, J. (2002). The Impact of Neo-liberal Economics on Peruvian Peasant Agriculture in the 1990s. The Journal of Peasant Studies, 29(3-4), 131-161.

Crabtree, J. (2016). Peru Under Garcia: An Opportunity Lost (1 ed.). London: Palgrave Macmillan UK.

Crisóstomo, M. (2016). Las herencias culturales del gamonalismo y la reforma agraria en la costa y sierra del Perú. Revista Argumentos, 4, 17-22.

Dagne, T. (2015). Beyond Economic Considerations: (Re)Conceptualizing Geographical Indications for Protecting Traditional Agricultural Products. IIC - International Review of Intellectual Property and Competition Law, 46(6), 682-706.

Dargent Chamot, E. (2014). Vino y pisco en la historia del Perú. Lima: Fondo Editorial Universidad San Martín de Porres. 
Davies, T. M., Burr, R. N., Moore, J. P., Pulgar-Vidal, J., \& Kus, J. S. (2018). History of Peru. Britannica Online Academic Edition: Encyclopædia Britannica, inc.

del Pozo, J. (1995). Vina Santa Rita and Wine Production in Chile Since the Mid-19th Century. Journal of Wine Research, 6(2), 133.

del Pozo, J. (2014). Historia del vino chileno: desde la época colonial hasta hoy (1st ed.). Santiago: LOM Ediciones.

Della Porta, D., \& Keating, M. (2008). Approaches and Methodologies in the Social Sciences: A Pluralist Perspective (D. Della Porta \& M. Keating Eds.). Cambridge: Cambridge University Press.

Días, P., \& Korovkin, T. (1990). Neo-Liberalism in Agriculture: Capitalist Modernization in the Chilean Countryside during the Pinochet Years. Canadian Journal of Latin American and Caribbean Studies, 15(30), 197-219.

Dicken, P. (2007). Global Shift: Mapping the Changing Contours of the World Economy. New York: SAGE Publications Ltd.

Dicken, P., Kelly, P. F., Olds, K., \& Wai-Chung Yeung, H. (2001). Chains and Networks, Territories and Scales: Towards a Relational Framework for Analysing the Global Economy. Global Networks, 1(2), 89-112.

Dirección de Signos Distintivos. (2017). Guía Práctica de la Denomiación de Origen Pisco. Lima INDECOPI.

Dos Santos, T. (1970). The Structure of Dependence. The American Economic Review, 60(2), 231-236.

Dragusanu, R., Giovannucci, D., \& Nunn, N. (2014). The Economics of Fair Trade. Journal of Economic Perspectives, 28(3), 217-236.

Drake, P. W. (1993). Chile, 1930-1958. In L. Bethell (Ed.), Chile Since Independence (pp. 87-128). Cambridge: Cambridge University Press.

Easton, G. (2010). Critical Realism in Case Study Research. Industrial Marketing Management, 39(1), 118-128.

Edwards, M. (1989). The Irrelevance of Development Studies. Third World Quarterly, 11(1), 116-135.

Eguren, F. (2004). Las políticas agrarias en la última década: una evaluación (F. Eguren, M. I. Remy \& P. Oliart Eds.). Lima: SEPIA,OXFAM.

Eguren, L., Eguren, F., \& Durand, F. (2018). Concentración de la tierra y poder político en el Perú. Lima: Oxfam América/Centro Peruano de Estudios Sociales (CEPES).

Elliott, K. (2012). Is My Fair Trade Coffee Really Fair? Trends and Challenges in Fair Trade Certification CGD Policy Paper (Vol. 17). Washington, D.C: Center for Global Development.

Ensalaco, M. (2000a). The New Order. In M. Ensalaco (Ed.), Chile Under Pinochet (pp. 47-68). Philadelphia: University of Pennsylvania Press.

Ensalaco, M. (2000b). The Victors and the Vanquished. In M. Ensalaco (Ed.), Chile Under Pinochet (pp. 1-21). Philadelphia: University of Pennsylvania Press.

Equal Exchange. (2012). Support the Authentic Fair Trade Movement. Retrieved 08/12, 2015, from http://equalexchange.coop/small-farmer-campaign

Escobar, A. (2010). Latin America at a Crossroads: Alternative Modernizations, Post-liberalism, or Post-development? Cultural Studies, 24(1), 1-65.

Esteva, G., \& Escobar, A. (2017). Post-Development @ 25: on 'Being Stuck' and Moving Forward, Sideways, Backward and Otherwise. Third World Quarterly, 1-14.

European Commission. (2015). Quality Policy: Geographical indications and traditional specialities. $\quad$ Retrieved 1/12, 2015, from http://ec.europa.eu/agriculture/quality/schemes/index en.htm

Evans, P. (2004). Development as Institutional Change: the Pitfalls of Monocropping and the Potentials of Deliberation. Studies in comparative international development, 38(4), 30-52. 
Fair for Life. (n.d.-a). About For Life and Fair for Life. Retrieved 04/06, 2019, from http://www.fairforlife.org/pmws/indexDOM.php?client id=fairforlife\&page id=abou t\&lang iso639=en

Fair for Life. (n.d.-b). Frequently Asked Questions - How much does the certification cost? Retrieved 04/06, 2019, from http://www.fairforlife.org/pmws/indexDOM.php?client id=fairforlife\&page id=mate rials\&lang iso639=en

Fair Trade International. (2014). Monitoring the Scope and Benefits of FairTrade. (6th ed.). Bonn: Fair Trade International.

Fair Trade International. (2015). Global Change, Local Leadership. Annual Report 2014-2015. Bonn, Germany

Fair Trade USA. (2012). Fair Trade for All Update. Retrieved 08/12, 2015, from http://fairtradeusa.org/

Fairtrade International. (2015). Standard for Hired Labour. Retrieved 2 November 2017, from https://www.fairtrade.net/standards/our-standards/hired-labour-standards.html

Farinelli, F., Fernández-Stark, K., Meneses, J., Meneses, S., Mulder, N., \& Reuse, K. (2017). Use of Knowledge-intensive Services in the Chilean Wine Industry (Vol. 136). Santiago: Economic Comission for Latin America and the Caribbean

Feenstra, R. C., \& Hamilton, G. G. (2006). Emergent Economies, Divergent Paths: Economic Organization and International Trade in South Korea and Taiwan (Vol. 29). Cambridge: Cambridge University Press.

FLO International. (n.d.). Certifying Fairtrade. Retrieved 04/06, 2019, from https://www.fairtrade.net/about-fairtrade/certifying-

fairtrade.html?utm medium=email\&utm campaign=Fairtrade\%2520Insider\%2520Ju ne\%25202016\&utm content=Fairtrade\%2520Insider\%2520June $\% 25202016 \% 2520 \mathrm{Cl}$

D 39e5d6f30910742c748f16e668614e3a\&utm source=\&utm term=Find\%2520out\% 2520more\%2520about $\% 2520$ these $\% 2520$ Projects

FLOCERT. (2019). Minimum Price and Premium Information. Retrieved 04/06, 2019, from https://www.fairtrade.net/standards/price-and-premium-info.html

FLOCERT. (n.d.). Cost Calculator. Retrieved 04/06, 2019, from https://www.flocert.net/starttrading-fair-today/

Frank, A. G. (1966). The Development of Underdevelopment. Boston, MA: New England Free Press

Frank, A. G. (1969a). Capitalism and underdevelopment in Latin America : historical studies of Chile and Brazil. New York, London: Monthly Review Press.

Frank, A. G. (1969b). Capitalism and Underdevelopment in Latin America: Historical Studies of Chile and Brazil. New York: Monthly Review Press.

Fridell, G. (2007). Fair-Trade Coffee and Commodity Fetishism: The Limits of Market-Driven Social Justice. Historical Materialism, 15(4), 79-104.

Friedland, W. H. (1994). The Global Fresh Fruit and Vegetable System: An Industrial Organization Analysis. In P. McMichael (Ed.), The Global Restructuring of Agro-food Systems. Ithaca: Cornell University Press.

Friedman, D. (1984). The State and Underdevelopment in Spanish America: The Political Roots of Dependency in Peru and Argentina Boulder: Westview Press.

Galeano, E. (1997). Open Veins of Latin America: Five Centuries of the Pillage of a Continent (C. Belfrage, Trans.). New York: New York University Press.

Gazmuri, G. R., Clavel, P. A., \& Escobedo, A. G. (1996). Eduardo Frei Montalva (1911-1982). San Diego: Fondo De Cultura Economica USA.

Gerdes, L. I. (2009). Introduction to Latin America: Opposing Viewpoints. In L. I. Gerdes (Ed.), Latin America. Detroit: Greenhaven Press.

Gereffi, G. (1994). The Organization of Buyer-Driven Commodity Chains: How U.S. Retailers Shape Overseas Production. In G. Gereffi \& M. Korzeniewicz (Eds.), Commodity Chains and Global Capitalism (pp. 95-122). Praeger: Westport. 
Gereffi, G. (2001). Shifting Governance Structures in Global Commodity Chains, With Special Reference to the Internet. American Behavioral Scientist, 44(10), 1616-1637.

Gereffi, G., \& Fernandez-Stark, K. (2011). Global Value Chain Analysis: A Primer. Durham: Center on Globalization, Governance \& Competitiveness (CGGC).

Gereffi, G., Humphrey, J., \& Sturgeon, T. (2005). The governance of global value chains. Review of International Political Economy, 12(1), 78-104.

Gereffi, G., \& Korzeniewicz, M. (1994). Commodity Chains and Global Capitalism. Santa Barbara: ABC-CLIO.

Gereffi, G., \& Lee, J. (2012). Why the World Suddenly Cares about Global Supply Chains. Journal of Supply Chain Management, 48(3), 24-32.

Gerencia de Estudios Económicos. (2016). Observatorio de mercados año 10 (Vol. 33). Lima: Instituto Nacional de Defensa de la Competencia y de la Protección de la Propiedad Intelectual (INDECOPI).

Gerhard, P. (1972). A Guide to the Historical Geography of the New World. Cambridge: Cambridge University Press.

Gerz, A., \& Dupont, F. (2006). Comté cheese in France: Impact of a geographical indication on rural development. In P. van de Kop, S. Denis \& G. Astrid (Eds.), Origin-based products : Lessons for pro-poor market development. (Vol. 372, pp. 75-86). Amsterdam: KIT Publishers.

Gibbon, P. (2001). Upgrading Primary Production: a Global Commodity Chain Approach. World Development, 29(2), 345-363.

Gibbon, P., Bair, J., \& Ponte, S. (2008). Governing Global Value Chains: An Introduction. Economy and Society, 37(3), 315-338.

Giovannucci, D. (2009). Guide to Geographical Indications: Linking Products and Their Origins: International Trade Centre.

Given, L. (2008). The SAGE Encyclopedia of Qualitative Research Methods. Thousand Oaks, California: SAGE Publications.

Goodman, D. (2004). Rural Europe Redux? Reflections on Alternative Agro-Food Networks and Paradigm Change. Sociologia Ruralis, 44(1), 3-16.

Goodman, D., \& Watts, M. (1997). Globalising Food: Agrarian Questions and Global Restructuring. London: Psychology Press.

Gould, K. A., Garcia, M. M., \& Remes, J. A. (2016). Beyond "Natural-disasters-are-not-natural": The Work of State and Nature after the 2010 Earthquake in Chile. Journal of Political Ecology, 23(1), 93-114.

Griffiths, P. (2012). Ethical Objections to Fairtrade. Journal of Business Ethics, 105(3), 357-373.

Grugel, J., \& Riggirozzi, P. (2012). Post-neoliberalism in Latin America: Rebuilding and Reclaiming the State after Crisis. Development and Change, 43(1), 1-21.

Guerrero, C. C. (2004). La protección jurídica de las denominaciones de origen peruanas. Docentia et Investigatio, 6(1), 139-151.

Gutiérrez, G. (2003). El pisco, denominación de origen peruana. Agenda Internacional, 10(19), 245-298.

Gutiérrez, G. (2011). El desarrollo de la denominación de origen peruana pisco. Paper presented at the Simposio Mundial sobre Indicaciones Geográficas Lima, Perú.

Gwynne, R. N. (2004). Clusters and Commodity Chains: Firm Responses to Neoliberalism in Latin America. Latin American Research Review, 39(3), 243-255.

Gwynne, R. N. (2008). UK retail concentration, Chilean wine producers and value chains. Geographical Journal, 174(2), 97-108.

Gwynne, R. N., \& Kay, C. (2000). Views from the Periphery: Futures of Neoliberalism in Latin America. Third World Quarterly, 21(1), 141-156.

Halperin, S. (2013a). development theory. Encyclopædia Britannica. Retrieved 24/09, 2013, from https://www.britannica.com/topic/development-theory

Halperin, S. (2013b). Development Theory. Britannica Online Academic Edition: Encyclopædia Britannica, inc. 
Harvey, D. (2007). Neoliberalism as creative destruction. The annals of the American academy of political and social science, 610(1), 21-44.

Heffernan, W. D., \& Constance, D. H. (1994). Transnational Corporations and the Globalization of the Food System In A. Bonanno, L. Busch, W. Friedland, L. Goveia \& E. Migione (Eds.), From Columbus to ConAgra: The Globalization of Agriculture and Food: University Press of Kansas.

Henderson, J., Dicken, P., Hess, M., Coe, N., \& Yeung, H. W.-C. (2002). Global Production Networks and the Analysis of Economic Development. Review of International Political Economy, 9(3), 436-464.

Hoffman, K., \& Centeno, M. A. (2003). The Lopsided Continent: Inequality in Latin America. Annual Review of Sociology, 29(1), 363-390.

Hojman, D. E. (1996). Poverty and Inequality in Chile: Are Democratic Politics and Neoliberal Economics Good for You? Journal of Interamerican Studies and World Affairs, 38(2-3), 73-96.

Holland, T., Smit, B., \& Jones, G. V. (2014). Toward a Conceptual Framework of Terroir Tourism: A Case Study of the Prince Edward County, Ontario Wine Region. Tourism Planning \& Development, 11(3), 275-291.

Hopkins, R. (1998). The Impact of Structural Adjustment on Agriculture. In John Crabtree \& J. Thomas (Eds.), Fujimori's Peru: The Political Economy. London: Institute of Latin American Studies.

Howson, K. (2018). Bottling the Colonial Unconscious: Ethical Value Networks and the Commodification of Fairness in the South African Wine Industry. (Doctor of Philosophy), Victoria University of Wellington Wellington.

Hudson, R. (1992). Peru: A Country Study (Vol. 2). Washington, DC: Government Printing Office.

Hudson, R. A. (1994). Chile, A Country Study (Vol. 550). Washington D.C: Government Printing Office.

Huertas Vallejos, L. (2004). Historia de la producción de vinos y piscos en el Perú. Universum (Talca), 19, 44-61.

Huertas Vallejos, L. (2012). Cronología de la producción del vino y del pisco: Perú, 1548-2010. Lima: Universidad Ricardo Palma.

Hughes, A. (2005). Geographies of Exchange and Circulation: Alternative Trading Spaces. Progress in Human Geography, 29(4), 496-504.

Hughes, A., Wrigley, N., \& Buttle, M. (2008). Global Production Networks, Ethical Campaigning, and the Embeddedness of Responsible Governance. Journal of Economic Geography, $8(3), 345-367$.

Hughes, J. (2009). Coffee and chocolate - can we help developing country farmers through geographical indications? Washington, D.C.: International Intellectual Property Institute.

Human Rights Watch. (2003). Peru: Prosecutions Should Follow Truth Commission Report. Retrieved 1 April 2018, from http://www.hrw.org/news

Humphrey, J. (2008). Private Standards, Small Farmers and Donor Policy: EUREPGAP in Kenya. IDS Working Paper, 308. Institute of Development Studies. Sussex.

Hunt, S. J. (1973). Growth and Guano in Nineteenth Century Peru. New Jersey: Research Program in Economic Development, Woodrow Wilson School, Princeton University.

Illanes, M. A., \& Riesco, M. (2007). Developmentalism and Social Change in Chile. In M. Riesco (Ed.), Latin America. Social Policy in a Development Context (pp. 378-424). London: Palgrave Macmillan.

INDAP. (2014). Lineamientos estrategios 2014-2018 por un Chile rural inclusivo. Santiago: Instituto de Desarrollo Agropecuario (INDAP).

INEI. (2012). Resultados definitivos. iv censo nacional agropecuario Lima: Instituto Nacional de Estadística e Informática (INEI). 
Instituto Tecnológico de la Producción. (n.d.). Análisis de Laboratorio Agrícola. Retrieved 05/06, 2019, from https://www.itp.gob.pe/nuestros-cite/agroindustrial-yalimentario/cite-ica/citeagroindustrial-ica-ensayos-laboratorio/

Jaffee, D., Kloppenburg, J. R., \& Monroy, M. B. (2004). Bringing the "Moral Charge" Home: Fair Trade within the North and within the South*. Rural Sociology, 69(2), 169-196.

Jano, P. (2016). Collective Action in Agriculture: The Case of Wine-grape Farmer Cooperatives in Chile. Viña del Mar: Universidad Adolfo Ibáñez.

Johnson, J. J., Carmagnani, M. A., Drake, P. W., \& Caviedes, C. N. (2018). Chile. Britannica Online Academic Edition: Encyclopædia Britannica, inc.

Josling, T. (2006). The War on Terroir: Geographical Indications as a Transatlantic Trade Conflict. Journal of Agricultural Economics, 57(3), 337-363.

Kay, C. (1978). Agrarian Reform and the Class Struggle in Chile. Latin American Perspectives, 5(3), 117-142.

Kay, C. (1980). The Landlord Road and the Subordinate Peasant Road to Capitalism in Latin America. Etudes rurales, 77, 5-20.

Kay, C. (1981). Political Economy, Class Alliances and Agrarian Change in Chile. The Journal of Peasant Studies, 8(4), 485-513.

Kay, C. (2001). Reflections on Rural Violence in Latin America. Third World Quarterly, 22(5), 741-775.

Kay, C. (2002a). Agrarian Reform and the Neoliberal Counter-reform in Latin America. In J. Chase (Ed.), The Spaces of Neoliberalism: Land, Place and Family in Latin America (pp. 25-52). Bloomfield Kumarian Press Inc.

Kay, C. (2002b). Chile's Neoliberal Agrarian Transformation and the Peasantry. Journal of Agrarian Change, 2(4), 464-501.

Kay, C. (2008). Reflections on Latin American Rural Studies in the Neoliberal Globalization Period: A New Rurality? Development and Change, 39(6), 915-943.

Kleine, D. (2008). Negotiating partnerships, understanding power: doing action research on Chilean Fairtrade wine value chains. Geographical Journal, 174(2), 109-123.

Knowles, T., \& Sharples, L. (2002). The History and Development of Chilean Wines. International Journal of Wine Marketing, 14(2), 7-16.

Koo, W. (2017). Pisco Perú exportación 2017 - Octubre. Retrieved 04 April 2018, from https://www.agrodataperu.com/2017/11/pisco-peru-exportacion-2017-octubre.html

Kuramoto, J. R., \& Bank, I.-A. D. (2011). Innovation, R\&D and Productivity: Case Studies from Peru: Inter-American Development Bank Department of Research and Chief Economist.

La Comisión de la Verdad y Reconciliación. (2003). General Conclusions of the Final Report [English]. Lima: La Comisión de la Verdad y Reconciliación (CVR).

Lacoste, P. (2006). Viñas y vinos en el Maule colonial (Reino de Chile, 1700-1750). Universum (Talca), 21(1), 48-67.

Lacoste, P. (2007). Complejidad de la industria vitivinícola colonial: Crianza biológica de Vino (Reino de Chile Siglo XVIII). Latin American Research Review, 42(2), 154-168.

Lacoste, P. (2016). El pisco nació en Chile. Génesis de la primera denominación de origen de américa. Santiago: Ril Editores.

Lacoste, P., Jimenez, D., Castro, A., Rendon, B., \& Soto, N. (2013). A bi-national appellation of origin: Pisco in Chile and Peru. Chilean journal of agricultural research, 73, 424-429.

Lambin, E. F., \& Meyfroidt, P. (2011). Global Land Use Change, Economic Globalization, and the Looming Land Scarcity. Proceedings of the National Academy of Sciences, 108(9), 34653472.

Larson, J. (2007). Relevance of geographical indications and designations of origin for the sustainable use of genetic resources. Rome: Global Facilitation Unit for Underutilized Species.

Latin American Center for Rural Development. (2011). Poverty and Inequality. Latin America Report. Latin American Center for Rural Development (RIMISP). Santiago. 
Latour, B. (1996). On Actor-network Theory: A Few Clarifications. Soziale Welt, 47(4), 369-381.

Lear, J., \& Collins, J. (1995). Working in Chile's Free Market. Latin American Perspectives, 22(1), 10-29.

Leiva, F. I. (2008). Introduction: Latin America's Post-neoliberal Turn Latin American Neostructuralism: The Contradictions of Post-Neoliberal Development. (pp. xvii). Minneapolis/London: University of Minnesota Press.

Linton, A. (2012). Growing Fair Trade in South Africa. Globalizations, 9(5), 725-740.

Loayza, N., \& Rigolini, J. (2016). The Local Impact of Mining on Poverty and Inequality: Evidence from the Commodity Boom in Peru. World Development, 84, 219-234.

Lockhart, J. (1994). Spanish Peru, 1532-1560 a Social History (2nd ed.). Madison: University of Wisconsin Press.

Lynch, J. (1985). The Origins of Spanish American Independence. In L. Bethell (Ed.), The Cambridge History of Latin America (Vol. 3, pp. 3-50): Cambridge University Press.

Madge, C. (1997). The Ethics of Research in the 'Third World'. In E. Robson \& K. Willis (Eds.), Postgraduate Fieldwork in Developing Areas: A Rough Guide Monograph (Vol. 9, pp. 113-124.). London: Royal Geographical Society, and Institute of British Geographers.

Malik, K. (2013). Human Development Report 2013. The Rise of the South: Human Progress in a Diverse World. United Nations Development Programme. New York.

Malo, M. C., \& Mori, T. (2003). Impactos del comercio justo del vino. Tres casos de empresas colectivas de productores en Chile. revista de economía pública, social y cooperativa, 46, 265-289.

Mancini, M. C. (2013). Geographical Indications in Latin America Value Chains: A "branding from below" strategy or a mechanism excluding the poorest? Journal of Rural Studies, 32, 295-306.

Mandel, J. L. (2003). Negotiating Expectations in the Field: Gatekeepers, Research Fatigue and Cultural Biases. Singapore Journal of Tropical Geography, 24(2), 198-210.

Martens, P., \& Rotmans, J. (2005). Transitions in a Globalising World. Futures, 37(10), 11331144.

Martin, J. M. C. (2004). TRIPS Agreement: Towards a Better Protection for Geographical Indications? Brooklyn Journal of International Law, 30(1), 117-184.

Mauceri, P. (1995). State Reform, Coalitions, and the Neoliberal Autogolpe in Peru. Latin American Research Review, 30(1), 7-37.

McCarthy, J. (2006). Rural Geography: Alternative Rural Economies -the Search for Alterity in Forests, Fisheries, Food, and Fair Trade. Progress in Human Geography, 30(6), 803-811.

McMichael, P. (1994). The Global Restructuring of Agro-food Systems. Ithaca: Cornell University Press.

McMichael, P. (2012). The Land Grab and Corporate Food Regime Restructuring. The Journal of Peasant Studies, 39(3-4), 681-701.

McMurtry, J. J. (2009). Ethical Value-Added: Fair Trade and the Case of Café Femenino. Journal of Business Ethics, 86(1), 27-49.

Méndez, V. E., Bacon, C. M., Olson, M., Petchers, S., Herrador, D., Carranza, C., . . Mendoza, A. (2010). Effects of Fair Trade and organic certifications on small-scale coffee farmer households in Central America and Mexico. Renewable Agriculture and Food Systems, 25(03), 236-251.

Mendoza, A. (2011). Neoliberalism. In A. J. Andrea (Ed.), World History Encyclopedia. Santa Barbara: ABC-CLIO.

Mendoza Solari, K. (2015). Diseño de una bodega vitivinícola pisquera en el valle de Ica utilizando acondicionamiento ambiental pasivo. (Ingeniero Agrícola), Universidad Nacional Agraria La Molina, Lima.

Miller, R. (1983). The Grace Contract, the Peruvian Corporation, and Peruvian History. IberoAmerikanisches Archiv, 9(3/4), 319-348.

Mishkin, D. (1966). The American Colonial Wine Industry: An Economic Interpretation. (Doctor of Philosophy), University of Illinois, Champaign. 
Mitchell, J. T., \& Terry, W. C. (2011). CONTESTING PISCO: CHILE, PERU, AND THE POLITICS OF TRADE*. Geographical Review, 101(4), 518-535.

MITINCI. (1999). El pisco tiene sabor peruano. Lima: Ministerio de Industria, Turismo, Integración y Negociaciones Comerciales Internacionales (MITINCI).

Moquillaza, J. (2011). Patrimonio monumental y expresiones culturales como factores generadores de valor en las denominaciones de origen: el caso del Perú. Perspectivas Rurales. Nueva época, Año 10(19), 83-96.

Morel-Astorga, P. (2002). Patterns of Entrepreneurship, Development of Chilean Wine Industry 1850-2000. Lund Papers in Economic History. Department of Economic History, Lund University. Lund.

Mowforth, M., \& Munt, I. (1998). Tourism and Sustainability: New Tourism in the Third World. London: Routledge.

Muñoz, K. (2017). Tourism under the Influence of Peruvian Pisco. Retrieved 31 August 2018, from http://antiguareport.com/2017/12/tourism-under-the-influence-of-peruvianpisco/

Murdoch, J., Marsden, T., \& Banks, J. (2000). Quality, Nature, and Embeddedness: Some Theoretical Considerations in the Context of the Food Sector*. Economic Geography, 76(2), 107-125.

Murray, D., Raynolds, L. T., \& Taylor, P. L. (2003). One Cup at a Time: Poverty Alleviation and Fair Trade Coffee in Latin America: Fair Trade Research Group.

Murray, W. E. (1997). Competitive Global Fruit Export Markets: Marketing Intermediaries and Impacts on Small-scale Growers in Chile. Bulletin of Latin American Research, 16(1), 4355.

Murray, W. E. (2002a). From Dependency to Reform and Back Again: the Chilean Peasantry during the Twentieth Century. The Journal of Peasant Studies, 29(3-4), 190-227.

Murray, W. E. (2002b). The Neoliberal Inheritance: Agrarian Policy and Rural Differentiation in Democratic Chile. Bulletin of Latin American Research, 21(3), 425-441.

Murray, W. E. (2006a). Geographies of Globalization (1st ed.). London: Routledge.

Murray, W. E. (2006b). Neo-feudalism in Latin America? Globalisation, Agribusiness, and Land Re-concentration in Chile. The Journal of Peasant Studies, 33(4), 646-677.

Murray, W. E. (2009). Neoliberalism and Development. International Encyclopedia of Human Geography (Vol. 7, pp. 379-384).

Murray, W. E., \& Overton, J. (2003). Designing development Research. In R. Scheyvens \& D. Storey (Eds.), Development Fieldwork (pp. 18-35). London: SAGE Publications Ltd.

Murray, W. E., \& Overton, J. (2011a). Divergent pasts, parallel futures? Between competition and co-operation in the Argentinian, Chilean and New Zealand wine sectors. Journal of New Zealand Studies(11), 171-190.

Murray, W. E., \& Overton, J. (2011b). Neoliberalism is dead, long live neoliberalism? Neostructuralism and the international aid regime of the 2000s. Progress in Development Studies, 11(4), 307-319.

Murray, W. E., \& Overton, J. (2014). Geographies of Globalization (2nd ed.). London: Taylor \& Francis.

Mutersbaugh, T. (2005). Fighting Standards with Standards: Harmonization, Rents, and Social Accountability in Certified Agrofood Networks. Environment and Planning A, 37(11), 2033-2051.

Nieto, C. A. (2012). De vuelta a la concentración de tierras en el Perú. Investigaciones Sociales, 16(28), 49-58.

Odeh, L. E. (2010). A Comparative Analysis of Global North and Global South Economies. Journal of Sustainable Development in Africa, 12(3), 1-12.

OECD. (1997). Economic Globalisation and the Environment. Paris: Organisation for Economic Co-operation and Development (OECD) Publishing.

Organisation of Vine and Wine. (2016). Global Economic Vitiviniculture Data for 2015. Organisation of Vine and Wine OIV Annual Conference. 
Overton, J., \& Heitger, J. (2008). Maps, Markets and Merlot: The Making of an Antipodean Wine Appellation. Journal of Rural Studies, 24(4), 440-449.

Overton, J., \& Murray, W. E. (2011). Playing the scales: Regional transformations and the differentiation of rural space in the Chilean wine industry. Journal of Rural Studies, 27(1), 63-72.

Overton, J., \& Murray, W. E. (2013). Class in a Glass: Capital, Neoliberalism and Social Space in the Global Wine Industry. Antipode, 45(3), 702-718.

Overton, J., Murray, W. E., \& Banks, G. (2012). The Race to the Bottom of the Glass? Wine, Geography, and Globalization. Globalizations, 9(2), 273-287.

Overton, J., Murray, W. E., \& Silva, F. P. (2012). The remaking of Casablanca: the sources and impacts of rapid local transformation in Chile's wine industry. Journal of Wine Research, 23(1), 47-59.

Pain, R. (2004). Social Geography: Participatory Research. Progress in Human Geography, 28(5), 652-663.

Parasecoli, F., \& Tasaki, A. (2011). Shared meals and food fights: geographical indications, rural development, and the environment. Environment and Society, 2, 106+.

Parfitt, T. (2011). Post-Development and its Discontents. Journal of Critical Realism, 10(4), 442464.

Parra, C. M. (2009). Colchagua, un paisaje ordenándose en torno al vino. Cuadernos de Investigación Urbanística(66), 15-32.

Pérezgrovas, V., \& Cervantes, E. (2002). Poverty Alleviation through Participation in Fair Trade Coffee Networks: The Case of Unión Majomut, Chiapas, Mexico. The Ford Foundation. New York.

Petras, J. (1981). Dependency and World System Theory: a Critique and New Directions. Latin American Perspectives, 8(3-4), 148-155.

Pflucker, M. G. V. (2015). Los secretos del pisco. Lima: Universidad de San Martín de Porres, Fondo Editorial.

Philip, G. (2013). Nationalism and the Rise of Peru's General Velasco. Bulletin of Latin American Research, 32(3), 279-293.

Pingali, P. (2007). Agricultural Growth and Economic Development: A View through the Globalization Lens. Agricultural Economics, 37(s1), 1-12.

Pingali, P., \& Khwaja, Y. (2004). Globalisation of Indian Diets and the Transformation of Food Supply Systems. ESA Working Paper. Food and Agriculture Organization (FAO). Rome.

Polaski, S. (2006). Winners and Losers: Impact of the Doha Round on Developing Countries. Carnegie Endowment for International Peace. Washington, D.C.

Ponte, S., \& Ewert, J. (2009). Which Way is "Up" in Upgrading? Trajectories of Change in the Value Chain for South African Wine. World Development, 37(10), 1637-1650.

Portes, A. (2006). Institutions and Development: A Conceptual Reanalysis. Population and Development Review, 32(2), 233-262.

Prado, F. (2012). The Fringes of Empires: Recent Scholarship on Colonial Frontiers and Borderlands in Latin America. History Compass, 10(4), 318-333.

Prebisch, R. (1962). The Economic Development of Latin America and its Principal Problems. Santiago: Economic Commission for Latin America

Raynolds, L. (1997). Restructuring National Agriculture, Agro-food Trade, and Agrarian Livelihoods in the Caribbean In D. Goodman \& M. Watts (Eds.), Globalising Food: Agrarian Questions and Global Restructuring. London: Routledge.

Raynolds, L. T. (2012). Fair Trade: Social regulation in global food markets. Journal of Rural Studies, 28(3), 276-287.

Reardon, T., \& Barrett, C. B. (2000). Agroindustrialization, Globalization, and International Development: An Overview of Issues, patterns, and Determinants. Agricultural Economics, 23(3), 195-205.

Renard, M.-C. (2005). Quality certification, regulation and power in fair trade. Journal of Rural Studies, 21(4), 419-431. 
Réviron, S., \& Paus, M. (2006). Special Report: Impact Analysis Methods. WP2, Social and Economic Issues. SINER-GI Project. European Commission - Sixth Framework Programme.

Rice, P. M. (1996). Peru's Colonial Wine Industry and its European Background. Antiquity, 70(270), 785-800.

Rice, P. M. (2011a). Part II Wine: The Commodity. In P. M. Rice (Ed.), History, Wine, and Archaeology on a Colonial Peruvian Periphery (pp. 75-131). Austin: University of Texas Press.

Rice, P. M. (2011b). Vintage Moquegua: History, Wine, and Archaeology on a Colonial Peruvian Periphery (P. M. Rice Ed.). Austin: University of Texas Press.

Riddell, D. (1968). Review: Capitalism and Under-development in Latin America: Historical Studies of Chile and Brazil by Andre Gundar Frank. Sociology, 2(3), 361.

Riessman, C. K., \& Quinney, L. (2005). Narrative in Social Work:A Critical Review. Qualitative Social Work, 4(4), 391-412.

Rudolph, J. D. (1992). Peru: the Evolution of a Crisis. Westport: Praeger Publishers.

Sachs, W. (2013). Liberating the World from Development. New Internationalist(460), 22-27.

Saldanha, K., \& Klopfer, L. (2014). On Seeing Monkeys, Cows, and Beggars: Between Ethnography and Tourism. Cultural Studies - Critical Methodologies, 14(4), 324-332.

Santa Cruz, F. (1999). La nueva institucionalidad rural: el caso de Perú. Food and Agriculture Organization/Centro Peruano de Estudios Sociales. Lima.

Sautier, D., \& van de Kop, P. (2006). Origin-based marketing : A rural development tool? In P. van de Kop, S. Denis \& G. Astrid (Eds.), Origin-based products : Lessons for pro-poor market development. (Vol. 372, pp. 17-20). Amsterdam: KIT Publishers.

Sayer, A. (2000). Realism and social science. London: Sage Publications.

Scheyvens, R., \& Storey, D. (2003). Development Fieldwork: A Practical Guide. London: SAGE Publications.

Servicio Agricola y Ganadero. (2018). Informe ejecutivo producción de vinos 2017. Servicio Agricola y Ganadero (SAG). Santiago.

Servicio Agrícola y Ganadero. (2015). Evolución de la superficie regional de vides para vinificación. Servicio Agrícola y Ganadero (SAG). Santiago.

Sidaway, J. D. (1992). In Other Worlds: On the Politics of Research by 'First World' Geographers in the 'Third World'. Area, 24(4), 403-408.

Silva, A. D. (2011). Peru-Country Program Evaluation for the World Bank Group, 2003-09. Washington D.C: World Bank.

Silva, E. (2009). Challenging Neoliberalism in Latin America. Cambridge Cambridge University Press.

Sorinel, C. (2010). Immanuel Wallerstein's World System Theory. Annals of Faculty of Economics, 1(2), 220-224.

Stanziani, A. (2004). Wine Reputation and Quality Controls: The Origin of the AOCs in 19th Century France. European Journal of Law and Economics, 18(2), 149-167.

Starbucks Corporation. (ND). Ethical Sourcing: Coffee. Retrieved 2 June 2018, from https://www.starbucks.com/responsibility/sourcing/coffee

Stein, S. J., \& Stein, B. H. (1970). The Colonial Heritage of Latin America: Essays on Economic Dependence in Perspective. New York: Oxford University Press.

Stern, S. J. (1988). Feudalism, Capitalism, and the World-system in the Perspective of Latin America and the Caribbean. The American Historical Review, 93(4), 829-872.

Stiglitz, J. E. (2002). Globalization and its Discontents (Vol. 500). New York: WW Norton \& Co.

Sturgeon, T. J. (2008). From Commodity Chains to Value Chains: Interdisciplinary Theory Building in an Age of Globalization. Industry Studies Working Paper: 2008-02.

Superintendencia Nacional de Aduanas y de Administración Tributaria. (2016). Estadísticas y estudios. Lima: Superintendencia Nacional de Aduanas y de Administración Tributaria (SUNAT). 
Swinnen, J. F. M., \& Maertens, M. (2007). Globalization, Privatization, and Vertical Coordination in Food Value Chains in Developing and Transition Countries. Agricultural Economics, $37,89-102$.

Taft-Morales, M. (2016). Peru: Politics, Economy, and Elections in Brief. Congressional Research Service. Washington D.C.

Taylor, M. (2006). 'Chicago to the Rescue': The Emergence of Neoliberalism in Chile. In M. Taylor (Ed.), From Pinochet to the 'Third Way' (pp. 30-52). London: Pluto Press.

The Economist Intelligence Unit. (2017). Country Forecast: Peru September 2017. London: The Economist Group.

Thorp, R. (1998). Progress, Poverty and Exclusion: An Economic History of Latin America in the 20th Century. Washington, D.C: Inter-American Development Bank.

Thorp, R., \& Bertram, G. (1978). Peru 1890-1977: Growth and Policy in an Open Economy New York: Columbia University Press.

Thrupp, L. A. (1995). Bittersweet Harvests for Global Supermarkets: Challenges in Latin America's Agricultural Export Boom. Washington, D.C: World Resources Institute.

Trade for Development Centre. (2005). Fair for Life (IMO). Retrieved 27 October 2017, from http://www.befair.be/

Tribuna del Bío Bío. (2015). Indignados viñateros del Valle del Itata protestaron en Concepción por bajo precio de la uva. Tribuna del Bío Bío. Retrieved 05 August 2018, from http://www.tribunadelbiobio.cl/portal/index.php?option=com content\&task=view\&i $\mathrm{d}=9518 \&$ Itemid $=87$

Undurraga, T. (2015). Neoliberalism in Argentina and Chile: Common Antecedents, Divergent Paths. Revista de Sociologia e Política, 23(55), 11-34.

United Nations. (2011). Map of Peru. Retrieved 27 August 2018, from www.legacy.lib.utexas.edu

United Nations Human Development Programme. (2016a). Human Development Indicators; Chile. Retrieved 25 May 2018, from http://hdr.undp.org/en/countries/profiles/CHL

United Nations Human Development Programme. (2016b). Human Development Indicators; Peru. Retrieved 25 May 2018, from http://hdr.undp.org/en/countries/profiles/PER

Unwin, P. T. H. (1991). Wine and the Vine: An Historical Geography of Viticulture and the Wine Trade. London: Routledge.

Van de Kop, P., \& Sautier, D. (2006). Regional Identity: An Overview In P. Van de Kop, D. Sautier \& A. Gerz (Eds.), Origin-based Products: Lessons for Pro-poor Market Development. Amsterdam: KIT Publishers.

van de Kop, P., Sautier, D., \& Gerz, A. (2006). Origin-based products : lessons for pro-poor market development (K. I. T. R. T. Institute Ed.): KIT Publishers.

Vázquez-Rowe, I., Cáceres, A. L., Torres-García, J. R., Quispe, I., \& Kahhat, R. (2017). Life Cycle Assessment of the Production of Pisco in Peru. Journal of Cleaner Production, 142, 4369-4383.

Velasco Alvarado, J. (1970). Velasco, la voz de la revolución (Vol. 1). Lima: PEISA.

Wade, P. (2017). Race and Ethnicity in Latin America (2nd ed.). London: Pluto Press.

Wallerstein, I. M. (2004). World-systems Analysis: An Introduction. Durham: Duke University Press.

White, S. C. (1993). Male Bias in the Development Process. Public Administration and Development, 13(1), 84-85.

Wiedner, D. L. (1960). Forced Labor in Colonial Peru. The Americas, 16(4), 357-383.

Wijnant, G., Raga, R., \& Ramakers, R. (2015). Identificación y caracterización del sector comercio justo y consumo responsable. Santiago: Proqualitas Consultora.

Williams, P., \& Murray, W. E. (2018). Behind the 'Miracle': Non-Traditional Agro-Exports and Water Stress in Marginalised Areas of Ica, Peru. Bulletin of Latin American Research.

Wills, M. E. (2003). Peru's Failed Search for Political Stability (1968-2000). Working papers series no.1. Crisis States Programme, Development Research Centre. London. 
Wilson, B. R. (2010). Indebted to Fair Trade? Coffee and Crisis in Nicaragua. Geoforum, 41(1), 84-92.

Winter, M. (2004). Geographies of Food: Agro-food Geographies- Farming, Food and Politics. Progress in Human Geography, 28(5), 664-670.

WIPO. (2013). Geographical Indications: An Introduction. World Intellectual Property Organization (WIPO). Geneva.

Wise, T. A. (2009). Promise or Pitfall? The Limited Gains from Agricultural Trade Liberalisation for Developing Countries. The Journal of Peasant Studies, 36(4), 855-870.

World Bank. (2018a). World Development Indicators database; Chile. Retrieved 25 May 2018, from https://data.worldbank.org/country/chile

World Bank. (2018b). World Development Indicators database; Peru. Retrieved 25 May 2018, from https://data.worldbank.org/country/peru

World Trade Organisation (Producer). (1994). Agreement on Trade-Related Aspects of Intellectual Property Rights, Part II, Section 3: Geographical Indications. Retrieved from https://www.wto.org/english/tratop e/trips e/t agm3b e.htm

Yeung, H. W., \& Coe, N. (2015). Toward a Dynamic Theory of Global Production Networks. Economic Geography, 91(1), 29-58.

Zamora, J., \& Barril, M. E. (2007). Turismo y vino: Un estudio formativo sobre la evolución de las rutas del Vino en Chile. Estudios y perspectivas en turismo, 16, 173-194.

Zhang, J. J. (2017). Research Ethics and Ethical Research: Some Observations from the Global South. Journal of Geography in Higher Education, 41(1), 147-154.

Ziai, A. (2017). 'I am not a Post-Developmentalist, but...' The Influence of Post-Development on Development Studies. Third World Quarterly, 38(12), 1-16. 